\title{
Earthquake Behavior and Structure of Oceanic Transform Faults
}

\author{
by \\ Emily Carlson Roland \\ B.S., Colorado School of Mines, 2005 \\ Submitted in partial fulfillment of the requirements for the degree of \\ Doctor of Philosophy \\ at the \\ MASSACHUSETTS INSTITUTE OF TECHNOLOGY \\ and the \\ WOODS HOLE OCEANOGRAPHIC INSTITUTION
}

\author{
February 2012 \\ (C) 2012 Emily Carlson Roland. \\ All rights reserved.
}

The author hereby grants MIT and WHOI permission to reproduce and to distribute publicly paper and electronic copies of this thesis document in whole or in part in any medium now known or hereafter created.

Author

Joint Program in Oceanography/Applied Ocean Science and Engineering Department of Geology and Geophysics Massachusetts Institute of Technology and Woods Hole Oceanographic Institution November 4, 2011

Certified by

Jeffrey J. McGuire Associate Scientist, Department of Geology and Geophysics, WHOI Thesis Supervisor

Accepted by

Rob L. Evans

Senior Scientist, Department of Geology and Geophysics, WHOI Chairman, Joint Committee for Geology and Geophysics 


\title{
Earthquake Behavior and Structure of Oceanic Transform Faults
}

\author{
by \\ Emily Carlson Roland \\ Submitted to the department of Marine Geology and Geophysics, \\ Massachusetts Institute of Technology-Woods Hole Oceanographic Institution \\ Joint Program in Oceanography/Applied Ocean Science and Engineering \\ on November 4, 2011 in partial fulfillment of the requirements for the \\ degree of Doctor of Philosophy
}

\begin{abstract}
Oceanic transform faults that accommodate strain at mid-ocean ridge offsets represent a unique environment for studying fault mechanics. Here, I use seismic observations and models to explore how fault structure affects mechanisms of slip at oceanic transforms. Using teleseismic data, I find that seismic swarms on East Pacific Rise (EPR) transforms exhibit characteristics consistent with the rupture propagation velocity of shallow aseismic creep transients. I also develop new thermal models for the ridge-transform fault environment to estimate the spatial distribution of earthquakes at transforms. Assuming a temperature-dependent rheology, thermal models indicated that a significant amount of slip within the predicted temperature-dependent seismogenic area occurs without producing large-magnitude earthquakes. Using a set of local seismic observations, I consider how along-fault variation in the mechanical behavior may be linked to material properties and fault structure. I use wide-angle refraction data from the Gofar and Quebrada faults on the equatorial EPR to determine the seismic velocity structure, and image wide low-velocity zones at both faults. Evidence for fractured fault zone rocks throughout the crust suggests that unique friction characteristics may influence earthquake behavior. Together, earthquake observations and fault structure provide new information about the controls on fault slip at oceanic transform faults.
\end{abstract}

Thesis Supervisor: Jeffrey J. McGuire

Title: Associate Scientist, Department of Geology and Geophysics, WHOI 


\section{Acknowledgments}

I have had the good fortune to work with many scientists who have impacted my experience as a graduate student, and the type of science I will do in the future. Firstly, I'd like to thank Jeff McGuire for sharing his enthusiasm for earthquake swarms, giving me access to the most interesting parts of the QDG dataset, and teaching me how to body surf (not to mention, model surface waves). I am indebted to Mark Behn, Greg Hirth, and Dan Lizarralde for imparting their own elegant strategies for approaching geodynamics, rock mechanics, and marine seismology. I'd also like to thank John Collins for his encouragement and useful discussions, and for trusting me to use the deck-box on the Thompson and Atlantis, if begrudgingly. Wenlu Zhu and Margaret Boettcher provided useful insights on many occasions about earthquake processes at oceanic transform faults. Most importantly, I am grateful to all of the scientists at Woods Hole for keeping their doors open to my tough and my stupid questions alike.

The research presented in this thesis wouldn't have been possible without the efforts of the WHOI OBS Engineers and the crews of the $R / V$ Thomas $G$. Thompson, $R / V$ Marcus $G$. Langseth, and $R / V$ Atlantis. My graduate work wouldn't have been possible without the patient help of Julia Westwater, and other fairies in the Education Office at WHOI.

My fellow students in the Joint Program, EAPS, and WHOI postdocs have provided invaluable comradely, commiseration, and answers to all but the toughest questions during my graduate time at WHOI. They've also been great running partners. I am grateful to Johan Lissenberg, Trish Gregg, Matt Jackson, Mike Krawczynski, Mike Brosnahan, Chris Waters, Michael Holcomb, Andrea Llenos, Min Xu, Camilo Ponton, Nathan Miller, Claire Pontbriand, Eric Mittelstaedt, Dorsey Wanless, Sandy Baldwin, and my gang of officemates, Evy Mervine, Andrea Burke, Sam Nakata (past), Helen Feng (current) and Maya Bhatia.

My family and closest family friends provided me with the confidence, energy, and will to keep persisting, especially through the difficult parts of the past half-decade of work this thesis represents. Equally as important, they have helped me to celebrate the triumphant parts, as I know they will continue to do in the future.

Casey Saenger, my husband and best friend, deserves credit for keeping me in graduate school. He has served as my sounding board and singer-of-songs throughout the past many years. I dedicated all of the Love waves to him.

Material presented in this thesis is based on work supported by the National Science Foundation Division of Ocean Science (OCE) grants \#0548785, \#0623188, \#0649103, and \#0242117 and Division of Earth Sciences (EAR) grants \#0814513 and \#0943480. This work was also supported by the W. M. Keck Foundation and the Deep Ocean Exploration Institute. 


\section{Table of Contents}

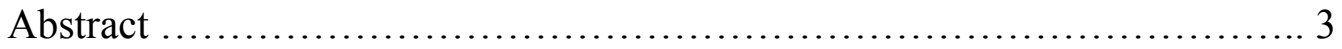

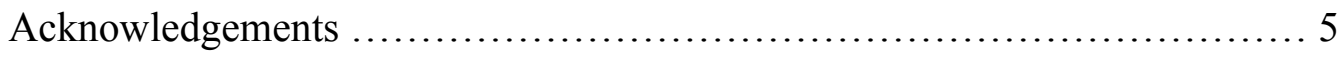

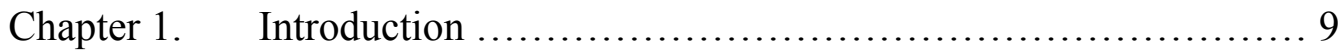

Chapter 2. Earthquake swarms on transform faults ................... 17

Chapter 3. Thermal-mechanical behavior of oceanic transform faults:

Implications for the spatial distribution of seismicity ......... 33

Chapter 4. The seismic velocity structure of East Pacific Rise transform faults: Exploring material properties that control earthquake behavior .............................. 49

Chapter 5. Seafloor strong-motion observations of intermediatemagnitude earthquakes on the Gofar Fault, EPR 


\section{Chapter 1}

\section{Introduction}

The fundamental controls on the timing, location and maximum size of earthquakes on plate-boundary faults remain poorly understood, despite ever-improving capabilities to characterize fault slip and fault zone properties. With current observational tools, it is possible to identify distinct fault segments that release strain during fast, dynamic rupture events, and others that slip stably, without producing seismic waves. However, determining which aspects of rheology and fault dynamics control slip partitioning between seismic and aseismic slip mechanisms remains a central problem. Recently, improvements in geodesy and seismic recording tools have led us to distinguish a spectrum of seismic and aseismic fault slip phenomena [Ide et al., 2007]. These phenomena include discrete episodes of transient aseismic fault slip as well as periods of rapid, small magnitude seismic slip events (i.e., earthquake swarms and tectonic tremor) that do not conform to spatial and temporal moment release patterns typically associated with large "mainshock" earthquakes. As our understanding of these different styles of fault slip improves, earthquake scientists are tasked with refining mechanical models to account for the nuances of how different fault environments accommodate strain. The traditional view, that plate motions are accommodated by a simple cycle of stress accumulation and release, is being revised to reflect the importance of complex interactions between faults zones that exhibit vastly different mechanical behavior, including strongly "locked" seismic asperities, continuously slipping aseismic fault segments, and faults that release strain as smaller magnitude slip events at shorter, or 
sometimes periodic timescales.

It is likely that spatial variation in fault zone properties is a determining factor that affects the style of fault slip and the spatial extent, size and timing of earthquake ruptures. Understanding more completely the fault conditions that inhibit and favor seismic slip would have important implications for anticipating earthquake behavior. For example, velocity-strengthening aseismic fault patches likely form rupture barriers that limit the maximum size of earthquakes on neighboring seismic asperities and could influence the temporal pattern of tectonic loading associated with continuous or transient strain events. It is thus remarkable how little is known about the physical conditions within the seismogenic zone. The factors thought to affect fault slip behavior include rock strength and frictional velocity dependence, differential and effective normal stress, the presence of pore fluids, and temperature. However, because few if any of these can be observed directly, to study the fault zone environment we rely on geophysical imaging and geodynamical models to estimate physical conditions using field- and laboratory-derived information about composition and rheology. In this thesis, I seek to combine observations of earthquake behavior with investigations of the fault zone using seismic imaging and models in order to establish the dependence of earthquake rupture patterns on observable fault zone properties.

Work presented here focuses primarily on strike-slip faults that accommodate strain at mid-ocean ridge offsets, commonly referred to as oceanic transform faults. A key observation that motivates research in this unique tectonic setting is the observation that, on a global scale, oceanic transform faults demonstrate low average seismic coupling [Boettcher and Jordan, 2004]. Comparing the predicted total seismic moment release based on a rheology and thermal structure appropriate for the oceanic lithosphere to that observed teleseismically, Boettcher and Jordan [2004] found that on average as much as $85 \%$ of the predicted seismogenic area slips aseismically at oceanic transform faults. Additionally, even the largest oceanic transform earthquakes do not appear to 
rupture the entire length of the fault [Boettcher and McGuire, 2009]. Although their remote location, far from land-based seismic arrays, makes earthquake source properties difficult to determine, teleseismic observations suggest oceanic transform faults exhibit unique earthquake behavior including frequent foreshocks [McGuire et al., 2005] and seismic swarms of small-moderate magnitude earthquakes that lack a clear mainshock event [Forsyth et al., 2003]. Consistent with their overall low seismic coupling, these observations have motivated the hypothesis that oceanic transform faults sustain frequent aseismic slip transients, which trigger foreshock seismicity and subsequently load adjacent fault patches, leading to large mainshock ruptures.

Using seismic observations and models, I take advantage of the diversity in the styles of slip phenomena exhibited at oceanic transforms to consider how fault slip occurs, and what physical properties of the fault zone influence the mechanical behavior. Specifically, I address four questions:

1) What can we learn about aseismic slip phenomena on transform faults by studying earthquake behavior? (Chapter 2)

2) How does the temperature structure influence the size and shape of the seismogenic zone? (Chapter 3)

3) What are the material properties within the fault zone? (Chapter 4)

4) How do those material properties influence the mechanical behavior and source properties of earthquakes? (Chapter 5)

In Chapter 2, I investigate a series of earthquake swarms that occur on transform faults in the Pacific Ocean to gain insight into their driving mechanisms from spatial and temporal seismicity characteristics. This chapter also considers earthquake swarms in the Salton Trough, in Southern California, where aseismic slip transients have been observed geodetically [Lohman and McGuire, 2007]. After determining precise locations of oceanic transform fault swarm events, I compare moment release and spatial migration patterns to the rupture process of aseismic transients inferred from friction models and 
geodetic observations. I find that spatial migration rates of earthquake swarms in the Pacific and Southern California are consistent with the rupture propagation rate of slow slip transients (on the order of $10 \mathrm{~km} /$ day). This conclusion supports the hypothesis that aseismic slip causes the unique seismicity observed on oceanic transforms.

In Chapter 3, I develop a new thermal-mechanical model for the temperature structure of the oceanic lithosphere surrounding transform faults to improve predictions of the seismogenic area. Laboratory experiments indicate that oceanic lower crust and upper mantle rocks exhibit a strongly temperature-dependent rheology, with stick-slip behavior necessary for earthquake rupture confined to temperatures less than $500-600^{\circ} \mathrm{C}$ [Boettcher et al., 2007; He et al., 2007]. Previous estimates of seismic coupling on transform faults have relied on simple analytical conductive cooling models commonly used to predict the thermal structure in the oceanic lithosphere [McKenzie, 1969]. However, these models neglect many important processes known to occur in the transform fault environment, including viscous mantle flow, shallow brittle deformation, alteration and frictional weakening, shear heating, and hydrothermal circulation. The numerical model I develop in Chapter 3 incorporates each of these processes. Using results from this model, I am able to 1) improve estimates of the size and shape of the temperature-dependent seismogenic zone, 2) assess the accuracy of previous estimates of the size of the seismogenic zone made using the simple half-space model, and 3) apply model results to evaluate the amount of hydrothermal alteration that may occur in the lower crust and upper mantle surrounding transform faults. The thermal model developed in Chapter 3 is a tool I utilize throughout subsequent chapters of this thesis to interpret locally observed seismicity patterns.

Following the first half of this thesis, which is focused on general slip characteristics and fault structure that apply to oceanic transform faults globally, the second half focuses on complexities of a specific transform fault systems using an extraordinary dataset of local seismic observations. In Chapters 4 and 5, I present results from a comprehensive active- and passive- source seismic experiment at a fault system 
on the equatorial East Pacific Rise. The Quebrada-Discovery-Gofar (QDG) transform faults exhibit unique seismic behavior that makes them an excellent setting for studying fault mechanics. One scientifically advantageous quality of the warm, extremely fast slipping ( $\sim 14 \mathrm{~cm} /$ year) QDG faults is their short earthquake cycle. Based on more than 20 year of teleseismic observations, the Gofar and Discovery faults demonstrate a $\sim 5$ year earthquake cycles of relatively small magnitude ( $\mathrm{Mw}$ 5.5-6.2) overlapping earthquake ruptures [McGuire, 2008]. In contrast, almost all other active plate boundary faults exhibit orders of magnitude longer periods between characteristic earthquakes (40-200 years in much of Southern California, 110 year in Tokai, Japan, 500 years in Cascadia). The short seismic cycle of the QDG transforms provides the opportunity to observe multiple earthquake cycles in the instrumental record and estimate a particular fault's current timing within an earthquake cycle.

In 2008, these characteristics motivated the design of a large-scale local array of ocean bottom seismographs (OBS) to observe the Gofar fault during the end of its seismic cycle. The resulting dataset can be considered the product of the first successfully 'forecasted' large earthquake. In the second half of 2008, a series of three westward-propagating rupture events completed the seismic cycle at Gofar. These rupture events included a significant foreshocks sequence of more than 20,000 earthquakes, an Mw 6.0 earthquake with a typical aftershock sequence, and a seismic swarm several months later. Seismic recordings made at the Gofar fault represent the most comprehensive oceanic transform fault earthquake observations to date, and have certainly captured new features of the rupture process never before observed at close range.

Passive source seismic observations from the QDG Transform Fault Experiment were complemented by an active source survey including two wide-angle refraction lines crossing the seismically active Gofar fault and the almost entirely aseismic Quebrada fault. In Chapter 4, I present results from a tomographic inversion for the P-wave velocity structure using this refraction data. Fortuitously, the Gofar seismic line crosses 
the fault segment that sustained the foreshock sequence during the 2008 rupture. Results from this work provide a unique view of the fault zone and may capture the structure of a primarily aseismic fault. A striking result of this work is a significant low velocity zone that I image throughout the entire crust at the Gofar fault. I interpret the seismic velocity results using effective media analyses, and find evidence for enhanced fracturing and the influence of fluids throughout the crust, likely accompanied by some degree of hydrothermal alteration. This result is also interpreted in the context of variable mechanical behavior evidenced by the spatial distribution of earthquakes in the foreshock, aftershock, and swarm fault segments.

In the future, characterizing the precise spatial distribution of significant slip during moderate- to large-magnitude earthquake rupture on oceanic transform faults will help to answer several remaining questions about their mechanical behavior.

How well does the lower bound of dynamic slip conform to the $600^{\circ} \mathrm{C}$ isotherm inferred by various thermal models?

Is the source and depth-distribution of seismic slip during the swarm or foreshock sequences distinct from that of the mainshock event or its aftershocks?

These questions could potentially be answered by taking advantage of strong-motion observations from an array of 10 accelerometers mounted on OBS deployed at the Gofar fault in 2008. Currently, only a few examples of strong motion seafloor recordings exist, and few if any of those have been successfully used to model source properties. In Chapter 5, I evaluate the utility of accelerometer recordings for modeling depth and source properties of moderate- to large-magnitude earthquakes on the Gofar fault. I find that Gofar accelerometer data is of high quality and capable of being modeled in future studies to determine a more detailed picture of the spatial and source properties of earthquake slip during the 2008 Gofar rupture event.

Examined as a whole, this thesis contributes to recent work that has brought the 
view of oceanic transform faults from that through a telescope to that through a window. Earthquake behavior, including seismic swarms, foreshocks and overlapping quasiperiodic mainshock ruptures, is now seen as an interrelated series of rupture events, some of which slip during slow aseismic transients, and others that sustain fast dynamic earthquake rupture. Evidence presented here for along-strike variation in material properties influencing the mechanical behavior of these faults should motivate future work imaging the fault zones at oceanic transforms and in other tectonic regimes. For example, although data from active source imaging at Gofar and Quebrada (Chapter 4) provides insight into the fault zone structure within a velocity-strengthening environment, it would be useful to compare these results to fault structure within a "typical" velocityweakening seismogenic rupture zone. This type of further investigation could illuminate specific differences that may be used to distinguish the mechanical behavior from observable properties.

This progress toward characterizing oceanic transform faults is happening at a time when paradigms in other tectonic regimes are shifting towards models that recognize the importance of variations in seismic coupling along strike and with depth. Although many differences exist between continental and oceanic systems, insight into the mechanisms of fault slip prevalent on oceanic transforms should inform future studies of earthquake behavior on faults closer to land and large population centers. Ultimately, developing a more comprehensive view of how fault slip is accommodated, and how the fault environment influences earthquake behavior will be used to advance seismic hazard analyses, and define the risk from large potentially damaging earthquakes with more accuracy. 


\section{References}

Boettcher, M. S., and T. H. Jordan (2004), Earthquake scaling relations for mid-ocean ridge transform faults, Journal of Geophysical Research 109 (2004): B12302

Boettcher, M. S., and J. J. McGuire (2009), Scaling relations for seismic cycles on midocean ridge transform faults, Geophysical Research Letters 36 (2009): L21301

Boettcher, M. S., G. Hirth, and B. Evans (2007), Olivine friction at the base of oceanic seismogenic zones, Journal of Geophysical Research 112 (2007): B01205, doi:10.1029/2006JB004301.

Forsyth, D. W., Y. Yang, M. D. Mangriotis, and Y. Shen (2003), Coupled seismic slip on adjacent oceanic transform faults, Geophys. Res. Lett, 30(12), 1618.

He, C., Z. Wang, and W. Yao (2007), Frictional sliding of gabbro gouge under hydrothermal conditions, Tectonophysics, 445(3-4), 353-362.

Ide, S., G. C. Beroza, D. R. Shelly, and T. Uchide (2007), A scaling law for slow earthquakes, Nature, 447(7140), 76.

Lohman, R. B., and J. J. McGuire (2007), Earthquake swarms driven by aseismic creep in the Salton Trough, California, Journal of Geophysical Research 112 (2007): B04405

McGuire, J. J. (2008), Seismic cycles and earthquake predictability on East Pacific Rise transform faults, Bulletin of the Seismological Society of America, 98(3), 1067.

McGuire, J. J., M. S. Boettcher, and T. H. Jordan (2005), Foreshock sequences and shortterm earthquake predictability on East Pacific Rise transform faults, Nature, 434(7032), 457-461.

McKenzie, D. P. (1969), Speculations on the Consequences and Causes of Plate Motions*, Geophysical Journal of the Royal Astronomical Society, 18(1), 1-32. 


\title{
Chapter 2
}

\section{Earthquake swarms on transform faults ${ }^{*}$}

\begin{abstract}
Swarm-like earthquake sequences are commonly observed in a diverse range of geological settings including volcanic and geothermal regions as well as along transform plate boundaries. They typically lack a clear mainshock, cover an unusually large spatial area relative to their total seismic moment release, and fail to decay in time according to standard aftershock scaling laws. Swarms often result from a clear driving phenomenon, such as a magma intrusion, but most lack the necessary geophysical data to constrain their driving process. To identify the mechanisms that cause swarms on strike-slip faults, we use relative earthquake locations to quantify the spatial and temporal characteristics of swarms along Southern California and East Pacific Rise transform faults. Swarms in these regions exhibit distinctive characteristics, including a relatively narrow range of hypocentral migration velocities, on the order of a kilometer per hour. This rate corresponds to the rupture propagation velocity of shallow creep transients that are sometimes observed geodetically in conjunction with swarms, and is significantly faster than the earthquake migration rates typically associated with fluid diffusion. The uniformity of migration rates and low effective stress drops observed here suggest that shallow aseismic creep transients are the primary process driving swarms on strike-slip faults. Moreover, the migration rates are consistent with laboratory values of the ratestate friction parameter b (0.01) as long as the Salton Trough faults fail under hydrostatic conditions.
\end{abstract}

\footnotetext{
* Published as: Roland, E., and J. J. McGuire (2009), Earthquake swarms on transform faults, Geophysical Journal International, 178(3), 1677-1690.
} 


\title{
Earthquake swarms on transform faults
}

\author{
Emily Roland ${ }^{1}$ and Jeffrey J. McGuire ${ }^{2}$ \\ ${ }^{1}$ MIT-WHOI Joint Program, Woods Hole, MA 02543, USA. E-mail: eroland@mit.edu \\ ${ }^{2}$ Woods Hole Oceanographic Institution, Woods Hole, MA 02543, USA
}

Accepted 2009 April 15. Received 2009 April 9; in original form 2008 October 7

\begin{abstract}
SUMMAR Y
Swarm-like earthquake sequences are commonly observed in a diverse range of geological settings including volcanic and geothermal regions as well as along transform plate boundaries. They typically lack a clear mainshock, cover an unusually large spatial area relative to their total seismic moment release, and fail to decay in time according to standard aftershock scaling laws. Swarms often result from a clear driving phenomenon, such as a magma intrusion, but most lack the necessary geophysical data to constrain their driving process. To identify the mechanisms that cause swarms on strike-slip faults, we use relative earthquake locations to quantify the spatial and temporal characteristics of swarms along Southern California and East Pacific Rise transform faults. Swarms in these regions exhibit distinctive characteristics, including a relatively narrow range of hypocentral migration velocities, on the order of a kilometre per hour. This rate corresponds to the rupture propagation velocity of shallow creep transients that are sometimes observed geodetically in conjunction with swarms, and is significantly faster than the earthquake migration rates typically associated with fluid diffusion. The uniformity of migration rates and low effective stress drops observed here suggest that shallow aseismic creep transients are the primary process driving swarms on strike-slip faults. Moreover, the migration rates are consistent with laboratory values of the rate-state friction parameter $\mathrm{b}(0.01)$ as long as the Salton Trough faults fail under hydrostatic conditions.
\end{abstract}

Key words: Creep and deformation; Earthquake source observations; Transform faults.

\section{INTRODUCTION}

The term 'earthquake swarm' typically refers to a cluster of moderate earthquakes that occur over a period of hours to days without a distinct mainshock. In regions of magma intrusion and $\mathrm{CO}_{2}$ degassing, swarms have been linked to fluid-flow processes that alter the stress field and trigger seismicity (Hill 1977; Smith et al. 2004; Hainzl \& Ogata 2005). However, with recent improvements in seismic observation capabilities, it is becoming clear that swarms occur in a variety of tectonic settings, not just in areas of volcanism. High rates of seismic swarms have been observed historically in the southern region of the San Andreas transform fault system, where it extends into the Salton Trough in Southern California (Richter 1958; Brune \& Allen 1967; Johnson \& Hadley 1976). Recent studies of high-quality earthquake catalogues have demonstrated that swarms are a common feature of various large-scale tectonic fault systems including those in California and Japan (Vidale \& Shearer 2006; Vidale et al. 2006). Additionally, analysis of aftershock productivity and foreshock occurrence rates on mid-ocean ridge transform faults indicates that oceanic sequences are generally more swarmlike than typical sequences on continental strike-slip boundaries (McGuire et al. 2005).

Although in may cases, geophysical observations are not available to constrain the specific process, certain swarm seismicity character-

(C) 2009 The Authors

Journal compilation (C) 2009 RAS istics reflect an underlying driving mechanism that is fundamentally different from mainshock-aftershock Coulomb stress triggering. Earthquake swarms are often characterized by an effective seismic stress drop (the ratio of total seismic moment release to fault area) that is an order of magnitude lower than stress drop values typical for mainshock-aftershock sequences on strike-slip faults (Vidale \& Shearer 2006). Empirical laws developed from observations of aftershock sequences triggered from a single large event also do a poor job of fitting swarms on transform boundaries. Omori's Law of seismicity rate decay following a main shock (Omori 1894) and Båth's law, which describes the difference in the magnitude of a mainshock and its largest aftershock (Helmstetter \& Sornette 2003b), cannot be applied to earthquake swarm seismicity with parameters typical of continental strike-slip fault systems. The unusual temporal and spatial seismicity patters associated with swarms on continental faults are also observed for earthquake sequences on the East Pacific Rise (EPR). McGuire et al. (2005) showed that foreshocks are an order of magnitude more common on EPR transform faults than on faults in California, while aftershocks are an order of magnitude less common. This analysis demonstrated that EPR transform seismicity cannot be explained by typical earthquake triggering models, and suggested that an aseismic driving process was likely responsible for the increased foreshock activity. Forsyth et al. (2003), inferred an anomalously low stress drop associated with a swarm on the 
western boundary of the Easter Microplate. An aseismic slip event was similarly hypothesized as the triggering phenomenon driving the seismicity there based on the unusual spatial properties of the swarm.

A few studies have directly associated swarms on transform faults with geodetically observed aseismic creep. On the central San Andreas, Linde et al. (1996) used creepmeter observations to connect a small number of earthquakes with magnitude $\sim 5$ creep events that had timescales of a few days. Lohman \& McGuire (2007) studied a large swarm in the Salton Trough using both seismic and geodetic data, and inferred that the magnitude of surface deformation that occurred during the swarm could not be explained by the recorded seismicity alone. Modelling of the observed deformation required a significant contribution from shallow aseismic creep coincident with the swarm. A hypocentral migration velocity on the order of $0.5 \mathrm{~km} \mathrm{hr}^{-1}$, which was observed during the early stage of the Lohman and McGuire sequence is a common feature of strike-slip swarms in the Salton Trough (Johnson \& Hadley 1976). This velocity is consistent with estimated rupture propagation speeds of creep events in California (King et al. 1973; Burford 1977; Linde et al. 1996; Glowacka et al. 2001) and along-strike migration rates associated with episodic slow slip events at subduction zones. Observations of tremor and episodic slow slip along Cascadia (McGuire \& Segall 2003; Dragert et al. 2006; Kao et al. 2006) and in Japan (Obara 2002) have been used to determine along-strike migration velocities between 0.2 and $0.7 \mathrm{~km} \mathrm{hr}^{-1}\left(5-15 \mathrm{~km} \mathrm{~d}^{-1}\right)$ for episodes with durations between 5 and $20 \mathrm{~d}$ and equivalent moment magnitudes of approximately $6.5-6.8$. The $0.1-1.0 \mathrm{~km} \mathrm{hr}^{-1}$ migration rate associated with aseismic fault slip and slow events is significantly faster than the migration rate of earthquakes observed in regions of $\mathrm{CO}_{2}$ degassing and borehole fluid injections. Seismicity initiated by fluid overpressure tends to reflect fluid diffusion timescales, with earthquakes spreading spatially proportional to $t^{1 / 2}$ and migration velocities not exceeding fractions of a kilometre per day (Audigane et al. 2002; Hainzl \& Ogata 2005; Shapiro et al. 2005). Based on the disparity between migration rates associated with fluid diffusion and aseismic slip, hypocentral migration velocities observed during seismic swarms may be used to infer the specific stress transfer mechanism driving seismicity, even if direct observational evidence of the mechanism is not available.

Here, we continue to investigate the physical mechanisms that cause earthquake swarms, and explore the possibility that swarms on strike-slip plate boundaries are generally associated with aseismic creep. In this study, seven swarms are analysed from Southern California and EPR transform faults. Reliable earthquake locations are derived and are used to identify spatial migration patterns, which are taken as a proxy for the physical triggering mechanism driving the sequences. We employ temporal characteristics of the moment release to develop an objective definition of an earthquake swarm, and identify spatial moment release characteristics that are common to most swarms in our data set. We utilize estimates of hypocentral migration rate and the effective stress drop to constrain the potential mechanism causing swarms on strike-slip faults in Southern California and the EPR, and compare our results to predictions calculated from rate-state friction and crack propagation models.

\section{DATA AND METHODS}

We systematically explore the physical mechanisms causing tectonic swarms by analysing a number of sequences from the Salton Trough and Pacific transforms. Owing to the vast difference in the quality and density of seismic data available, sequences from these two regions are analysed with different relocation methods. Seven earthquake sequences are analysed in total: three in Southern California that have accurate relocations available from prior studies, one in Southern California that we relocate using body waves recorded by local arrays and three oceanic transform sequences that are detected and located using teleseismic surface wave arrivals at Global Seismic Network (GSN) stations (Fig. 1). Using event locations and magnitudes, we estimate the effective stress drop and along-fault hypocentral migration rate of each swarm. We also calculate the skew of the temporal history of seismic moment release for each episode, which is used as a quantitative way to distinguish swarms from aftershock sequences. Below we describe the details of each calculation.

\subsection{Southern California seismicity: body wave relocations}

For each Southern California swarm analysed here, relative hypocentral locations were derived using body wave arrival times from local seismometer arrays. A swarm in 1975 was relocated by Johnson \& Hadley (1976), and locations were derived for two swarms in 1981 and 2005 by Lohman \& McGuire (2007). Migration velocities reported here are obtained using event locations from these two analyses. For a swarm in the Imperial fault zone in 2003, arrival time data was combined from two catalogues to determine relative relocations using the double-difference algorithm (Waldhauser \& Ellsworth 2000). Arrival time picks from the Southern California Earthquake Data Center (SCEDC) were combined with arrivals from the Seismic Network of the Northwest Mexico (RESNOM), maintained by the 'Centro de Investigación Científica y de Educación Superior de Ensenada' (CICESE), which provided additional azimuthal coverage south of the US-Mexico border (Castro 1998). For the Imperial fault double-difference relocations, we required event arrival pairs to be observed at a minimum of eight stations within $500 \mathrm{~km}$ and separated by no more than $5 \mathrm{~km}$. We employed a 1-D velocity model appropriate for the Salton Trough, which was extracted from the Southern California Earthquake Center's 3-D unified Southern California reference velocity model, version 4 (Magistrale et al. 2000).

\subsection{EPR seismicity: surface wave relocation}

We analyse three swarms from transform faults on the EPR and the Galapagos Ridge (Fig. 1) using a surface wave earthquake detection and location method that makes use of Rayleigh wave empirical Green's functions (EGFs). In the frequency band between 0.02 and $0.05 \mathrm{~Hz}$, first-orbit Raleigh (R1) waves have a high signal-to-noise ratio and a group velocity that is fairly constant for young oceanic lithosphere, around $3.7 \mathrm{~km} \mathrm{~s}^{-1}$ (Nishimura \& Forsyth 1988). This allows arrival times to be interpreted in terms of source location differences rather than dispersion (Forsyth et al. 2003). Waveforms from individual earthquakes on the same fault are essentially identical, and at low frequencies the amplitude of the waveforms scale with the moment of the earthquake. We identify and locate swarm events relative to an EGF based on their correlation coefficients and differential arrival times from a set of azimuthally distributed GSN stations. The magnitude and location of the selected EGF are taken from the Global Centroid Moment Tensor (CMT) catalogue directly when a CMT solution is available for one of the earthquakes in the sequence. If a moment calculation is not available, one of the large earthquakes in the sequence is cross-correlated with an appropriate 


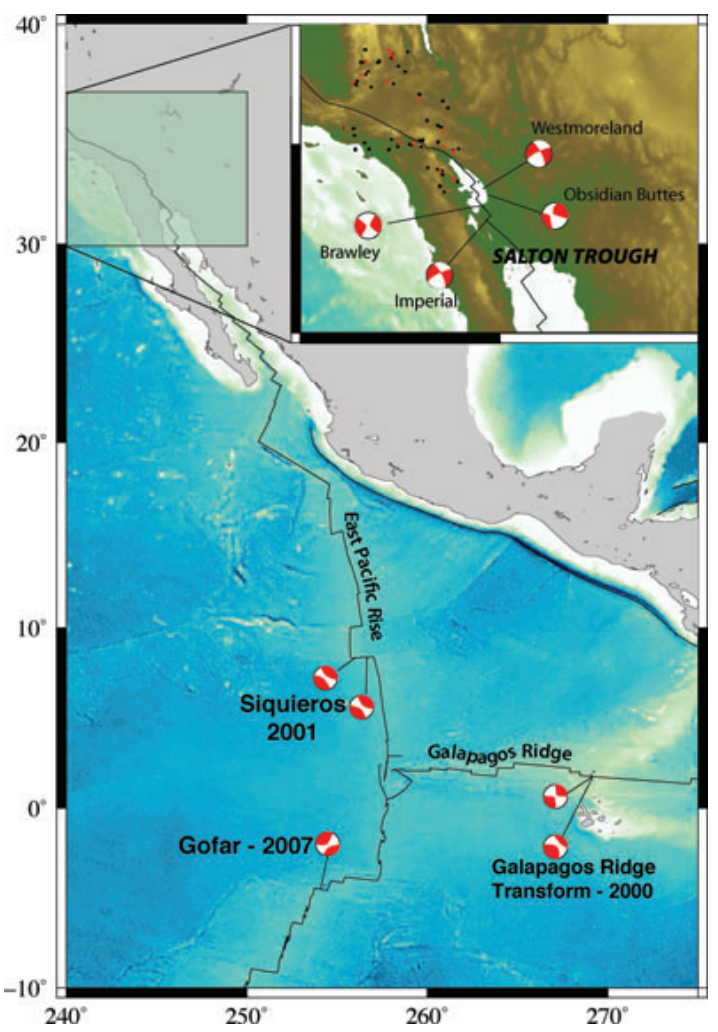

Figure 1. Strike-slip focal mechanisms from Global Centroid Moment Tensor (CMT) solutions representative of the three oceanic transform fault earthquakes analysed here: EPR sequences from the Siqueiros (2001) and Gofar (2007) transform faults, as well as the Galapagos Ridge transform (2000). Inlay map displays Southern California seismicity, including focal mechanisms representative of four Salton Trough swarms: Obsidian Buttes, West Moreland, Imperial fault and Brawley swarms. Dots show Southern California locations of seismic bursts identified by Vidale \& Shearer (2006) as swarm-like (red dots) and those identified as aftershock sequences (black).

CMT catalogue event from the same fault to determine its seismic moment. That event is used as the EGF for the rest of the event locations. All of the EGF events used here are greater than $M_{\mathrm{w}} 4.7$.

A swarm that occurred on the Galapagos Ridge transform in 2000 and a swarm on the Siqueiros transform in 2001 were detected by an array of autonomous hydrophones moored in the eastern equatorial Pacific maintained by NOAA (Fox et al. 2001). The earthquake catalogue derived from $t$-phases recorded by these hydrophones has a detection threshold of approximately $M_{\mathrm{w}} 3$. We utilized these catalogues for identifying the source times of large swarm events Magnitude estimates from the hydroacoustic catalogues are unreliable however, owing to complicated wave phenomena and the high-frequency energy of the $t$-phase (McGuire 2008). To determine reliable $M_{\mathrm{w}}$ estimates and locations, GSN waveforms for each $t$-phase event were extracted from a number of stations, bandpass filtered and cross-correlated with the EGF R1 waveform. Relative event locations were then obtained by fitting a cosine function to the differential R1 arrival times using an L1-norm fit. Best-fitting cosine scale and phase parameters characterize the distance and azimuth of the earthquake relative to the Green's function event (McGuire
2008). The location error is estimated using a bootstrap algorithm that assumes a Gaussian distribution with a $1 \mathrm{~s}$ standard deviation for the differential traveltime measurement errors (Shearer 1997; McGuire 2008). For the Gofar transform swarm that occurred in 2007, no events were detected by standard teleseismic catalogues. One of the sequence events was utilized as the EGF after its moment was first estimated relative to an earlier Gofar CMT event; this CMT event was effectively used as a preliminary Green's function for the single EGF moment calculation. The other events in the swarm were then detected by cross-correlating the 2007 EGF waveform with seismograms from several GSN stations. Individual events were identified in the cross-correlation process as arrivals with a high cross-correlation coefficient at a number of stations sufficient to ensure azimuthal coverage. The relative locations of these newly detected events were determined using the same procedure as was used for the Galapagos and Siqueiros swarms.

\subsection{Skew of moment release}

Seismic swarms are distinguished from typical mainshockaftershock sequences by their unique seismicity patterns: the largest swarm events tend to occur later in the sequence, swarms contain several large events as opposed to one clear mainshock, and elevated swarm seismicity is more prolonged in time (Fig. 2). Swarms thus deviate from established triggering models developed for aftershock sequences, such as Omori's law, which describes the decay rate of earthquakes following a mainshock (Omori 1894). Because of these deviations, quantitative earthquake triggering models such as the Epidemic Type Aftershock Sequence (ETAS) model (Ogata 1988) do not provide a good fit to the temporal evolution of moment release during a swarm (Llenos et al. 2009). One simple way to quantitatively identify earthquake clusters with swarm-like properties is through characterizing the timing of the largest earthquakes relative to the rest of the seismicity. To accomplish this, we calculate the skew of the seismic moment release history (i.e. the standardized third central moment) for each of the sequences that we analyse.

To calculate a skew value for a given sequence from its moment release history, we define the duration of the swarm as the period of time during which the seismicity rate is at least 20 per cent of its maximum value. This 20 per cent seismicity rate convention provides us with a consistent way to define the beginning $\left(t_{1}\right)$ and end of the sequence. The seismicity rate is calculated here using 2-hr time bins. Moments used to determine the moment release history, $F(t)=\int_{t_{1}}^{t} M_{\mathrm{o}} \mathrm{d} t$, are calculated using the definition of $M_{\mathrm{w}}$ (Kanamori 1977). For swarms in Southern California with local magnitudes $\left(M_{\mathrm{L}}\right)$ taken from SCEDC, we assume that $M_{\mathrm{L}}$ is equivalent to $M_{\mathrm{w}} \cdot F(t)$ is normalized so that within the determined time period of heightened seismicity $\lim _{t \rightarrow \infty} F(t)=1$. The third central moment is then calculated as an integral over the duration of the sequence:

$\bar{\mu}_{3}=\int\left(t-t^{*}\right)^{3} \mathrm{~d} F(t)$,

where $t^{*}$ is the centroid time (Jordan 1991). The skew of seismic moment release is represented by the standardized third central moment, which is equal to the third central moment divided by the standard deviation cubed, so that skew $=\bar{\mu}_{3} / \sigma^{3}$ (Panik 2005). Skew values quantitatively reflect the temporal evolution of the moment release during an earthquake sequence, with a value of zero for a symmetric sequence, a negative value for a sequence that begins slowly and ends abruptly, or a positive value for a sequence that begins abruptly and decays slowly, such as a typical 



Figure 2. The seven transform earthquake swarms are displayed in terms of event times and magnitudes, with time in hours relative to the largest event. Seismicity patterns differ from those usually associated with mainshock-aftershock triggering. In several sequences the largest events occurred several hours after the onset of increased seismicity and multiple large events occurred rather than one distinct main shock.

mainshock-aftershock sequence. This value serves as a rough way of quantitatively differentiating swarm-like sequences from main shock-aftershock sequences (see Discussion).

\subsection{Stress drop}

To differentiate swarm and aftershock sequences based on their spatial properties, we calculate an effective seismic stress drop for each sequence. While stress drop values for large strike-slip earthquakes are on the order of 1-10 MPa (Kanamori 1994; Peyrat et al. 2001; Abercrombie \& Rice 2005), the effective stress drop of swarms in Southern California tends to be an order of magnitude lower than mainshock-aftershock sequences (Vidale \& Shearer 2006). We estimate the effective stress drop for each swarm using an approach similar to that of Vidale \& Shearer (2006). Earthquake locations are used to make a rough approximation of the fault length as well as the fault width for events with reliable depth estimates. The cumulative moment of the sequence is calculated as the sum of the moments of the events in the sequence, which are estimated from catalogue reported values of $M_{\mathrm{L}}$ or $M_{\mathrm{w}}$. We assume a vertical strike-slip fault and estimate stress drop as:

$\Delta \sigma=\frac{2}{\pi} \mu \frac{\bar{D}}{w}, \quad$ with $\bar{D}=\frac{M_{\mathrm{o}}}{\mu S}$

(Kanamori \& Anderson 1975). Here, $\mu$ is the shear modulus, $\bar{D}$ is the average slip, $w$ is the seismic width and $S=w L$ is the fault area with $L$ equal to the fault length. For the swarms in Southern California, a rough estimate of width is made from the depths of the earthquakes and on the EPR transforms width is assumed to be $5 \mathrm{~km}$ (Trèhu \& Solomon 1983).

\section{RESULTS}

\subsection{Brawley Swarm}

In 1975 a large earthquake swarm occurred in the NW-striking Brawley seismic zone, just south of the Salton Sea. This swarm was analysed by Johnson \& Hadley (1976) using data recorded by 16 short-period instruments that were part of the USGS Imperial Valley array. Locations were derived for 264 events spanning $8 \mathrm{~d}$; the occurrence times and magnitudes of these events are displayed in the first panel of Fig. 2. Epicentres exhibit bilateral migration, spreading outward at a rate of approximately $0.5 \mathrm{~km} \mathrm{hr}^{-1}$ (Johnson $\&$ Hadley 1976). A source model involving the propagation of a right-lateral creep event was hypothesized as an explanation for the hypocentral migration. Johnson and Hadley cited a number of observations as support for this model, including an increase in detected shallow seismicity directly before the onset of the swarm, as well as the existence of seismically quiescent fault segments in the region.

During the 1975 Brawley swarm, elevated seismicity levels persisted for over $100 \mathrm{hr}$ after the largest events, resulting in a positive skew value of 1.8 (Table 1). Including the largest event, there were six earthquakes with moment magnitudes greater than 4.0 , several of which preceded the largest, $M_{\mathrm{L}} 4.7$ event. The effective stress drop calculated for this sequence using a fault length of $12 \mathrm{~km}$ and width of $9 \mathrm{~km}$ estimated from SCEDC catalogue locations is $0.032 \mathrm{MPa}$. Our estimate of fault length and width are consistent with the Johnson and Hadley estimate of the swarm's spatial extent, which was determined using local network data.

\subsection{West Moreland and Obsidian Buttes swarms}

The 1981 West Moreland swarm and 2005 Obsidian Buttes swarm also both occurred within the Brawley Seismic Zone. Events

(C) 2009 The Authors, GJI Journal compilation (C) 2009 RAS 
Table 1. Southern California and RTF Swarm Seismicity parameters

\begin{tabular}{|c|c|c|c|c|c|c|}
\hline Sequence & skew & Total $M_{\mathrm{w}}$ & Fault length & Width & Total stress drop & Approx. migration rate \\
\hline Brawley 1975 & +1.8 & 5.04 & $12 \mathrm{~km}$ & $8 \mathrm{~km}$ & $0.038 \mathrm{MPa}$ & $0.5 \mathrm{~km} \mathrm{hr}^{-1}$ (Johnson \& Hadley) \\
\hline West Moreland 1981 & -11.1 & 5.80 & $16 \mathrm{~km}$ & $6 \mathrm{~km}$ & $0.71 \mathrm{MPa}$ & $1.0 \mathrm{~km} \mathrm{hr}^{-1}$ (Lohman \& McGuire) \\
\hline Obsidian Buttes 2005 & -0.9 & 5.27 & $8 \mathrm{~km}$ & $5 \mathrm{~km}$ & $0.33 \mathrm{MPa}$ & $0.5 \mathrm{~km} \mathrm{hr}^{-1}$ (Lohman \& McGuire) \\
\hline Imperial 2003 & -1.6 & 3.84 & $2.5 \mathrm{~km}$ & $2 \mathrm{~km}$ & $0.047 \mathrm{MPa}$ & $0.5 \mathrm{~km} \mathrm{hr}^{-1}$ (this study) \\
\hline Galapagos 2000 & -0.29 & 5.90 & $45 \mathrm{~km}$ & $5 \mathrm{~km}$ & $0.50 \mathrm{MPa}$ & $1.0 \mathrm{~km} \mathrm{hr}^{-1}$ (this study) \\
\hline Siqueiros 2001 & +1.5 & 5.85 & $40 \mathrm{~km}$ & $5 \mathrm{~km}$ & $0.49 \mathrm{MPa}$ & Uncertain \\
\hline Gofar 2007 & +0.5 & 5.05 & $25 \mathrm{~km}$ & $5 \mathrm{~km}$ & $0.049 \mathrm{MPa}$ & $\sim 0.5-1.0 \mathrm{~km} \mathrm{hr}^{-1}$ (this study) \\
\hline Hector Mine 1999 & +33.3 & 7.1 & $85 \mathrm{~km}$ & $10 \mathrm{~km}$ & $4.31 \mathrm{MPa}$ & - \\
\hline San Simeon 2003 & +16.7 & 6.50 & $35 \mathrm{~km}$ & $10 \mathrm{~km}$ & $1.30 \mathrm{MPa}$ & - \\
\hline Joshua Tree 1992 & +8.11 & 6.11 & $20 \mathrm{~km}$ & $10 \mathrm{~km}$ & $0.59 \mathrm{MPa}$ & - \\
\hline
\end{tabular}
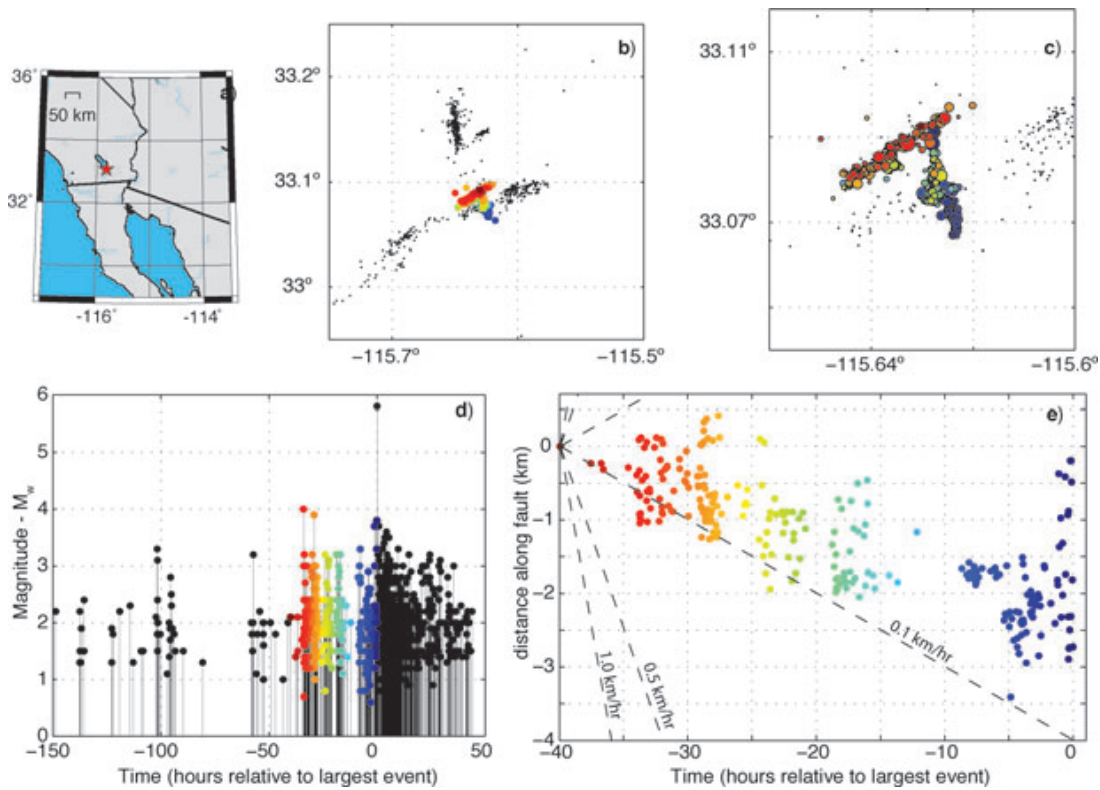

Figure 3. 1981 West Moreland swarm. (a) General geographic location of sequence south of the Salton Sea. (b) Event locations derived from HypoDD double-difference arrival time relocation algorithm (Lohman \& McGuire 2007). In panels (b)-(e) colour indicates relative occurrence time of individual event. (c) Larger scale diagram of earthquake locations for events that occurred $\sim 30-0 \mathrm{hr}$ before the largest event of the sequence. Bilateral hypocentral migration along a NE-striking fault early in this time period is followed by southward migration of events. (d) Local magnitude $\left(M_{\mathrm{L}}\right)$ versus time in hours relative to the largest event. (e) Distance along the fault plotted against occurrence time for events that occurred in the same $-30-0$ hr time period preceding the largest event. A migration rate of approximately $0.1 \mathrm{~km} \mathrm{hr}^{-1}$ is apparent for events spreading southward along the NW striking fault.

associated with these sequences were recorded by the Southern California Seismic Network and were the focus of the study by Lohman \& McGuire (2007). Peak seismicity during the West Moreland swarm spanned more than $3 \mathrm{~d}$, and seismicity was elevated above the background rate for over $130 \mathrm{hr}$ before the occurrence of the largest event, a $M_{\mathrm{w}}$ 5.9. Swarm events demonstrated a complicated hypocentral migration pattern. Early in the sequence, hypocentres spread bilaterally along a northeast-southwest striking fault and then migrate south within the seismic zone on along a northwest-southeast striking fault during the $30 \mathrm{hr}$ preceding the largest event at a rate of about $0.1 \mathrm{~km} \mathrm{hr}^{-1}$ (Fig. 3). Event migration is difficult to interpret following the largest swarm event because the rupture area associated with the $M_{\mathrm{w}} 5.9$ obscures spatial patterns. Similar to the West Moreland swarm, bilateral migration was observed during the initial stages of the multiple day Obsidian Buttes swarm. Earthquake hypocentres demonstrate bilateral spreading along the northeast-striking fault at a rate of approximately $0.5 \mathrm{~km} \mathrm{hr}^{-1}$ during two distinct seismicity bursts that occurred approximately 35 and $25 \mathrm{hr}$ before the largest swarm event (Fig. 4). Deformation associated with this swarm was also observed geodetically, using InSAR observations, and was recorded by two nearby Southern California Integrated GPS Network (SGIGN) stations. An inversion of the InSAR data demonstrated that significant shallow aseismic slip was required during the Obsidian Buttes swarm to explain the extent of surface deformation (Lohman \& McGuire 2007).

We calculate skew values of -11.1 and -0.9 for the West Moreland and Obsidian Buttes swarms, respectively. These negative values result from a large amount of moment release before the sequences' temporal centroid, which is essentially coincident with the largest event. The negative skew values signify the ramping up of seismic activity before the largest events occur. The effective 


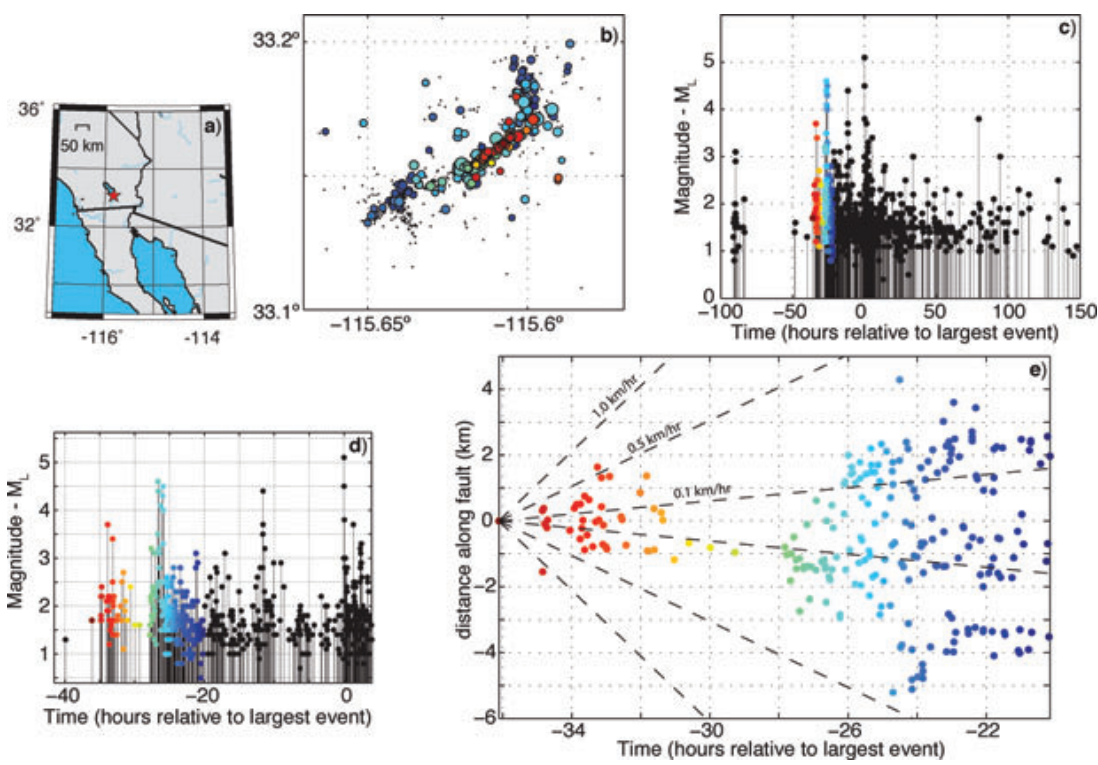

Figure 4. 2005 Obsidian Buttes swarm. (a) General geographic location. (b) Event locations derived from HypoDD double-difference arrival time relocation algorithm (Lohman \& McGuire 2007). In panels (b)-(e) colour corresponds to relative occurrence time of event. (c) Local magnitude $\left(M_{\mathrm{L}}\right)$ versus time in hours relative to the largest event. (d) Larger scale time-magnitude plot highlights the time period preceding the largest event of the sequence ( $\sim-30$ to $-20 \mathrm{hr}$ ) when spatial migration is apparent along the NE-striking fault. (e) During this time period, hypocentres migrate bilaterally during two distinct seismicity bursts at a rate between 0.1 and $0.5 \mathrm{~km} \mathrm{hr}^{-1}$.

stress drop for these sequences was estimated at approximately 0.71 and $0.33 \mathrm{MPa}$, again relatively low compared to effective stress drop values typical of large mainshocks in the region.

\subsection{Imperial fault swarm}

In 2003 May, an earthquake swarm occurred on a NE-striking fault within the Imperial fault zone. During this sequence, seismic activity was elevated for approximately $30 \mathrm{hr}$, with the largest earthquake, a $M_{\mathrm{L}} 3.8$, occurring about $9 \mathrm{hr}$ after the onset of elevated seismicity. Arrival times from the Mexican RESNOM and SCSN catalogues were combined and used to relocate swarm events. About 10000 traveltime differences for pairs of events were used to relatively relocate 51 earthquakes from $P$ - and $S$-wave arrivals observed from a combination of 46 Californian and Mexican stations (Fig. 5b). Event hypocentres focus onto a fault plane approximately $2.5 \mathrm{~km}$ long, with location errors of $10 \mathrm{~m}$ based on the SVD error analysis. Events of this sequence also demonstrate northward hypocentral migration along the fault, at a rate between 0.1 and $0.5 \mathrm{~km} \mathrm{hr}^{-1}$ (Fig. 5). The skew value calculated for the moment release of the Imperial fault swarm is -1.6 , again reflecting a pattern of abundant small-magnitude seismicity ramping up to the largest events. The effective stress drop was estimated at $0.047 \mathrm{MPa}$.

\subsection{Galapagos Swarm}

In 2000 October a seismic swarm was recorded on a left-lateral transform fault offsetting the Galapagos Ridge, just north of the Galapagos Islands. One hundred and thirty eight events associated with this episode were recorded by the NOAA hydrophone array deployed in the eastern Pacific Ocean (Fox et al. 2001). Approximately, $5 \mathrm{hr}$ after the onset of the swarm, a $M_{\mathrm{w}} 5.2$ event occurred, followed by a decrease in moment release rate until approximately hour 12, when a doublet ( $M_{\mathrm{w}} 5.7$ and 5.5) occurred. These were followed a few hours later by the largest event, a $M_{\mathrm{w}}$ 5.9. The two largest earthquakes had focal mechanisms calculated in Global CMT catalogue (Dziewonsk et al. 2003), both of which were strike slip. In total, 30 events greater than $M_{\mathrm{w}} 4.0$ occurred before the seismicity rate abruptly returned to background levels, approximately $36 \mathrm{hr}$ after the swarm began.

Events associated with the Galapagos swarm were located relative to an EGF that occurred on 10/21 at 15:52:53 UTC using the surface wave relative relocation method (see Section 2) with GSN waveform data from 19 stations. The EGF was the largest event of the sequence and had a $M_{\mathrm{w}}$ calculated in Global CMT catalogue (Dziewonsk et al. 2003). Twelve events with the best constrained centroid inversions have been used here to analyse the spatial characteristics of this swarm (Fig. 6). Based on these locations, bilateral hypocentral migration along the transform occurred at a rate between 0.1 and $1.0 \mathrm{~km} \mathrm{hr}^{-1}$ (Fig. 7).

Seismicity associated with the Galapagos swarm was also recorded by an 11 station broad-band seismometer array, deployed on the Galapagos Islands (Hooft et al. 2003). Although the landbased seismometer array, located entirely to the south of the fault, and the hydrophone array, located entirely to the west of the fault, were not well placed for constraining Galapagos Ridge transform earthquake locations, they were useful for determining event magnitudes with a higher degree of accuracy than can be achieved from teleseismic data. Love-wave arrivals from rotated transversecomponent records were identified using an EGF technique similar to that used with the teleseismic R1-arrivals, as described in Section 2. One hundred and nine events were detected with cross-correlation coefficients greater than 0.7 from seismograms filtered to $0.03-0.08$ Hz. Magnitude estimates for these events are displayed in Fig. 7(c) as black symbols. Based on this Love-wave derived catalogue we 

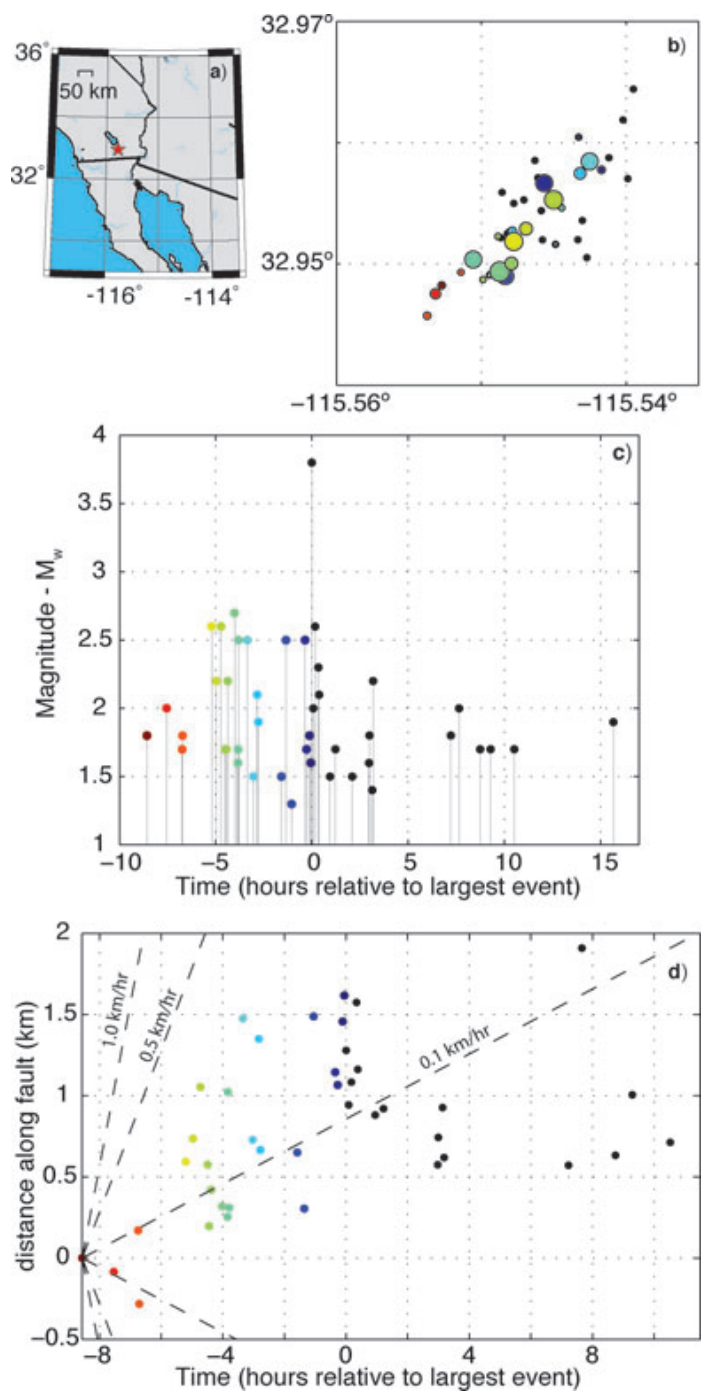

Figure 5. 2003 Imperial fault swarm. (a) General geographic location (b) Event locations derived from HypoDD double-difference arrival time relocation algorithm using data from SCEDC (California) and RESNOM (Mexico) seismic arrays. In panels (b)-(d) colour corresponds to time of event. (c) Local magnitude versus time plot shows small magnitude seismicity ramping up to the largest event $10 \mathrm{hr}$ into the sequence. (d) Hypocentres migrate unilaterally along the NE-striking fault from the southwest to the northeast at rates between 0.1 and $0.5 \mathrm{~km} \mathrm{hr}^{-1}$.

calculated a skew of -0.29 , reflecting the significant amount of moment release that occurred before the largest event of the sequence. The cumulative moment from the Love-wave determined magnitudes was used with the fault length estimated from surface wave relocations to determine an effective stress drop of $0.50 \mathrm{MPa}$.

\subsection{Siqueiros swarm}

A large earthquake sequence occurred on the Siqueiros transform fault in 2001 April and was also detected by the eastern Pacific

(C) 2009 The Authors, GJI

Journal compilation (C) 2009 RAS
NOAA hydroacoustic array. One hundred and seventy $t$-phase events associated with the 2001 sequence were observed by hydrophones; these events were located on the $\mathrm{S} 2$ and $\mathrm{S} 3$ segments of the Siqueiros fault (Gregg et al. 2006, Fig. 8a). The largest event was a $M_{\mathrm{w}}$ 5.7, as calculated in the Global CMT catalogue (Ekström et al. 2003), which occurred very early in the sequence. With the CMT event as the Green's function, 13 events with magnitudes greater than 4.2 were detected and located using the surface wave method. Seismograms used in the centroid location inversions came from 21 GSN stations that were bandpass filtered to $0.02-0.04 \mathrm{~Hz}$. Earthquake centroids clearly locate onto the two fault segments, however the spatial evolution of seismicity during the sequence is difficult to interpret (Fig. 8). During the first $8 \mathrm{hr}$ following the largest event, centroids migrated from west to east along the $\mathrm{S} 3$ segment of the Siqueiros fault, corresponding to the first $45 t$-phase events. Seismicity then became active on the S2 segment to the west, and again migrated east for the remainder of the episode. These two fault segments are separated by an intertransform spreading centre (ITSC). Gregg et al. (2006) proposed that some of the seismicity that occurred later and to the west was associated with secondary normal faults flanking the ITSC. While this may account for some of the smaller seismicity seen in the $t$-phase data, based on the surface wave locations and waveform similarity, the large events occurred as right-lateral strike-slip earthquakes, similar to the CMT catalogue event (Ekström et al. 2003). The skew of the Siqueiros sequence is positive, around +1.5 , reflecting the occurrence of the largest event early in the sequences, followed by prolonged seismic activity. The total stress drop from earthquakes on both segments was calculated at approximately $0.49 \mathrm{MPa}$.

\subsection{Gofar swarm}

The Gofar transform fault is the southernmost and most seismically active of the Quebrada-Discovery-Gofar fault system that offsets the EPR at approximately $4^{\circ}$ south. In the end of 2007 December, a 2-d-long earthquake sequence was recorded on the eastern segment of the Gofar transform. Events associated with this sequence were detected and located using the R1 surface wave method, with data from $15 \mathrm{GSN}$ stations. The location and magnitude of the empirical Green's function event used in this analysis were calculated relative to a CMT event that occurred on the same fault segment in 2003. The EGF used for locating the remainder of the sequence events was a $M_{\text {w }} 5.3$ that occurred on 12/29 at 00:48:00, approximately $5 \mathrm{hr}$ after the the beginning of elevated swarm seismicity. The 13 events with the best surface wave derived centroid locations focus onto a $25 \mathrm{~km}$ long segment of the fault (Fig. 9). From these locations it appears that earthquakes spread bilaterally along the east-west striking fault a rate of approximately $0.5-1.0 \mathrm{~km} \mathrm{hr}^{-1}$. This sequence has a skew of +0.5 and a stress drop of approximately $0.049 \mathrm{MPa}$.

\subsection{Southern California distributed seismicity}

In order to develop a basis for comparison in our analysis of earthquake swarms on transform boundaries, we combine our findings from the seven moderate-sized recent and historical sequences described above, to those recently published by Vidale \& Shearer (2006). In their analysis of small seismicity clusters (burst radius $<2 \mathrm{~km}$ ) in Southern California, 71 seismic bursts were identified using data from the SHLK_1.01 catalogue of cross-correlation relocations (Shearer et al. 2005). Fourteen of these events were classified as aftershock sequences on the basis that they began with their 
a.) Galapagos Locations

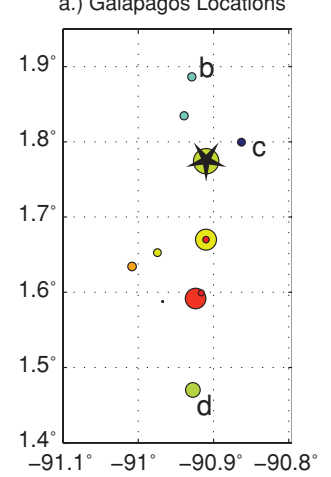

d.) 10/21/00 16:32:37 UTC - Mw 4.911

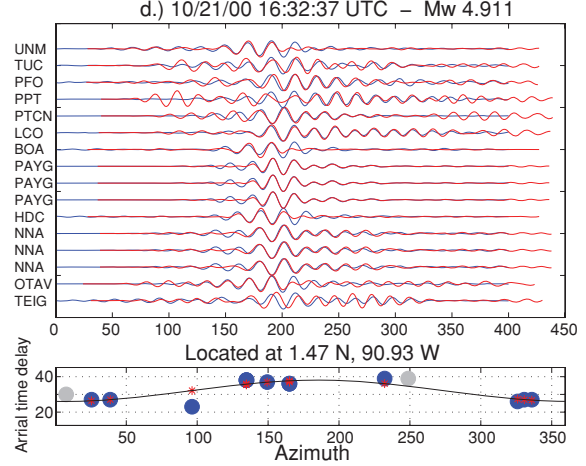

b.) $10 / 21 / 0020: 55: 50$ UTC - Mw 4.6358

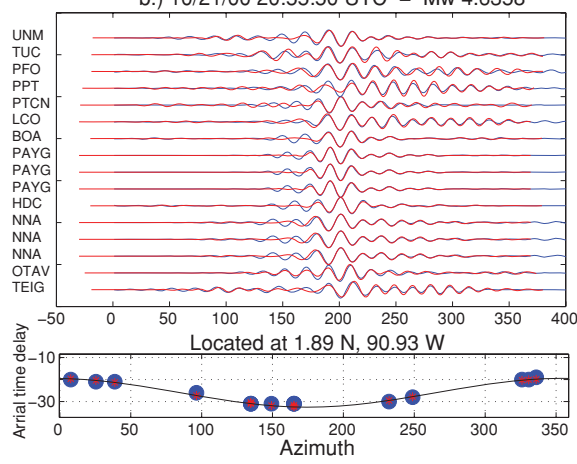

c.) 10/22/00 12:01:40 UTC - Mw 4.3831

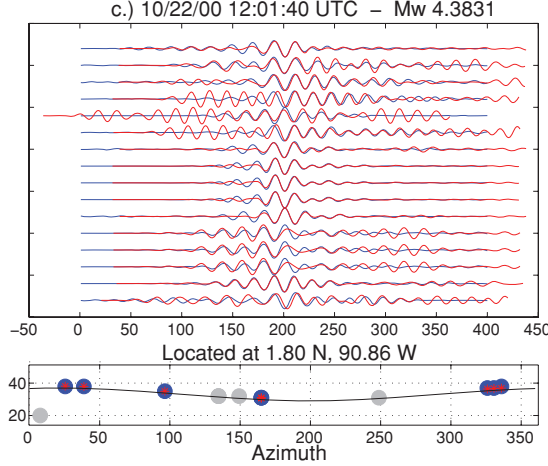

Figure 6. (a). Locations of events associated with the 2000 Galapagos sequence derived from R1 surface waves. Panels (b)-(d) illustrate three example centroid location inversions. The upper panel of each location figure demonstrates the empirical Green's function cross-correlation technique that was used to identify arrivals with similar focal mechanisms recorded at GSN stations. Blue lines represent the bandpass-filtered EGF waveform at each station, red lines represent waveforms of the event being located. Locations are derived by fitting a cosine function to relative arrival time delays from a set of azimuthally distributed stations. The cosine fit is displayed in lower panels of each location figure. The Green's function event used in this analysis is labelled with a star in panel (a). Events which located north of the Green's function event (b) and (c) are represented by an azimuth-dt cosine function with a $180^{\circ}$ phase shift as compared to events that locate south of the Green's function event (d).

largest event, and 18 events were identified as swarm-like based on various qualitative factors. Specifically, swarms were recognized as episodes with the largest events occurring later into the sequence, large spatial extents relative to the largest earthquake (implying a low stress drop), and in many cases, a systematic spatial evolution of hypocentres, spreading either outward along the fault or linearly in one direction with time. We calculate skew and stress drop values for the 14 aftershock and 18 swarm-like sequences in the Vidale and Shearer data set; these are displayed in Fig. 10. Skew and stress drop values that were calculated for the seven swarms presented above are also displayed, as well as values for three large historical California earthquakes: Hector Mine, San Simeon and Joshua Tree and their aftershock sequences (Table 1). For all skew and stress drop calculations, swarms were defined using the 20 per cent seismicity rate cutoff convention for the temporal limits of swarm extent, outlined in Section 2. The estimated stress drop values for the Vidale and Shearer seismic bursts were calculated assuming circular faulting with a burst radius that is the mean of the distances to the events in each sequence form the centroid of the sequence (Vidale $\&$ Shearer 2006). The stress drop for the three large California aftershock sequences is calculated by estimating a fault length and width and assuming a vertical strike-slip fault, similar to the stress drop calculations made for the seven large swarms. Although these stress drop values should not be taken to be equivalent to effective stress drop values associated with a single large rupture, they do provide a means of approximately characterizing the ratio of moment release to rupture area. Fault length, width, stress drop and skew values are also presented in Table 1.

Based on the seismicity parameters displayed in Fig. 10, swarmlike sequences cluster toward the low stress drop-low skew quadrant of the plot, with most swarms displaying negative skew values or small positive values, below +5 . Both the aftershock-like seismicity bursts and the large aftershock sequences meanwhile, cluster fairly regularly into the quadrant representative of higher stress drops and high positive skew values. These positive skew values reflect established empirical triggering patterns such as Omori's Law. The quantitative skew and stress drop parametrization of earthquake sequences presented in this way corresponds well with the Vidale and Shearer observational classification of a sequence being 'aftershock-like' or 'swarm-like' based on the duration and presence or lack of an initiating main shock, as well as the spatial extent.

\section{DISCUSSION}

Our analysis of the spacial and temporal characteristics of swarms on Southern California and EPR transform faults exposes three

(c) 2009 The Authors, GJI Journal compilation (C) 2009 RAS 

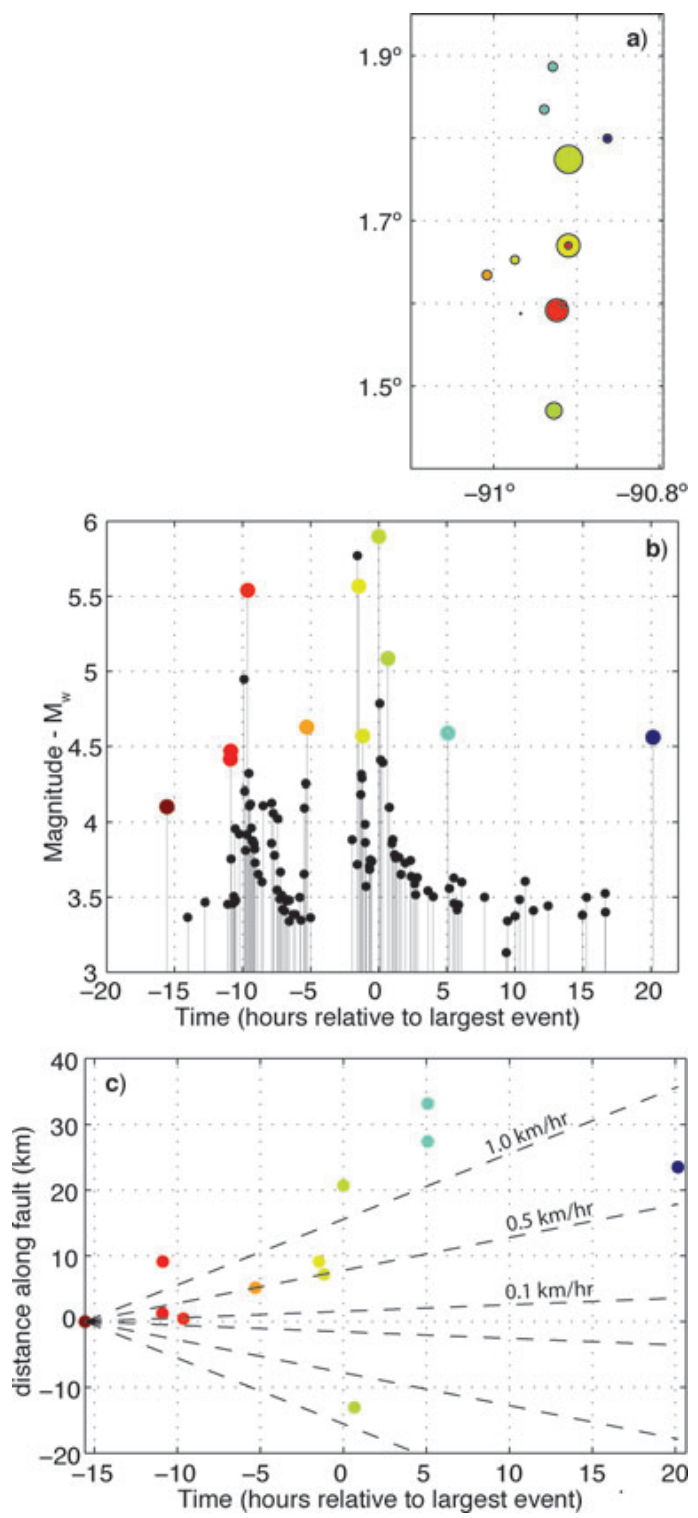

Figure 7. 2000 Galapagos Swarm (a) Centroid locations derived using R surface wave relocation method. Colour in panels (a)-(c) indicates time of event. (b) Time versus moment magnitude. Black symbols correspond to magnitudes derived from Love-wave cross-correlation using data from the Galapagos Islands seismometer array (Hooft et al. 2003). Coloured symbols correspond to events relocated using teleseismic R1 surface wave data (c) Surface wave located events demonstrate northward migration along the Galapagos Ridge transform during the swarm at approximately $1.0 \mathrm{~km} \mathrm{hr}^{-1}$.

distinct properties of these sequences that signify a consistent physical driving mechanism. A deviation of the temporal evolution of moment-release from typical scaling laws (i.e. low skew), low effective stress drop values, and migration velocities of $0.1-1.0 \mathrm{~km} \mathrm{hr}^{-1}$ are all consistent with a model in which aseismic fault slip modifies the stress-field and triggers swarm seismicity. Historical sur-
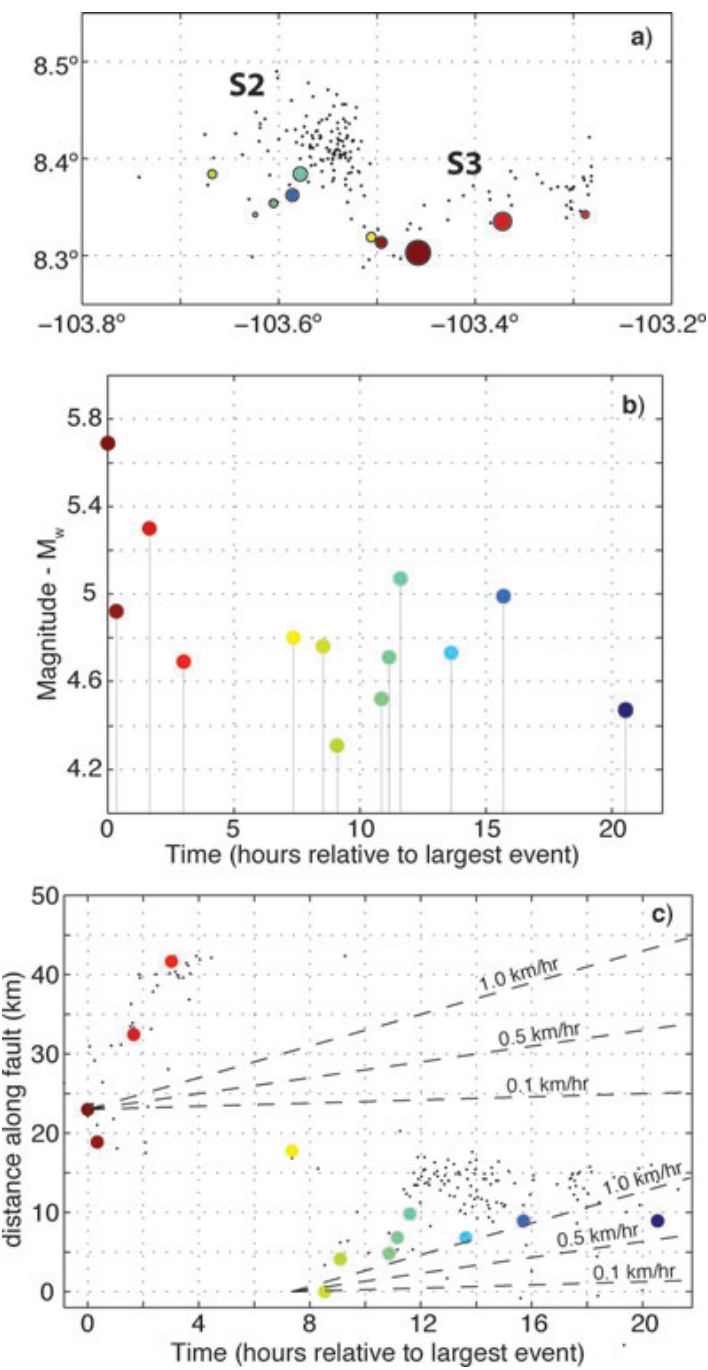

Figure 8. 2001 Siqueiros transform sequence. (a) Locations of events derived from surface wave relocation technique are displayed as coloured symbols. In panels (a)-(c) colour corresponds to occurrence time of individual events. Black dots represent $t$-phase data from the NOAA hydroacoustic catalogue. Earthquakes occurred on the S2 and S3 segments of the Siqueiros fault. (b) Time and moment magnitudes. (c) Seismicity demonstrates complex temporal-spatial migration patterns. During the swarm events migrated from west to east along the S3 segment, and then late in the sequence demonstrate migration again from west to east along the S2 segment at approximately $1.0 \mathrm{~km} \mathrm{hr}^{-1}$.

face deformation observations as well as recent geodetic studies in the Salton Trough have noted a prevalence of shallow creep events (Lyons et al. 2002; Lyons \& Sandwell 2003; Lohman \& McGuire 2007), demonstrating the feasibility of this mechanism for the Southern California faults. There have been no direct geodetic observations of creep on EPR transform faults, but it is well documented that oceanic transforms must have a significant component of aseismic fault slip (Bird et al. 2002; Boettcher \& Jordan

(C) 2009 The Authors, GJI

Journal compilation (C) 2009 RAS 

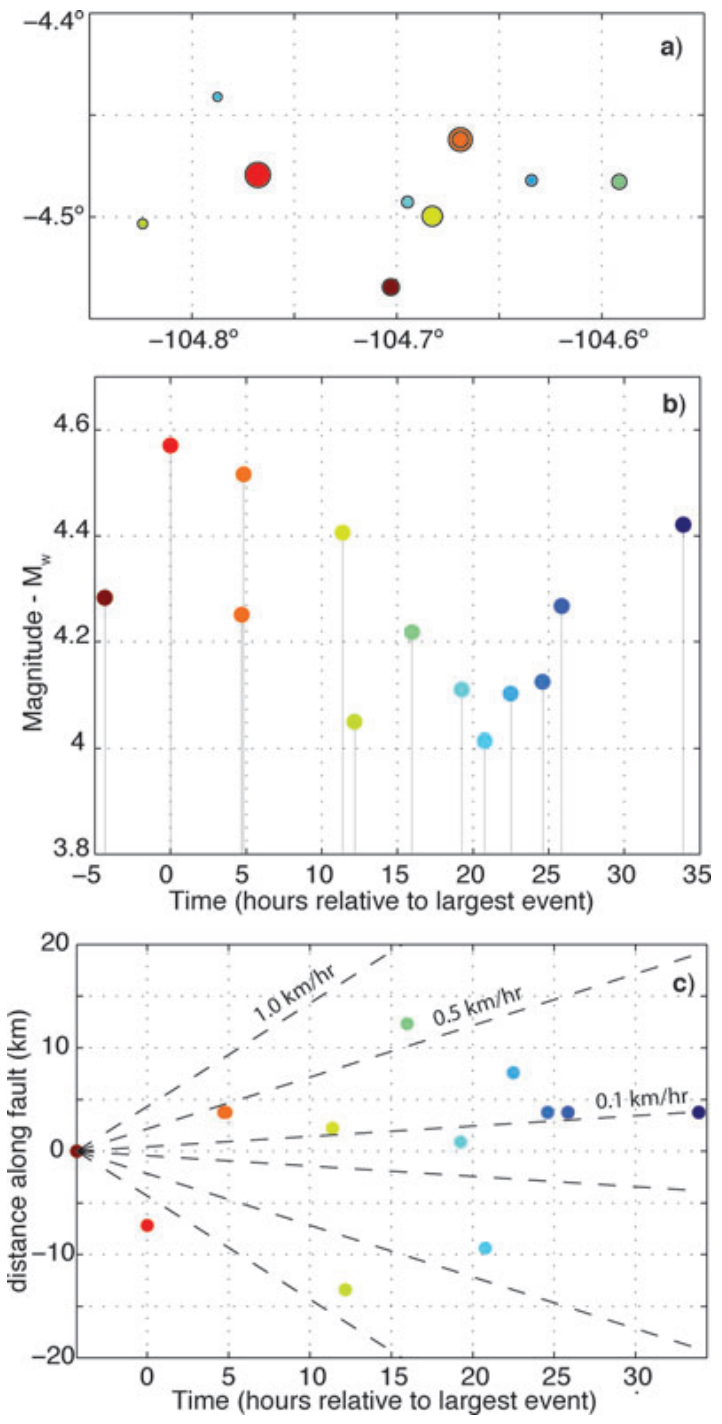

Figure 9. 2007 Gofar Swarm (a) Hypocentre locations derived using R surface wave location technique. In panels (a)-(c) colour corresponds to the occurrence time of individual events. (b) Time and moment magnitude of 13 large events. (c) Event centroid locations migrate along the eastern segment of the Gofar transform from west to east at a rate of approximately $0.5-$ $1.0 \mathrm{~km} \mathrm{hr}^{-1}$

2004), making creep a plausible explanation for the EPR swarms as well.

Many of the sequences examined here display a gradual rampingup of moment release, with the largest events occurring late in the sequence, multiple large events and seismicity that is prolonged in time. These characteristic features of seismic swarms: the deviation from both the empirical Båth's Law and Omori-like temporal decay, are manifest into small positive or often negative skew values relative to those associated with aftershock sequences (Fig. 10). Especially when they are combined with observations of the characteristic spatial migration rate associated with swarms and low seismic stress drop, anomalous skew values calculated here may indicate episodes in which seismicity deviates from aftershock-like Coulomb stress-triggering patterns, and is driven instead by a transient stressing event.

In order to quantitatively demonstrate the deviation from typical mainshock-aftershock triggering statistics that occurs during swarm-like bursts, Llenos et al. applied the empirical EpidemicType Aftershock Sequence (ETAS) model to a number of sequences and found that it could not fit swarm-like seismicity patterns (Llenos et al. 2009). The ETAS model combines empirical triggering laws, including Omori's Law, and has been used to represent the normal occurrence rate of earthquakes triggered by previous events (Ogata 1988; Helmstetter \& Sornette 2003a). Here, we use the ETAS model to investigate how these empirical laws can be applied to simulate seismicity associated with the Galapagos swarm. We first optimize ETAS seismicity parameters over a 26-month time period preceding the large swarm in 2000 on the Galapagos Ridge transform fault. Values of the ETAS parameters are derived here as the maximum likelihood fit based on events greater than $M_{\mathrm{w}} 3.6$ (the magnitude threshold of our surface wave derived catalogue) assuming an Omori time decay parameter, $p$, that is constrained to 1.0 (Bohnenstiehl et al. 2002) and the moment-distribution exponent, $\alpha$, constrained to 0.8 (Boettcher \& Jordan 2004; McGuire et al. 2005). For this fault, the best-fitting background seismicity rate is $\mu=0.03$ earthquakes/d and local seismicity parameters $c=0.01 \mathrm{~d}$ and $K=0.3$. In Fig. 11, the observed seismicity catalogue (blue line) of Galapagos events spanning 1999 May to 2002 September, including the 2000 swarm, is presented along with ETAS-predicted seismicity derived using the optimized parameters (red line). The seismicity is displayed in the form of the number of cumulative events versus ETAS-transformed time (Ogata 2005), which represents the amount of time predicted to elapse before the next seismic event based on the background seismicity rate and the aftershocks of previous seismicity. The observed seismicity deviates significantly from that which is predicted using the ETAS model during the period of the swarm (shaded region). Early in the sequence, the cumulative number of observed earthquakes far exceeds that predicted by the ETAS model, and then following the largest swarm event exhibits a relatively diminished rate compared to the ETAS prediction. Anomalous skew values, like the -0.29 skew of the Galapagos swarm, reflect these types of deviations, and indicate a triggering phenomenon that cannot be represented by a stationary stochastic model that emulates aftershock seismicity. Similar to the findings of the Llenos et al. study, this analysis indicates that in order to reproduce seismicity rates observed during swarms, an additional stressing phenomenon is required beyond the triggering associated with one seismic event triggering another.

The low effective stress drop values characteristic of swarms also provide evidence for a unique driving process. Values calculated for sequences here, on the order of 0.01-1.0 MPa, are lower than values for typical mainshock-aftershock sequences of similar size (i.e. 1-10 MPa). Recently, Brodsky \& Mori (2007) demonstrated that creep events have lower stress drops than ordinary earthquakes, on the order of $0.1 \mathrm{MPa}$. Low effective stress drop values estimated for swarms in this study are thus consistent with values that would be expected for aseismic creep events. Assuming the $0.1 \mathrm{MPa}$ value applies to creep events driving the EPR swarms as well, we can roughly estimate the magnitude of the aseismic slip. For the example of the Gofar sequence, with a fault length $L=25 \mathrm{~km}$, width $w=$ $5 \mathrm{~km}$ and stress drop $\Delta \sigma=0.1 \mathrm{MPa}$ we find an aseismic moment release of approximately $M_{\mathrm{w}} 5.3$. While this is clearly only a first order estimate, it suggests that aseismic slip during the EPR swarms 


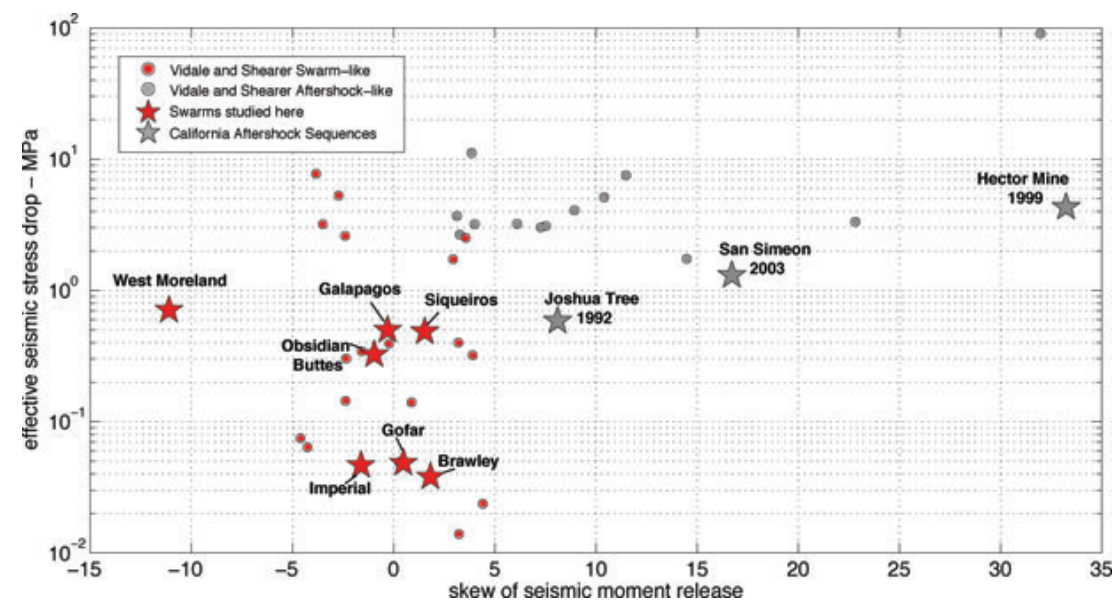

Figure 10. Comparison of calculated values of the skew of seismic moment release history and effective seismic stress drop for each of the seven sequences presented here along with those from the Vidale \& Shearer (2006) analysis of seismic bursts in Southern California. Three large historical mainshock-aftershock sequences from California are also displayed for comparison purposes. Oceanic transform sequences and continental transform swarms from the Salton Trough (red stars) as well as the Vidale \& Shearer 'swarm-like' bursts (red dots) trend toward the low skew-low stress drop quadrant of the parameter space. This differs from those values associated with the aftershock sequences shown (i.e. skew $>5, \Delta \sigma>\sim 1 \mathrm{MPa}$, grey stars and dots).

would be comparable in size to the seismic component, roughly agreeing with the long-term partitioning of slip between the two failure modes as seen in global studies of the slip deficit on oceanic transforms (Bird et al. 2002; Boettcher \& Jordan 2004).

The relatively narrow range of spatial migration velocities between 0.1 and $1.0 \mathrm{~km} \mathrm{hr}^{-1}$ may be the most direct evidence of aseismic fault slip. Observations of seismicity triggered by borehole fluid injection (Audigane et al. 2002; Shapiro et al. 2005) and subsurface fluid flow from magma degassing (Hainzl \& Ogata 2005) consistently show earthquake hypocentres that spread following much slower pore-pressure diffusion, with distances that increase proportional to $t^{1 / 2}$ at rates not exceeding metres per day. Based on the migration rates seen here, the Salton Trough and EPR swarms are most likely not caused by fluid-flow transients. Geodetic observations further rule out magma intrusion in favor of fault slip (Lohman \& McGuire 2007). Limited geodetic observations of propagation speeds associated with slow earthquakes and aseismic creep events are, to first order, consistent with migration rates between 0.1 and $1.0 \mathrm{~km} \mathrm{hr}^{-1}$. Studies using creepmeters to observe creep events on the San Andreas, Calaveras and Hayward faults determine propagation speeds on the order of $10 \mathrm{~km} \mathrm{~d}^{-1}$ $\left(0.4 \mathrm{~km} \mathrm{hr}^{-1}\right)$ (King et al. 1973; Burford 1977). More recently, borehole strainmeter observations of a slow earthquake sequence on the San Andreas were found to be consistent with rupture propagation rates between 0.2 and $0.35 \mathrm{~ms}^{-1}\left(0.7-1.3 \mathrm{~km} \mathrm{hr}^{-1}\right.$ ) (Linde et al. 1996). In the Salton Trough, creep events from the Cerro Prieto stepover at the southern end of the Imperial fault have been observed with a rupture propagation velocity of $4 \mathrm{~cm} \mathrm{~s}^{-1}\left(0.14 \mathrm{~km} \mathrm{hr}^{-1}\right)$ using multiple creepmeters (Glowacka et al. 2001). While data on creep rupture propagation velocity is limited due to sparse instrumentation, values from strike-slip faults in California and Mexico are within the range of our observations of seismicity migration rates.

Theoretical expressions relating stress drop, rupture propagation velocity and slip velocity provide the final link between earthquake swarms and aseismic creep events. Ida (1973) and Ohnaka and

(C) 2009 The Authors, GJI

Journal compilation (C) 2009 RAS
Yamashita (1989) derived a relation between maximum slip velocity, $v_{\max }$, and rupture propagation velocity, $v_{r}$, for a mode II shear rupture propagating with a constant velocity of the form:

$v_{\max }=\gamma \frac{\Delta \sigma_{b}}{\mu} v_{r}$.

Here, $\gamma$ is a constant on the order of one and $\Delta \sigma_{b}$ is the breakdown stress drop, which characterizes the difference between the the peak stress and stress level during frictional sliding (Shibazaki \& Shimamoto 2007). Rate-state friction models were used by Rubin (2008) to determine essentially the same relation for a propagating rupture front with a quasi-steady shape

$\frac{v_{r}}{v_{\max }}=\frac{\mu}{\Delta \sigma}, \quad$ and $\quad \Delta \sigma=\frac{b \sigma}{\ln \left[v_{\max } \theta / D_{c}\right]}$,

with $\theta$ representing the 'state' ahead of the propagating front, $D_{c}$, the characteristic slip distance for state evolution, $b$, a lab-derived friction parameter that characterizes the drop in friction from peak to steady-state sliding levels and $\sigma$ the effective normal stress. Using this relation for slip and rupture propagation velocity with approximate values derived from our analyses of swarm seismicity, $\Delta \sigma \sim$ $0.1 \mathrm{MPa}, v_{r} \sim 0.5 \mathrm{~km} \mathrm{hr}^{-1} \sim 0.14 \mathrm{~m} \mathrm{~s}^{-1}$ (Table 1) and the shear modulus $\mu=30 \mathrm{GPa}$, we derive a maximum slip velocity, $v_{\max }$ $\sim 5 \times 10^{-7} \mathrm{~m} \mathrm{~s}^{-1}$. This value is significantly slower than slip speeds during typical earthquakes, which are on the order of metres per second, but is comparable to surface displacement rates observed during creep events. On the Imperial fault, Glowacka et al. (2001) observed peak slip-rates using creepmeters on the order of $100 \mathrm{~mm} \mathrm{~d}^{-1}\left(10^{-6} \mathrm{~m} \mathrm{~s}^{-1}\right)$ during creep transients. Based on these relations, as long as the dominant slip mode is aseismic creep $\left(v_{\max } \sim 10^{-7} \mathrm{~m} \mathrm{~s}^{-1}\right)$ rather than seismic fault slip $\left(v_{\max } \sim 1 \mathrm{~m} \mathrm{~s}^{-1}\right)$, our estimates of stress drop and rupture propagation velocity provide a self-consistent model of fault failure with either crack or ratestate equations. These calculations are also consistent with geodetic observations of shallow aseismic creep in the Salton Trough. By applying our estimate of rupture propagation velocity $\left(v_{r}=0.28 \mathrm{~m} \mathrm{~s}^{-1}\right.$, 


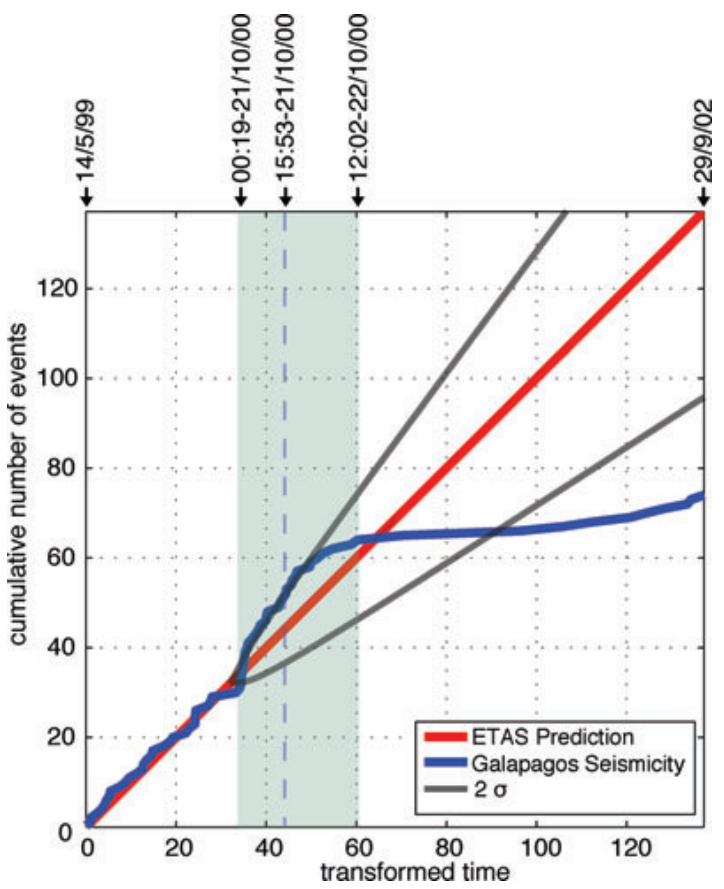

Figure 11. ETAS-transformed time versus cumulative number of events that occurred on the Galapagos Ridge transform fault from 1999 May to 2002 September. The seismicity rate predicted by the ETAS model is dependent on the time elapsed since the last event as well as the occurrence times and magnitudes of other previous events and the background seismicity rate (Ogata 1988). Maximum likelihood estimates of ETAS parameters derived here $(\mu=0.03$ events $/ \mathrm{d}, \mathrm{c}=0.01 \mathrm{~d}$ and $k=0.3)$ are optimized for the first 26 month time period with $\mathrm{p}$ and $\alpha$ constrained to 1.0 and 0.8 , respectively. We assume a lower magnitude threshold of $M_{\mathrm{w}} 3.6$. The best-fitting ETAS parameters are used to extrapolate the predicted cumulative number of events for the entire data set (red line). Blue line represents observed data. A significant deviation from the ETAS prediction is associated with the 2-d earthquake swarm in 2000 October (shaded region). The largest event of that sequence, a $M_{\mathrm{w}} 5.9$ at 15:53 on October 21 , is indicated with dotted line. Grey lines represent the $2 \sigma$ confidence interval for the extrapolation of the ETAS prediction beyond the optimization time period assuming a standard Brownian process with a linear trend slope of 1 (Ogata 2005).

for the Obsidian Buttes swarm) and the observed slip velocity of Salton Trough creep events, $v_{\max } \sim 10^{-6} \mathrm{~ms}^{-1}$ (Glowacka et al. 2001 ) with laboratory values of $b \sim 10^{-2}$, a density of $2500 \mathrm{~kg} \mathrm{~m}^{-3}$, an $S$-wave velocity of $2.7 \mathrm{~km} \mathrm{~s}^{-1}$ (i.e. a shear modulus of $19 \mathrm{GPa}$ ) and a representative value of $\ln \left[v_{\max } \theta / D_{c}\right]$ of 5 (Rubin 2008), eq. (4) yields a normal stress of $33 \mathrm{MPa}$. This value matches the expected effective normal stress for hydrostatic conditions at a depth of $2.3 \mathrm{~km}$. Lohman \& McGuire (2007) found the peak aseismic slip during the Obsidian Buttes swarm occurred between depths of 1 and $3 \mathrm{~km}$. By combining this observation with the calculations made using the rate and state friction expression and seismicity parameters associated with swarms studied here, we find that the observed rupture propagation velocity of the Salton Trough and EPR swarms and a slip velocity on the order of that assumed for aseismic creep are consistent with laboratory derived values of the rate-state friction parameter $b \sim 0.01$ (Kilgore et al. 1993) as long as the Salton Trough faults fail under hydrostatic conditions.
Similarities between our findings and recent observations of silent slip and episodic slow slip transients in subduction zones bring up the question of whether or not these two phenomena could be related. Along strike propagation velocities have been observed for tremor and episodic slow slip $\left(\sim 0.2-0.7 \mathrm{~km} \mathrm{hr}^{-1}\right.$, Obara 2002; Kao et al. 2006; Dragert et al. 2006) that are remarkably similar to those observed here associated with swarms on transform faults. This is surprising when it is considered in the context of the rate and state relations outlined in eq. (4) because tremor is believed to occur along the deep unstable-stable transition zone of the slab interface, around $30-40 \mathrm{~km}$, and assuming a similar $v_{\max }$, confining stress conditions there would require a drastically different propagation velocity as compared to our shallow ( $2-5 \mathrm{~km})$ transform slip. Recent modeling of short-interval silent slip events by Shibazaki \& Shimamoto (2007) as well as laboratory friction data for gabbro and GPS observations that have been applied to rate and state models by Liu \& Rice (2009) however, have demonstrated that episodic slow slip like that observed along subduction zone interfaces can only be reproduced using numerical models if the effective normal stress $(\sigma)$ along the fault is greatly reduced by a near-lithostatic pore pressure. With this requirement, effective normal stress conditions appropriate for deep-subduction zone slow slip transients are similar to stress conditions along the shallow transform faults we consider.

\section{CONCLUSIONS}

Based on our analysis of seismic swarms on Southern California and EPR transform faults, we have identified several parameters that point to aseismic creep as the likely driving mechanism for the recurrent swarms on these strike-slip plate boundaries. Swarms show a large spatial extent relative to their cumulative seismic moment and a correspondingly low effective stress drop, a temporal evolution that is inconsistent with standard scaling laws and spatial migration speeds on the order of $0.1-1.0 \mathrm{~km} \mathrm{hr}^{-1}$. These characteristics are consistent with field observations of creep events as well as with theoretical models of fault slip at creep rates. Given the relative frequency of swarms in the Salton Trough and EPR, it appears likely that a significant fraction of moderate and large earthquakes on these boundaries are triggered by aseismic fault slip. Moreover, all three properties of swarms could be easily identified in real time if high precision locations were available. In view of the significant damage Salton Trough swarms have caused in the past, these systematic properties could be used to improve real-time hazard estimates by detecting the existence of a swarm-like sequence relatively early in its evolution and identifying the increased level of hazard compared to a typical aftershock sequence.

\section{ACKNOWLEDGMENTS}

We are grateful to R. Lohman for her insight regarding the Salton Trough sequences, and to J. Vidale for making the Southern California seismic bursts data set available for comparison with our swarm data. We would also like to thank D. Toomey for providing the Galapagos Island broadband data and are grateful to $\mathrm{H}$. Kao and one anonymous reviewer for insightful and constructive comments that improved this paper. The material presented here is based upon work supported by the National Science Foundation Division of Ocean Science (OCE) grant \#0548785. 


\section{REFERENCES}

Abercrombie, R.E. \& Rice, J.R., 2005. Can observations of earthquake scaling constrain slip weakening, Geophys. J. Int., 162, 406-424.

Audigane, P., Royer, J.J. \& Kaieda, H., 2002, Permeability characterization of the Soultz and Ogachi large-scale reservoir using induced microseismicity, Geophysics., 67, 204-211.

Bird, P., Kagan, Y.Y. \& Jackson, D.D., 2002. Plate tectonics and earthquake potential of spreading ridges and oceanic transform faults, in Plate Boundary Zones, AGU Monograph, Vol. 30, eds Stein, S. \& Freymueller, J.T., pp. 203-218, Geodyn. Ser.

Boettcher, M.S. \& Jordan, T.H., 2004. Earthquake scaling relations for mid-ocean ridge transform faults, J. geophys. Res. 109(B12), B12302, doi:10.1029/2004JB003110.

Bohnenstiehl, D.R., Tolstoy, M., Dziak, R.P., Fox, C.G. \& Smith, D.K., 2002. Aftershock sequences in the mid-ocean ridge environment: an analysis using hydroacoustic data, Tectonophysics, 354, 49-70.

Brodsky, E.E. \& Mori, J., 2007. Creep events slip less than ordinary earthquakes, Geophys. Res. Lett., 34, L16309, doi:10.1029/2007GL030917.

Brune, J.N. \& Allen, C.R., 1967. A low-stress-drop, low-magnitude earthquake with surface faulting: the Imperial, California, earthquake of March 4, 1966, Bull. seism. Soc. Am., 57, 501-514.

Burford, R.O., 1977. Bimodal distribution of creep event amplitudes on the San Andreas fault, California, Nature, 268, 424 426.

Castro, R.R. \& RESNOM Working Group, 1998. P- and S- Wave Site Response of the Seismic Network RESNOM Determined from Earthquakes of Northern Baja California, Mexico, Pure appl. geophys., 152, $125-138$.

Dragert, H., Wang, K. \& Rogers, G., 2004, Geodetic and seismic signatures of episodic tremor and slip in the northern Cascadia subduction zone, Earth Planets Space, 56, 1143-1150.

Dziewonski, A.M., Ekström, G. \& Maternovskaya, N.N., 2003. Centroidmoment tensor solutions for October-December 2000, Phys. Earth planet Inter, 136, 145-163.

Ekström, G., Dziewonski, A.M., Maternovskaya, N.N. \& Nettles, M., 2003. Global seismicity of 2001: centroid-moment tensor solutions for 961 earthquakes, Phys. Earth planet. Inter., 136, 165-185.

Forsyth, D.W., Yang, Y., Mangriotis, M.D. \& Shen, Y., 2003. Coupled seismic slip on adjacent oceanic transform faults Geophys. Res. Lett., 30(12), 1618, doi:10.1029/2002GL016454.

Fox, C.G., Matsumoto, H. \& Lau, T.K.A., 2001. Monitoring Pacific Ocean seismicity from an autonomous hydrophone array, J. geophys. Res., 106, 4183-4206.

Glowacka, E., Gonzalez, J.J., Nava, F.A., Farfan, F. \& Díaz de Cossio, G., 2001. Monitoring surface deformation in the Mexicali Valley, BC, Mexico, Paper presented at the 10th FIG International Symposium on Deformation Measurements, CA. Inst. of Technol., Orange, CA.

Gregg, P.M., Lin, J. \& Smith, D.K., 2006. Segmentation of transform systems on the East Pacific Rise: implications for earthquake processes at fastslipping oceanic transform faults, Geology, 34(B05S07), 289-292.

Hainzl, S. \& Ogata, Y., 2005. Detecting fluid signals in seismicity data through statistical earthquake modeling, J. geophys. Res., 110, B05S07, doi: 10.1029/2004JB003247.

Helmstetter, A., Sornette, D., 2003a. Importance of direct and indirect triggered seismicity in the ETAS model of seismicity, Geophys. Res. Lett., 30(11), 1576-1579.

Helmstetter, A., Sornette, D., 2003b. Bath's law Derived from the GutenbergRichter law and from Aftershock Properties J. geophys. Res., 30(20), 2069-2072, doi:10.1029/2003GL018186.

Hill, D.P., 1977. A model for earthquake swarms, J. geophys. Res. 82, $1347-$ 1352.

Hooft, E.E., Toomey, D.R. \& Solomon, S.C., 2003. Anomalously thin transition zone beneath the Galápagos hotspot, Earth planet. Sci. Lett., 216, $55-64$.

Johnson, C.E. \& Hadley, D.M., 1976. Tectonic implications of the Brawley earthquake swarm, Imperial Valley, California, January 1975, Bull. seism. Soc. Am., 66, 1133-1144.

(C) 2009 The Authors, GJI

Journal compilation (C) 2009 RAS
Jordan, T.H., 1991. Far-field detection of slow precursors to fast seismic ruptures, Geophys. Res. Lett., 18, 2019-2022.

Kanamori, H., 1977. Energy release in great earthquakes, J. geophys. Res. 82(20), 2981-2987.

Kanamori, H., 1994. Mechanics of earthquakes, Ann. Rev. Earth Planet. Sci., 22, 207-237, doi:10.1146/annurev.ea.22.050194.001231.

Kanamori, H. \& Anderson, D.L., 1975. Theoretical basis of some empirical relations in seismology, Bull. seism. Soc. Am., 65, 1073-1095.

Kao, H., Shan, S., Dragert, H., Rogers, G., Cassidy, J.F., Wang, K., James, T.S. \& Ramachandran, K., 2006. Spatial-temporal patterns of seismic tremors in northern Cascadia. J. geophys. Res., 111, B03309, doi:10.1029/2005JB003727.

Kilgore, B.D., Blanpied, M.L. \& Dieterich, J.H., 1993. Velocity dependent friction of granite over a wide range of conditions, Geophys. Res. Lett., 274, 355-360.

King, C.Y., Nason, R.D. \& Tocher, D., 1973. Kinematics of fault creep, Phil. Trans. Roy. Soe. Lond., Ser. A., 274, 355-360.

Linde, A.T., Gladwin, M.T., Johnston, M.J.S., Gwyther, R.L. \& Bilham, R.G., 1996. A slow earthquake sequence on the San Andreas fault, Nature, 383, 65-68.

Liu, Y. \& Rice, J., 2009. Slow slip predictions based on gabbro friction data compared to GPS measurements in northern Cascadia, J. geophys. Res., submitted

Llenos, A.L., McGuire, J.J. \& Ogata, Y., 2009. Modeling Seismic Swarms Triggered by Aseismic Transients, Earth planet. Sci. Lett., 281, 59-69.

Lohman, R.B. \& McGuire, J.J., 2007. Earthquake swarms driven by aseismic creep in the Salton Trough, California, J. geophys. Res., 112, B04405, doi:10.1029/2006JB004596.

Lyons, S. \& Sandwell, D., 2003. Fault creep along the southern San Andreas from interferometric synthetic aperture radar, permanent scatterers, and stacking, J. geophys. Res., 108(B1), 2047, doi:10.1029/2002JB001831.

Lyons, S.N., Bock, Y. \& Sandwell, D.T., 2002. Creep along the imperial fault, southern California, from GPS measurements, J. geophys. Res., 107(B10), doi:10.1029/2001JB000763.

Magistrale, H., Day, S., Clayton, R.W. \& Graves, R., 2000. The SCEC southern California reference three-dimensional seismic velocity model Version 2, Bull. seism. Soc. Am., 90, S65-S76.

McGuire, J.J., 2008. Seismic cycles and earthquake predictability on east pacific rise transform faults, Bull. seism. Soc. Am., 98, 1067-1084.

McGuire, J.J. \& Segall P., 2003 Imaging of aseismic fault slip transients recorded by dense geodetic networks, Geophys. J. Int.., 155, 778788.

McGuire, J.J., Boettcher, M.S. \& Jordan, T.H., 2005. Foreshock sequences and short-term earthquake predictability on East Pacific Rise transform faults, Nature, 434, 457-461.

Nishimura, C.E. \& Forsyth, D.W., 1988. Rayleigh wave phase velocities in the Pacific with implications for azimuthal anisotropy and lateral heterogeneities, Geophys. J., 94, 479-501.

Obara, K., 2002. Nonvolcanic deep tremor associated with subduction in southwest Japan, Science, 296, 1679-1681.

Ogata, Y., 1988. Statistical models for earthquake occurrences and residual analysis for point processes, J. Am. Stat. Assn. 83, 9-27.

Ogata, Y., 2005. Detection of anomalous seismicity as a stress change sensor, J. geophys. Res., 110(B5), B05506, doi:10.1029/2004JB003245.

Omori, F., 1894. On the aftershocks of earthquakes, J. Coll. Sci. Imp. Univ. Tokyo., 7, 111-200.

Panik, M.J., 2005. Advanced Statistics from an Elementary Point of View, Elsevier Academic Press, Amsterdam.

Peyrat S., Olsen, K. \& Madariaga, R., 2001. Dynamic modeling of the 1992 Landers Earthquake, J. geophys. Res., 106(B11), 26467-26482.

Richter, C.F., 1958. Elementary Seismology, W.H. Freeman, San Francisco, CA.

Rubin, A.M., 2008. Episodic slow slip events and rate-and-state friction. $J$. geophys. Res., 113, B11414, doi:10.1029/2008JB005642.

Shapiro, S.A., Rentsch, S. \& Rothert, E., 2005. Characterization of hydraulic properties of rocks using probability of fluid-induced microearthquakes, Geophysics., 70, F27-F33. 
Shearer, P.M., 1997. Improving local earthquake locations using the L1 norm and waveform cross correlation: application to the Whittier Narrows, California, aftershock sequence, J. geophys. Res., 102, 8269-8283.

Shearer, P.M., Hauksson, E. \& Lin, G., 2005. Southern California hypocenter relocation with waveform cross-correlation. Part 2: results using sourcespecific station terms and cluster analysis, Bull. seism. Soc. Am., 95, 904-915.

Shibazaki, B. \& Shimamoto, T., 2007, Modelling of short-interval silent slip events in deeper subduction interfaces considering the frictional properties at the unstablestable transition regime, Geophys. J. Int., 171, 191-205

Smith, K.D., von Seggern, D., Blewitt, G., Preston, L., Anderson, J.G., Wernicke, B.P. \& Davis, J.L., 2004. Evidence for deep magma injection beneath Lake Tahoe, Nevada-California, Science, 305, 1277-1280.
Trèhu, A.M. \& Solomon, S.C., 1983. Earthquakes in the Orozco transform zone; seismicity, source mechanisms, and tectonics, J. geophys. Res., $\mathbf{8 8}$, $8203-8225$.

Vidale J.E. \& Shearer, P.M., 2006. A survey of 71 earthquake bursts across southern California: exploring the role of pore fluid pressure fluctuations and aseismic slip as drivers, J. geophys. Res., 111, B05312, doi: $10.1029 / 2005 J B 004034$.

Vidale J.E., Boyle, K.L. \& Shearer, P.M., 2006. Crustal earthquake bursts in California and Japan: their patterns and relation to volcanoes, Geophys. Res. Lett., 33, L20313, doi:10.1029/2006GL027723.

Waldhauser, F. \& Ellsworth, W.L., 2000. A Double-Difference Earthquake Location Algorithm: method and application to the Northern Hayward Fault, California, Bull. seism. Soc. Am., 90, 13531368 


\title{
Chapter 3
}

\section{Thermal-mechanical behavior of oceanic transform faults: Implications for the spatial distribution of seismicity $^{*}$}

\begin{abstract}
To investigate the spatial distribution of earthquakes along oceanic transform faults, we utilize a 3-D finite element model to calculate the mantle flow field and temperature structure associated with a ridge-transform-ridge system. The model incorporates a viscoplastic rheology to simulate brittle failure in the lithosphere and a non-Newtonian temperature-dependent viscous flow law in the underlying mantle. We consider the effects of three key thermal and rheological feedbacks: (1) frictional weakening due to mantle alteration, (2) shear heating, and (3) hydrothermal circulation in the shallow lithosphere. Of these effects, the thermal structure is most strongly influenced by hydrothermal cooling. We quantify the thermally-controlled seismogenic area for a range of fault parameters, including slip rate and fault length, and find that the area between the $350^{\circ} \mathrm{C}$ and $600^{\circ} \mathrm{C}$ isotherms (analogous to the zone of seismic slip) is nearly identical to that predicted from a half-space cooling model. However, in contrast to the half-space cooling model, we find that the depth to the $600^{\circ} \mathrm{C}$ isotherm and the width of the seismogenic zone are nearly constant along the fault, consistent with seismic observations. The calculated temperature structure and zone of permeable fluid flow are also used to approximate the stability field of hydrous phases in the upper mantle. We find that for slow slipping faults, the potential zone of hydrous alteration extends greater than $10 \mathrm{~km}$ in depth, suggesting that transform faults serve as a significant pathway for water to enter the oceanic upper mantle.
\end{abstract}

* Published as: Roland, E., M. D. Behn, and G. Hirth (2010), Thermal-mechanical behavior of oceanic transform faults: Implications for the spatial distribution of seismicity, Geochemistry Geophysics Geosystems, 11(7), Q07001. 


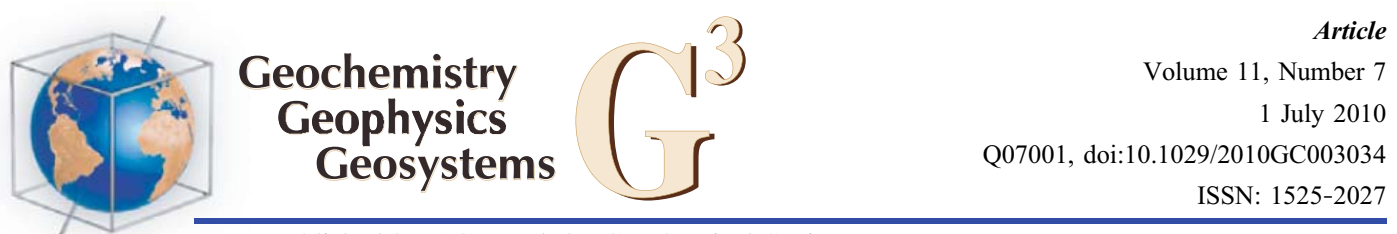

Published by AGU and the Geochemical Society

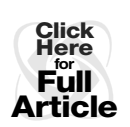

\title{
Thermal-mechanical behavior of oceanic transform faults: Implications for the spatial distribution of seismicity
}

\author{
Emily Roland \\ MIT-WHOI Joint Program in Oceanography, Department of Marine Geology and Geophysics, Woods Hole \\ Oceanographic Institution, 266 Woods Hole Road, Woods Hole, Massachusetts 02540, USA (eroland@mit.edu)
}

\section{Mark D. Behn}

Department of Geology and Geophysics, Woods Hole Oceanographic Institution, 266 Woods Hole Road, Woods Hole, Massachusetts 02543, USA (mbehn@whoi.edu)

\author{
Greg Hirth \\ Department of Geological Sciences, Brown University, 324 Brook Street, Providence, Rhode Island 02912, USA \\ (greg_hirth@brown.edu)
}

[1] To investigate the spatial distribution of earthquakes along oceanic transform faults, we utilize a 3-D finite element model to calculate the mantle flow field and temperature structure associated with a ridge-transformridge system. The model incorporates a viscoplastic rheology to simulate brittle failure in the lithosphere and a non-Newtonian temperature-dependent viscous flow law in the underlying mantle. We consider the effects of three key thermal and rheological feedbacks: (1) frictional weakening due to mantle alteration, (2) shear heating, and (3) hydrothermal circulation in the shallow lithosphere. Of these effects, the thermal structure is most strongly influenced by hydrothermal cooling. We quantify the thermally controlled seismogenic area for a range of fault parameters, including slip rate and fault length, and find that the area between the $350^{\circ} \mathrm{C}$ and $600^{\circ} \mathrm{C}$ isotherms (analogous to the zone of seismic slip) is nearly identical to that predicted from a half-space cooling model. However, in contrast to the half-space cooling model, we find that the depth to the $600^{\circ} \mathrm{C}$ isotherm and the width of the seismogenic zone are nearly constant along the fault, consistent with seismic observations. The calculated temperature structure and zone of permeable fluid flow are also used to approximate the stability field of hydrous phases in the upper mantle. We find that for slow slipping faults, the potential zone of hydrous alteration extends greater than $10 \mathrm{~km}$ in depth, suggesting that transform faults serve as a significant pathway for water to enter the oceanic upper mantle.

Components: 8600 words, 10 figures, 1 table.

Keywords: oceanic transform faults; fault rheology; serpentinization; fault mechanics.

Index Terms: 3039 Marine Geology and Geophysics: Oceanic transform and fracture zone processes (1207); 7250 Seismology: Transform faults (1207); 7230 Seismology: Seismicity and tectonics (1207).

Received 7 January 2010; Revised 30 March 2010; Accepted 1 April 2010; Published 1 July 2010.

Roland, E., M. D. Behn, and G. Hirth (2010), Thermal-mechanical behavior of oceanic transform faults: Implications for the spatial distribution of seismicity, Geochem. Geophys. Geosyst., 11, Q07001, doi:10.1029/2010GC003034. 


\section{Introduction}

[2] The relatively simple fault geometry and wellcharacterized slip rates associated with oceanic transform faults make them excellent locations for studying earthquake behavior. Several aspects of the mechanical behavior of transform faults are relatively well understood. Total seismic moment release rates and the size of the largest earthquakes are linked to variations in fault properties, such as slip rate and fault length [Engeln et al., 1986; Bird et al., 2002; Boettcher and Jordan, 2004]. Furthermore, global observations indicate that oceanic transforms sustain a higher degree of aseismic slip and a relatively narrow seismic fault width compared to continental strike-slip systems [Bird et al., 2002; Boettcher and Jordan, 2004]. Geodynamic modeling of normal fault rotations adjacent to transforms [Phipps Morgan and Parmentier, 1984; Behn et al., 2002] also demonstrate that oceanic transform faults are mechanically weak. Observations of oceanic earthquakes [Wiens and Stein, 1983; Engeln et al., 1986; Bergman and Solomon, 1988; Abercrombie and Ekstrom, 2001; Braunmiller and Nábélek, 2008] indicate that in the oceanic lithosphere, the maximum depth of seismicity is thermally controlled. Therefore, characterizing the temperature structure of oceanic transforms is fundamental for understanding the partitioning of seismic and aseismic slip and for determining the spatial distribution of earthquakes.

[3] Transform fault thermal structure is commonly estimated using analytic solutions that average the temperature predicted from a half-space cooling model across the two sides of the fault [e.g., McKenzie, 1969]. Results from these calculations have been used to investigate the temperature control on the depth of earthquakes [Engeln et al., 1986; Bergman and Solomon, 1988; Abercrombie and Ekstrom, 2001; Braunmiller and Nábělek, 2008], and to estimate seismic coupling along oceanic transform faults [Bird et al., 2002; Boettcher and Jordan, 2004]. These studies indicate that seismicity is limited to temperatures less than $600^{\circ} \mathrm{C}$, consistent with laboratory experiments on olivine [Boettcher et al., 2007]. An alternative method for calculating transform fault thermal structure utilizes geodynamic models that incorporate advective heat transport due to mantle flow [Phipps Morgan and Forsyth, 1988; Shen and Forsyth, 1992; Furlong et al., 2001]. As discussed by Behn et al. [2007] these geodynamic models predict much colder transform thermal structure unless the weakness of the brittle portion of the fault is explicitly included.
Behn et al. [2007] showed that by incorporating a viscoplastic rheology, the depth to the $600^{\circ} \mathrm{C}$ isotherm at the fault center is similar to that calculated from the half-space model. However, while this model improved upon previous models, it neglected several key processes such as non-Newtonian viscous flow, hydrothermal circulation, and shear heating, and did not explore the effects of fault length and slip rate.

[4] The primary motivation of our study is to explore the links between hydrothermal circulation, thermal structure, and rheology along oceanic transform faults. Enhanced permeability associated with fracturing provides a mechanism for increased fluid circulation and subsequent alteration of the crust and mantle. Hydrothermal cooling has been shown to significantly influence the thermal structure along highly tectonized parts of the oceanic lithosphere [Sleep, 1975; Phipps Morgan et al., 1987; Phipps Morgan and Chen, 1993; Cherkaoui et al., 2003]. Metamorphic alteration also occurs when water comes into contact with rocks of mantle composition, evidenced by reduced seismic velocities observed along transform faults [Detrick et al., 1987, 1993; Van Avendonk et al., 1998; Canales et al., 2000] and the presence of altered mantle phases recovered by seafloor dredging [Dick, 1989; Cannat et al., 1995]. There are several ways that mantle alteration at transform faults may influence tectonic and petrologic processes. Hydrous mantle minerals are weaker than most other minerals in the oceanic crust and upper mantle [O'Hanley, 1996; Moore et al., 1997]. Their presence in fracture zones influences frictional behavior and may control the transition between stable sliding and stick-slip behavior. Although serpentine demonstrates stable sliding at low temperatures, under warmer conditions $\left(>\sim 350^{\circ} \mathrm{C}\right)$ a transition to velocity weakening is observed [Moore et al., 1997]. This change in the frictional behavior of serpentine may control the upper depth limit of the seismogenic zone. Additionally, because altered peridotite can contain large amounts of water, hydrated mantle minerals formed along transform faults would also contribute significantly to the water budget of the mantle [Hacker, 2008]. For example, serpentine contains up to $14 \mathrm{wt}$ $\%$ water in its crystal structure [O'Hanley, 1996]. Altered mantle rocks formed in transform fault settings will be advected off axis with plate motion and eventually subducted at convergent margins. In this way, mineralogically bound water along transform faults can influence arc volcanism when dehydration occurs during heating of the subducted slab [Grove et al., 2006]. 
Table 1. Imposed Boundary Conditions and Material Properties

\begin{tabular}{|c|c|c|}
\hline Symbol & Parameter & Value \\
\hline$\rho$ & average lithospheric density & $3300 \mathrm{~kg} \mathrm{~m}^{-3}$ \\
\hline$\rho_{w}$ & water density & $1000 \mathrm{~kg} \mathrm{~m}^{-3}$ \\
\hline$\eta$ & viscosity & $\eta_{0}=1 e 19, \eta_{\max }=1 e 24 \mathrm{~Pa} \mathrm{~s}$ \\
\hline$k$ & thermal conductivity & $k_{0}=3 \mathrm{~W} \mathrm{~m}^{-1} \mathrm{~K}^{-1}$ \\
\hline$C_{p}$ & specific heat & $1000 \mathrm{~J} \mathrm{Kg}^{-1} \mathrm{~K}^{-1}$ \\
\hline$Q_{s h}$ & heat source & $2 \eta_{\text {eff }} \dot{\epsilon}_{I I}^{2}$ (shear heating) \\
\hline$L_{T}$ & transform fault length & $50-500 \mathrm{~km}$ \\
\hline$u_{0}$ & imposed full slip rate & $3-12 \mathrm{~cm} \mathrm{yr}^{-1}$ \\
\hline$T_{s}$ & surface temperature & $0^{\circ} \mathrm{C}$ \\
\hline$T_{m}$ & mantle temperature & $1300^{\circ} \mathrm{C}$ \\
\hline $\mathrm{R}$ & gas constant & $8.3145 \mathrm{~J} \mathrm{~mol}^{-1} \mathrm{~K}^{-1}$ \\
\hline A & preexponential factor & $1.1 \times 10^{5}[$ Hirth and Kohlstedt, 2003] \\
\hline $\mathrm{n}$ & stress exponent & $3.5[$ Hirth and Kohlstedt, 2003] \\
\hline $\mathrm{E}$ & activation energy & $520 \mathrm{~kJ} \mathrm{~mol}^{-1}[$ Hirth and Kohlstedt, 2003] \\
\hline$\mu$ & coefficient of friction (serpentine) & $0.85(0.1)$ \\
\hline $\mathrm{C}$ & cohesion & $20 \mathrm{MPa}$ \\
\hline $\mathrm{g}$ & gravitational acceleration & $9.8 \mathrm{~m} \mathrm{~s}^{-1}$ \\
\hline $\mathrm{Nu}$ & Nusselt number & $1-8$ \\
\hline$C_{S}$ & $k_{\text {eff }}$ smoothing constant, stress & 100 \\
\hline$C_{D}$ & $k_{e f f}$ smoothing constant, depth & 4 \\
\hline
\end{tabular}

[5] Here, we develop a more realistic model for oceanic transform fault thermal structure by exploring three important thermal and rheological feedbacks: (1) frictional weakening due to mantle alteration, (2) shear heating, and (3) enhanced hydrothermal cooling associated with brittle deformation. We incorporate these feedbacks into numerical models that simulate mantle flow using a viscoplastic rheology, similar to the Behn et al. [2007] model, but with the temperature-dependent viscous flow law replaced with a nonlinear power law appropriate for non-Newtonian dislocation creep. We discuss our predicted thermal structure for a range of fault lengths and slip rates. Our findings are then related to the observed distribution of seismicity in a number of settings and the extent of alteration of the oceanic upper mantle.

\section{Methods}

\subsection{Model Setup}

[6] We use the finite element software package, COMSOL Multiphysics v.3.5, to solve for conservation of mass, momentum and energy assuming steady state incompressible flow:

$$
\begin{gathered}
\nabla \cdot \mathbf{u}=0 \\
\rho(\mathbf{u} \cdot \nabla) \mathbf{u}=\nabla \cdot\left[-p I+\eta\left(\nabla \mathbf{u}+(\nabla \mathbf{u})^{T}\right)\right] \\
\nabla \cdot(-k \nabla T)=Q_{s h}-\rho C_{p}(\mathbf{u} \cdot \nabla) T .
\end{gathered}
$$

In the conservation equations outlined above, $\mathbf{u}$ is velocity, $T$ is temperature and $p$ is pressure. Other symbols represent constants and material properties, which are described in Table 1 . We assume the infinite Prandtl number approximation, for which the left-hand side of equation (2) is negligible. COMSOL has been benchmarked for non-Newtonian temperature-dependent flow in geologic settings [van Keken et al., 2008], and used previously to model mantle flow and temperature structure around oceanic transform faults [Behn et al., 2007].

[7] We model a ridge-transform-ridge system in which a transform fault of length, $L_{T}$, offsets two ridge segments, each extending a distance, $L_{T} / 2$, on either side of the transform (Figure 1). In this way, the lateral extent of the model domain is dependent on the fault length, with dimensions of $2 L_{T}$ in the along-fault $(X)$ direction, and $L_{T}$ in the faultperpendicular $(Y)$ direction (Figure 1). All models extend to a depth of $100 \mathrm{~km}$. The model domain was chosen such that the sides and bottom of the model do not influence the solution. Mantle flow is driven by imposing a surface velocity with a half slip rate, $u_{0} / 2$, on either side of the fault. The boundary conditions on the sides and bottom of the model are stress-free, allowing convective flux in and out of the model space and mantle upwelling from below. Temperature is fixed to $T_{s}=0^{\circ} \mathrm{C}$ and $T_{m}=1300^{\circ} \mathrm{C}$ at the surface and bottom boundaries of the model space, respectively (Figure 1).

[8] Numerical solutions for the temperature and flow field are determined using a 3-D mesh of second-order brick elements with finer grid spacing 


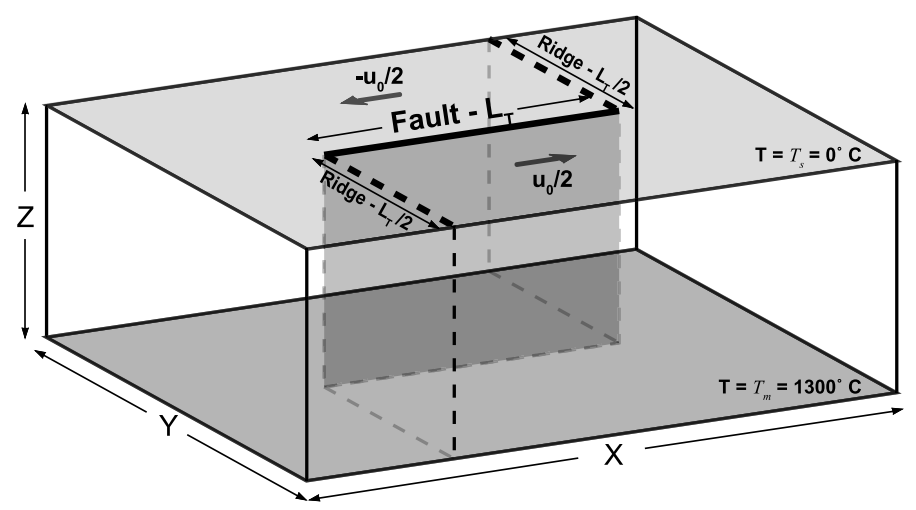

Figure 1. Model geometry. A transform fault of length $L_{T}$ offsets two ridge segments of length $L_{T} / 2$. The 3-D steady state incompressible mantle flow is driven by an imposed full slip rate, $u_{0}$, at the surface. Sides and bottom of the model space are stress-free. The top and bottom of the model are set to $0^{\circ} \mathrm{C}$ and $1300^{\circ} \mathrm{C}$, respectively.

at shallow depths and along the fault plane. We tested a range of gridded mesh spacings along the fault-parallel and fault-perpendicular directions, to insure that the grid spacing is sufficiently fine as to not influence the model solutions. Exact numerical grid spacing of the models presented here varies for different fault length solutions to minimize computation time while still maintaining the insensitivity to mesh spacing. For a $100 \mathrm{~km}$ fault model, we use an $\sim 8 \mathrm{~km}$ mesh along the $x$ direction and a $\sim 7 \mathrm{~km}$ mesh along the $y$ direction. The numerical solution follows a basic Newton method of residual minimization, with a convergence criterion based on a weighted Euclidean norm and a tolerance of 1e- 6 for the estimated relative error. Full slip rates modeled here range from 3 to $12 \mathrm{~cm} /$ year, and we explore solutions for transform faults with lengths ranging from $L_{T}=50-500 \mathrm{~km}$.

\subsection{Rheology Model}

[9] We develop a rheologic model for oceanic transform faults using deformation laws that simulate the processes we expect to occur in transform settings. In the oceanic lithosphere, permanent deformation is accommodated by two primary mechanisms. At shallow depths, yielding occurs by brittle failure along preexisting fault planes and can be described by a linear, pressure-dependent friction law. Deeper in the lithosphere, viscous flow dominates deformation, characterized by thermally activated dislocation creep. To account for both of these processes, we employ a nonlinear viscous rheology with a plastic approximation that allows for brittle weakening in the shallow, cooler part of the lithosphere.

[10] Where temperatures are sufficiently high for rocks to deform by dislocation creep, strain rate and differential stress are related through a temperaturedependent non-Newtonian power law rheology [Kirby, 1983]:

$$
\dot{\epsilon}_{a}=A\left(\sigma_{1}-\sigma_{3}\right)^{n} \exp \left(-\frac{E}{R T}\right) .
$$

The parameters in equation (4) are determined from triaxial experiments, where $\dot{\epsilon}_{a}$ represents the axial strain rate, $\sigma_{1}-\sigma_{3}$ is the differential stress, and $R$ is the gas constant. We use values for $A$, the preexponential constant, $n$, the power law exponent, and $E$, the activation energy appropriate for dry olivine [Hirth and Kohlstedt, 2003] (Table 1).

[11] To incorporate the experimentally derived flow law into our viscoplastic rheology model, we calculate a "creep viscosity" $\left(\eta_{\text {creep }}\right)$ that is a function of the strain rate and temperature everywhere within the model. The expression for $\eta_{\text {creep }}$ is derived from equation (4) and the isotropic stress-strain relation, $\sigma_{i j}=2 \eta \dot{\epsilon}_{i j}$ such that:

$$
\eta_{\text {creep }}=\frac{1}{4}\left(\frac{4}{3 A}\right)^{\frac{1}{n}}\left(\frac{\dot{\epsilon}_{I I}}{\sqrt{2}}\right)^{\frac{1-n}{n}} \exp \left(\frac{E}{n R T}\right) .
$$

This relation follows from the assumption that, for an incompressible material, the axial strain rate $\left(\dot{\epsilon}_{a}\right)$ in equation (4) can be related to the second invariant of the strain rate tensor, $\dot{\epsilon}_{I I}$ [Chen and Morgan, 1990]. 

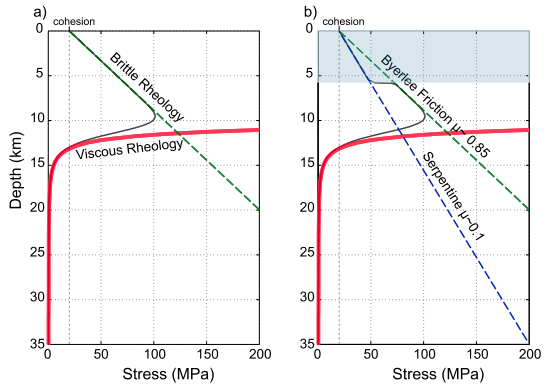

Figure 2. Differential stress versus depth at the center of the transform for the viscoplastic composite rheology (black solid lines). (a) The brittle mechanism described by Byerlee's Law (green dashed line) is dominant at shallow depths and the nonlinear viscous dislocation creep law (red line) dictates deformation at depth. (b) Similar to Figure 2a but with the friction law adjusted with a lower friction coefficient (blue dashed line) in the region where metamorphic alteration is predicted (shaded) simulating weaker serpentinized rocks.

[12] In the cooler lithosphere, where deformation occurs by brittle failure, we use the Coulomb friction criteria to calculate the maximum stress. The maximum shear stress, $\tau_{\max }$, is a function of the friction coefficient, $\mu$, the cohesive strength, $C$, and the effective normal stress, $\bar{\sigma}_{n}$, acting on the fault plane:

$$
\tau_{\max }=\mu \bar{\sigma}_{n}+C .
$$

The shear and effective normal stresses can be represented in terms of the maximum and minimum principal effective compressive stresses, $\bar{\sigma}_{1}$ and $\bar{\sigma}_{3}$ [Zoback and Townend, 2001]:

$$
\bar{\sigma}_{1}=f_{1}(\mu) \bar{\sigma}_{3}+f_{2}(\mu, C),
$$

where

$$
f_{1}(\mu)=\frac{\sqrt{\mu^{2}+1}+\mu}{\sqrt{\mu^{2}+1}-\mu}, \text { and } f_{2}(\mu, C)=\frac{2 C}{\sqrt{\mu^{2}+1}-\mu} .
$$

For a mid-ocean ridge setting, we assume that $\bar{\sigma}_{1}$ is the effective vertical stress, $\bar{\sigma}_{v}=\left(\rho-\rho_{w}\right) g h$. The maximum differential stress supported within the lithosphere, $\Delta \sigma_{\text {brittle }}$, can then be expressed in terms of the effective vertical stress, the coefficient of friction and the cohesion:

$$
\Delta \sigma_{\text {brittle }}=\bar{\sigma}_{v} \frac{f_{1}(\mu)-1}{f_{1}(\mu)}+\frac{f_{2}(\mu, C)}{f_{1}(\mu)} .
$$

[13] We incorporate the brittle deformation law into our rheology model by specifying a "frictional viscosity" $\left(\eta_{\text {fric }}\right)$ that is a function of the maximum stress calculated from our brittle law (equation (9)) and the strain rate [Chen and Morgan, 1990]:

$$
\eta_{\text {fric }}=\frac{\Delta \sigma_{\text {brittle }}}{2 \sqrt{2} \dot{\epsilon}_{I I}} .
$$

$\eta_{\text {fric }}$ forces the flow in our model to be consistent with the maximum stress in regions where the brittle failure criteria controls deformation. We use $\eta_{\text {fric }}$ in our composite rheology to mimic properties of a plastic rheology within the context of a viscous model.

[14] The assumption that $\bar{\sigma}_{1}=\bar{\sigma}_{v}$ made in the above formulation is valid for tectonic settings under horizontal extension, and is therefore appropriate for most of the mid-ocean spreading ridge environment. For simplicity, we assume this is valid everywhere within the model space, acknowledging that $\bar{\sigma}_{v}=\bar{\sigma}_{2}$ within the transform domain. Applying this assumption within the transform allows strike-slip fracture planes to fail at a slightly lower differential stress than theoretically predicted. However, as we show in section 3.1, decreasing the coefficient of friction has a relatively small effect on the predicted flow field and derived temperature structure, and thus should not greatly influence our model results.

[15] To incorporate both brittle and viscous deformation mechanisms into a composite rheological model, we assume that under a given set of conditions, deformation occurs by the mechanism with the smallest viscosity. This is accomplished by calculating an effective viscosity such that:

$$
\eta_{\text {eff }}=\left(\frac{1}{\eta_{\text {creep }}}+\frac{1}{\eta_{\text {fric }}}+\frac{1}{\eta_{\max }}\right)^{-1}
$$

$\eta_{\text {eff }}$ is specified in equation (2) to compute the flow field. The third term in equation (11) represents a maximum viscosity that is included to aid numerical convergence. In our solution process, mantle flow and temperature are first calculated for a constant viscosity $\left(\eta_{0}=10^{19} \mathrm{~Pa} \mathrm{~s}\right)$. We use the strain rate from the initial solution to calculate viscosity values (equations (5) and (10)) and incorporate the composite rheology (equation (11)) in the flow laws of subsequent solutions. We then iteratively increase the maximum viscosity term in our composite rheology, from $\eta_{\max }=\eta_{0}$ to $10^{24} \mathrm{~Pa}$ s. A stress versus depth profile beneath the transform that results from this composite rheology model is displayed in Figure $2 \mathrm{a}$. 
[16] The constitutive equations and rheology model outlined thus far compose our base model. We build upon this base model by exploring three additional rheological and thermal feedbacks that simulate processes that potentially influence fault temperature and stress conditions.

\subsection{Frictional Weakening}

[17] In a transform environment, the lithosphere deforms brittlely to depths that extend into the upper mantle [Brace and Kohlstedt, 1980; Kirby, 1983]. Increased permeability associated with brittle cracking may provide a conduit for seawater to come into contact with mantle rocks, leading to alteration. The presence of hydrated phases in the oceanic lithosphere has important implications for the mode of brittle failure. Laboratory studies demonstrate that rocks with even a small degree of serpentinization may be significantly weaker than unaltered peridotite [Escartin et al., 2001].

[18] We incorporate the effects of mechanical weakening associated with serpentinization by modifying equation (9) when two conditions are met: (1) deformation occurs brittlely $\left(\eta_{\text {fric }}<\eta_{\text {creep }}\right)$ and (2) serpentine or talc is stable based on the stability fields of Poli and Schmidt [2002] for watersaturated peridotites. For a hydrous lherzolite composition, serpentine is stable at temperatures below $540^{\circ} \mathrm{C}$ and talc is stable for temperatures between approximately $540^{\circ} \mathrm{C}-640^{\circ} \mathrm{C}$ at a depth of $10 \mathrm{~km}$ (pressures of $\sim 300 \mathrm{MPa}$ ) [Poli and Schmidt, 2002]. In serpentinized regions, the coefficient of friction $(\mu)$ in equations (6)-(9) is adjusted from the unaltered olivine value of 0.85 to 0.1 , the lower labderived value appropriate for lizardite, chrysotile, and talc [Reinen et al., 1994; Moore et al., 1997]. A schematic diagram showing a stress profile that reflects our composite viscoplastic rheology modified by the effects of serpentinization is shown in Figure $2 b$.

\subsection{Shear Heating}

[19] During deformation, most dissipated mechanical energy is converted into heat, increasing the temperature in zones of localized strain. Analytical calculations demonstrate that shear heating will result in considerable heat production along faults that support shear stresses $\geq 10 \mathrm{MPa}$ [Fleitout and Froidevaux, 1980]. To analyze the importance of shear heating in transform settings, we incorporate a heat source term into equation (3) that represents the rate of energy dissipation per unit volume due to viscous dissipation. This value is the product of the stress and strain rate. Using the isotropic stress-strain equation [Chen and Morgan, 1990, section 2.2], we calculate the heat source term as a function of the strain rate invariant and the viscosity [Brun and Cobbold, 1980]:

$$
Q_{s h}=2 \eta_{e f f} \dot{\epsilon}_{I I}^{2},
$$

where $\eta_{\text {eff }}$ is taken from equation (11).

\subsection{Hydrothermal Cooling}

[20] In young oceanic crust, heat flow patterns are strongly affected by convection of seawater through regions of the lithosphere that experience brittle cracking and enhanced permeability [Phipps Morgan and Chen, 1993]. We approximate the effects of hydrothermal cooling by increasing thermal conductivity [e.g., Sleep, 1975; Phipps Morgan et al., 1987; Cherkaoui et al., 2003] in regions of predicted brittle failure and fluid circulation. In our model, this increase in conductivity is simulated by a Nusselt number $(\mathrm{Nu})$, which represents the ratio of the total heat transport within a permeable layer to heat transfer by conduction alone [Phipps Morgan et al., 1987]. We investigate results for $N u=1-$ 8 to simulate different efficiencies of hydrothermal cooling. The upper end of this range is motivated by Phipps Morgan and Chen [1993], who found that $N u=8$ was required to match seismic velocity observations of the presence and depth of a steady state magma lens over a range of spreading rates.

[21] Temperatures recorded in hydrothermal vent discharge [Phipps Morgan et al., 1987] and geochemical data [Bonatti and Honnorez, 1976; Francis, 1981; Kelley and Gillis, 2002] indicate that hydrothermal circulation may extend to lithospheric depths corresponding to temperatures of $400^{\circ} \mathrm{C}$ to $700^{\circ} \mathrm{C}$. These data suggest that the depth limit of hydrothermal fluid circulation is controlled by the maximum depth of brittle failure. Here, we constrain the region of simulated hydrothermal cooling to be within the predicted zone of brittle failure (i.e., the zone in which our brittle rheology law dominates the effective viscosity). To simulate a decrease in permeability with depth, we decrease the efficiency of hydrothermal cooling, down to a reference depth $\left(z_{\text {ref }}\right)$, below which we assume fractures are closed by the overburden pressure [e.g., David et al., 1994; Cherkaoui et al., 2003].

[22] This hydrothermal feedback is incorporated into equation (3) via an effective thermal conductiv- 


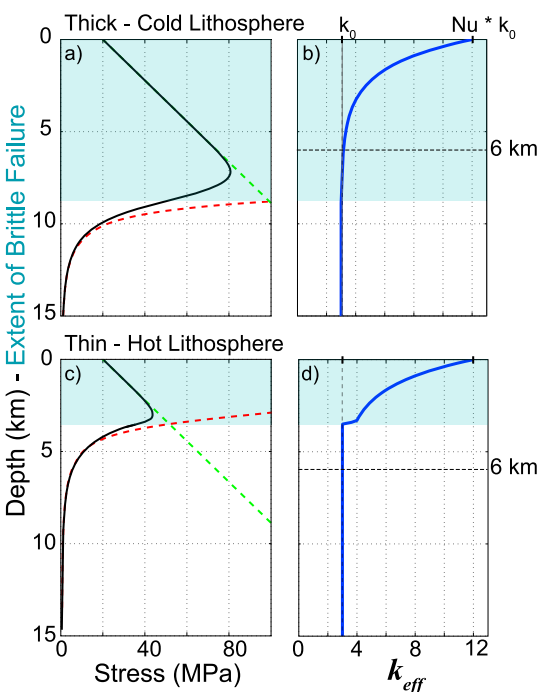

Figure 3. Effective thermal conductivity versus depth, used to simulate hydrothermal cooling for two end-member thermal/stress regimes. The shaded region indicates the extent of brittle deformation. ( $a$ and $b$ ) In regions where the lithosphere is cool and thick, permeability decreases exponentially with depth down to $Z_{\text {ref }}=6 \mathrm{~km}$, as illustrated by the blue line in Figure 3b. (c and d) In regions where the lithosphere is hot and weak, hydrothermal circulation is confined to the brittlely deforming zone. Under these conditions, increased values of thermal conductivity are reduced to the reference value smoothly across the brittle-ductile transition via an error function, as indicated by the blue line in Figure $3 \mathrm{~d}$.

ity, $k_{\text {eff, }}$ that is a function of $N u, z_{\text {ref }}$ and the ratio of the differential stress associated with the brittle and viscous deformation laws:

$$
\begin{aligned}
k_{\text {eff }}= & k_{0}\left\{1+(N u-1) \times 0.5\left[1-\operatorname{erf}\left(C_{S} \log \left(\frac{\Delta \sigma_{\text {brittle }}}{\Delta \sigma_{\text {creep }}}\right)\right]\right.\right. \\
& \left.\times \exp \left(C_{D} \frac{z}{z_{\text {ref }}}\right)\right\},
\end{aligned}
$$

where $k_{0}$ represents the reference thermal conductivity without hydrothermal circulation (Table 1). The error function and exponential terms in this expression, with the associated nondimensional constants $C_{S}$ and $C_{D}$, control the smoothness of the effective conductivity across the brittle-ductile transition and with depth, respectively. In warm/thin lithosphere, where only a thin region deforms brittlely, hydrothermal circulation is limited to the shallow brittle zone, decreasing to the reference conductivity value at the maximum depth of brittle failure (Figures $3 \mathrm{c}$ and $3 \mathrm{~d}$ ). In cold/thick lithosphere, brittle deformation likely extends to depths at which the overburden is too high for connected cracks to be supported. Under these conditions, the maximum depth of the hydrothermal cooling is controlled by the effect of overburden pressure on permeability (Figures $3 \mathrm{a}$ and $3 \mathrm{~b}$ ).

\section{Model Results}

[23] The thermal structure calculated using our base model is displayed in Figure 4 for a full slip rate $\left(u_{0}\right)$ of $3.0 \mathrm{~cm} / \mathrm{yr}$ and transform length $\left(L_{T}\right)$ of $100 \mathrm{~km}$. One key feature of these results is the mantle upwelling in the center of the transform beneath the zone of high strain rate and lower effective viscosity. In this zone, advection of hot mantle leads to warmer temperatures relative to the surrounding lithosphere of the same age (Figures 4a and 4d). The combined effects of conductive cooling with distance from the ridge and advective heating in the center of the fault result in a relatively uniform thermal structure along the fault, with no significant shoaling of the isotherms except near the fault ends (Figures $4 \mathrm{~b}$ and $4 \mathrm{c}$ ). These general characteristics of the thermal structure are consistent over the full suite of model parameters we examined.

[24] To compare differences in individual model runs, we characterize solutions in terms of the maximum depth of the $600^{\circ} \mathrm{C}$ isotherm $\left(Z_{600}^{m}\right)$ and the area above the $600^{\circ} \mathrm{C}$ isotherm $\left(A_{600}\right)$. We also calculate the area between the $350^{\circ} \mathrm{C}$ and $600^{\circ} \mathrm{C}$ isotherms $\left(A_{350-600}\right)$. As discussed above, the $350^{\circ} \mathrm{C}$ and $600^{\circ} \mathrm{C}$ isotherms likely represent the lower and upper temperature bounds on the seismogenic zone in mantle rocks. Using these parameters, we can quantify the dependence of the temperature structure on slip rate and fault length. As slip rate decreases from 12 to $3 \mathrm{~cm} / \mathrm{yr}, Z_{600}^{m}$ deepens from approximately 4.0 to $7.3 \mathrm{~km}$ in models with $L_{T}=100 \mathrm{~km}$ (Figure 5b). Similarly, both $A_{600}$ and $A_{350-600}$ increase with decreasing slip rate (Figure 5a). The area of the seismogenic zone also correlates with fault length (Figure 6). For longer faults, $A_{600}$ increases due to the greater contribution of conductive cooling near the center of the fault. For example, for a slow slipping fault $\left(u_{0}=3 \mathrm{~cm} / \mathrm{yr}\right)$, $A_{600}$ increases by approximately an order of magnitude between solutions with $L_{T}=50$ and $200 \mathrm{~km}$. This change is also observed in $Z_{600}^{m}$, which deepens from $\sim 5$ to $10 \mathrm{~km}$ between $L_{T}=50$ and $200 \mathrm{~km}$.

[25] When we compare our model results to a halfspace cooling model, we find that estimates of $A_{600}$ and $A_{350-600}$ are remarkably similar for a range of 

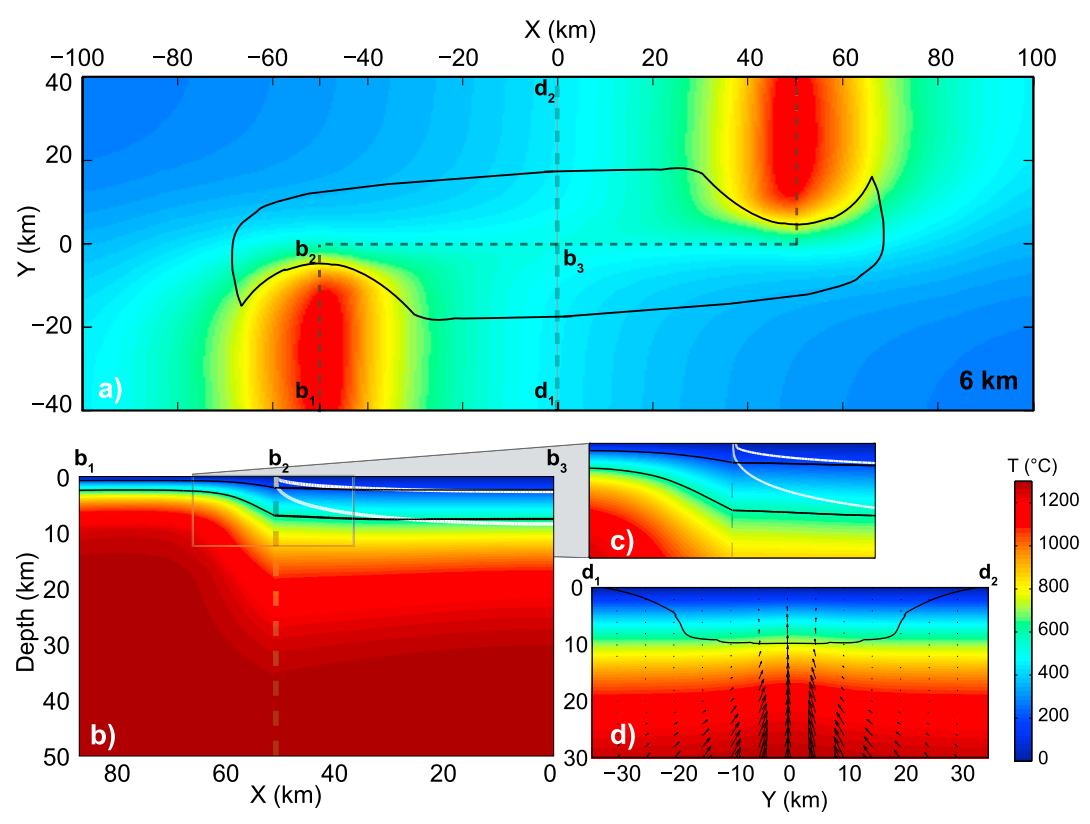

Figure 4. Base model solution with $u_{0}=3.0 \mathrm{~cm} / \mathrm{yr}$ and $L_{T}=100 \mathrm{~km}$. Hydrothermal cooling, alteration, and shear heating feedbacks are not incorporated. (a) Map view of temperature at $6 \mathrm{~km}$ depth. Solid black line outlines zone of brittle deformation. Dashed lines and letter labels indicate the location of along-fault and across-fault profiles in Figures $4 \mathrm{~b}$ and $4 \mathrm{~d}$, respectively. (b) Cross section along the ridge and transform fault. Solid black lines outline the calculated $350^{\circ} \mathrm{C}$ and $600^{\circ} \mathrm{C}$ isotherms. White lines show the location of the same isotherms calculated from a half-space cooling model. The half-space approximation is determined as an average of the temperatures calculated from each side of the fault using a lithospheric 2-D half-space cooling model that assumes conductive cooling with plate age [McKenzie, 1969]. (c) Expanded view of the of ridge-transform intersection, highlighting the shape of the isotherms from the numerical and half-space model calculations at the end of the transform fault. (d) Cross section perpendicular to the center of the fault. Solid black line indicates the maximum depth of brittle deformation. Arrows illustrate the velocity field and focused mantle upwelling in the center of the fault.

slip rates and fault lengths (Figures 5a and 6a). However, solutions calculated using the half-space model are characterized by a lithosphere that cools and thickens with distance from the ridge-transform intersection and isotherms that gradually deepen toward the center of the transform fault (white lines in Figures $4 \mathrm{~b}$ and $4 \mathrm{c}$ ). In contrast, isotherms predicted from our model deepen more steeply near the ridge, and then flatten, maintaining a relatively constant depth to center of the fault (Figures $4 b$ and $4 c$ ). As a result, the width of the seismogenic zone is uniform along most of the fault (Figure 5b). Below, we discuss the effects of weakening due to mantle alteration, shear heating, and hydrothermal cooling on our thermal results.

\subsection{Frictional Weakening}

[26] The colder thermal structures predicted for longer faults and slower slip rates result in brittle deformation and zones of hydrous alteration that extend deeper into the lithosphere. However, frictional weakening associated with serpentinization results in negligible changes to the thermal structure. For example, models in which the friction coefficient is lowered within the zone of serpentinization, show changes in $Z_{600}^{m}$ and $A_{600}$ on the order of $0.1 \mathrm{~km}$ and $1 \%$, respectively, for a fault with $u_{0}=$ $3.0, L_{T}=100 \mathrm{~km}$.

[27] We further explore the sensitivity of our results to fault weakening, using constant values of the friction parameters $(\mu, C)$ throughout the entire model space (Figure 7). $\mu$ and $C$ limit the maximum differential stress in the brittle part of the lithosphere. Three trends are found between frictional strength and fault thermal structure, highlighted by arrows in Figure 7b. First, as $C$ increases, the amount of passive mantle upwelling beneath the transform decreases, resulting in less heat transport to the fault 

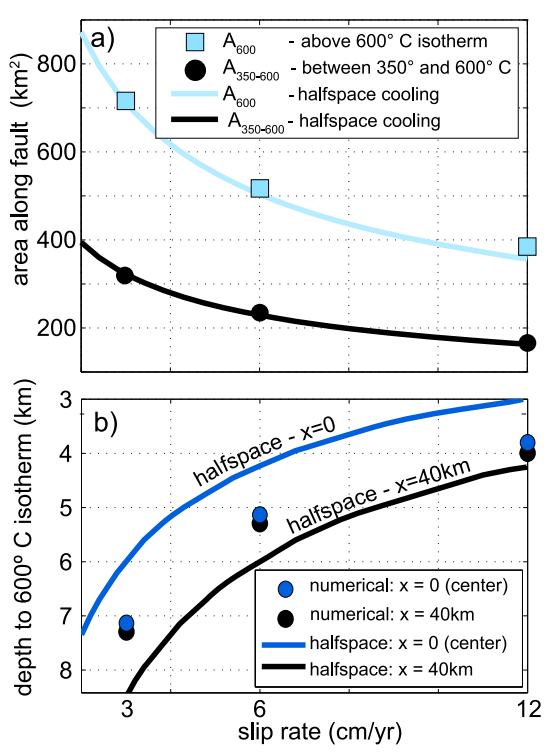

Figure 5. (a) $A_{600}$ (light blue squares) and $A_{350-600}$ (black circles) as a function of slip rate for the base model assuming $L_{T}=100 \mathrm{~km}$. Light blue and black lines indicate the same calculations made using a half-space cooling model. (b) Depth to the $600^{\circ} \mathrm{C}$ isotherm calculated at two locations along the fault. Black circles indicate the depth calculated at a distance $0.1 L_{T}$ away from the end of the fault ( $X= \pm 40 \mathrm{~km}$ for a $100 \mathrm{~km}$ fault). Blue circles indicate the depth at $0.5 L_{T}(\mathrm{X}=0$, the center of the fault). Black and blue lines indicate the depth to the $600^{\circ} \mathrm{C}$ isotherm calculated using a half-space cooling model.

and cooler fault temperatures (trend I in Figure $7 \mathrm{~b}$ ). Second, for models with $C=10-40 \mathrm{MPa}$, decreasing $\mu$ leads to more localized strain along the fault. This also reduces advective heat transport into the fault domain, leading to cooler temperatures (trend II in Figure 7b). Finally, when the $C<\sim 3 \mathrm{MPa}$ the lithosphere cannot support large differential stresses. In this case, decreasing $\mu$ promotes modest strain localization, which facilitates mantle upwelling along the transform and slightly warmer fault solutions (trend III in Figure 7b). Overall, for the range of $\mu$ and $C$ examined, the total change in the calculated temperature structure is relatively small, $\sim 1 \mathrm{~km}$ in $Z_{600}^{m}$ over all frictional parameters.

\subsection{Shear Heating}

[28] Models that incorporate shear heating show a small increase in temperature along the fault (Figure 6). The magnitude of the temperature increase associated with shear heating scales with the fault length. For example, a transform of length $L_{T}=100 \mathrm{~km}$ produces a positive temperature anomaly of $20^{\circ} \mathrm{C}$, while a transform of length, $L_{T}=$ $500 \mathrm{~km}$ produces an anomaly of $\sim 45^{\circ} \mathrm{C}$. However, even for the longest transforms we examined, including shear heating only decreases $A_{600}$ by $\sim 1 \%$ and $Z_{600}^{m}$ by $<1 \mathrm{~km}$ relative to the base model (Figure 6). This results because $Q_{s h}$ is largest along the base of the fault zone, where strain rate and effective confining stress are high. As shear heating warms the base of the fault, the brittle-ductile transition shallows, due to the temperature dependence of viscosity. This reduces $Q_{s h}$ and effectively buffers the effect of shear heating on fault thermal structure.
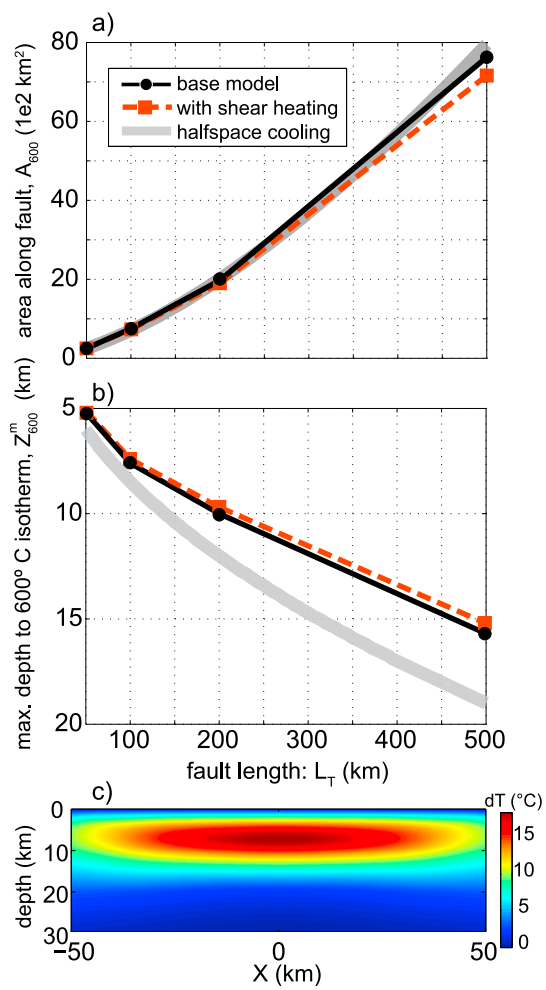

Figure 6. (a) $A_{600}$ and (b) $Z_{600}^{m}$ as a function of fault length $\left(L_{T}\right)$ for the base model (black circles), the base model plus shear heating (red squares), and the half-space cooling model (solid grey line) with $u_{0}=3.0 \mathrm{~cm} / \mathrm{yr}$. (c) Temperature difference between the base model solution and that with a shear heating heat source for $u_{0}=3.0 \mathrm{~cm} / \mathrm{yr}$ and $L_{T}=100 \mathrm{~km}$. 


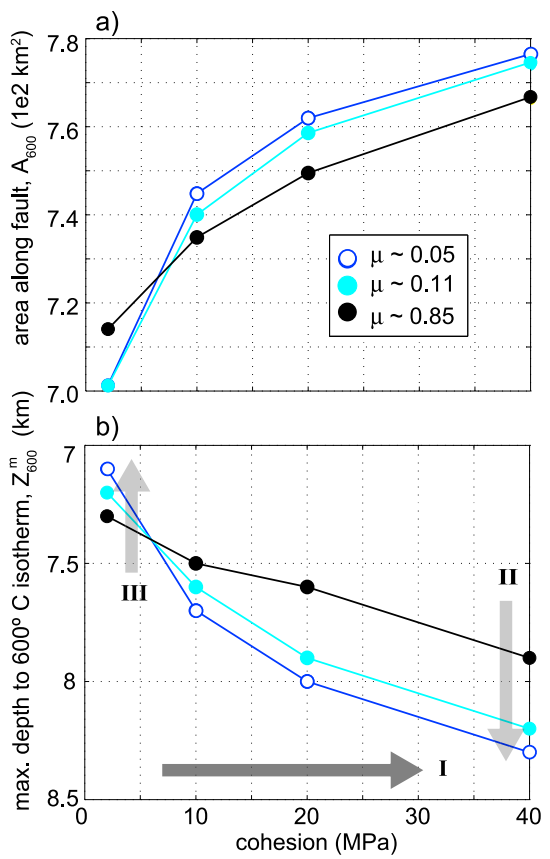

Figure 7. Summary of the change in (a) $A_{600}$ and (b) $Z_{600}^{m}$ as a function of cohesion ( $x$ axis) and friction coefficient ( $\mu$, black, cyan, and blue curves). Each symbol illustrates an individual model run. Arrows in Figure $7 \mathrm{~b}$ indicate three trends in the dependence of temperature on lithospheric strength, which are outlined in section 3.1.

\subsection{Hydrothermal Cooling}

[29] For all transform geometries, hydrothermal cooling has a significant effect on the derived thermal structure. As the efficiency of fluid circulation increases (simulated by higher $N u$ ), transform faults become progressively cooler. For models with $Z_{r e f}=$ $6 \mathrm{~km}$, the most significant cooling occurs between $N u=1-4$ (Figure 8) with smaller changes for $N u>4$.

[30] The decrease in relative cooling for higher Nusselt numbers reflects the importance of the permeability structure for limiting hydrothermal circulation in regions of thick lithosphere. Initially, as $N u$ increases, the greater efficiency of hydrothermal circulation rapidly cools the transform. However, as the effective thermal conductivity continues to increase, heat flow becomes limited by the assumed pressure dependence of permeability. We explore this effect by varying $Z_{r e f}$, the approximate depth of pore closure. For $Z_{r e f}=6 \mathrm{~km}, Z_{600}^{m}$ increases by less than $2 \mathrm{~km}$ between $N u=2$ and $N u=8$, regardless of slip rate or fault length. In contrast, for $Z_{\text {ref }}=15 \mathrm{~km}$, the region of high permeability extends to greater depths, and $Z_{600}^{m}$ increases by $\sim 5 \mathrm{~km}$ for the $N u=8$, slow slipping solution (Figure 8b).

\section{Discussion}

[31] Our numerical model provides insight into the size and shape of the seismogenic zone along oceanic transform faults. It also serves as a tool for estimating the amount of alteration along the transform and in the surrounding lithosphere. We find that both the size of the seismogenic zone and the extent of mantle hydration increase for longer faults, slower slip rates, and more efficient hydrothermal circulation. Below, we discuss the implications of our results for seismicity at oceanic transform faults

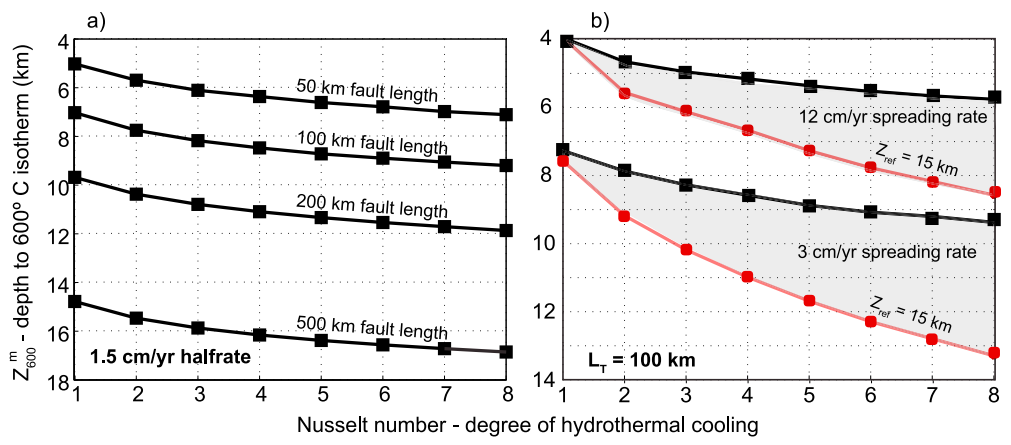

Figure 8. $\quad Z_{600}^{m}$ as a function of the efficiency of hydrothermal cooling $(N u)$ for different (a) slip rates and (b) fault lengths. Solutions associated with models with efficient hydrothermal cooling (high $\mathrm{Nu}$ ), slower slip rates, and/or longer faults show $Z_{600}^{m}$ extending into the upper oceanic mantle $(z>6 \mathrm{~km})$. Black lines indicate model runs with $Z_{r e f}=6 \mathrm{~km}$. Red lines indicate model runs with $Z_{r e f}=15 \mathrm{~km}$. Each square represents results from an individual model solution. 


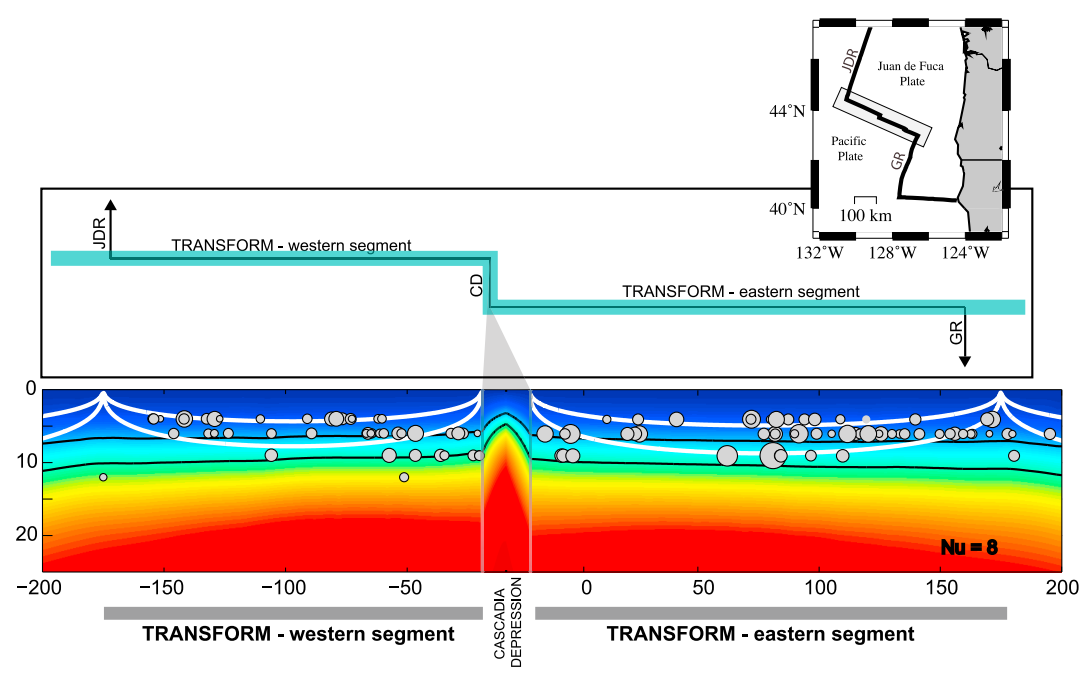

Figure 9. Temperature structure calculated for the Blanco Transform fault assuming $u_{0}=5.6 \mathrm{~cm} / \mathrm{yr}$ and $N u=8$. Two active fault segments are separated by the $20 \mathrm{~km}$ Cascadia Depression. The lengths of the western and eastern segments are 155 and $195 \mathrm{~km}$, respectively. White lines indicate the $350^{\circ} \mathrm{C}$ and $600^{\circ} \mathrm{C}$ isotherms calculated from a half-space cooling mode. Black lines indicate the same isotherms for the numerical model. Grey circles show the centroid depth distribution of quality A (i.e., best fit location within $3 \mathrm{~km}$ of $5 \%$ variance increase bound) strike-slip events from Braunmiller and Nábèlek [2008]. Size of circle is approximately proportional to the magnitude of the individual earthquake.

and their role in the transport of water from the hydrosphere to the upper mantle.

\subsection{Implications for Oceanic Transform Fault Seismicity}

[32] The seismogenic area estimated from either $A_{350-600}$ or $A_{600}$ is remarkably consistent between our model results and those derived from the halfspace model (Figures 5 and 6). This result implies that half-space models can be used to accurately estimate seismic coupling across oceanic transform faults. However, our models show significant differences in the geometry of the seismogenic zone compared to that predicted by the half-space cooling model. Specifically, the upper and lower isothermal bounds on the seismogenic zone deepen quickly near the ridge-transform intersection and then maintain a constant depth along the length of the fault. This differs from the seismogenic zone predicted from the half-space cooling model, in which isotherms deepen gradually with distance from the ridge-transform intersection to the center of the fault. The seismogenic width predicted from the half-space model thus thickens appreciably toward the center of the fault, in contrast to our numerical results that predict the seismogenic width remains nearly constant (Figure 4).
[33] To date, local and global-scale studies of oceanic transform fault seismicity have not definitively resolved any deepening of seismicity toward the center of transform faults. For example, ocean bottom seismic studies indicate the depth of seismicity along the Orozco [Trehu and Solomon, 1983] and Kane [Wilcock et al., 1990] transform faults show no systematic deepening away from the ridgetransform intersection. Teleseismic body wave inversions [Bergman and Solomon, 1988; Abercrombie and Ekstrom, 2001] correlate earthquake distributions along the fault with the average depth of the $600^{\circ} \mathrm{C}$ isotherm predicted by the half-space model, but are unable to resolve along fault variations in focal depths.

[34] A regional inversion of surface waves from the Blanco transform also shows relatively constant fault width [Braunmiller and Nábělek, 2008]. In Figure 9 we compare earthquake depths along the Blanco transform with the thermal structures derived from half-space cooling and our model. In both models, we incorporate the Cascadia Depression as an intratransform spreading center, motivated by observations from seismic reflection data [Embley et al., 1987], as well as the morphological expression of the offset [Embley and Wilson, 1992] and 

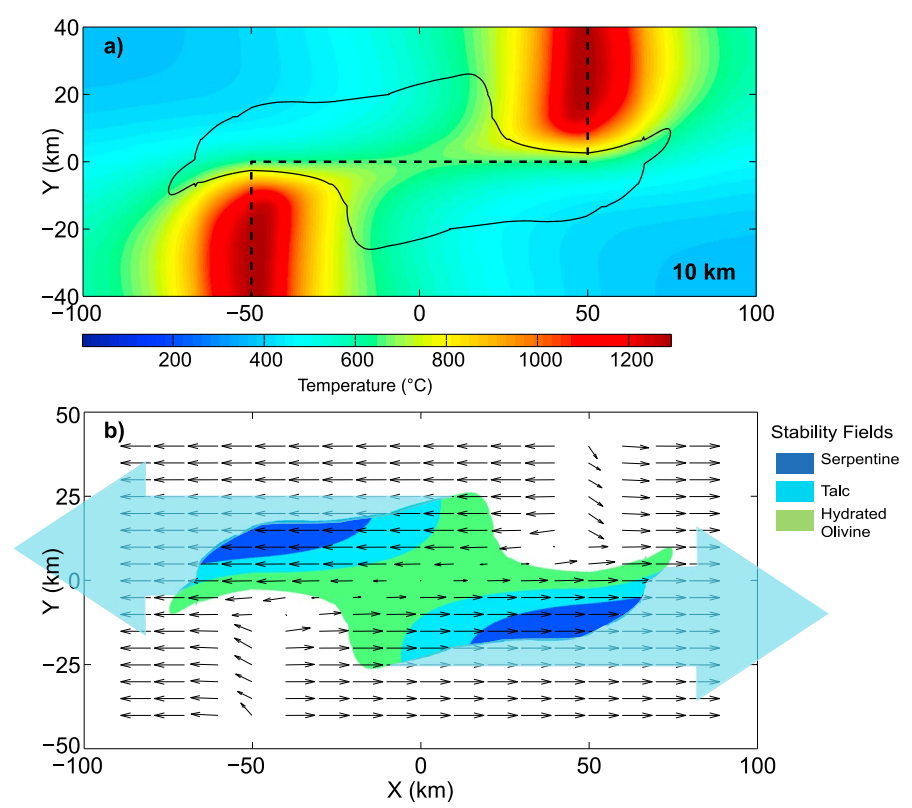

Figure 10. (a) Temperature solution at $10 \mathrm{~km}$ depth for a slow slipping transform fault $\left(u_{0}=3.0 \mathrm{~cm} / \mathrm{yr}\right)$ with efficient hydrothermal cooling, $N u=8$. Black line outlines zone of brittle deformation where permeability may provide for fluids to reach mantle depths. (b) Estimated zones of stable hydrous phases at $10 \mathrm{~km}$ based on phase stability field of Poli and Schmidt [2002]. Light blue arrows indicate the advection of hydrated material, which is carried with plate motion off axis.

earthquake T axes [Braunmiller and Nábélek, 2008]. We find that while the half-space cooling model predicts the approximate maximum depth of seismicity at the center of the active eastern and western Blanco segments, it significantly underpredicts the depth of seismicity surrounding the ridge-transform intersections and the Cascadia Depression. In contrast, our numerical model predicts deeper seismicity near the end of the fault segments, in better agreement with the observed earthquake depths. Assuming hydrothermal circulation with $N u=8$ results in a good fit of the $600^{\circ} \mathrm{C}$ isotherm with the lower limit of seismicity along each of the fault segments. This Nusselt number is consistent with the preferred value used by Phipps Morgan and Chen [1993] to match magma lens depths along the global ridge system. The $N u=8$ model predicts that some of the Blanco earthquakes occur in lithosphere cooler than $350^{\circ} \mathrm{C}$. The $350^{\circ} \mathrm{C}$ isotherm approximates the upper bound on the seismogenic zone based on the frictional characteristics of serpentine, which may not be present in the zones of shallow seismicity located within the crust. Thus, it appears that our model does a better job capturing the seismogenic zone of the
Blanco transform as compared to the half-space cooling model.

\subsection{Hydration of the Oceanic Mantle at Transform Faults}

[35] Transform faults have long been recognized as tectonic settings where the mantle may undergo extensive alteration and serpentinization [Bonatti and Honnorez, 1976; Francis, 1981; Dick, 1989; Cannat et al., 1995; Detrick et al., 1987, 1993; Canales et al., 2000]. Results from our numerical models provide a basis for quantitatively estimating the amount of hydration expected in transform settings. Simulations of relatively longer faults and slower slip rates show that brittle deformation extends into the upper mantle (Figure 4). Incorporating hydrothermal cooling further increases the depth of brittle deformation. In Figure 10 we show the calculated stability of antigorite and talc [Poli and Schmidt, 2002] at a depth of $10 \mathrm{~km}$ for a slow slipping transform fault. Figure 10 illustrates the enhanced hydration surrounding the transform fault 
relative to the adjacent ridge axes, and shows how this region of alteration may be advected off axis.

[36] Hydrated peridotite is capable of transporting significant amounts of water to the arc melting region and postarc depths in subduction zones [Hacker, 2008]. Thus, the subduction of oceanic mantle that is hydrated at transform faults may promote arc magmagenesis and contribute appreciably to the flux of water to the deep mantle. Several studies have identified alteration at fracture zones as localized sources of water in the subducting slab. Grove et al. [2002] suggest that $\mathrm{H}_{2} 0$-rich lavas erupted from Mount Shasta were derived from the dehydration of subducted serpentine that formed along the Blanco transform. Similarly, highly localized, water-rich magmas found along the Andean Southern Volcanic Zone have been correlated with the subduction of lithosphere influenced by the Mocha Fracture zone [Rodríguez et al., 2007]. Future studies are required to determine whether there is a spreading rate dependence to the transport of water into the mantle, as would be predicted from our calculations.

\section{Conclusions}

[37] We have developed a new rheologic model to calculate the thermal structure of oceanic transform faults, which incorporates both nonlinear viscosity and brittle deformation into a viscoplastic rheology. We also incorporate the effects of three key feedbacks: frictional weakening due to mantle alteration, shear heating, and hydrothermal circulation.

[38] Numerical results predict cooler thermal structures for longer faults and slower slip rates. Although frictional weakening due to alteration may affect the mechanical properties of fault zones, we find that such weakening has a negligible effect on the resulting thermal structure. Similarly, incorporating shear heating leads to only slightly warmer thermal profiles. Hydrothermal circulation, conversely, has a significant cooling effect on the temperature structure in the transform zone, particularly in models with deep, efficient circulation.

[39] Our model can be used to estimate the geometry of the seismogenic zone and the degree of mantle hydration along oceanic transform faults. In contrast to the predictions made using the analytic half-space cooling model, our model predicts that the seismogenic zone along transform faults has a relatively uniform width, consistent with seismic observations. However, the total seismogenic area predicted from the two models is similar. For fault solutions with longer fault lengths and slow slip rates, we predict cooler temperature structure and brittle deformation that extends into the upper mantle. Alteration and subsequent subduction of such zones may play an important role in melting and arc volcanism at subduction zones. The results of our study are a first step toward developing a means of mapping the extent of serpentinization around transform faults that can be quantitatively correlated with along-arc geochemical anomalies.

\section{Acknowledgments}

[40] We would like to thank T. Grove, P. Fryer, J. McGuire, $\mathrm{M}$. Boettcher, and T. Jordan for helpful discussions during the completion of this work. We would also like to thank T. Becker, C. Hieronymus, and R. Govers for their help improving this paper as well as R. Yanick for constructive comments on an earlier version of this manuscript. The material presented here is based on work supported by the National Science Foundation Division of Ocean Sciences (OCE) grants 0623188 (M.B. and G.H.) and 0649103 (M.B.) and Division of Earth Sciences (EAR) grant 0814513 (G.H.).

\section{References}

Abercrombie, R. E., and G. Ekstrom (2001), Earthquake slip on oceanic transform faults, Nature, 410, 74-77, doi: $10.1038 / 35065064$.

Behn, M. D., J. Lin, and M. T. Zuber (2002), Mechanisms of normal fault development at mid-ocean ridges, J. Geophys. Res., 107(B4), 2083, doi:10.1029/2001JB000503.

Behn, M. D., M. S. Boettcher, and G. Hirth (2007), Thermal structure of oceanic transform faults, Geology, 35, 307-310, doi:10.1130/G23112A.1

Bergman, E. A., and S. C. Solomon (1988), Transform fault earthquakes in the North Atlantic: Source mechanisms and depth of faulting, J. Geophys. Res., 93(B8), 9027-9057.

Bird, P., Y. Y. Kagan, and D. D. Jackson (2002), Plate tectonics and earthquake potential of spreading ridges and oceanic transform faults, in Plate Boundary Zones, Geodyn. Ser., vol. 30, pp. 203-218, AGU, Washington, D. C.

Boettcher, M. S., and T. H. Jordan (2004), Earthquake scaling relations for mid-ocean ridge transform faults, J. Geophys. Res., 109, B12302, doi:10.1029/2004JB003110.

Boettcher, M. S., G. Hirth, and B. Evans (2007), Olivine friction at the base of oceanic seismogenic zones, J. Geophys. Res., 112, B01205, doi:10.1029/2006JB004301.

Bonatti, E., and J. Honnorez (1976), Sections of the Earth's crust in the equatorial Atlantic, J. Geophys. Res., 81(23), 4140-4116.

Brace, W. F., and D. L. Kohlstedt (1980), Limits on lithospheric stress imposed by laboratory experiment, Geophys. Res. Lett., 85(B11), 6248-6252.

Braunmiller, J., and J. Nábělek (2008), Segmentation of the Blanco Transform Fault Zone from earthquake analysis: Complex tectonics of an oceanic transform fault, J. Geophys. Res., 113, B07108, doi:10.1029/2007JB005213. 
Brun, J., and P. Cobbold (1980), Strain heating and thermal softening in continental shear zones: A review, J. Struct. Geol., 2, 149-158, doi:10.1016/0191-8141(80)90045-0.

Canales, J. P., J. L. R. S. Detrick, and J. A. Collins (2000), Crustal and upper mantle seismic structure beneath the rift mountains and across a nontransform offset at the MidAtlantic Ridge (35n), J. Geophys. Res., 105, 2699-2719.

Cannat, M., et al. (1995), Thin crust, ultramafic exposures, and rugged faulting patterns at the Mid-Atlantic Ridge $\left(22^{\circ}-24^{\circ} \mathrm{N}\right)$, Geology, 23, 49-52, doi:10.1130/0091-7613(1995)0230049: TCUEAR2.3.CO;2.

Chen, Y., and W. J. Morgan (1990), A nonlinear rheology model for mid-ocean ridge axis topography, J. Geophys. Res., 95, 17,583-17,604.

Cherkaoui, A. S. M., W. S. D. Wilcock, R. A. Dunn, and D. R. Toomey (2003), A numerical model of hydrothermal cooling and crustal accretion at a fast spreading mid-ocean ridge, Geochem. Geophys. Geosyst., 4(9), 8616, doi:10.1029/ $2001 \mathrm{GC} 000215$

David, C., T. F. Wong, W. Zhu, and J. Zhang (1994), Laboratory measurement of compaction-induced permeability change in porous rocks: Implications for the generation and maintenance of pore pressure excess in the crust, Pure Appl. Geophys., 143, 425-456.

Detrick, R. S., M. H. Cormier, R. A. Prince, D. W. Forsyth, and E. L. Ambos (1987), Seismic constraints on the crustal structure within the Vema fracture zone, J. Geophys. Res., 87(B13), 10,599-10,612.

Detrick, R. S., R. S. White, and G. M. Purdy (1993), Crustal structure of North Atlantic fracture zones, Rev. Geophys., 31(4), 439-458.

Dick, H. J. B. (1989), Abyssal peridotites, very slow spreading ridges and ocean ridge magmatism, Geol. Soc. Spec. Publ., 42, 71-105.

Embley, R. W., and D. S. Wilson (1992), Morphology of the Blanco transform fault zone-NE Pacific: Implications for its tectonic evolution, Mar. Geophys. Res., 14, 25-45.

Embley, R. W., L. D. Klum, G. Massoth, D. Abbott, and M. Holmes (1987), Morphology, structure and resonance potential of the Blanco Transform Fault Zone, in Geology and Resource Potential for the Continental Margin of Western North America and Adjacent Ocean Basins-Beaufort Sea to Baja California, Earth Sci. Ser., vol. 6, edited by D. W. Scroll, A. Grantz, and J. G. Vetter, pp. 549-562, Circum-Pac. Res. Counc., Houston, Tex.

Engeln, J. F., D. A. Wiens, and S. Stein (1986), Mechanisms and depths of Atlantic transform earthquakes, J. Geophys. Res., 91, 548-577.

Escartin, J., G. Hirth, and B. Evans (2001), Strength of slightly serpentinized peridotites: Implications for the tectonics of oceanic lithosphere, Geology, 29, 1023-1026.

Fleitout, L., and C. Froidevaux (1980), Thermal and mechanical evolution of shear zones, J. Struct. Geol., 2, 159-164, doi:10.1016/0191-8141(80)90046-2.

Francis, T. J. (1981), Serpentinization faults and their role in the tectonics of slow spreading ridges, J. Geophys. Res., 86(B12), 11,616-11,622.

Furlong, K. P., S. D. Sheaffer, and R. Malservisi (2001), Thermal-rheological controls on deformation within oceanic transforms, The Nature and Tectonic Significance of Fault Zone Weakening, Geol. Soc. Spec. Publ., 186, 65-83.

Grove, T. L., S. W. Parman, S. A. Bowring, R. C. Price, and M. B. Baker (2002), The role of an $\mathrm{H}_{2} \mathrm{O}$-rich fluid component in the generation of primitive basaltic andesites and andesites from the Mt. Shasta region, N California, Contrib. Mineral. Petrol., 142, 375-396.

Grove, T. L., N. Chatterjee, S. W. Parman, and E. Médard (2006), The influence of $\mathrm{H}_{2} \mathrm{O}$ on mantle wedge melting, Earth Planet. Sci. Lett., 249(1-2), 74-89, doi:10.1016/ j.eps1.2006.06.043.

Hacker, B. R. (2008), $\mathrm{H}_{2} \mathrm{O}$ subduction beyond arcs, Geochem. Geophys. Geosyst., 9, Q03001, doi:10.1029/2007GC001707. Hirth, G., and D. Kohlstedt (2003), Rheology of the upper mantle and the mantle wedge: A view from the experimentalists, in Inside the Subduction Factory, Geophys. Monogr. Ser., vol. 138, edited by J. Eiler, pp. 83-105, AGU, Washington, D. C

Kelley, D. S., and K. M. Gillis (2002), Petrologic constraints upon hydrothermal circulation, paper presented at InterRidge Theoretical Institute: Thermal Structure of Ocean Crust and Dynamics of Hydrothermal Circulation, Pavia, Italy.

Kirby, S. H. (1983), Rheology of the lithosphere, Rev. Geophys., 21(6), 1458-1487.

McKenzie, D. P. (1969), Speculations on the consequences and causes of plate motions, Geophys. J. R. Astron. Soc., $18,1-32$.

Moore, D. E., D. A. Lockner, M. Shengli, R. Summers, and J. D. Byerlee (1997), Strengths of serpentinite gouges at elevated temperatures, J. Geophys. Res., 102(B7), 14,787-14,801.

O'Hanley, D. S. (1996), Serpentinites: Recorders of Tectonic and Petrological History, 296 pp., Oxford Univ. Press, New York.

Phipps Morgan, J., and Y. J. Chen (1993), The genesis of oceanic crust: Magma injection, hydrothermal circulation, and crustal flow, J. Geophys. Res., 98, 6283-6297.

Phipps Morgan, J., and D. W. Forsyth (1988), Three-dimensional flow and temperature perturbations due to a transform offset: Effects on oceanic crustal and upper mantle structure, J. Geophys. Res., 93, 2955-2966.

Phipps Morgan, J., and E. M. Parmentier (1984), Lithospheric stress near a ridge-transform intersection, Geophys. Res. Lett., 11(2), 113-116.

Phipps Morgan, J., E. M. Parmentier, and J. Lin (1987), Mechanisms for the origin of mid-ocean ridge axial topography: Implications for the thermal and mechanical structure of accreting plate boundaries, J. Geophys. Res., 92, $12,823-12,836$.

Poli, S., and M. W. Schmidt (2002), Petrology of subducted slabs, Annu. Rev. Earth Planet. Sci., 30, 207-235.

Reinen, L. A., J. D. Weeks, and T. E. Tullis (1994), The frictional behavior of lizardite and antigorite serpentinites: Experiments, constitutive models, and implications for natural faults, Pure Appl. Geophys., 143, 318-358.

Rodríguez, C., D. Sellés, M. Dungan, C. Langmuir, and W. Leeman (2007), Adakitic dacites formed by intracrustal crystal fractionation of water-rich parent magmas at Nevado de Longaví volcano (36.2 s; Andean southern volcanic zone, central Chile), J. Petrol., 48(11), 2033-2061.

Shen, Y., and D. W. Forsyth (1992), The effects of temperatureand pressure-dependent viscosity on three-dimensional passive flow of the mantle beneath a ridge-transform system, J. Geophys. Res., 97, 19,717-19,728.

Sleep, N. H. (1975), Formation of oceanic crust: Some thermal constraints, J. Geophys. Res., 80(29), 4037-4042.

Trehu, A. M., and S. C. Solomon (1983), Earthquakes in the Orozco transform zone: Seismicity, source mechanisms, and tectonics, J. Geophys. Res., 88(B10), 8203-8225.

Van Avendonk, H. J. A., A. J. Harding, J. A. Orcutt, and J. S. McClain (1998), A two-dimensional tomographic study of 
the Clipperton transform fault, J. Geophys. Res., 103(B8), $17,885-17,899$

van Keken, P. E., et al. (2008), A community benchmark for subduction zone modeling, Phys. Earth Planet. Inter., 171 (1-4), 187-197, doi:10.1016/j.pepi.2008.04.015.

Wiens, D. A., and S. Stein (1983), Age dependence of oceanic intraplate seismicity and implications for lithospheric evolution, J. Geophys. Res., 88, 6455-6468.
Wilcock, W. S. D., G. M. Purdy, and S. C. Solomon (1990), Microearthquake evidence for extension across the Kane transform fault, J. Geophys. Res., 95(B10), 15,439-15,462. Zoback, M. D., and J. Townend (2001), Implications of hydrostatic pore pressures and high crustal strength for the deformation of intraplate lithosphere, Tectonophysics, 336, 19-30. 


\title{
Chapter 4
}

\section{The seismic velocity structure of East Pacific Rise transform faults: Exploring material properties that control earthquake behavior}

\begin{abstract}
We characterize the seismic velocity structure at two oceanic transform faults using Pwave travel time tomography with the goal of identifying material properties that influence earthquake behavior. The Quebrada-Discovery-Gofar (QDG) fault system offsets the East Pacific Rise at approximately $4^{\circ}$ South. Two wide-angle refraction lines were acquired across the Gofar and Quebrada faults in 2008 as a part of a combined active/passive-source seismic investigation. Wide-angle refraction data from the two transects are modeled using a 2D tomographic inversion strategy developed by Van Avendonk et al. [1998]. We explore variations in crustal P-wave velocity and thickness, and image a significant low velocity zone across the Gofar and Quebrada faults. Seismic velocities are reduced by as much as $0.5-1.0 \mathrm{~km} / \mathrm{s}$ within a several-km-wide region across the active faults. At the Gofar fault, the low velocity zone appears to extend throughout the entire crust, into the seismogenic zone. In order to interpret the material variations responsible for the reduction in seismic velocity, we consider effective media properties of fractured gabbro and altered mantle peridotite. Reduced seismic velocities at the base of the crust within the seismogenic zone are consistent with porosity values of 0.1 to $0.6 \%$ for water-saturated gabbro. This result is considered in the context of earthquake behavior observed on the Gofar fault during the 2008 QDG experiment. Combined, seismic velocity models and earthquake observations provide convincing evidence for extreme along-strike heterogeneity in material properties that likely has a first-order influence on the frictional properties of the fault zone.
\end{abstract}




\subsection{Introduction}

Plate motions and the distribution of earthquakes are influenced by deformation at active fault zones that are significantly weaker than the surrounding lithosphere. Oceanic transform faults represent perhaps the weakest plate boundary faults within the global tectonic system. The anomalously low strength associated with these faults is evidenced in the orthogonal ridge-transform geometry and the patterns of faulting and seismicity at ridge-transform intersections [Behn et al., 2002]. Moreover, oceanic transforms tend to occur as single, long-lived faults rather than branching, distributed fault systems. This indicates that material within the oceanic transform domain is significantly weaker than the surrounding rocks and is thus able to facilitate the localization of regional strain. The unique mechanical behavior exhibited by oceanic transform faults bears relevance to conceptual models of lithospheric deformation and earthquake processes. However, it is unclear how fault structure and material properties influence strain accommodation at oceanic transform offsets.

Field studies of mature strike-slip faults on land consistently reveal an internal structure that is zoned [Chester et al., 1993; Schulz and Evans, 2000; Sibson, 2003; Savage and Brodsky, 2011], with a narrow fault core that accommodates strain during earthquakes or fault creep contained within a damage zone that is orders of magnitude wider. The margin of fault-affected material or damage zone has generally been identified as a region with increased fracture density relative to the host rock, formed by brittle deformation during repeated ruptures. Recently, kilometer-scale compliant damage zones have been identified at several faults in California based on the elastic response to stressing by nearby earthquakes [Fialko et al., 2002; Fialko, 2004]. The widths of these damage zones are significantly greater than the 100 meter wide damage zones commonly identified in field studies [Chester et al., 1993; Schulz and Evans, 2000; Savage and Brodsky, 2011], but are consistent with the km-scale damage zones inferred from other geophysical observations including fault zone trapped waves along the Calico fault [Cochran et al., 2009], potential fields measurements at various parts of the San 
Andreas fault [Eberhart-Phillips et al., 1995; Ben-Zion and Sammis, 2003] and seismic anisotropy along the North Anatolian Fault [Peng and Ben-Zion, 2004]. Although it is well-established that material properties can be affected across $\sim \mathrm{km}$ wide regions surrounding mature strike-slip faults, the depth to which wide damage zones extend into the crust is somewhat unclear, and thus far, it has been difficult to image damage zone structure at seismogenic depths. Field-based observations as well as the majority of geophysical studies are able to identify damage zones that extend throughout the first few kilometers of the crust, but these studies have thus far lacked resolution below 3-4 km, the depth range where earthquakes occur on continents [Ben-Zion et al., 2003].

Within individual strike-slip fault systems, variability in the width and depth extent of damage zones may be associated with changes in the mechanical behavior of the fault along strike and with depth. In areas where shallow fault structure is well known, unstable slip during earthquakes tends to be restricted to depths below the surficial low velocity zone associated with weak unconsolidated sediments and distributed, stable shear [Shearer, 2002; Lewis et al., 2007; Wei et al., 2009]. This observation is supported by laboratory experiments showing that slip within thick gouge exhibits inherently stable, velocity-strengthening behavior [Marone and Scholz, 1988; Marone and Kilgore, 1993]. Unstable, velocity weakening fault behavior required for earthquake generation would thus be confined to areas where the fault zone consists of thin gouge layers within competent rock surfaces. This is consistent with determinations of seismic rupture at the Parkfield section of the San Andreas fault located within patches of high seismic wave speeds [Michael and Eberhart-Phillips, 1991; Thurber et al., 2006], as well as the deficit of coseismic slip within the shallow low-velocity layer exhibited by many Mw 6-7 strike-slip earthquakes [Fialko et al., 2005]. All together, these observations indicate a relationship between damage zone width and the propensity for large seismic slip, which suggests that unconsolidated, low seismic velocity material is unable to store strain necessary to generate significant earthquakes. 
Global studies of oceanic transform fault earthquakes indicate that, on average, these faults release relatively little strain in the form of large earthquakes [Bird et al., 2002; Boettcher and Jordan, 2004]. Low estimates of seismic coupling, based on slip rates from plate motions and the thermally controlled seismic area, indicate that the majority of the slip on oceanic transform faults is accommodated aseismically. However, significant variability exists in the mechanical behavior observed at different transforms. On the East Pacific Rise (EPR), individual transform faults with virtually identical slip rates and similar fault geometry exhibit highly variable degrees of seismic coupling, with some faults accommodating $\sim 50 \%$ of the total strain as large earthquakes, and others sustaining very little or no significant seismically detectable moment release [Boettcher and Jordan, 2004].

The unique properties of transform faults make them well suited for investigating material controls on fault mechanics. Relative to other tectonic regimes, oceanic transforms are geometrically simple, with average slip rates that are well characterized by plate spreading velocities, and they occur in young oceanic lithosphere that is generally less compositionally heterogeneous, compared to convergent boundaries or continental strike-slip faults. Based on laboratory experiments and earthquake observations, the rheology of the oceanic lithosphere is primarily controlled by temperature and strain rate. Gabbro exhibits velocity weakening behavior at temperatures less than $500^{\circ} \mathrm{C}$ [He et al., 2007] and peridotite is velocity weakening at temperatures less than $600^{\circ} \mathrm{C}$ [Boettcher et al., 2007]. Accordingly, the seismogenic area in global studies of oceanic transform fault scaling is commonly estimated using thermal models as the area above the $600^{\circ} \mathrm{C}$ isotherm [Wilcock et al., 1990; Abercrombie and Ekstrom, 2001; Braunmiller and Nábělek, 2008; Roland et al., 2010]. Consistently low values of seismic coupling inferred for transforms indicate that, unlike other tectonic regimes, a purely temperaturedependent rheology is unable to accurately predict the maximum size of earthquakes. Recently, the observation that large EPR transform earthquakes occur quasi-periodically on overlapping fault patches has provided evidence that seismogenic segments of oceanic transform faults are separated by stationary, velocity-strengthening rupture barriers 
[McGuire, 2008]. It appears that discrete fault segments do not permit propagation of large mainshock ruptures, and release strain instead through aseismic creep transients, seismic swarms of smaller events or a combination of the two [McGuire et al., 2009]. Ultimately, low seismic coupling and earthquake rupture patterns at oceanic transforms may signify strong spatial variations in fault frictional properties [Boatwright and Cocco, 1996; Marone, 1998; Kaneko et al., 2010] that are influenced by material differences other than temperature alone.

Past seismic and petrologic investigations at oceanic transform faults in the Atlantic and Pacific have identified compositional and material property variations that would be expected to influence seismic behavior [Van Avendonk et al., 1998a, 2001; Bonatti, 1978; Calvert and Potts, 1985; Detrick et al., 1993; Tréhu and Purdy, 1984]. In the Atlantic, numerous seismic investigations published in the 1980s determined fault zone structure at slow-slipping transform faults characterized by a wide zone of reduced seismic velocities. In some cases this was accompanied by evidence of significantly thinned crust associated with alteration of the upper mantle and serpentinite diapirism [Detrick et al., 1993]. The few seismic refraction studies that exist for Pacific Ocean transform faults [Van Avendonk et al., 1998a, 2001; Tréhu and Purdy, 1984] have found fault zone compressional wave velocities that are significantly reduced compared to normal oceanic crust. These low velocity zones have been interpreted as areas of intense fracturing and increased hydrothermal alteration associated with strike-slip motion along the active fault trace that extends throughout most of the crust. These previous seismic imaging studies on EPR transforms were designed primarily to characterize tectonic processes that influence the morphology and geometry of the ridge-transform environment, and did not focus on relating structural and material properties of these faults to earthquake processes.

Here, we present results of tomographic inversions for the P-wave velocity structure across neighboring EPR transform faults that demonstrate contrasting seismic behavior. Just south of the Equator, the Quebrada-Discovery-Gofar (QDG) fault system 
offsets the EPR in a series of three fast-slipping $(140 \mathrm{~mm} / \mathrm{yr})$ transforms (Figure 1). Based on teleseismic and hydroacoustic observations of earthquake behavior over the past $\sim 20$ years, segments of the Gofar and Discovery faults sustain Mw 5.3-6.2 earthquakes on overlapping rupture patches roughly every 5 years, while only one $\mathrm{Mw}$ 5.5 earthquake has occurred in the vicinity of Quebrada [McGuire, 2008]. This behavior indicates a distinct contrast in the degree of seismic coupling at the three faults within the QDG system. In 2008, as a part of the QDG Active-Passive Transform Fault Experiment, two wide-angle refraction lines were acquired across the western-most segment of the Gofar (G3), and eastern-most segment of the Quebrada (Q1) faults (Figure 1). We use 2D travel time tomography to characterize the seismic velocity structure across the Gofar and Quebrada faults with the goal of comparing structure and material properties of two faults that span the entire spectrum of seismic behavior found at EPR transforms. The seismic velocity structure provides insight into the broad-scale variation in composition, fracture density, and possible rock/fluid interactions, all of which are expected to influence frictional and stress conditions along the fault. This experiment was specifically designed to explore for the lateral and depth extent of a low velocity zone present at the faults and the nature of any low or high seismic wave speeds within seismogenic depths. We interpret the implications of the velocity structure for the mechanical behavior of the faults in conjunction with information available from thermal models, gravity data, and earthquake observations from an extensive passive seismic deployment that was also conducted as a part of the QDG experiment.

\subsection{Tectonic Setting and Data Acquisition}

The QDG faults make up a $400 \mathrm{~km}$ offset in the EPR that ranges in latitude between 3.5$5^{\circ}$ South. Each of the three primary faults are broken up into multiple secondary active transform fault segments, separated by short intra-transform spreading centers (ITSCs) that range in length from 5 to $16 \mathrm{~km}$. The individual active transform faults were named by Searle [2008] following the first detailed side-scan sonar reconnaissance study of the 
QDG system. Quebrada is composed of four active segments, designated from east to west as Q1-Q4; Discovery has two segments D1 and D2; and Gofar has three active segments, G1-G3. At each fault, the active fault trace (white line, Figure 1), as indicated by pseudo-sidescan backscatter [Langmuir and Forsyth, 2007], is located within a transverse valley that is relatively narrow at the Gofar and Discover faults $(\sim 5 \mathrm{~km})$, and becomes a broader and deeper fracture zone valley at Quebrada [Searle, 1983].

The two wide-angle refraction lines were acquired in April of 2008, roughly perpendicular to the $103^{\circ}$-striking faults, crossing the $\sim 100-\mathrm{km}$-long G3 fault $60 \mathrm{~km}$ from the eastern end and crossing the $\sim 40-\mathrm{km}$-long Q1 fault $20 \mathrm{~km}$ from the eastern end. Hereafter, the Gofar and Quebrada seismic lines will be referred to as the G3 and Q1 lines. The exceptionally fast spreading rate of the EPR at this location leads to these faults occurring in relatively young oceanic crust. Assuming a constant half-slip rate of 7 $\mathrm{mm} / \mathrm{yr}$, the south side of G1 is $\sim 0.58 \mathrm{~m}$.y. and the north side increases with distance from the fault (as crust is created at progressively more northern spreading centers) from $\sim 0.86$ m.y. near the transform to $\sim 2 \mathrm{~m} . \mathrm{y}$. at the far northern end of the seismic line. Crust on the north side of the Q1 line is $\sim 0.28$ m.y., while crust south of the transform ranges in age from $\sim 0.28 \mathrm{~m}$.y. near the transform to $1.42 \mathrm{~m}$.y. at the far southern end.

Seismic data was collected on the R/V Marcus G. Langseth, with shots fired from a 40 element, 6600 cubic inch airgun array. The parallel $125 \mathrm{~km}$ long G3 and $107 \mathrm{~km}$ long Q1 lines were acquired during 7 days of shooting. Along the central $50 \mathrm{~km}$ crossing the fault, shots were fired at $100 \mathrm{~m}$ spacing, and along the outer $25+\mathrm{km}$ sections of each line, a wider spacing of $150 \mathrm{~m}$ was used. Eight WHOI 4-channel (3 component seismometer and hydrophone) short-period ocean bottom seismometers recorded crustal and upper mantle refractions and Moho reflections. These receivers were deployed at roughly $10 \mathrm{~km}$ spacing perpendicular to the active fault traces. The G3 and Q1 surveys occurred during a year-long passive deployment of an array of seismographs that recorded local seismicity at the QDG faults. At each fault, two of the WHOI 4-channel OBS associated with the passive experiment were located roughly along the refraction 
lines within $20 \mathrm{~km}$ of the fault. These instruments also recorded wide-angle active source data during the G3 and Q1 shooting (red stars,-Figure 1) that was used in the tomographic inversions presented here.

High-quality compressional-wave seismograms were recorded on the verticalcomponent seismometer and the hydrophone at each of the 10 stations on both the G3 and Q1 lines. The short-period instruments sampled at a rate of $200 \mathrm{~Hz}$ and the broadband OBS sampled at $50 \mathrm{~Hz}$. Vertical-component seismogram data were used to pick first arrival times of crustal refractions, upper mantle refractions and Moho reflections ( $\mathrm{Pg}, \mathrm{Pn}$, and $\mathrm{P}_{\mathrm{M}} \mathrm{P}$, respectively), except at stations G3-6 and G3-4 (Figure 1) where the seismometers appear to have been poorly coupled to the sea floor, and hydrophone data were used due to superior signal to noise. Data were bandpass filtered between 3-15 Hz using a minimum phase Butterworth filter, and predictive deconvolution was applied to reduce noise from reverberation and previous shot noise. For phase picking, record sections were reduced to $7 \mathrm{~km} / \mathrm{s}$ and refraction and reflection first arrivals were picked by hand. In order to account for any DC offset in picked travel times resulting from a residual instrument response not accounted for in the preliminary processing of the short-period, broadband and hydrophone data, water column direct arrival times were also picked and compared to the predicted arrival time at each station assuming the correct station location and a water velocity of $1.5 \mathrm{~km} / \mathrm{s}$. At stations G3-6 and G3-p8, where the predicted direct water column arrivals showed a systematic delay with respect to the observed arrival times, corrections were made to all refraction and reflection phase picks of less than $+0.2 s$ to account for the instrument response.

Although high quality first arrivals were recorded at all stations, the extreme bathymetric relief across both the Gofar and Quebrada faults made it difficult to recognize changes in the slope of travel time curves associated with distinct seismic layers within the oceanic crust (i.e. seismic layers 2 and 3), as well as the transition between crustal and upper mantle phases. High amplitude arrivals associated with the Moho triplication and dipping Moho reflections were similarly difficult to identify. 
Several measures were taken to verify the $\mathrm{Pg}, \mathrm{Pn}$, and $\mathrm{P}_{\mathrm{M}} \mathrm{P}$ picks. By assuming reciprocity between source-receiver pairs, we confirmed consistency of picked first arrivals at multiple stations by comparing arrival times that shared similar ray paths (i.e. phases with similar ray paths but source-receiver locations reversed). To guide arrival picking, particularly of $\mathrm{P}_{\mathrm{M}} \mathrm{P}$, which was often obscured by the expression of complex bathymetry, we also compared the observed data to synthetic wave fields calculated using a pseudo-spectral approach [Kosloff and Baysal, 1982].

Reduced to $7.0 \mathrm{~km} / \mathrm{s}$, phases that passed through the non-faulted side of the G3 and Q1 lines had first arrival travel times that ranged from roughly 2.4-3.0 $\mathrm{s}$ and 2.3-2.8 $s$, respectively, while reduced times associated with phases passing through the fault ranged between 2.4-3.4 $s$ and 2.3-3.5 $s$. Although at several instruments it was possible to make picks out to significant offsets $(>50 \mathrm{~km})$, irregular travel time curves influenced by extreme bathymetry made the $\mathrm{Pg} / \mathrm{Pn}$ crossover difficult to identify, and $\mathrm{Pn}$ arrivals were only picked with certainty at a few instruments. The few $\mathrm{Pg} / \mathrm{Pn}$ crossovers in this dataset occur at offsets between $32-35 \mathrm{~km}$. The presence of $\mathrm{P}_{\mathrm{M}} \mathrm{P}$ mantle reflections was also variable along both of the lines. Particularly along the $\mathrm{Q} 1$ line, $\mathrm{P}_{\mathrm{M}} \mathrm{P}$ appears to rarely propagate through the fault zone. At both the G3 and Q1 lines, $9 \mathrm{P}_{\mathrm{M}} \mathrm{P}$ branches were picked and used in the inversions. Where $\mathrm{P}_{\mathrm{M}} \mathrm{P}$ is present, it was picked at offsets that ranged between $15-35 \mathrm{~km}$ and, with a few exceptions, approached the first arrival at offsets of roughly $23-26 \mathrm{~km}$. We estimated conservative pick errors, guided in part by the dominant period of the first arrival phase, and in part by a subjective estimation of our confidence the first arrival phase picks. We assign errors of $20 \mathrm{~ms}$ to all Pg and Pn picks, and higher error values of $40 \mathrm{~ms}$ for $\mathrm{P}_{\mathrm{M}} \mathrm{P}$.

\subsection{Ray tracing and tomographic inversion}

The tomographic method fundamentally involves three steps: specification of an initial velocity model, ray tracing (the forward problem), and the tomographic inversion to 
update the model as required by the data. In this work we utilize a seismic tomography code first developed by Harm Van Avendonk and recently updated by Alistair Harding at Scripps Institution of Oceanography that follows the basic strategy outlined by Van Avendonk et al. [1998a, 2001; 1998b]. This code incorporates the graph method ray tracing scheme (or shortest path method) [Moser et al., 1992a; Toomey et al., 1994; Van Avendonk et al., 1998a; Van Avendonk, 1998b]. The tomographic inversion is implemented in the form of a damped least squares minimization of the travel time residuals with a smoothing constraints to regularize the inverse problem.

\subsubsection{Graph Method of Ray Tracing}

The initial velocity model is parameterized as a $2 \mathrm{D}$ grid of nodal points with assigned slowness values, and columns of nodes are sheared vertically to incorporate the seafloor bathymetry. We use a ray tracing scheme that employs the graph method to solve the forward problem with both a high degree of accuracy and relatively little computational cost. The graph method is used to approximate ray paths by connecting straight-line segments between neighboring grid points. In this way, the cumulative travel time is propagated from a source location to all other points in space and the true path is determined to be the global minimum time path, in agreement with Fermat's principal. Here, following Moser et al. [1992b] and Van Avendonk et al. [1998a], the grid search is limited to the forward propagation direction, termed the forward star. For this study, we employ a forward star with a minimum angle of $0.5^{\circ}$ specified between search directions. We consider 6 nodes in the $\mathrm{x}$-direction and 12 nodes in the z-direction during the graph method search; this preferential search in the downward direction is effective in environments where the vertical velocity gradient dominates the horizontal gradient [Korenaga et al., 2000], as would be expected throughout most of the oceanic lithosphere. The grid method is used as the first phase of the forward calculation to determine the global minimum travel time ray path. The minimum error that this ray tracing method can achieve is dependent on the grid spacing, and if coarse grid spacing is used, travel times will be systematically over predicted. For the 2D problem, we chose a 
grid spacing that was sufficiently fine so as to determine an accurate minimum travel time using the graph method alone. We thus did not need to incorporate secondary measures such as ray bending used by Van Avendonk et al. [1998a]. The graph method is well suited for marine wide-angle refraction datasets. It allows for ray tracing to be implemented through models with complex seafloor topography, like that in the vicinity of the mid-ocean ridge and transform domain, parameterized here as the sheared slowness grid. Adopting the graph method in this study has also been advantageous due to its ability to find first arrival travel times of non-geometric diffracted waves [Van Avendonk et al., 1998a], like those that would be expected to occur due to the kilometerscale relief within the transform valley.

\subsubsection{Tomographic Inversion}

The inversion approach used here follows closely that outlined by Van Avendonk et al. [1998b], and we again utilize code for the inversion developed and maintained by Van Avendonk and Harding at SIO. This approach solves the damped least squares problem to minimize an objective function for the preferred model slowness perturbation based on a set of scaled travel time residuals. A linear set of equations is derived from Fermat's principal, which relates a variation in travel time to a variation in model slowness along the stationary ray path, $p_{i}$. The travel time residual, $\delta T_{i}$, can thus be expressed as a path integral over a slowness perturbation $\delta u$ to a predefined slowness model along $p_{i}$ :

$$
\delta T_{i}=\int_{p_{i}} \delta u d S .
$$

Applying Equation (1) to the full suite of travel time picks leads to a set of linear equations that is solved in the least squares inversion. First arrival refraction and reflection travel time differences determined for the picked phases and the forward ray traced arrival times are scaled by the pick error and combined in an $n \times 1$ vector of scaled travel time residuals. This data vector is related to the Frechét derivative matrix and the 
unknown slowness perturbation vector, which is normalized by the slowness of the reference model, to arrive upon the matrix equation:

$$
\mathbf{d}=\mathbf{G m} \text {. }
$$

In the above equation, the vector $\mathbf{d}$ is composed of the scaled travel time residuals, $\mathbf{G}$ is the Frechét derivative matrix and $\mathbf{m}$ is the normalized slowness perturbation vector. In order to calculate accurate graph method ray paths, we choose a grid spacing that is finer than expected velocity variations. Consequently, it is likely that the least squares matrix equation above is over parameterized, with many more model grid points than travel time picks. Where the model is unconstrained by data, a smooth model is assumed by imposing roughness penalties, $F_{s_{1}}$ and $F_{s_{2}}$, that are functions of the first and second derivatives of the model slowness:

$$
F_{s_{1,2}}=\left(\mathrm{P}_{1}, \mathrm{P}_{2}\right) \int_{\text {model }}\left[L_{H}^{2}\left(\frac{d^{1,2} u}{d x^{1,2}}\right)+L_{V}^{2}\left(\frac{d^{1,2} u}{d y^{1,2}}\right)\right]
$$

The specified length scales of smoothing, $L_{H}$ and $L_{V}$, and the smoothing regularizations, $\mathrm{P}_{1}$ and $\mathrm{P}_{2}$ control the smoothing penalty functions, and are chosen to facilitate a solution that is consistent with the expected physical environment. In many tomographic problems, it is reasonable to assume that the length scale of heterogeneity is greater in the horizontal versus the vertical direction, and so the aspect ratio $\mathrm{L}_{\mathrm{H}} / \mathrm{L}_{\mathrm{V}}$ is large (usually > 10). Here, based on the horizontal dimensions of dramatic seafloor morphology in the vicinity of the active transform and knowledge of continental transform fault structure, we have reason to believe that the aspect ratio of heterogeneity is much smaller. As such, we assume an $\mathrm{L}_{\mathrm{H}} / \mathrm{L}_{\mathrm{V}}$ of 2 for the inversions on both the $\mathrm{G} 3$ and $\mathrm{Q} 1$ lines. The strength of the first and second derivative smoothing penalties are controlled by $\mathrm{P}_{1}$ and $\mathrm{P}_{2}$, and these regularizations are changed frequently during progressive inversion iterations. The choice of preferred values of first and second derivative regularizations is made in a largely subjective manner. At each inversion iteration, $\mathrm{P}_{1}$ and $\mathrm{P}_{2}$ are selected with the goal of reducing the occurrence of non-physical artifacts, such as ray streaks and high frequency lateral oscillations, while also not over-smoothing velocity perturbations along 
the ray paths. Throughout the tomographic process, we typically specify $\mathrm{P}_{2}$ to be 1.3 2.0 times greater than $\mathrm{P}_{1}$. Early in the tomographic process, when the starting model is far from the true velocity structure, large first and second derivative regularization values are specified, and the strength of smoothing is reduced as model error is decreases in progressive inversion iterations.

The rate at which slowness perturbations are incorporated into the model is controlled by a damping value, which balances the improvement of data fit with the norm of the model perturbation. Damping is also applied to changes in the depth of the specified reflector interface and changes in the slowness jump across the interface. The damped least squares approach penalizes the magnitude of these perturbations via a damping penalty that is a function of the magnitude of the model perturbations and specified damping coefficients that control the strength of the damping applied:

$$
F_{d}=\mathrm{P}_{0} \int_{\text {model }}(\delta u)^{2} d A+P_{s j} \int_{\text {interface }}\left(\delta d u_{r}\right)^{2} d S+P_{d} \int_{\text {interface }}\left(\delta z_{r}\right)^{2} d S
$$

Here, $\mathrm{P}_{0}, \mathrm{P}_{s j}$ and $\mathrm{P}_{d}$ are the damping values for the general slowness perturbation, the slowness jump across the Moho reflector, and the depth of the Moho reflector, respectively. Especially for problems with initial travel time residuals that are significant, applying damping to the least squares inversion maintains the assumption of linearity expressed in Equation (1) by keeping the ray paths from changing too quickly (i.e. requiring that the travel time is stationary with respect to $p_{j}(u)$ and $p_{j}(u+\delta u)$ ). During the inversion process, we choose a regularization value that, similar to the smoothing operators, is high in early inversions, and then is decreased as the model error is iteratively reduced in the starting model. As we will discuss in more detail in the following paragraph, we begin our tomographic process by inverting only for travel time residuals associated with shallow crustal phases that do not extend to the lower crust. As such, early in the inversion process, we insure that the Moho slowness jump and depth do not change by specifying high slowness jump and reflector depth damping regularizations 
$\left(\mathrm{P}_{s j}\right.$ and $\left.\mathrm{P}_{d}\right)$. As we incorporate more travel time data, these values are also reduced, allowing some change to the Moho interface as required by the $\mathrm{P}_{\mathrm{M}} \mathrm{P}$ and $\mathrm{Pn}$ travel time picks.

\subsubsection{Solution Procedure}

Ray paths determined during the forward problem are strongly dependent on the initial velocity model. It is thus advantageous to choose an initial model that emulates the real local velocity heterogeneity as closely as possible. In order to accomplish this without biasing our starting model with pre-imposed fault zone structure, we employed an iterative approach to the tomographic method outlined above in which we alternate between the forward and inverse problems, first using a small subset of the travel time data within the most well resolved portion of the model space, then updating the starting model appropriately based on the inversion results. Subsequent rounds of forward and inverse calculations are conducted using the new starting model and more travel time data. We thus begin by inverting for the shallow structure within the center of the model space (where station spacing is slightly finer) using only close-range Pg arrivals, and incrementally incorporate deeper and more wide-ranging Pg and Pn picks, capable of resolving the middle lower crust, and eventually $\mathrm{P}_{\mathrm{M}} \mathrm{P}$ arrivals that constrain the lower crustal velocities and the Moho. We repeat this multi-step approach to the tomographic inversion process until the starting model is close enough to the true model that only a few additional iterations of the nonlinear inversion results in a model with an acceptable

level of travel time fit. In Figure 2, we present a schematic diagram that demonstrates the strategy we perform to arrive upon our preferred models.

Following a forward calculation, total misfit between the modeled and observed data is calculated as a $\chi^{2}$ value, defined as:

$$
\chi^{2}=\sum_{n=1}^{N} \frac{\left(t_{n, \text { ray }}-t_{n, p i c k}\right)^{2}}{\sigma_{n}^{2}} .
$$


This number is used to inform the target error in the following inversion. As an additional strategy for limiting the amount of change allowed during the inversion, we decreased the target $\chi^{2}$ value gradually, starting with a target $10-20 \%$ error reduction, and then increasing the percent improvement until either unphysical artifacts are incorporated into the velocity model or we arrive upon our preferred solution. Ray "streaks", negative velocity gradients, and unrealistically high or low velocity patches are common features that arise in inversion results in regions of low ray coverage due to the extreme travel time anomalies present in our starting model. Increasing smoothing constraints can sometimes mitigate this, but even a significant amount of model smoothing is insufficient if the initial velocity model is too far from the model required by the data. We avoid incorporating unphysical slowness perturbations in our final velocity model by gradually decreasing the target misfit during iterations of the forward and inverse problems. If at some point an undesirable artifact is incorporated into the model while the total error is still too high, we remove this by updating the starting model manually to remove unphysical structure within low-resolution regions, and proceed with the tomographic process until an acceptable $\chi^{2}$ value is achieved. In this way we arrive upon a model that is physically realistic and fits the data.

\subsection{Inversion Results}

Starting models were constructed for both the G3 and Q1 transects from a verticallysheared 1D velocity profile similar to those determined for young Pacific oceanic crust [Harding et al., 1989; Vera et al., 1990; White et al., 1992]. The 1D model was hung from high-resolution bathymetry profiles across each line, acquired from combined multibeam surveys collected at $\sim 200 \mathrm{~m}$ resolution from aboard the R.V. Knorr in 2007 [Pickle et al., 2009] and improved during successive seismic deployment cruses on the $R / V$ Thomas G. Thompson and $R / V$ Marcus $G$. Langseth in 2008. Starting models included a flat Moho reflector that was specified at a depth of approximately $6 \mathrm{~km}$ 
beneath the seafloor. We use a nodal spacing of $50 \mathrm{~m}$ in both the vertical and horizontal directions. Models extend from the sea surface at $z=0$ to at $z=13 \mathrm{~km}$, leading to a $\mathrm{G} 3$ model parameterization composed of 2953 x 261 nodes and a Q1 model composed of 2121 x 261 nodes (124.6 and $106.0 \times 13 \mathrm{~km}$ respectively, at $0.05 \mathrm{~km}$ grid spacing).

In total 4428 first arrival ( $\mathrm{Pg}$ and $\mathrm{Pn})$ and $497 \mathrm{P}_{\mathrm{M}} \mathrm{P}$ picks were used for the $\mathrm{G} 3$ tomographic inversion, and 3678 first arrival and $528 \mathrm{P}_{\mathrm{M}} \mathrm{P}$ picks were used for $\mathrm{Q} 1$. Negative average travel time residuals at several of the off-fault instruments on both lines indicated that the data required a faster shallow velocity gradient than what was specified in the starting mode. However, despite the moderate over-prediction in travel times in the unfaulted shallow crust, rays that passed through the fault zone were delayed significantly, leading to dramatic positive travel time residuals. Starting model travel time residuals for rays passing through the $10-20 \mathrm{~km}$ of crust surrounding the fault were delayed as much as $350 \mathrm{~ms}$ at both the G3 and Q1 lines. The largest positive travel time residuals were recorded by instruments G3-4, G3-7, Q1-4, Q1-6 and Q1-p13, and these would have likely been larger had the starting model been more appropriate for the unfaulted crust. The starting $\chi^{2}$ value for the G3 line was 55, and this was reduced to the value in the preferred final model of $\chi^{2}=1.8$ after 34 iterations. The starting $\chi^{2}$ value at the Q1 line was 27, and it was reduced to the preferred model value of $\chi^{2}=2.0$ after 12 iterations. $\chi^{2}$ values reflect data fit relative to the estimated errors, and so by maintaining small error estimates, the $\chi^{2}$ value will be expected to be larger. Additionally, some of the remaining travel time residual in our final models is due to the level of smoothing we required in our final model. The inversion process would allow for the data to be fit more completely (with smaller final $\chi^{2}$ values), however we choose to maintain a level of smoothing appropriate for the length scale of heterogeneity we expect to resolve. 
Figure 3 displays the preferred P-wave velocity models for the G3 and Q1 lines. The most striking feature apparent in both of these seismic velocity profiles is the significant low velocity zone (LVZ) within the central fault zones. Dramatically reduced P-wave velocities are required to fit the travel time data at both the Gofar and Quebrada faults. LVZs at both faults occupy a $\sim 10-\mathrm{km}$-wide region within the shallow crust that decreases in width gradually with depth. Across the G3 fault, the modeled LVZ extends throughout the entire crust, with velocities that are reduced by more than $5 \%$ within the lower crust and by as much as 50\% at shallow depths. Within the shallow crust, the LVZ at the Q1 line is even more pronounced, wider laterally, and with slightly slower P-wave velocities as compared to the G3 model. However, no substantial reduction in velocity is resolved within the lower half of the crust at Q1. As we will discuss later, this may reflect ray coverage as opposed to differences in the actual depth extent of the LVZ along the two faults. It is interesting to note that the broad low velocity zones we resolve here are primarily centered around the location of the active fault trace determined from seafloor backscatter imaging (black arrow) slightly offset from the transform valley that is apparent in the seafloor morphology.

Away from the central fault zone, the seismic velocity structure is generally consistent with crustal velocities determined in past seismic refraction studies of young EPR crust [Harding et al., 1989; Vera et al., 1990; White et al., 1992]. Figure 4 shows velocity depth profiles at different offsets along the two lines compared with velocity depth profiles form previous studies. Some differences are apparent in the structure of the crust generated at "normal EPR" spreading center (south of the G3 line and north of the Q1 line), and that associated with intra-transform spreading (north of the G3 line and south of the Q1 line). Additionally, some lateral heterogeneity in the shallow crustal structure within both velocity models appears to correspond to bathymetric features present in the morphologically complex QDG region. Specifically, lateral transverse ridges and fossil fault traces that are apparent in the bathymetry correspond to minor velocity heterogeneities where they intersect the G3 model at approximately 82 and $96 \mathrm{~km}$ offset. The same appears to be the case in the vicinity of the morphologically complex Quebrada 
fault, where a transform-parallel ridge and linear trough are aligned with a less dramatic but discernible secondary low velocity region to the south of the active fault. Some lateral heterogeneity is also present north of the active fault trace that corresponds with complex seafloor fabric also apparent in the bathymetry within the $\sim 10 \mathrm{~km}$ north of the fault valley.

Average crustal thickness across the two faults is comparable, with the Moho discontinuity occurring at a depth of approximately $6.0-6.6 \mathrm{~km}$ beneath the sea floor. Within the central fault zones at both G3 and Q1 the Moho shallows somewhat, which combined with the bathymetric lows within the transform valleys, leads to a thinning of the crust within the fault zone to approximately $5 \mathrm{~km}$. This thinning is apparent at both faults. The general features of crustal thicknesses resolved here are roughly consistent with those determined in the region based on the residual mantle Bouguer anomaly derived from regional gravity data by Pickle et al. [2009].

\subsection{Data Fit and Model Resolution}

Tomographic inversions are inherently non-unique problems, and even with perfect data fit and dense data coverage, it is still possible that travel times will be modeled incorrectly. The capability to resolve structural features is limited by the geometry of the seismic experiment and the quality of the data acquired. Furthermore, imposed inversion correlation lengths and the long wavelength of the seismic waves that sample the subsurface lead to tomographic inversion results that are highly smoothed version of the real structure. All of these factors should be considered before interpreting tomographic inversion results.

In Figs. 5-7 we display the observed and modeled travel time curves along with ray diagrams for two of the Gofar stations, G3-3, G3-5, and G3-p7, and in Figs. 8-10 we

present similar data and ray coverage for two Quebrada stations, Q1-7, Q1-4, Q1-3. 
These figures illustrate the type of structure we are capable of fitting using the tomographic inversion process. Large-scale trends in travel times are modeled well; small scale features, however, like the small delay in travel times located at $\sim 15 \mathrm{~km}$ on G3, are difficult to image with the available ray coverage. Even more importantly, regions of the model with space ray coverage are often sampled by phases that are difficult to pick accurately, and travel times have large errors. The lower crust, for example, is primarily resolved by $\mathrm{P}_{\mathrm{M}} \mathrm{P}$ mantle reflections with the largest picking errors.

A good indication of the sampling of velocity model nodal locations can be calculated as the derivative weight sum (DWS). The DWS is a qualitative measure of ray density and is calculated by summing the influence of a model parameter on an integrated path length over all ray paths [Toomey and Foulger, 1989]. In Figure 11 the DWS for the two lines is displayed. Higher values of DWS in these regions indicate more wellsampled regions of the models space, although the DWS should only be used as a relative indicator of resolution, and the absolute value is not physically significant. Within the upper crust, both models are well sampled with a high density of rays, and coverage is moderately good throughout most of the central fault domain. Sections of the lower crust, however, have significantly lower DWS values, and parts of the lower crust are completely unresolved. In addition to the density of rays, coverage with crossing rays from different directions is also important for determining the correct location of velocity perturbations required by travel time residuals. Even within the lower crust where there is reasonable ray coverage, there are rarely abundant crossing rays. Of particular importance to this study is the paucity of ray coverage in the lower crust beneath the Quebrada transform valley. A key difference apparent in the velocity structure of the two faults is the depth extent of the LVZ imaged within the central fault zone. The low ray coverage beneath the Quebrada fault indicates that we may be unable to determine the true depth extent of reduced velocities in the Quebrada transform domain with this dataset. 
In order to further evaluate the tomographic inversions, we present results from a series of resolution tests in Figures 12-14. These tests utilize synthetic data that is produced by forward modeling travel times through a sheared 1D model with a velocity anomaly placed within some portion of the model space. The ability of the tomographic inversion to reproduce the velocity anomaly using the same ray configuration and a similar inversion strategy, (i.e. iterative process, smoothing and damping constraints, target error reduction), provides some insight into the signal we are able to model with these datasets. As indicated by the DWS values, our primary concern is with the resolution of any velocity heterogeneity in the lower crust, and in particular, lateral variation in velocity heterogeneity associated with the fault zone. In Figures 12 and 13 results are displayed from resolution tests in which we model a $5 \mathrm{~km}$ wide LVZ with a $30 \%$ velocity reduction that extends throughout the entire model space. With the ray coverage available for the G3 line, the imposed velocity anomaly is resolved well throughout the crust and into the upper mantle (Figure 12). In the shallow part of the crust, the entire velocity anomaly is accurately imaged with some lateral smoothing. At lower crustal depths ( $>5 \mathrm{~km}$ beneath the seafloor), the velocity anomaly that is reproduced is narrower and less slow than the original signal. The same velocity anomaly, when modeled using the Q1 ray configuration is reproduced well in the shallow crust, but by mid-crust depths, below $\sim 4 \mathrm{~km}$ beneath the sea floor, the resolved anomaly is reduced to only a few percent (Figure 13). This result shows a lack of resolution in the lower crust at Q1, and suggests we may not be capable of imaging deep fault structure at Quebrada.

Just as we are interested in evaluating the maximum depth of resolution, we are also interested in assessing the degree to which velocity anomalies may be smeared downward in the tomographic process. In Figure 14 results from a second G3 resolution test are displayed, in which we model a $5 \mathrm{~km}$ wide, $30 \%$ reduced velocity anomaly that is confined to the upper $2 \mathrm{~km}$ beneath the sea floor. Results from this test are encouraging, showing that very little downward smearing occurs. As would be expected, some small degree of both lateral and vertical smoothing of the true velocity signal is visible in the 
resolution tests, even within the most well resolved portions of the model space. Together, these resolution tests show that a LVZ imaged in the lower crust at G3 may be slightly exaggerated in width, but not in depth, and most likely underestimates the strength of the actual anomaly.

\subsection{Discussion}

\subsubsection{Influence of past and current QDG tectonics}

The QDG area has experienced a complex tectonic history resulting in a system of offset sub-parallel transform faults connected by ITSCs. A first order feature of the seismic velocity profiles across both the Gofar and Quebrada faults is a difference in the shallow structure of crust created at "normal EPR" north and south of the QDG offset, and that generated at ITSCs separating transform segments. Several differences in the crustal structure can be identified by comparing the velocity profiles on either side of the Gofar and Quebrada faults (Figure 4), specifically the thickness of the shallow crustal extrusive layer 2a, and lateral velocity heterogeneity coincident with fossil fracture zones.

ITSC-generated crust on the north side of the G3 fault exhibits a slower shallow velocity structure as compared to crust to the south. Seismic layer $2 \mathrm{a}$ is typically identified by a shallow low velocity layer over a sharp velocity gradient down to $\sim 5.2$ $\mathrm{km} / \mathrm{s}$ [Christeson et al., 1994]. Using this definition, the median layer 2a thickness increases from $\sim 500 \mathrm{~m}$ on the south side of the Gofar fault, to $\sim 700 \mathrm{~m}$ on the north side. Previous marine seismic experiments have noted a decrease in the thickness of layer $2 \mathrm{a}$ with age [Houtz and Ewing, 1976; Purdy, 1987], thought to result from hydrothermal alteration and reduction of the bulk porosity in pillow basalts, flows, and breccia that compose the shallow oceanic crust. At the location of the G3 line, the crust north of the fault is $0.3-1.4$ m.y. older than crust to the south, and thus a thicker layer $2 \mathrm{a}$ to the north more likely reflects a difference in the abundance of volcanic extrusives produced at the 
ITSC rather than age evolution of the high porosity layer. Average layer 2a thickness is greater in young oceanic crust created at the slow-spreading Mid Atlantic Ridge as compared to at the fast-spreading EPR [Houtz and Ewing, 1976]. The difference in shallow crustal structure across G3 may thus be evidence for a contrast in emplacement processes at the short ITSCs, signifying a more magma-starved ridge environment. Furthermore, the same trend is true for layers $2 b-c$, which increase in median thickness from $1.6 \mathrm{~km}$ south of the fault, typical for young EPR crust [Vera et al., 1990], to $2.3 \mathrm{~km}$ to the north, assuming it is bound by the $5.2-6.8 \mathrm{~km} / \mathrm{s}$ velocity contours. Combined, we see a significantly thicker layer 2 associated with crust created at the spreading centers north of the Gofar fault than what has been identified in other refraction studies in normal EPR crust [Harding et al., 1989; Vera et al., 1990] without necessarily resolving an equivalent increase in total crustal thickness.

Based on elemental compositions from basalts dredged at the ITSCs at QDG [Nagle et al., 2009] and other EPR transforms [Wendt et al., 1999; Saal and Forsyth, 2004], as well as numerical modeling of melt generation [Gregg et al., 2009], ITSCs appear to demonstrate unique geochemical compositions and dynamic melting processes. Variability in crustal thickness linked to differences in magma production at the spreading segments across the QDG area was proposed by Pickle et al. [2009] in a detailed analysis of regional gravity and bathymetry. The fact that we do not necessarily see an equivalent thickening in layer 2 south of the Quebrada transform is consistent with ITSC emplacement properties varying at different offsets throughout the region. Pickle et al. observed a correlation between ITSC segment length, ridge morphology and crustal thickness that may be equivalent to some of the variability we observe in crust created at different locations in the QDG environment.

A second feature of the velocity models at both the Quebrada and Gofar faults is the signature of fossil fracture zones. In Fig 15 we present the same preferred seismic velocity models, displayed in terms of the velocity anomaly relative to the $1 \mathrm{D}$ starting model (black lines in Figure 4). Black arrows on this figure indicate the location of 
fracture zones crossed by the refraction lines. Low velocity anomalies are apparent beneath the bathymetric expression of the younger fossil shear zones, however, the intensity of the velocity signature at the inactive shear zones is significantly diminished relative to the LVZ we resolve at the active fault zones. For example, at the location of the G2 fossil fault trace ( $\sim 81 \mathrm{~km}$ offset on the G3 line) a very clear low velocity anomaly is apparent within the top $2 \mathrm{~km}$ of the crust. The degree of velocity reduction and the depth extent of the fault signature however is much less dramatic than the primary active fault zone signature at G3. At the location of the G1 fossil trace ( $\sim 95 \mathrm{~km}$ offset) there is no definitive fault zone signature. Assuming the active fault signature at the active G1 and $\mathrm{G} 2$ faults is similar to the velocity anomaly we observe across $\mathrm{G} 3$, these observations indicates that significant healing must occur with time as these faults becomes inactive and fault-affected material is advected off axis. At the refraction line, the G1 fault trace has had $>1.25 \mathrm{~m}$.y. to heal since the edge of the fracture zone was advected off axis, and $\mathrm{G} 2$ has had $\sim 0.3$ m.y. Thermal contraction and thermal bending stresses are expected at inactive oceanic fault zones associated with cooling and differential subsidence rates of adjacent lithosphere [Wessel and Haxby, 1990], however these effects would enhance the low velocity signature of fractured porous rocks within the shallow fossil transform domain. The evolution to more normal seismic wave speeds at older fracture zones is thus an important result that tells us something about the compressive stresses working within the lithosphere that must contribute to the lower crustal rocks returning to typical layer 3 velocities in a relatively short amount of time ( 0.3-1 m.y.).

Similar lateral velocity heterogeneity is apparent on the Q1 line throughout the entire Quebrada transform domain, $\sim 30 \mathrm{~km}$ south of the active fault segment (Figure 15). Although the lower crust resolution at Q1 makes the relative difference in the active and fossil shear zone signatures less certain, the diminished shallow low velocity signature that coincides with the Q2-Q4 fault traces seems to be consistent with evidence of past faulting and lithospheric healing we observe at Gofar. Low velocity anomalies associated with the three southern Quebrada fault segments are significantly less dramatic than the Q1 signature we resolve across the active fault. The continuity of the low 
velocity zone within the upper crust throughout the entire Quebrada fault domain coincident with the other Quebrada shear zones to the south of Q1 also raises the question of whether some degree of distributed shear may occur across Quebrada domain, particularly within the shallowest crustal layers.

\subsubsection{Interpretation of low velocity fault zone}

In order to identify material properties responsible for earthquake behavior at oceanic transforms it is necessary first to consider what type of material variation may be causing the significantly reduced seismic velocities we image at both faults. Typical oceanic crustal layer 3 extends from $2-3 \mathrm{~km}$ beneath the seafloor to the base of the crust, and tends to demonstrate only a subtle increase in velocity with depth due to closing of microfractures with increasing effective pressure, temperature and differences in gabbroic composition [Carlson and Miller, 2004]. We are most interested in interpreting the fault zone velocities within layer 3 , as this likely corresponds the seismogenic zone, and thus may provide information about frictional heterogeneity that affects earthquake behavior. Based on previous studies of continental and oceanic strike-slip fault zones, the two most likely candidates for the significant reduction in seismic velocities we image within the central transform zone are intense fracturing associated with shear strain [Tréhu and Purdy, 1984; Chester et al., 1993; Eberhart-Phillips et al., 1995; Thurber et al., 1997; Van Avendonk et al., 1998a; Schulz and Evans, 2000; Van Avendonk et al., 2001; Cochran et al., 2009; Savage and Brodsky, 2011] and mineral alteration [Bonatti, 1978; Calvert and Potts, 1985; Cannat et al., 1990; Detrick and Purdy, 1980; Detrick et al., 1982; Minshull et al., 1991; White et al., 1984; Detrick et al., 1993; Faulkner et al., 2003]. Ultimately, both of these processes are likely at work within the transform domain. By evaluating the details of how seismic velocity is affected by increases in porosity and/or alteration we may be able to distinguish the dominant process based on our tomography results.

The degree of fracturing, and resulting porosity required to explain the low velocities we observe is highly dependent on the geometry assumed for the fluid-filled 
pores. In Figure 16a, we show the Hashkin-Strikman (HS) bounds on the compressionalwave seismic velocity for seawater-saturated gabbro with a range of porosities. The upper and lower HS bounds should encompass the full range of possible pore geometries [Hashin and Shtrikman, 1963; Avseth et al., 2005]. This leads to a very wide range of seismic velocities that are possible for a given porosity, thus making it necessary to consider the most likely fracture geometries present within the damage zone surrounding the fault. Several field studies of fault structure have identified fractures in the damage zone that are crack-like with large aspect ratios that are variably oriented with respect to the fault plane [Chester et al., 1993; Savage and Brodsky, 2011]. Based on theoretical calculations of scattering phenomena [Kuster and Toksoz, 1974], the crack aspect ratio $(\alpha)$ can be taken into account as well as the concentration of pores and elastic moduli of the constituent phases to estimate conditions consistent with the reduced seismic velocities we determine for the fault zone. Porosity associated with crack-like pores has a greater effect on the seismic velocity, and assuming aspect ratios that range from 0.1 to 0.001 , the seismic velocities we determine at the base of the crust $(\sim 4.5 \mathrm{~km}$ beneath the sea floor) within the Gofar fault are consistent with a range of porosity values from $\sim 0.1$ to $0.6 \%$. As some amount of lateral smoothing has likely occurred in the tomographic inversion process, the real fault zone rocks may exhibit even slower seismic velocities within a narrower zone, making these values a lower bound on the possible porosity.

Metamorphic alteration can also lead to significantly reduced seismic velocities in rocks of mafic composition. If fluid pathways exist down to lower crust and upper mantle depths, alteration of clinopyroxene and olivine in gabbroic rocks to amphibole, serpentine and talc, and serpentinization of upper mantle peridotite is likely to occur within the fault zone. Serpentinites have been dredged along Atlantic fracture zones [Bonatti, 1976, 1978] as well as at a few transform faults in the Pacific [Anderson and Nishimori, 1979; Hébert et al., 1983; Cannat et al., 1990], and serpentine diapirism has been proposed as the primary cause of transverse ridge formation at Atlantic transform faults [Bonatti, 1978]. The anomalously low strength of serpentine and reduced density relative to lower crustal rocks is thought to mobilize altered ultramafic rocks, allowing 
them to intrude shallower crustal depths. In support of this, seismic refraction experiments across Atlantic fracture zones have imaged low velocity zones accompanied by reduced crustal thickness, which are interpreted as resulting from upper mantle alteration and uplift [Detrick and Purdy, 1980; Detrick et al., 1982; White et al., 1984; Minshull et al., 1991; Detrick et al., 1993]. Serpentine and talc also outcrop along the Parkfield section of the San Andreas fault, and due to their low strength relative to other crustal crystalline and sedimentary rocks, their presence has been proposed as one possible explanation for the primarily aseismic nature of that fault segment [Moore et al., 1997].

Although we do not see significant thinning of the crust within the Gofar and Quebrada transform domains, the fault zone velocities are consistent with elastic properties of partially serpentinized mantle rocks. In Figure 16a, HS bounds for the range of seismic velocities associated with different degrees of lower crustal and upper mantle alteration are displayed as gray envelopes. Due to the unique elastic properties of serpentine and the high olivine content of peridotite, alteration of mantle phases has a much larger influence on seismic velocity than alteration of crustal material. Using the HS mixture relation and assuming that amphibole is the primary alteration phase in lower crust gabbroic rocks, metamorphosism of clinopyroxene alone cannot have a large enough effect on the elastic properties to explain the reduction in seismic velocities we determine within the fault zone (Figure 16a). If we assume rather that altered peridotite is present at crustal depths within the central fault zone at the G3 line, mantle material that is $\sim 35-45 \%$ percent altered would exhibit elastic properties consistent with those we determine (Figure 16c). It is important to keep in mind however that it is unlikely that alteration alone is responsible for the LVZ signal, as some small degree of fracturing would also be required to provide fluid pathways to the lower crust.

The question of whether or not mantle derived serpentine bodies are present within the fault zone at Gofar and Quebrada has major implications for the frictional properties that control earthquake behavior there. Because the density of even partially 
serpentinized peridotite is significantly reduced relative to unaltered mafic minerals (Fig 16c), gravity observations should provide some additional insight into the plausibility that a low density body of serpentinized mantle is present within the fault zone. In Figure 16 we display the free air anomaly (FAA) measured by the RV Knorr in 2008 at the QDG area [Pickle et al., 2009], as well as two gravity anomaly profiles parallel to the seismic refraction lines. Variations in FAA should reflect changes crustal properties; low FAA is usually associated with zones of thicker crust or less dense crustal material. Although interpreting gravity data, like seismic velocity, is non-unique, by making some simplistic assumptions about the density structure of the crust, we determine that the gravity anomaly for serpentinized mantle material emplaced in the crust is not observed across the fault zone on the Gofar or Quebrada faults (red lines, Fig 18). In contrast, because an increase in porosity of only fractions of a percent in the lower crust is enough to account for the low velocities there, a much smaller density contrast and a gravity signature below the measurement sensitivity would be expected if porosity increases are primarily responsible for the fault zone velocity signature.

The crustal velocity signatures of fossil fracture zones to the north and south of Gofar and Quebrada respectively, provide additional evidence in favor of the presence of enhanced porosity rather than a large serpentinite body. The G3 and Q1 refraction lines cross several previously active fracture zones associated with the G1-2, and Q2-4 segments, and yet, only a relatively much diminished or altogether absent fault zone signature is resolved in our models. This indicates that either the velocity structure at the other Quebrada and Gofar fault segments is fundamentally different from those at G3 and Q1, or an aging process has altered the material within the fossil fracture zones, restoring the elastic properties to more closely resemble typical layer 3 velocities. Although it is difficult to anticipate the details of geometric or bulk porosity changes that may be responsible for the evolution of the low velocity material with time, aging of high porosity oceanic crustal material to higher seismic velocities has been documented in the shallow crust [Houtz and Ewing, 1976; Purdy, 1987]. Because young oceanic lithosphere is in a state of compression, especially at lower crustal depths where the confining 
pressure is high (equal to $\sigma_{1}$, the maximum compressive stress in this environment), crack closure in fractured oceanic crust and modifications to the geometry of cracks could lead to a change in the elastic properties as the fault zone becomes inactive and material is advected off axis. If however the LVZ signal is a result of serpentinized mantle material within the fault zones, there is little reason to believe that seismic velocities would be restored with time. Conversely, the degree of hydrothermal alteration within a fault zone would be expected to increase as the lithosphere ages and cools with distance from the ridge, and the volume of the crust within the serpentine stability field increases [Roland et al., 2010].

Ultimately, it should also be noted that if fluid-filled pores are present at depth within the fault zones, some alteration will occur, and that if hydrothermally altered phases are present in the lower crust, some connected fluid pathways, and thus, some degree of enhanced porosity must also be present. Based on the results of our effective media analyses coupled with the gravity and off-fault seismic observations, it seems most plausible that extensive damage zones at both the Quebrada and Gofar faults sustain enhanced, high aspect ratio crack-like porosity, probably accompanied by some moderate degree of crustal alteration, and that it is primarily the damaged crust, as opposed to emplacement of serpentinized mantle, that is responsible for the reduced seismic velocities we determine.

\subsubsection{Differences between the Gofar and Quebrada faults}

One of the primary objectives of this experiment is to characterize the macro-scale material properties associated with two faults that demonstrate contrasting seismic behavior. Although the tomographic method lacks the fine-scale resolution to determine the structural details of the inner fault core, we would expect the clear differences in the mechanical behavior of the Gofar and Quebrada faults to correspond to an equally clear variation in the material properties of the fault damage zones. It is thus quite surprising to find no first order difference in the velocity structure at the two faults. Because, as we 
point out in section 4.5, the shallower extent of the LVZ at Quebrada confined to mid crustal depths may result primarily from poor ray coverage in the lower crust, we cannot rule out the possibility that the fault zone signature extends throughout the crust at both faults. A simple explanation for the primarily velocity-strengthening behavior of Quebrada and velocity weakening behavior at Gofar is thus not apparent based on the seismic velocity structure alone.

The most striking result of our study, the significant width of the low velocity zones at both faults, provides us with a new picture of the fault zone at both seismogenic and aseismic oceanic transform faults. Even transforms that regularly produce moderatesized earthquakes do not appear to be composed of two competent gabbroic blocks that slide past each other at a single shear surface. Rather, hundreds of kilometers of offset at these mature fault zones has damaged a significant area around the transform, likely incorporating numerous past and currently active slip surfaces, overprinting of fault cores and damage zones, and a generally complex fault environment. This type of setting would be expected to demonstrate along-strike and depth heterogeneity in porosity, permeability and general frictional behavior. The regions of affected material we image as 1-5 km wide LVZs, and the extent to which seismic velocities are reduced within these zones indicate several things about the material surrounding the active faults. Specifically, these results require that in general, Pacific transform faults are characterized by 1) a wide zone of highly fractured fault material, 2) fluid pathways and the potential for localized zones of elevated fluid pressure that may extend into the seismogenic zone, and 3) some degree of crust and/or mantle alteration. Under certain conditions, each of these properties could promote velocity-strengthening behavior. Thick layers of fault gouge favor stable sliding, with zones of distributed shear demonstrating large critical slip distances $\left(D_{c}\right.$ in rate- and state-dependent friction models; [Brace, 1972; Marone and Kilgore, 1993]), which would impede rate-weakening behavior required for dynamic slip [Marone, 1998]. The presence of fluids within highly fractured material has numerous possible implications for earthquake nucleation processes, as well as for the propensity for slow slip. Zones of fluid pressure elevated to 
near lithostatic levels have been identified in theoretical models as key to producing both unstable slip at lower stress conditions [Rice, 1992] as well as slow earthquakes on hightemperature gabbroic faults [Liu and Rice, 2007, 2009]. Particularly at great depths where low permeability may facilitate localized zones of elevated pore fluid pressure, our results are consistent with a fault environment where fluids distributed over a wide, variably fractured area lead to strong heterogeneity in stress conditions. Finally, even if large bodies of exhumed mantle are not present within the fault zone, pressure and temperature conditions are favorable for alteration of gabbro and the formation of serpentine and/or talc where fluid is present within the lower crust and upper mantle [Roland et al., 2010]. This is consistent with lower crustal rocks dredged in transform faults that are commonly at least a few percent altered [Iturrino et al., 1996, 1991; Carlson and Miller, 2004]. Laboratory studies of serpentine have shown that under certain stress and temperature conditions serpentinized minerals demonstrate velocitystrengthening behavior that would inhibit unstable earthquake rupture [Moore et al., 1997; Reinen, 2000]. It is likely that even very narrow zones of phylosillicates at seismogenic depths could promote stable sliding by lubrication of an inner fault core.

Unique temperature and stress conditions associated with young, warm oceanic transforms undoubtedly have an important affect on the physical properties of the fault zone at seismogenic depths. In Figure 18 we display the thermal structure calculated for the G3 fault using a model similar to that developed by Roland et al. [2010]. It is interesting to note that the temperature at seismogenic depths is very close to the stability transition of serpentine $\left(\sim 500^{\circ} \mathrm{C}\right)$. This provides an additional opportunity for reduced effective stress in isolated zones within the lower crust. If dehydration of serpentine minerals occurs as a result of shear heating during fault slip at adjacent seismic or aseismic asperities, fluids released at seismogenic depths would likely not be allowed to dissipate quickly, due to reduced permeability associated with high overburden pressures. It seems likely that the low velocities we image at both faults may arise from a combination of a thick, fluid saturated damage zone, possibly resulting from the overprinting of current and past slip zones, accompanied by some degree of crustal and 
mantle alteration. Under these conditions, small increases in temperature could lead to dehydration, and the release of fluids from serpentine deep within the crust, which would lead to complex lateral and depth heterogeneity in effective stress. Frictional heterogeneity associated with velocity-weakening fault patches that host repeated large earthquake ruptures and transitional or velocity-strengthening zones that deform during slow slip events may thus be related to the significant zones of enhanced porosity present along the transform, and the unique thermal conditions at seismogenic depths.

\subsubsection{Inferences from Earthquake Observations at the Gofar Fault}

Local earthquake observations of seismicity associated with the end of the 2008 seismic cycle on the G3 fault provide some additional insight into along-strike heterogeneity in frictional properties that exists at these faults. On September $18^{\text {th }}, 2008$ a local array of broadband OBS that were deployed for a year as a part of the passive-monitoring component of the QDG Transform Fault experiment captured an earthquake cycle-ending Mw 6.0 event on the western-most of two seismic asperities on the G3 fault. These seismic fault patches fail quasi-periodically every 5-6 years in Mw 6.0-6.2 events . Close range observations provided the first glimpse of fine-scale temporal and spatial details of the oceanic transform rupture process (J.J. McGuire et al., Capturing the End of a Seismic Cycle on the Gofar Transform Fault, East Pacific Rise, submitted to Nature Geoscience, 2011). Consistent with the generally high number of foreshocks sustained on EPR transform faults, as inferred previously from teleseismic observations [McGuire et al., 2005], the September 2008 mainshock event was preceded by a spectacular week-

long foreshock sequence of over 20,000 earthquakes that occurred on a fault patch just to the east of the mainshock rupture area. The westward-propagating series of ruptures concluded in December of 2008 with a seismic swarm on the western edge of the G3 fault. The G3 wide-angle refraction line we used in our analyses passes almost directly through the foreshock region. 
In Figure 19 the Gofar seismicity determined by McGuire et al. is plotted both along-strike as well as parallel to the G3 refraction line superimposed on a thermal model of the G3 fault. Earthquake observations illuminate important details of the rupture evolution in space and time, and also provide evidence of dramatic differences in the along-strike seismogenic properties of the fault. As compared to the fairly typical depth range of aftershocks $\left(3-5 \mathrm{~km}\right.$, shallower than the $600^{\circ} \mathrm{C}$ isotherm, (Figure 19) the maximum depth of seismicity within the foreshock and swarm regions is dramatically deeper. Along-strike differences in the mechanical behavior are revealed by sharp changes in the maximum depth of seismicity along-strike. McGuire et al. [submitted, 2011] suggests that the observed foreshock behavior may be explained by the presence of an isolated zone of enhanced fluid circulation, which alters the material properties and forms a velocity-strengthening rupture barrier, limiting the total size of large ruptures on asperities to either side. The presence of regions of enhanced fluid circulation is consistent with our interpretation of a wide zone of highly fractured porous material based on the LVZ we image across the Gofar and Quebrada faults. The considerable thickness and depth extent of the region of reduced seismic velocities at G3 would likely facilitate active hydrothermal cells, capable of influencing material properties and stress conditions within isolated zones along the fault. It may be that other moderate to low seismically coupled oceanic transforms in the Pacific sustain similar highly damaged porous fault zone structures. If this is the case, the presence of velocity-weakening fault patches that slip during large earthquakes via shear localization along narrow, highly competent slip zones may be more the exception than the rule. The alternate picture of a transform fault environment composed primarily of a thick zone of sheared, fluidsaturated, low competency material is consistent with our seismic velocity profiles, and may explain the low seismic coupling that has been inferred at oceanic transform faults globally [Bird et al., 2002; Boettcher and Jordan, 2004].

\subsection{Conclusions}


Seismic tomography results presented here show a significant low velocity zone associated with the active fault trace at two distinct oceanic transforms on the equatorial EPR. These LVZs are significantly wider that damage zones commonly identified during field studies of continental strike-slip faults $(\sim 100 \mathrm{~m})$, up to $5 \mathrm{~km}$-wide in the shallow crust. Where the model is well resolved at the Gofar fault, reduced velocities extend throughout the entire crust, maintaining a width $>2 \mathrm{~km}$ at lower crustal depths. Based on effective media analyses, we determine that the seismic velocities imaged within the deep portion of the fault, corresponding to the seismogenic zone, are consistent with increased porosity in gabbro of $0.1-0.6 \%$, in the form of fluid-filled, crack-shaped pores with high aspect ratios (0.001-0.1). Reduced seismic velocities are also consistent with the presence of mantle peridotite that has been $>40 \%$ hydrothermally altered, although free air anomaly observations and evidence for "healing" of the velocity anomaly at fossil fracture zones do not support the presence of serpentine or talc in such high quantities within the fault zone. It likely that if increased porosity is responsible for the wide LVZs we image here some degree of alteration has also occurred in the lower crust and upper mantle. In the context of fault mechanics, these results imply that a wide, compliant damage zone and the presence of fluids at seismogenic depths likely contribute to spatial heterogeneity in frictional conditions that influence earthquake behavior at oceanic transform faults.

\subsection{Acknowledgements}

I would like to thank Dan Lizarralde, John Collins, Jeff McGuire and Alistair Harding who will be coauthors on the submitted version of this manuscript. Results presented in this chapter benefited hugely from the hard work of Nathan Miller, installing and streamlining the VMTomo code. I am also grateful to Alistair Harding and Harm Van Avendonk for developing and sharing the tomographic inversion framework in VMTomo with us at WHOI. This work benefited from thoughtful discussion from Mark Behn and 
Min Xu. Finally, the high quality data sets used in this study were acquired with the help of the crew of the $R / V$ Marcus G. Langseth and the WHOI OBS team including, Dave Dubois and Peter Lemmond. 


\subsection{Bibliography}

Abercrombie, R. E., and G. Ekstrom (2001), Earthquake slip on oceanic transform faults, Nature, 410(6824), 74-77.

Anderson, R. N., and R. K. Nishimori (1979), Gabbro, serpentinite, and mafic breccia from the East Pacific, Journal of Physics of the Earth, 27, 467-480.

Van Avendonk, H. J. . (1998b), An investigation of the crustal structure of the Clipperton transform fault area using 3 D seismic tomography, University of California, San Diego.

Van Avendonk, H. J. ., A. J. Harding, J. A. Orcutt, and J. S. McClain (1998a), A twodimensional tomographic study of the Clipperton transform fault, Journal of Geophysical Research, 103(B8), 17885.

Van Avendonk, H. J. A., A. J. Harding, J. A. Orcutt, and J. S. McClain (2001), Contrast in crustal structure across the Clipperton transform fault from travel time tomography, Journal of Geophysical Research, 106(B6), 10961.

Avseth, P., T. Mukerji, and G. Mavko (2005), Quantitative seismic interpretation: Applying rock physics tools to reduce interpretation risk, Cambridge Univ Pr.

Behn, M. D., J. Lin, and M. T. Zuber (2002), Evidence for weak oceanic transform faults, Geophysical research letters, 29(24), 60-1.

Ben-Zion, Y., and C. G. Sammis (2003), Characterization of Fault Zones, Pure and Applied Geophysics, 160, 677-715, doi:10.1007/PL00012554.

Ben-Zion, Y., Z. Peng, D. Okaya, L. Seeber, J. G. Armbruster, N. Ozer, A. J. Michael, S. Baris, and M. Aktar (2003), A shallow fault-zone structure illuminated by trapped waves in the Karadere-Duzce branch of the North Anatolian Fault, western Turkey, Geophysical Journal International, 152(3), 699-717.

Bird, P., Y. Y. Kagan, and D. D. Jackson (2002), Plate tectonics and earthquake potential of spreading ridges and oceanic transform faults, Plate Boundary Zones, 203-218.

Boatwright, J., and M. Cocco (1996), Frictional constraints on crustal faulting, Journal of geophysical research, 101(B6), 13895-13.

Boettcher, M. S., and T. H. Jordan (2004), Earthquake scaling relations for mid-ocean ridge transform faults,

Boettcher, M. S., G. Hirth, and B. Evans (2007), Olivine friction at the base of oceanic seismogenic zones, 
Bonatti, E. (1976), Serpentinite protrusions in the oceanic crust, Earth and Planetary Science Letters, 32(2), 107-113.

Bonatti, E. (1978), Vertical tectonism in oceanic fracture zones, Earth and Planetary Science Letters, 37(3), 369-379.

Brace, W. (1972), Laboratory studies of stick-slip and their application to earthquakes, Tectonophysics, 14, 189-200.

Braunmiller, J., and J. Nábělek (2008), Segmentation of the Blanco Transform Fault Zone from earthquake analysis: Complex tectonics of an oceanic transform fault,

Calvert, A. J., and C. G. Potts (1985), Seismic evidence for hydrothermally altered mantle beneath old crust in the Tydeman fracture zone, Earth and planetary science letters, 75(4), 439-449.

Cannat, M., D. Bideau, and R. Hebert (1990), Plastic deformation and magmatic impregnation in serpentinized ultramafic rocks from the Garrett transform fault (East Pacific Rise), Earth and Planetary Science Letters, 101(2-4), 216-232.

Carlson, R. L., and D. J. Miller (2004), Influence of pressure and mineralogy on seismic velocities in oceanic gabbros: Implications for the composition and state of the lower oceanic crust, Journal of geophysical research, 109(B9), B09205.

Chester, F. M., J. P. Evans, and R. L. Biegel (1993), Internal structure and weakening mechanisms of the San Andreas fault, J. geophys. Res, 98, 771-786.

Christeson, G. L., G. M. Purdy, and G. J. Fryer (1994), Seismic constraints on shallow crustal emplacement processes at the fast spreading East Pacific Rise, Journal of geophysical research, 99(B9), 17957-17.

Cochran, E. S., Y. G. Li, P. M. Shearer, S. Barbot, Y. Fialko, and J. E. Vidale (2009), Seismic and geodetic evidence for extensive, long-lived fault damage zones, Geology, 37(4), 315.

Detrick, R. S., and G. M. Purdy (1980), The crustal structure of the Kane fracture zone from seismic refraction studies, Journal of Geophysical Research, 85(B7), 37593777.

Detrick, R. S., M. H. Cormier, R. A. Prince, D. W. Forsyth, and E. L. Ambos (1982), Seismic constraints on the crustal structure within the Vema Fracture Zone, Journal of Geophysical Research, 87(B13), 10599-10.

Detrick, R. S., R. S. White, and G. M. Purdy (1993), Crustal structure of North Atlantic fracture zones, Reviews of Geophysics, 31(4), 439-458. 
Eberhart-Phillips, D., W. D. Stanley, B. D. Rodriguez, and W. J. Lutter (1995), Surface seismic and electrical methods to detect fluids related to faulting, Journal of Geophysical Research, 100(B7), 12919-12.

Faulkner, D. R., A. C. Lewis, and E. H. Rutter (2003), On the internal structure and mechanics of large strike-slip fault zones: field observations of the Carboneras fault in southeastern Spain, Tectonophysics, 367(3-4), 235-251.

Fialko, Y. (2004), Probing the mechanical properties of seismically active crust with space geodesy: Study of the co-seismic deformation due to the 1992 Mw7. 3 Landers (southern California) earthquake, J. geophys. Res, 109.

Fialko, Y., D. Sandwell, D. Agnew, M. Simons, P. Shearer, and B. Minster (2002), Deformation on nearby faults induced by the 1999 Hector Mine earthquake, Science, 297(5588), 1858.

Fialko, Y., D. Sandwell, M. Simons, and P. Rosen (2005), Three-dimensional deformation caused by the Bam, Iran, earthquake and the origin of shallow slip deficit, Nature, 435(7040), 295-299.

Gregg, P. M., M. D. Behn, J. Lin, and T. L. Grove (2009), Melt generation, crystallization, and extraction beneath segmented oceanic transform faults,

Harding, A. J., J. A. Orcutt, M. E. Kappus, E. E. Vera, J. C. Mutter, P. Buhl, R. S. Detrick, and T. M. Brocher (1989), Structure of young oceanic crust at $13 \mathrm{~N}$ on the East Pacific Rise from expanding spread profiles, Journal of Geophysical Research, 94(B9), 12163.

Hashin, Z., and S. Shtrikman (1963), A variational approach to the theory of the elastic behaviour of multiphase materials, Journal of the Mechanics and Physics of Solids, 11(2), 127-140.

He, C., Z. Wang, and W. Yao (2007), Frictional sliding of gabbro gouge under hydrothermal conditions, Tectonophysics, 445(3-4), 353-362.

Hébert, R., D. Bideau, and R. Hekinian (1983), Ultramafic and mafic rocks from the Garret Transform Fault near 13 30'S on the East Pacific Rise: igneous petrology, Earth and planetary science letters, 65(1), 107-125.

Houtz, R., and J. Ewing (1976), Upper crustal structure as a function of plate age, Journal of Geophysical Research, 81(14), 2490-2498.

Iturrino, G. J., N. I. Christensen, S. Kirby, and M. H. Salisbury (1991), Seismic velocities and elastic properties of oceanic gabbroic rocks from Hole 735B, in Von Herzen, RP, Robinson, PT, et al., Proc. ODP, Sci. Results, vol. 118, pp. 227-244. 
Iturrino, G. J., D. J. Miller, and N. I. Christensen (1996), Velocity behavior of lower crustal and upper mantle rocks from a fast-spreading ridge at Hess Deep, in PROCEEDINGS-OCEAN DRILLING PROGRAM SCIENTIFIC RESULTS, pp. $417-442$.

Kaneko, Y., J. P. Avouac, and N. Lapusta (2010), Towards inferring earthquake patterns from geodetic observations of interseismic coupling, Nature Geoscience, 3(5), 363-369.

Korenaga, J., W. S. Holbrook, G. M. Kent, P. B. Kelemen, R. S. Detrick, H. C. Larsen, J. R. Hopper, and T. Dahl-Jensen (2000), Crustal structure of the southeast Greenland margin from joint refraction and reflection seismic tomography, Journal of Geophysical Research, 105(B9), 21591.

Kosloff, D. D., and E. Baysal (1982), Forward modeling by a Fourier method, Geophysics, 47, 1402.

Kuster, G. T., and M. N. Toksoz (1974), Velocity and attenuation of seismic waves in two-phase media; Part I, Theoretical formulations, Geophysics, 39(5), 587.

Langmuir, C., and D. W. Forsyth (2007), Mantle Melting Beneath Mid-Ocean Ridges, Oceanography, 20, 78-89.

Lewis, M., Y. Ben-Zion, and J. J. McGuire (2007), Imaging the deep structure of the San Andreas Fault south of Hollister with joint analysis of fault zone head and direct $\mathrm{P}$ arrivals,

Liu, Y., and J. R. Rice (2007), Spontaneous and triggered aseismic deformation transients in a subduction fault model, J. geophys. Res, 112(10.1029).

Liu, Y., and J. R. Rice (2009), Slow slip predictions based on granite and gabbro friction data compared to GPS measurements in northern Cascadia, Journal of Geophysical Research, 114(B9), B09407.

Marone, C. (1998), Laboratory-derived friction laws and their application to seismic faulting, Annual Review of Earth and Planetary Sciences, 26(1), 643-696.

Marone, C., and B. Kilgore (1993), Scaling of the critical slip distance for seismic faulting with shear strain in fault zones,

Marone, C., and C. H. Scholz (1988), The depth of seismic faulting and the upper transition from stable to unstable slip regimes, Geophysical Research Letters, $15(6), 621-624$.

McGuire, J. J. (2008), Seismic cycles and earthquake predictability on East Pacific Rise transform faults, Bulletin of the Seismological Society of America, 98(3), 1067. 
McGuire, J. J., M. S. Boettcher, and T. H. Jordan (2005), Foreshock sequences and shortterm earthquake predictability on East Pacific Rise transform faults, Nature, 434(7032), 457-461.

McGuire, J. J., J. A. Collins, E. C. Roland, and M. D. Behn (2009), Seismicity of the Quebrada, Discovery, and Gofar Transform Faults, [online] Available from: http://adsabs.harvard.edu/abs/2009AGUFM.S52A..07M (Accessed 26 September 2011)

Michael, A. J., and D. Eberhart-Phillips (1991), Relations among fault behavior, subsurface geology, and three-dimensional velocity models, Science, 253(5020), 651.

Minshull, T. A., R. S. White, J. C. Mutter, P. Buhl, R. S. Detrick, C. A. Williams, and E. Morris (1991), Crustal structure at the Blake Spur Fracture Zone from expanding spread profiles, Journal of Geophysical Research, 96(B6), 9955-9984.

Moore, D. E., D. A. Lockner, M. Shengli, R. Summers, and J. D. Byerlee (1997), Strengths of serpentinite gouges at elevated temperatures, Journal of Geophysical Research, 102(B7), 14787-14.

Moser, T. J., T. Van Eck, and G. Nolet (1992b), Hypocenter determination in strongly heterogeneous earth models using the shortest path method, Journal of Geophysical Research, 97(B5), 6563-6572.

Moser, T. J., G. Nolet, and R. Snieder (1992a), Ray bending revisited, Bulletin of the Seismological Society of America, 82(1), 259.

Nagle, A. N., A. Saal, R. C. Pickle, D. W. Forsyth, and S. R. Hart (2009), Twocomponent Mixing in MORB: Evidence from the Quebrada-Discovery-GoFar Fracture Zone (EPR 3 ${ }^{\circ} 5^{\circ} \mathrm{S}$ ), in AGU Fall Meeting Abstracts, vol. 1, p. 1985.

Peng, Z., and Y. Ben-Zion (2004), Systematic analysis of crustal anisotropy along the Karadere-D $\backslash$ üzce branch of the North Anatolian fault, Geophysical Journal International, 159(1), 253-274.

Pickle, R. C., D. W. Forsyth, N. Harmon, A. N. Nagle, and A. Saal (2009), Thermomechanical control of axial topography of intra-transform spreading centers, Earth and Planetary Science Letters, 284(3-4), 343-351.

Purdy, G. M. (1987), New observations of the shallow seismic structure of young oceanic crust, Journal of Geophysical Research, 92(B9), 9351-9361.

Reinen, L. A. (2000), Seismic and aseismic slip indicators in serpentinite gouge, Geology, 28(2), 135. 
Rice, J. R. (1992), Fault stress states, pore pressure distributions, and the weakness of the San Andreas fault, INTERNATIONAL GEOPHYSICS SERIES, 51, 475-475.

Roland, E., M. D. Behn, and G. Hirth (2010), Thermal-mechanical behavior of oceanic transform faults: Implications for the spatial distribution of seismicity, Geochemistry Geophysics Geosystems, 11(7), Q07001.

Saal, A. E., and D. W. Forsyth (2004), MORB Composition in Intra-transform Spreading Centers: A Key Test of Models of Mantle Flow and Melt Transport, [online] Available from: http://adsabs.harvard.edu/abs/2004AGUFM.T12A..04S (Accessed 28 June 2011)

Savage, H. M., and E. E. Brodsky (2011), Collateral damage: Evolution with displacement of fracture distribution and secondary fault strands in fault damage zones, Journal of Geophysical Research, 116(B3), B03405.

Schulz, S. E., and J. P. Evans (2000), Mesoscopic structure of the Punchbowl Fault, Southern California and the geologic and geophysical structure of active strikeslip faults, Journal of Structural Geology, 22(7), 913-930.

Searle, R. (1983), Multiple, closely spaced transform faults in fast-slipping fracture zones, Geology, 11(10), 607.

Shearer, P. M. (2002), Parallel fault strands at 9-km depth resolved on the Imperial Fault, southern California, Geophysical research letters, 29(14), 19-1.

Sibson, R. H. (2003), Thickness of the seismic slip zone, Bulletin of the Seismological Society of America, 93(3), 1169.

Thurber, C., S. Roecker, W. Ellsworth, Y. Chen, W. Lutter, and R. Sessions (1997), Twodimensional seismic image of the San Andreas Fault in the Northern Gabilan Range, central California Evidence for fluids in the fault zone,

Thurber, C., H. Zhang, F. Waldhauser, J. Hardebeck, A. Michael, and D. EberhartPhillips (2006), Three-dimensional compressional wavespeed model, earthquake relocations, and focal mechanisms for the Parkfield, California, region, Bulletin of the Seismological Society of America, 96(4B), S38.

Toomey, D. R., S. C. Solomon, and G. M. Purdy (1994), Tomographic imaging of the shallow crustal structure of the East Pacific Rise at 9॰30 N, J. geophys. Res, 99(24), 135-24.

Toomey, D., and G. Foulger (1989), Tomographic Inversion of Local Earthquake Data From the Hengill-Grensdalur Central Volcano Complex, Iceland, J. Geophys. Res, 94, 17497-17510. 
Tréhu, A. M., and G. M. Purdy (1984), Crustal structure in the Orozco transform zone, Journal of Geophysical Research, 89(B3), 1834-1842.

Vera, E. E., J. C. Mutter, P. Buhl, J. A. Orcutt, A. J. Harding, M. E. Kappus, R. S. Detrick, and T. M. Brocher (1990), The structure of 0-to 0.2-my-old oceanic crust at $9 \mathrm{~N}$ on the East Pacific Rise from expanded spread profiles, Journal of Geophysical Research, 95(B10), 15529.

Wei, M., D. Sandwell, and Y. Fialko (2009), A silent Mw 4.7 slip event of October 2006 on the Superstition Hills fault, southern California, J. Geophys. Res, 114.

Wendt, J. I., M. Regelous, Y. Niu, R. Hékinian, and K. D. Collerson (1999), Geochemistry of lavas from the Garrett Transform Fault: insights into mantle heterogeneity beneath the eastern Pacific, Earth and Planetary Science Letters, 173(3), 271-284.

Wessel, P., and W. F. Haxby (1990), Thermal stresses, differential subsidence, and flexure at oceanic fracture zones, Journal of Geophysical Research, 95(B1), 375391.

White, R. S., R. S. Detrick, M. C. Sinha, and M. H. Cormier (1984), Anomalous seismic crustal structure of oceanic fracture zones, Geophysical Journal of the Royal Astronomical Society, 79(3), 779-798.

White, R. S., D. McKenzie, and R. K. O’Nions (1992), Oceanic crustal thickness from seismic measurements and rare earth element inversions, Journal of Geophysical Research, 97(B13), 19683.

Wilcock, W. S. ., G. M. Purdy, and S. C. Solomon (1990), Microearthquake evidence for extension across the Kane transform fault, Journal of Geophysical Research, 95(B10), 15439-15. 


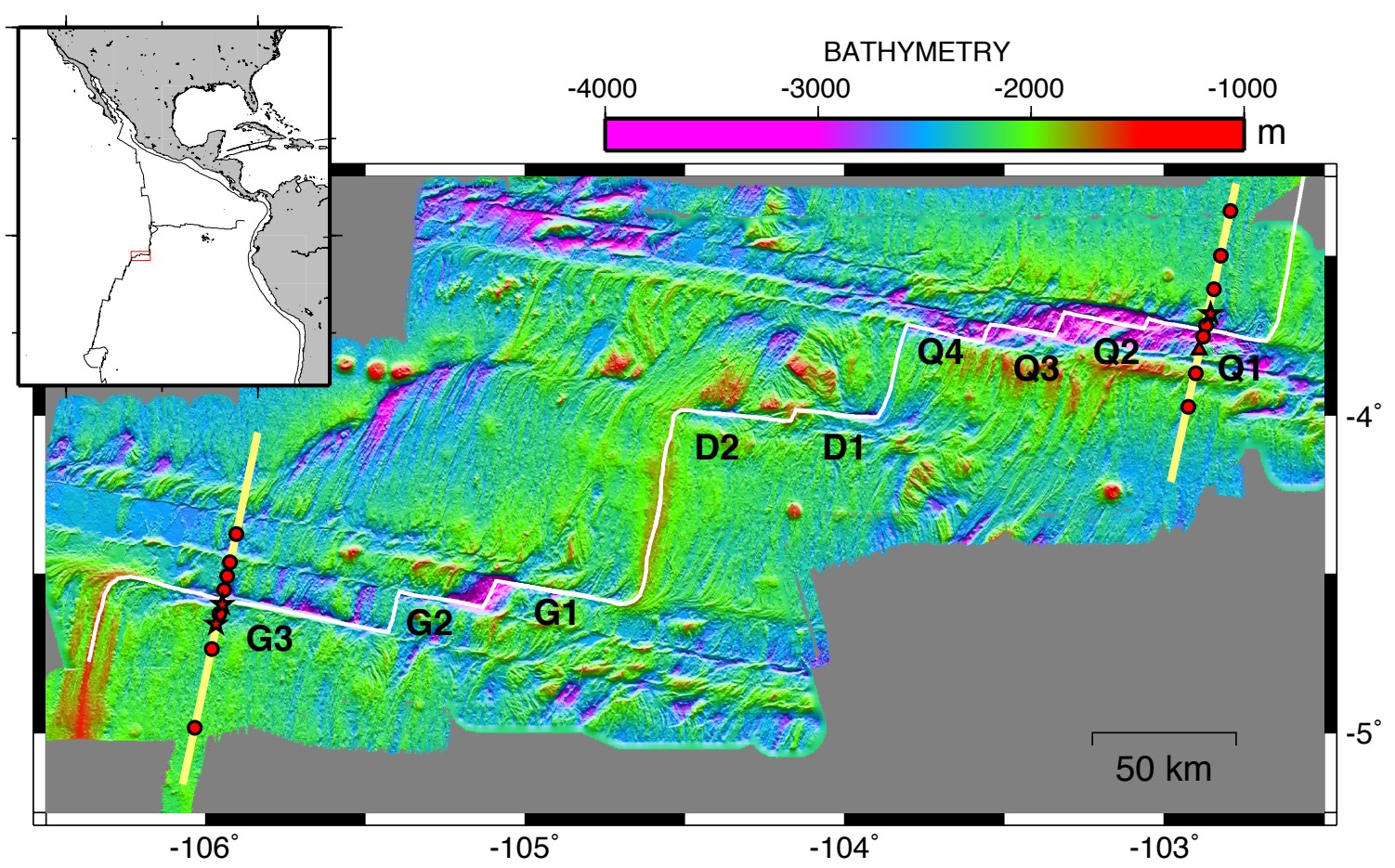

Figure 1: Bathymetric map of the Quebrada-Discovery-Gofar (QDG) fault system. Inset map shows the regional location of the transform offset on the southern East Pacific Rise. White line shows the plate boundary as indicated by pseudo-sidescan backscatter [Langmuir and Forsyth, 2007], and yellow lines show the location of two wide-angle refraction lines crossing the G3 segment of the Gofar fault and the Q1 segment of the Quebrada fault. Red circles show the locations of short-period ocean bottom seismometers (OBS); red stars and triangle show the locations of 4 OBS (broadband and short period respectively), deployed as part of the passive-source experiment that also recorded refraction data used in this study. Instrument numbers referred to in the text at both lines are shown in Figure 3. 


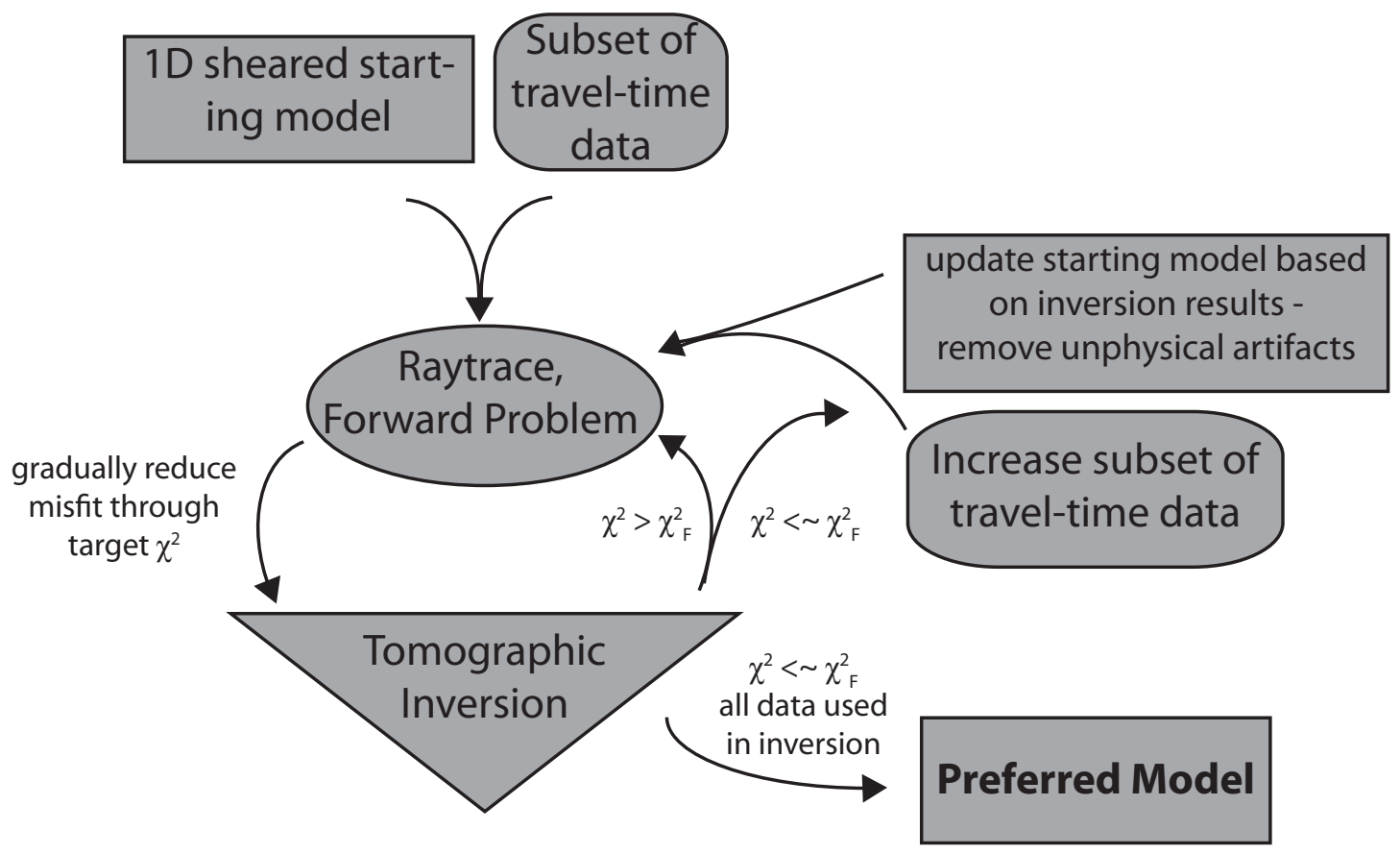

Figure 2: Schematic diagram that demonstrates the forward ray tracing and tomographic inversion approach we perform to arrive upon our preferred velocity models. We use a tomographic inversion code developed by Harm Van Avendonk and Alistair Harding that uses methodology presented by Van Avendonk et al. [1998]. 




Figure 3: P-wave velocity profiles determined from the G3 (top) and Q1 (bottom) wide-angle refraction datasets. Receivers located on the sea floor are shown as black triangles. All receivers are short-period OBS deployed for the refraction experiments, except for those with "p-" labels, which were deployed for the year-long passive-source experiment. p7, p8 and p9 are broadband seismometers, p13 is a short period seismometer. Black line located at approximately $0 \mathrm{~km}$ depth shows the location of shots (at $\sim 100-150 \mathrm{~m}$ spacing). Thick white lines show the location of the Moho reflector as determined by our inversions. Velocity is contoured at 4.2, 5.0, 6.0, 6.6 and $7.0 \mathrm{~km} / \mathrm{s}$. Black arrows show the approximate location of the active fault from pseudo-sidescan backscatter [Langmuir and Forsyth, 2007]. 

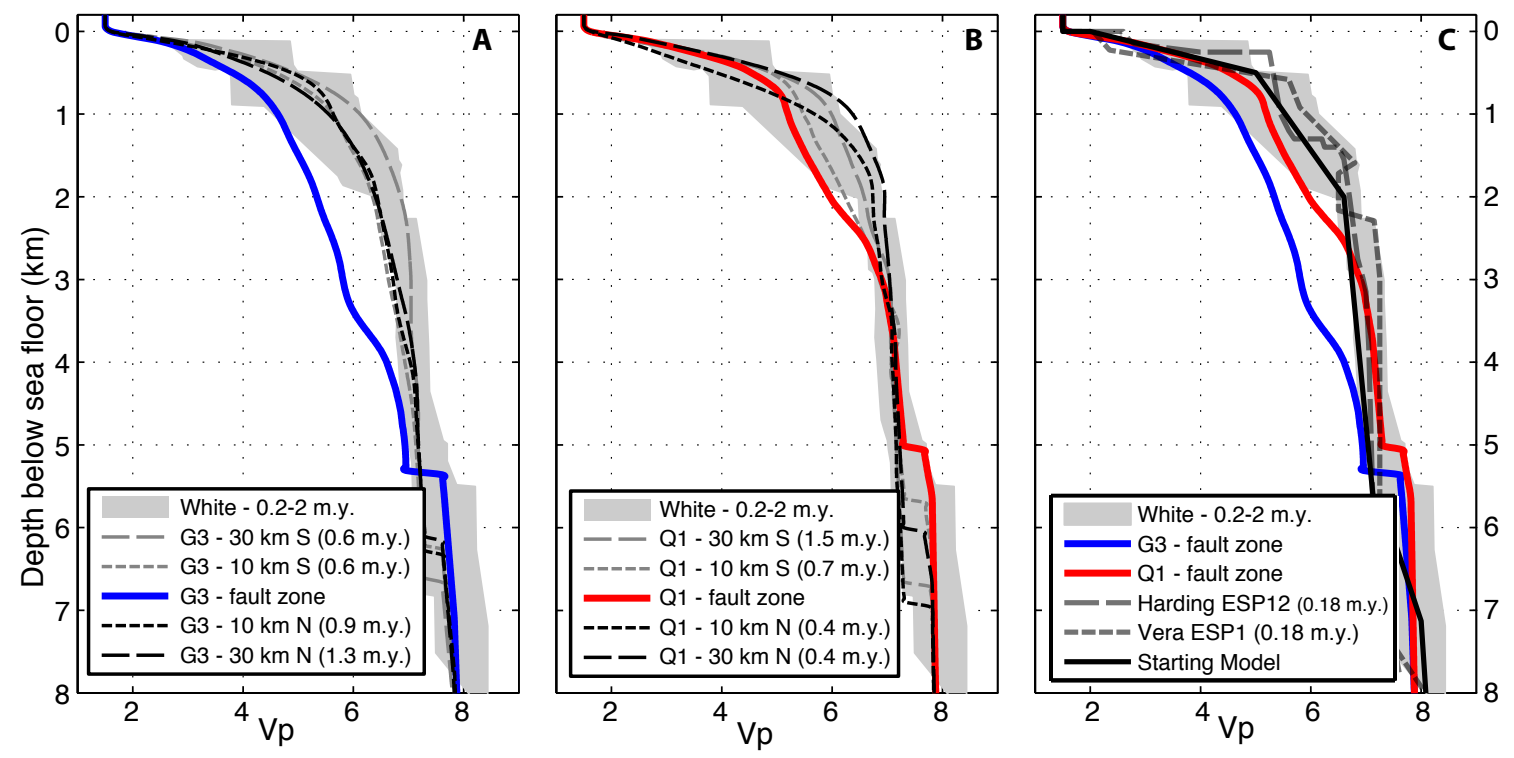

Figure 4: 1D velocity-depth profiles from the Gofar and Quebrada velocity models compared to other velocity models determined for Pacific Ocean crust. A) 1D velocity depth profile taken beneath the active trace of the Gofar fault ( $66 \mathrm{~km}$ offset, blue line) compared to profiles at 10 and $30 \mathrm{~km}$ south (gray lines) and north (black lines) of the fault zone. The gray shaded area shows a compilation of 9 profiles across normal young oceanic crust (0.2-2 m.y.) modeled using synthetic seismograms [White et al., 1992]. B) Similar comparison of profiles at the Quebrada fault, with the central fault zone (offset $52 \mathrm{~km}$ ) shown in blue. C) The Gofar and Quebrada fault zone velocity depth profiles compared to the starting model, and to several other models for young oceanic crust determined from expanding spread profiles ESP1 near the EPR at $9{ }^{\circ} \mathrm{N}$ [Vera et al., 1990], and ESP12, $10 \mathrm{~km}$ off axis of the EPR near $12^{\circ} \mathrm{N}$ [Harding et al., 1989]. 

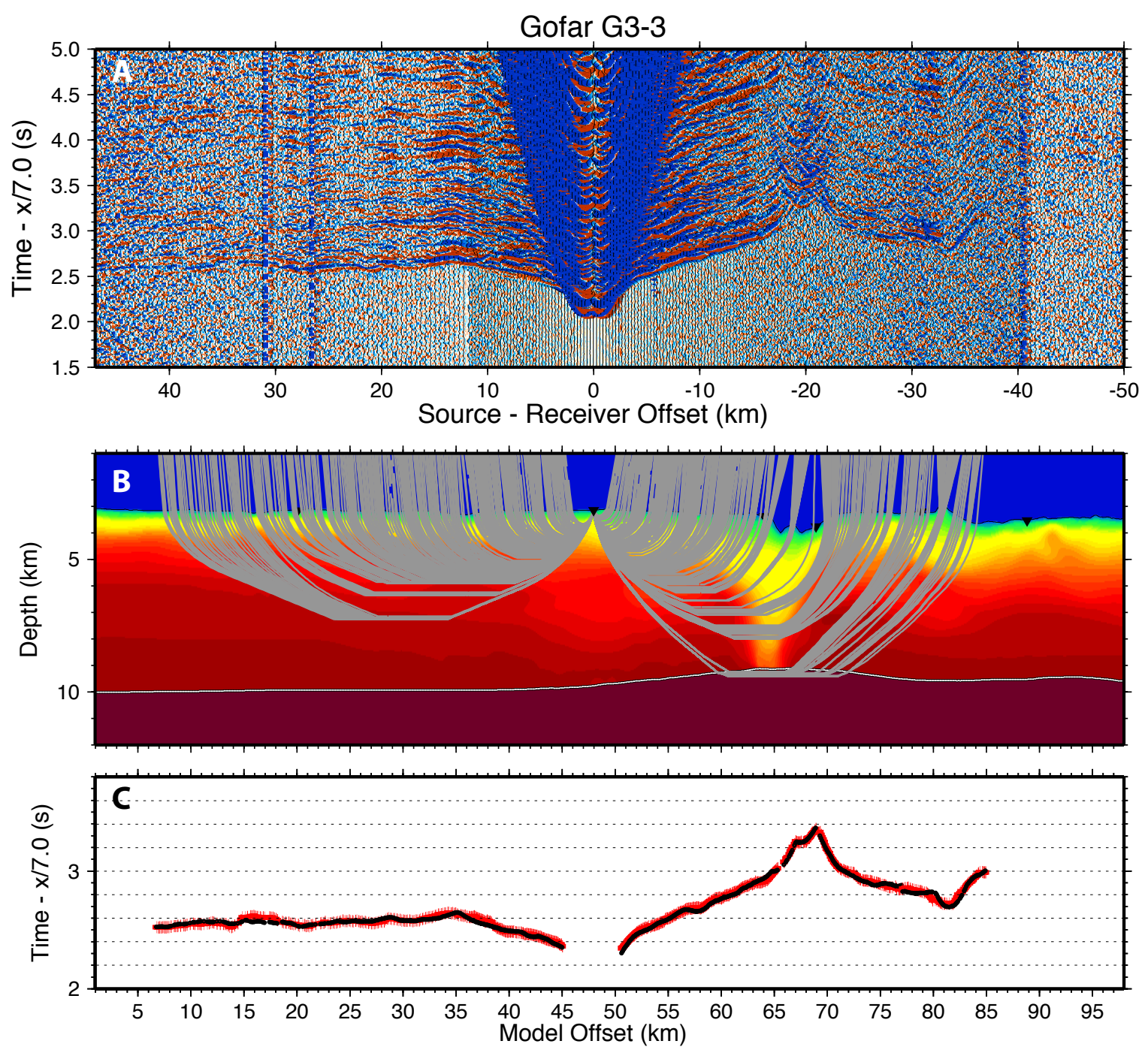

Figure 5: A) Data recorded at G3-3, reduced at $7.0 \mathrm{~km} / \mathrm{s}$. B) Rays traced through preferred Gofar-G3 velocity model using the graph method. Velocity color scale is same as that shown in Figure 3. White line indicates Moho, and black triangles show receiver locations. C) First arrival travel time picks for G3-3 (black) compared to the modeled travel times using preferred P-wave velocity model (red). Height of modeled data points indicates the assumed travel-time pick error. 

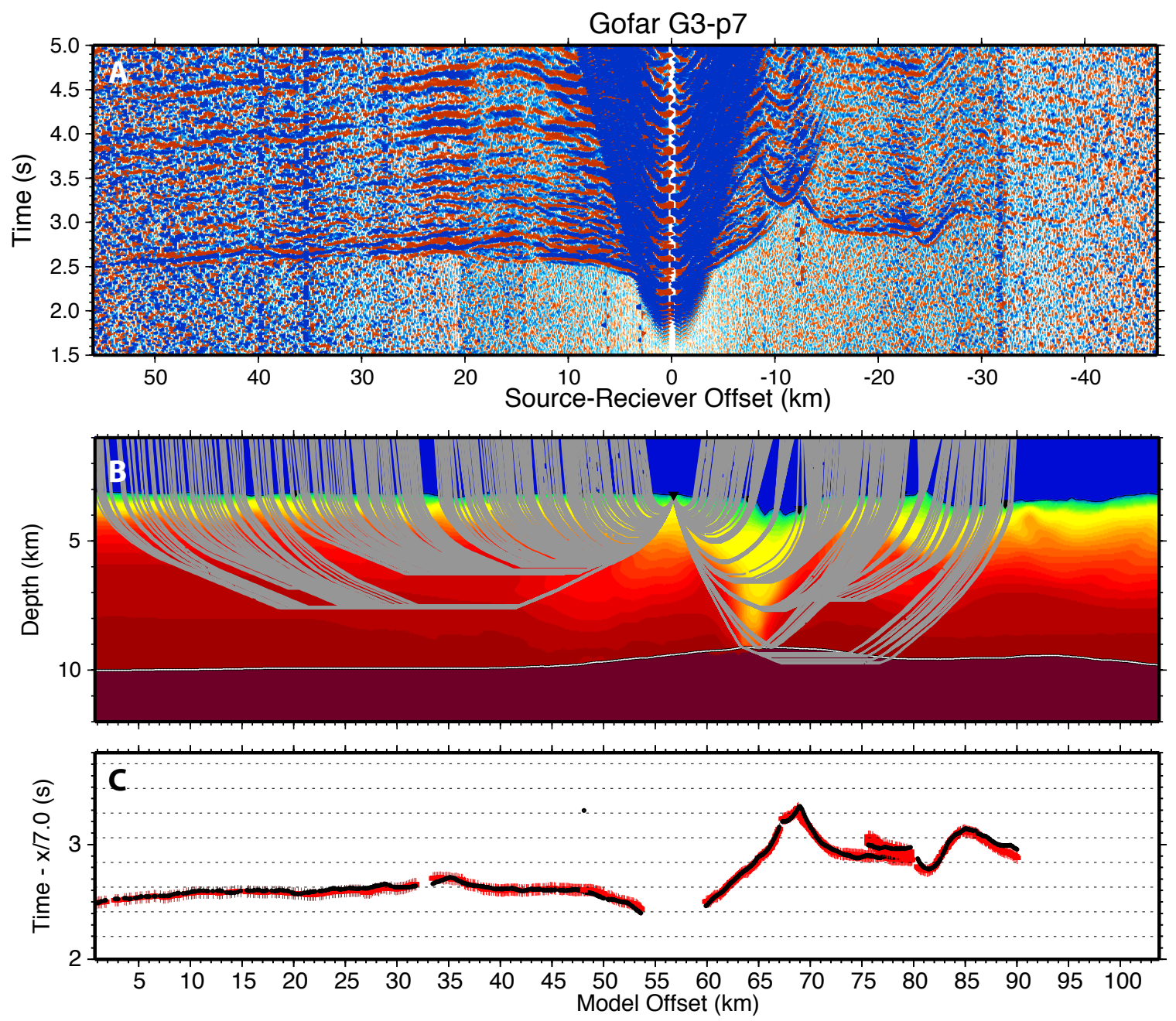

Figure 6: Data (A), ray diagram (B), and travel times (C) for station G3-p7 (for details, see Figure 5 caption). 

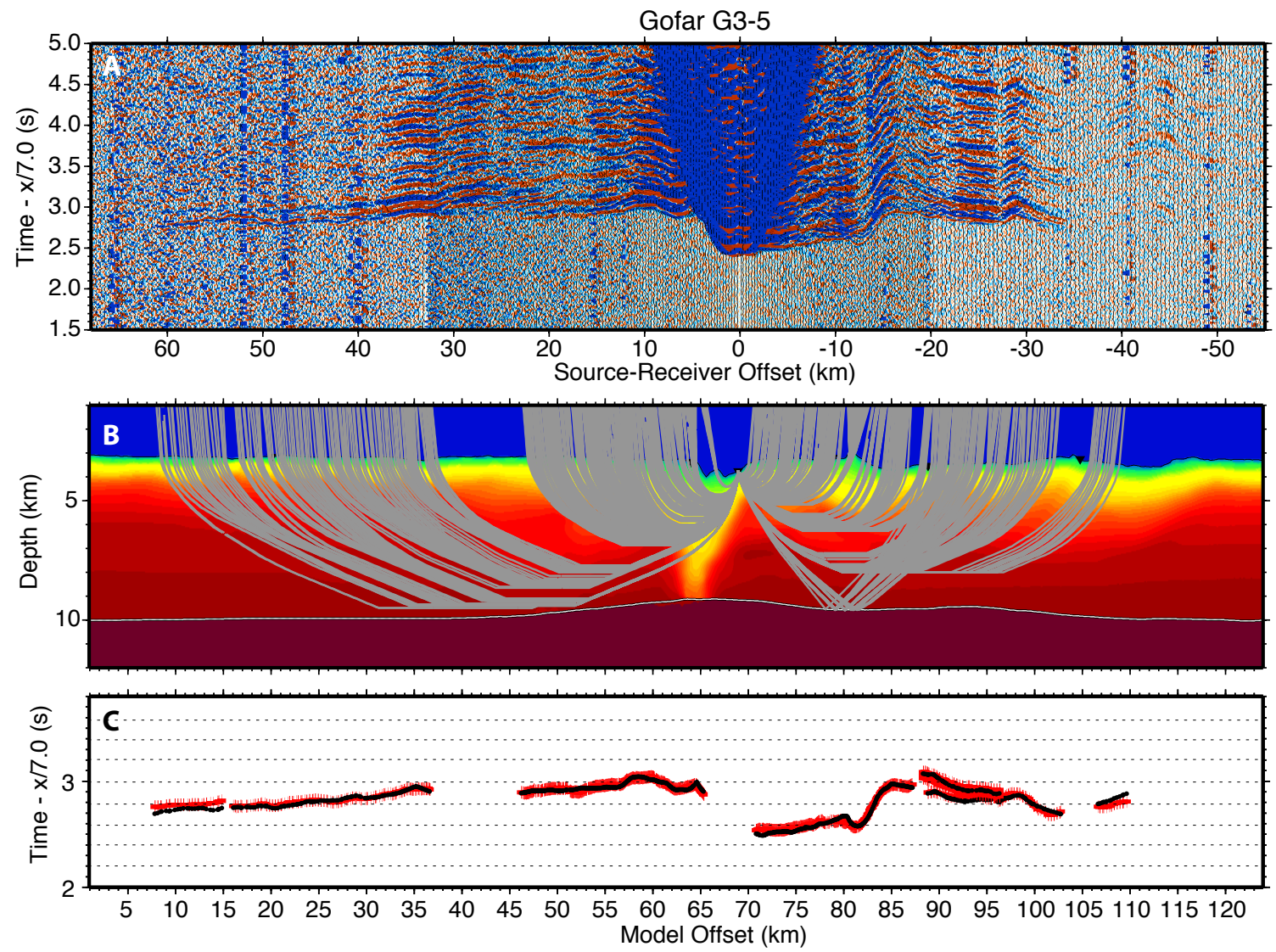

Figure 7: Data (A), ray diagram (B), and travel times (C) for station G3-5 (for details, see Figure 5 caption). 

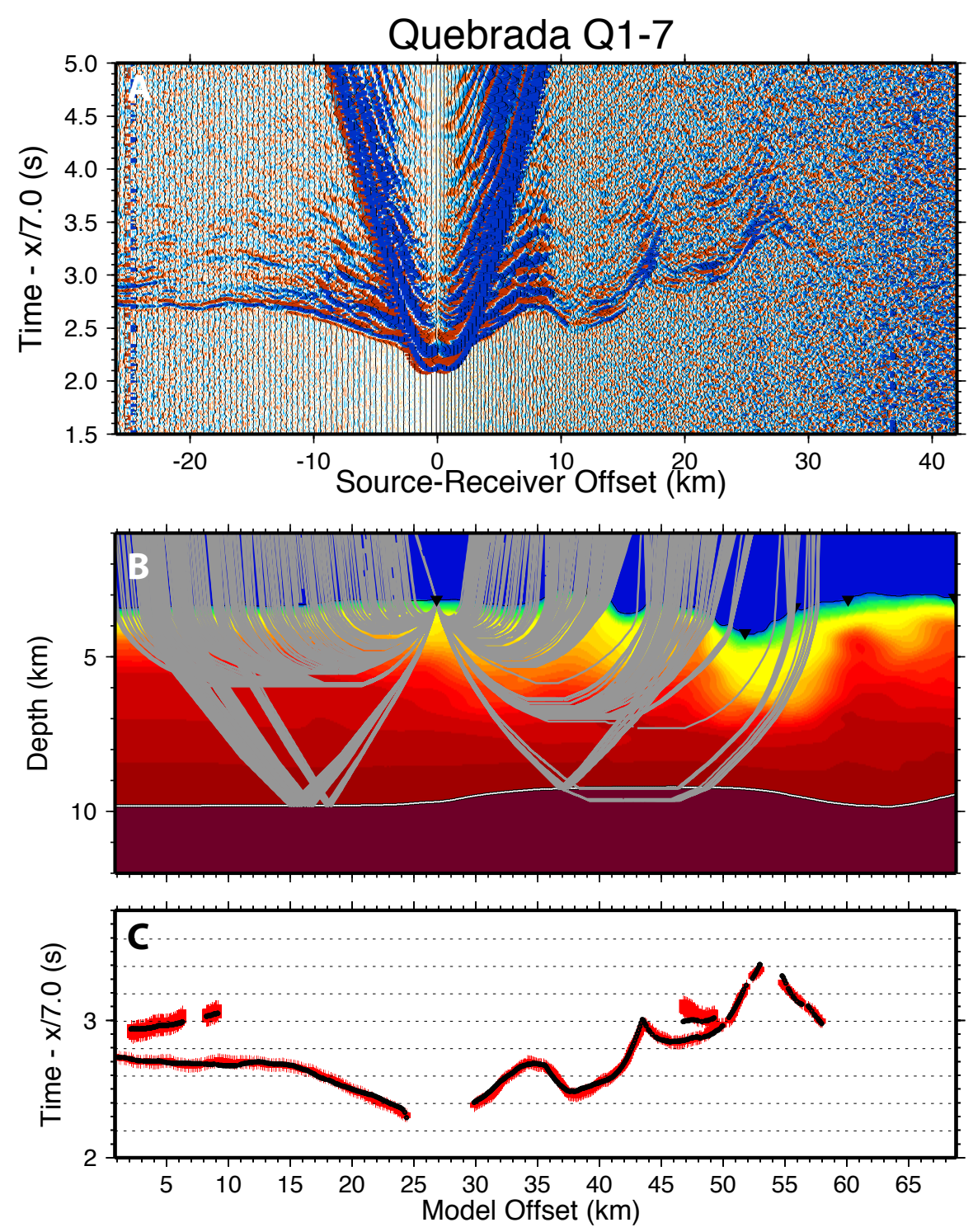

Figure 8. A) Data recorded at Q1-7, reduced at $7.0 \mathrm{~km} / \mathrm{s}$. B) Rays traced through preferred Quebrada-Q1 velocity model using graph method. Velocity color scale is same as that shown in Figure 3. White line indicates Moho, and black triangles show receiver locations. C) First arrival travel time picks for Q1-7 (black) compared to the modeled travel times using preferred P-wave velocity model (red). Length of modeled data point indicates the assumed travel-time pick error. 

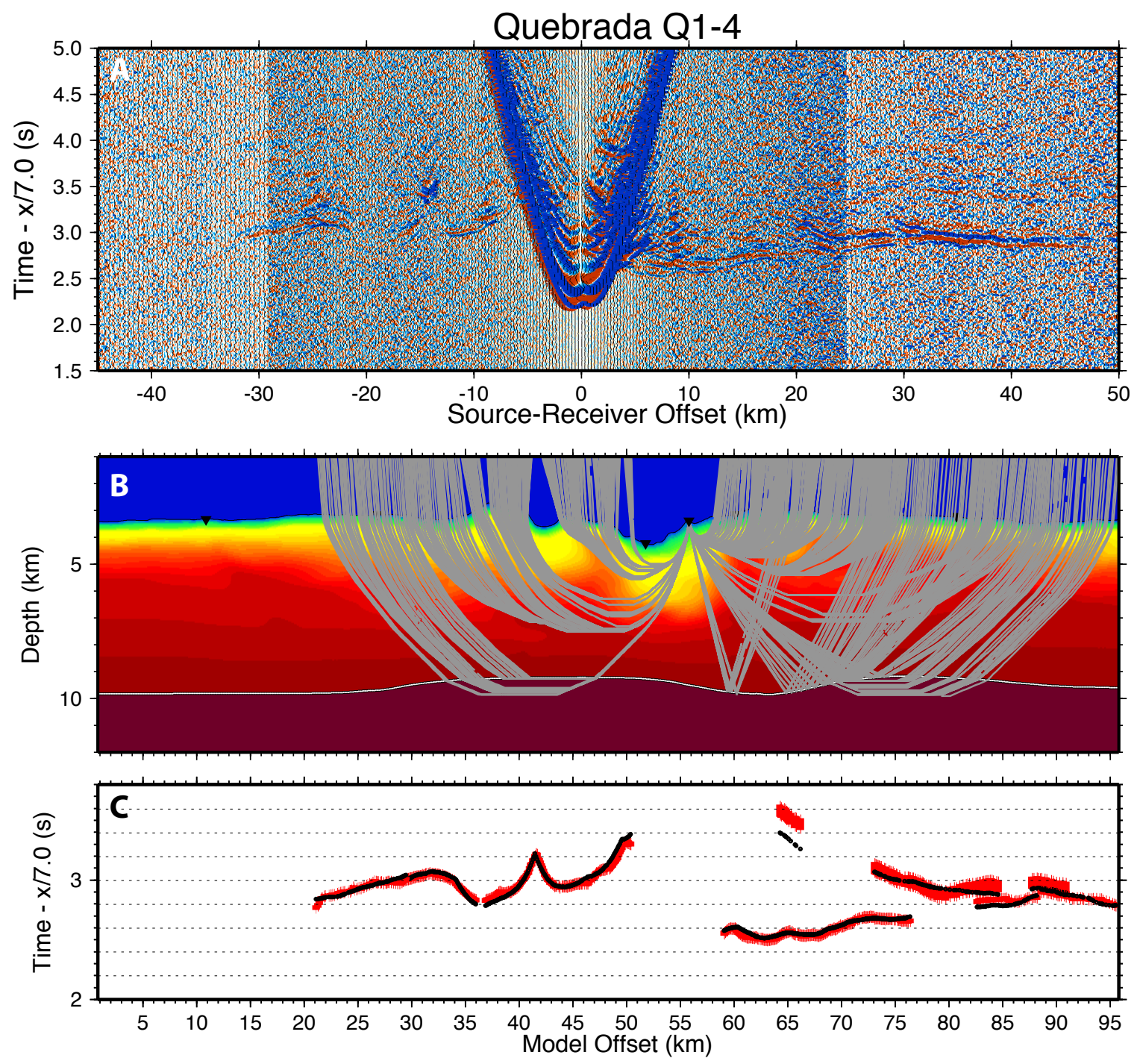

Figure 9: Data (A), ray diagram (B), and travel times (C) for station Q1-4 (for details, see Figure 8 caption). 

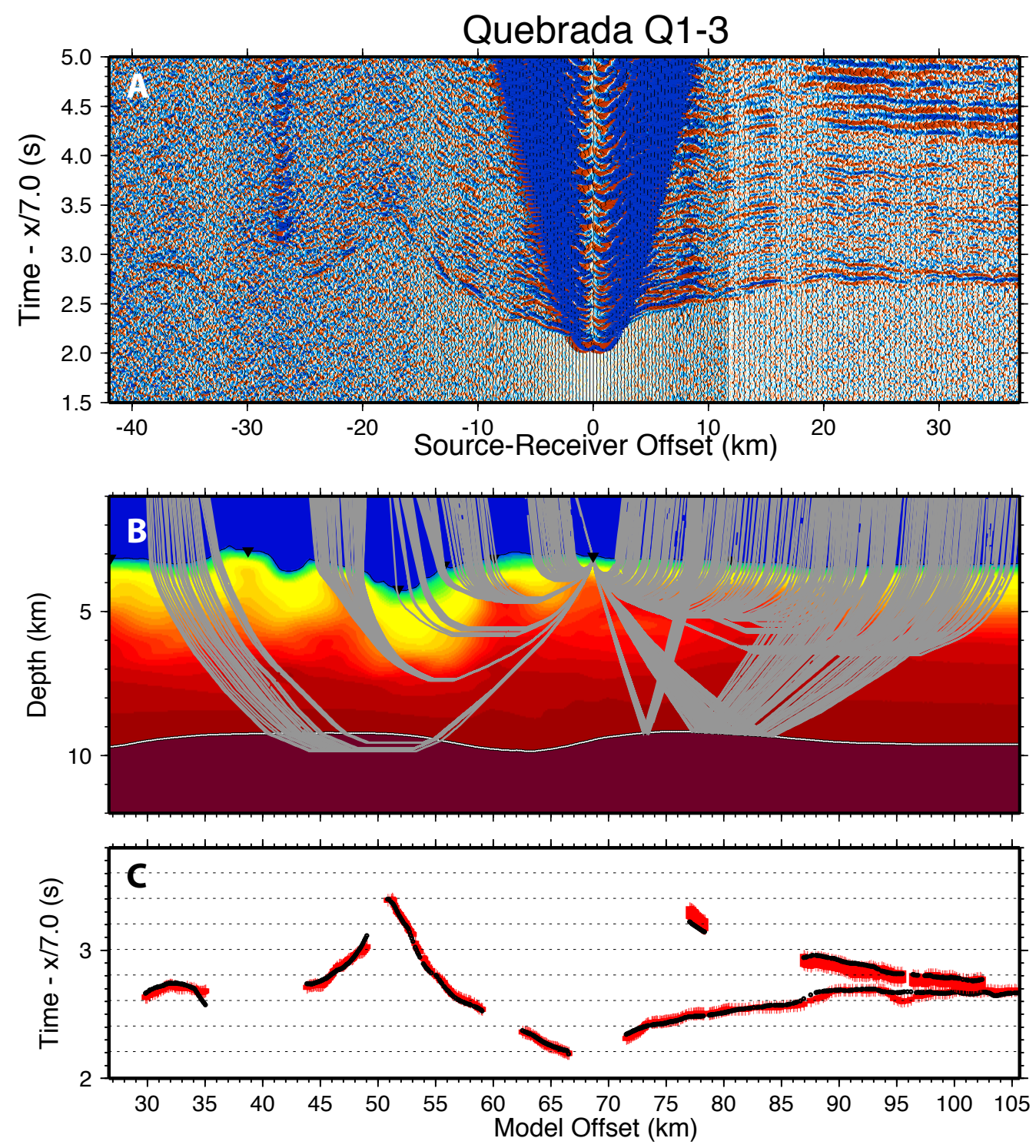

Figure 10: Data (A), ray diagram (B), and travel times (C) for station Q1-3 (for details, see Figure 8 caption). 


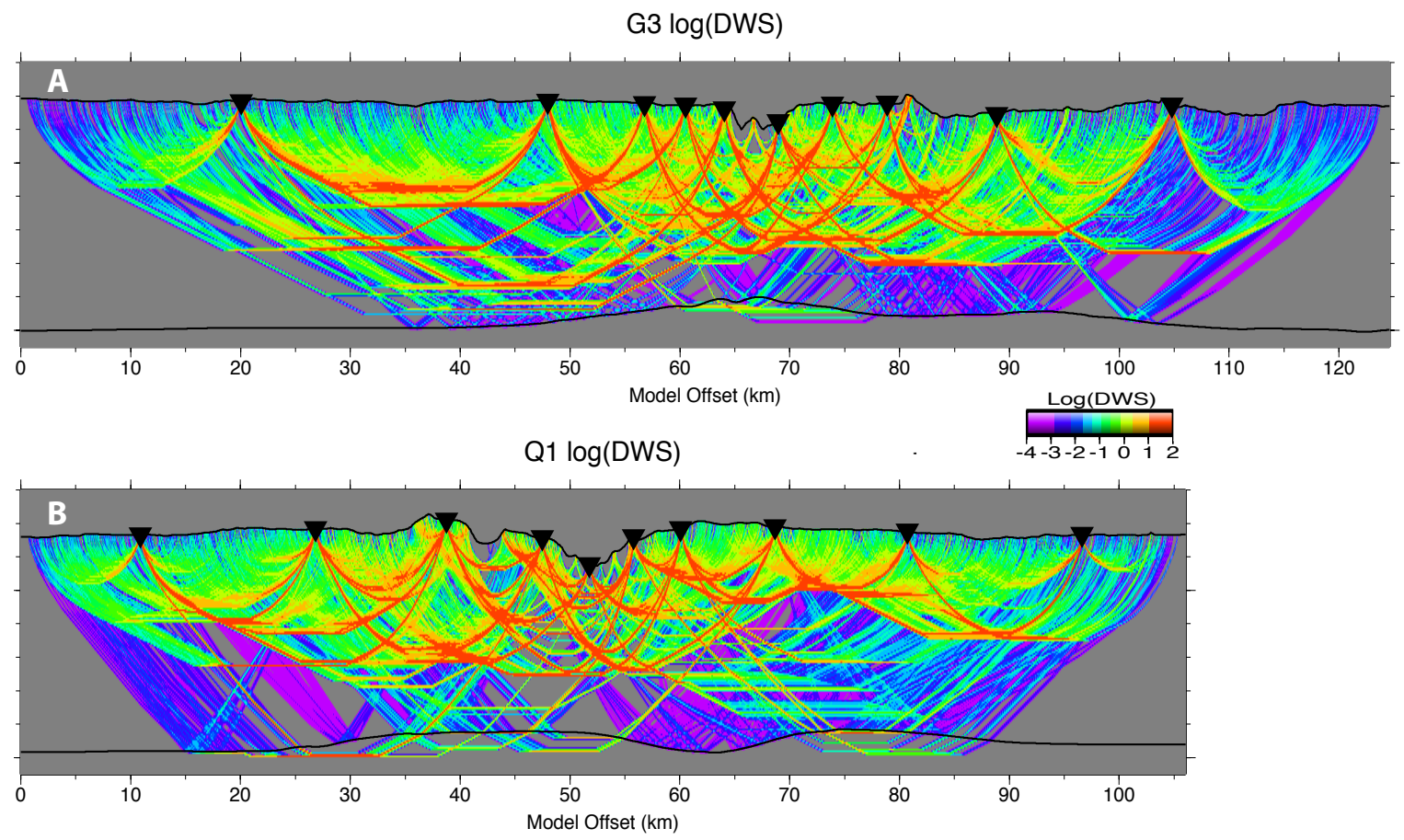

Figure 11: The derivative weight sum (DWS) for (A) the G3 and (B) Q1 models. The DWS is a weighted sum of the elements of each column of the Frechet matrix [Van Avendonk et al., 1998], and is a non-dimensional value that indicates the ray density throughout the model. 


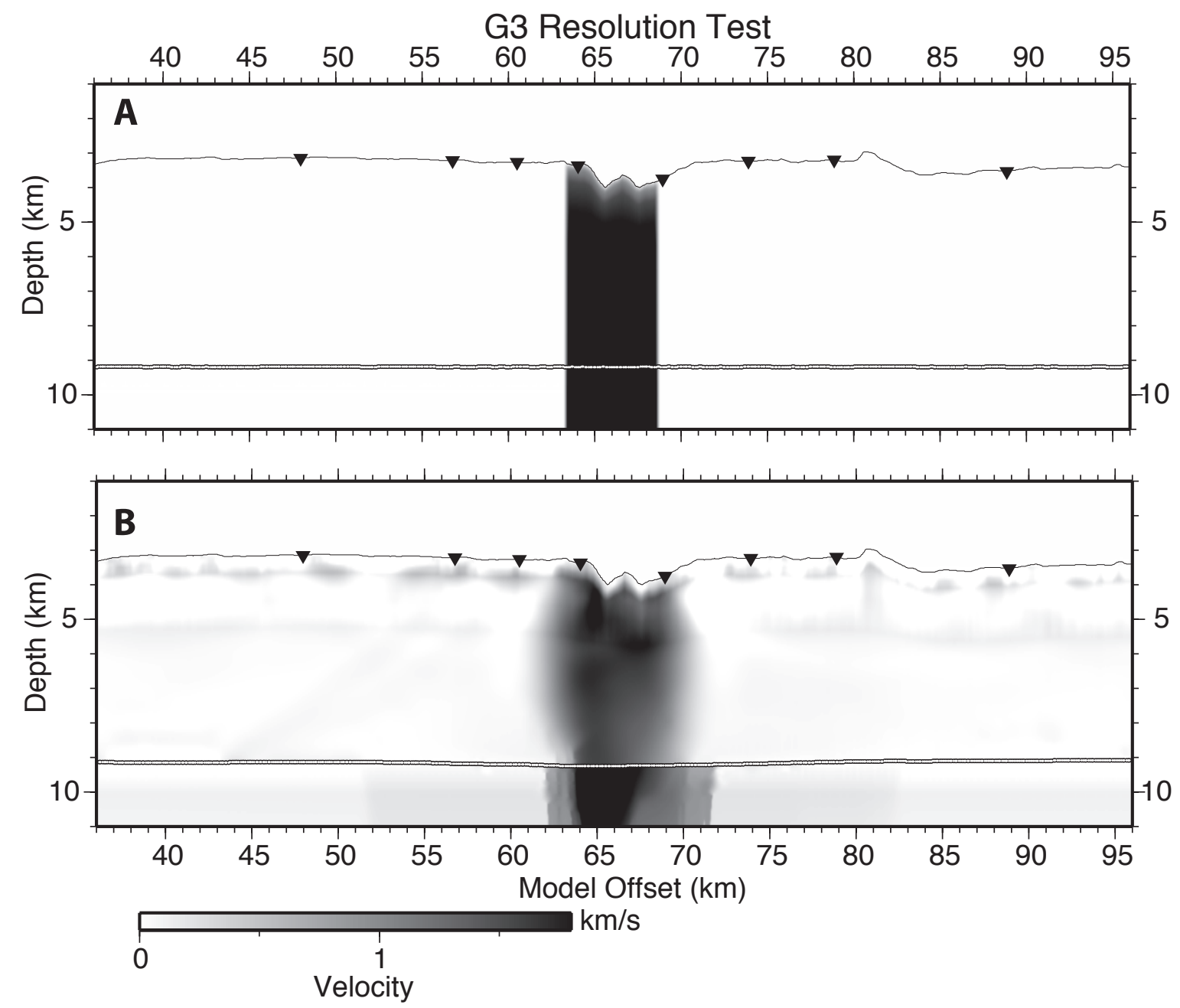

Figure 12: Resolution test for a $5 \mathrm{~km}$ wide fault zone with $\mathrm{P}$-wave velocities reduced by $30 \%$ that extends throughout the crust and upper mantle (A). Synthetic data was first calculated by forward modeling travel times with the same source-receiver geometry used in the tomographic inversion for the Gofar velocity model. Synthetic travel times were then modeled using the tomographic strategy outlined in section 3.2. B) With the exception of some smoothing in the lower crust, the $5 \mathrm{~km}$ wide fault zone signal is reproduced well with the model resolution available here. 

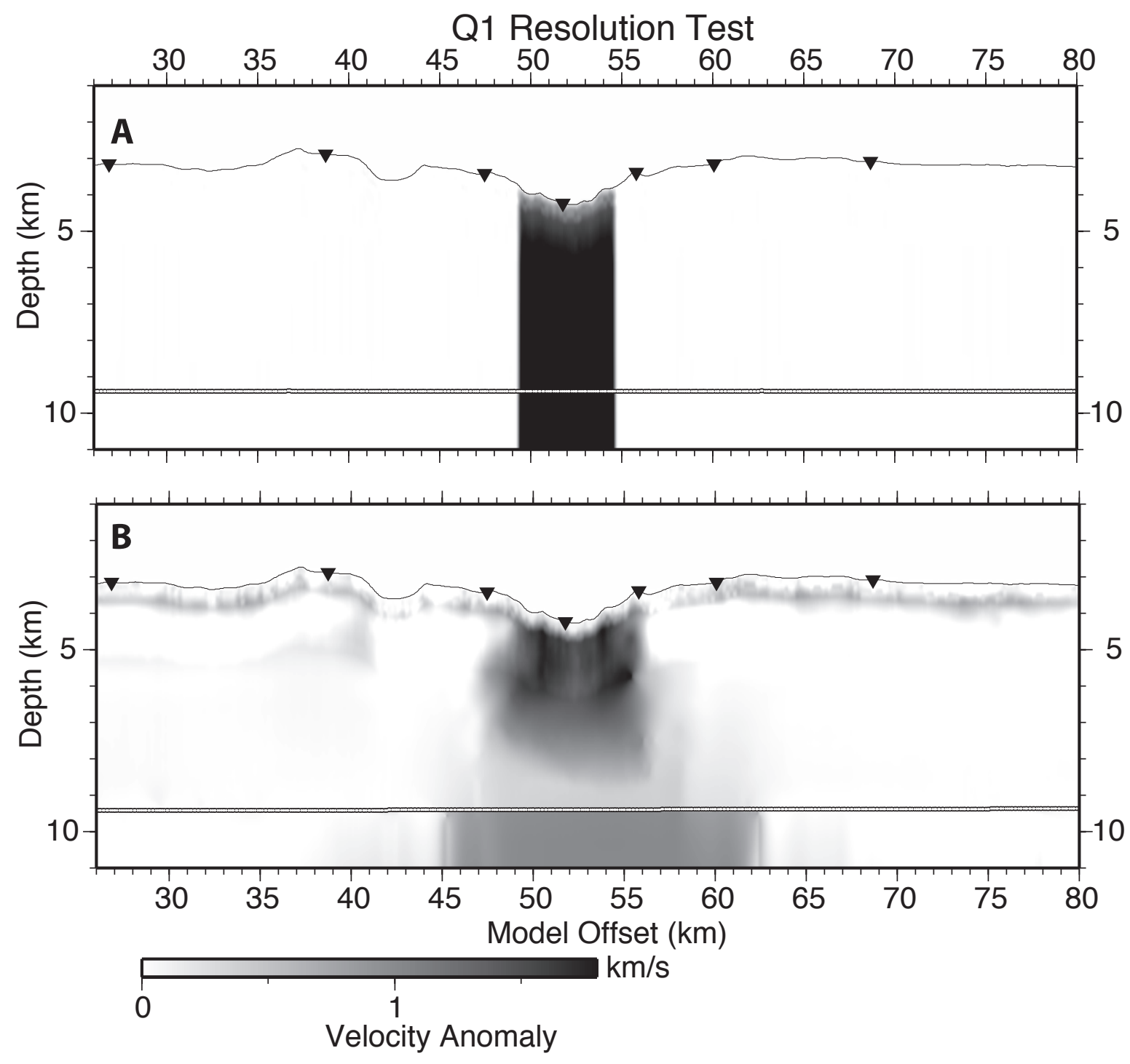

Figure 13: Resolution test similar to that presented in Figure 12, except using the model and data geometry from the Quebrada tomographic inversion. The 30\% velocity reduction in the 5-km-wide fault zone is resolved throughout the upper crust, however with the model resolution available at the Q1 line, reduced velocities are not able to be resolved in the lower crust or upper mantle. 


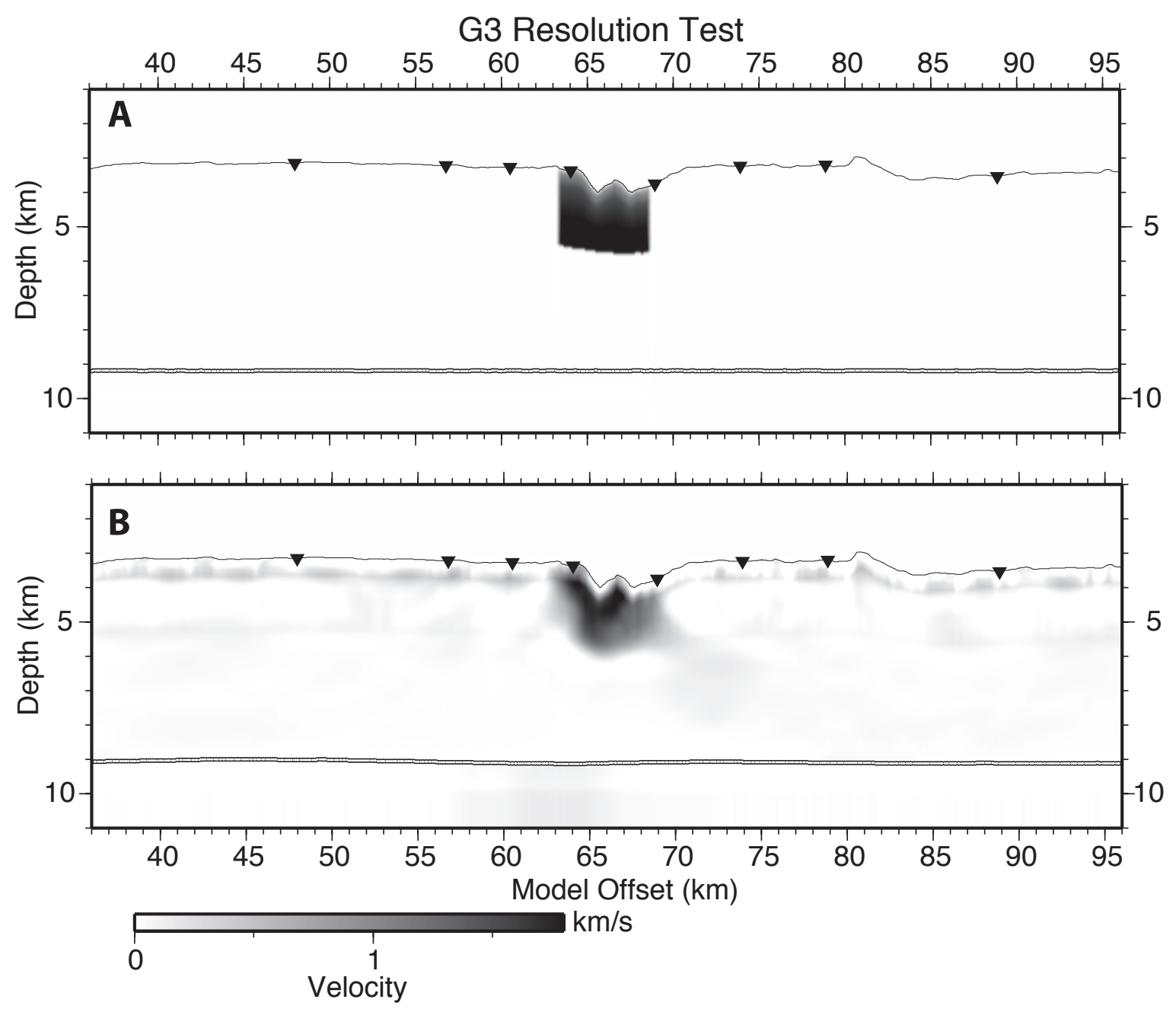

Figure 14: Resolution test for a 5-km-wide, 30\% reduced P-wave velocity fault zone that is confined to the shallowest $2 \mathrm{~km}$ of the upper crust. Using the model and data geometry available for the G3 line, the shallow velocity anomaly is well resolved, with little or no "smearing" of the signal laterally or in depth. 

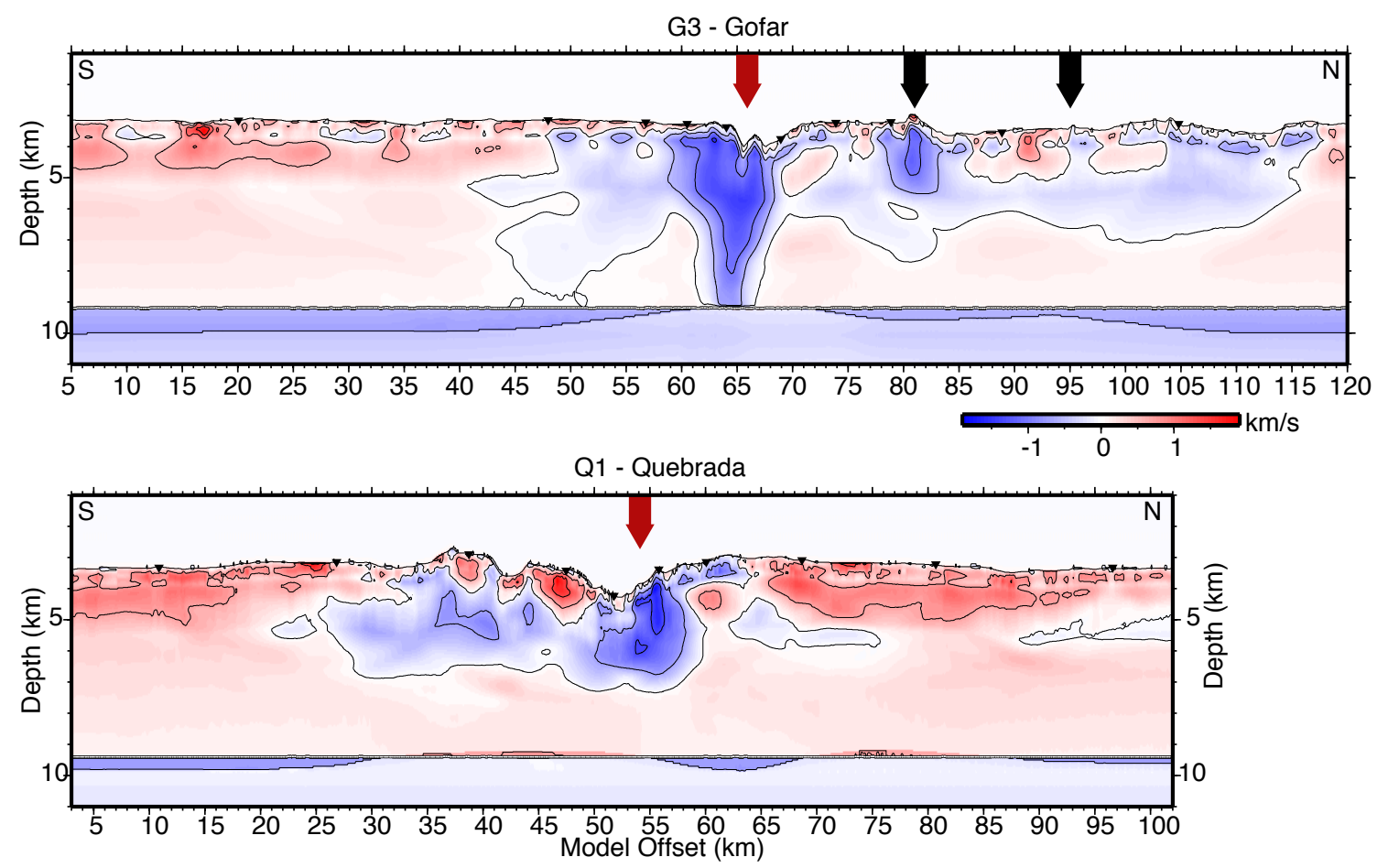

Figure 15: Preferred velocity model determined for the Gofar, G3 line and Quebrada, Q1 line (displayed in Figure 3), plotted in terms of the velocity anomaly relative to the starting model (shown in Figure 4c). Red arrow shows the location of the active fault trace, black arrows show the location where the transect crosses fossil fracture zones associated with faults G2 ( $\sim 0.88$ m.y. since active) and G1 ( 1.29 m.y. since active) to the north of G3. 

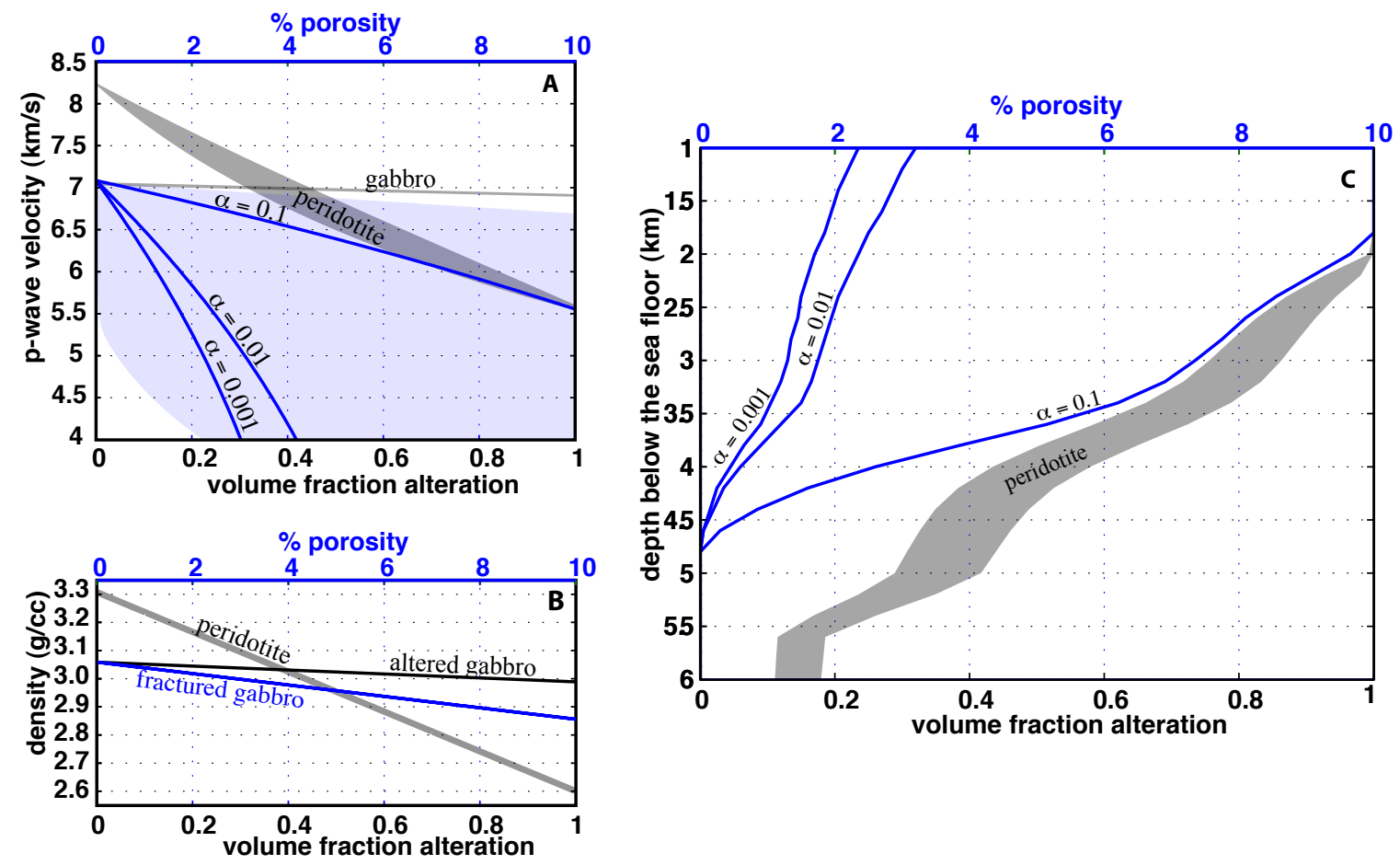

Figure 16: Effective media analyses assuming fluid-saturated porosity (blue curves throughout A, B and C), or alteration of upper mantle material (black/grey curves). A) Seismic P-wave velocity variation with increased sea water-saturated porosity in gabbro (top axis) or alteration of upper mantle peridotite (bottom axis) using Hashin-Strikman (H-S) mixing relations [Hashin and Shtrikman, 1963] and the two-phase media relations of Kuster and Toksöz [1974] for cracks with aspect ratios $(\alpha)$ of $0.1,0.01$, and 0.001 . Gabbro composition used here is $18 \%$ olivine, $47 \%$ Plagioclase, and 35\% clinopyroxene. Elastic properties come from Carlson and Miller [2004] and are corrected for depth. Peridotite composition is $90 \%$ olivine, $4 \%$ pyroxene, and $6 \%$ hornblende, which we take along with the elastic properties from Iturrino [1996]. H-S bounds are calculated assuming a depth of $4 \mathrm{~km}$ below the sea floor. Velocities are also corrected for the effect of closing micro-fractures with depth. B) Change in bulk density associated with increased porosity (top axis) and alteration of peridotite (bottom), equivalent to material properties shown in (A). C) The predicted porosity or percent alteration based on the seismic velocities determined for the center (model range $66 \mathrm{~km}$ ) of the Gofar, G3 refraction profile. Porosity and degree of alteration are calculated assuming the average $\mathrm{H}-\mathrm{S}$ velocity values shown in (A). 

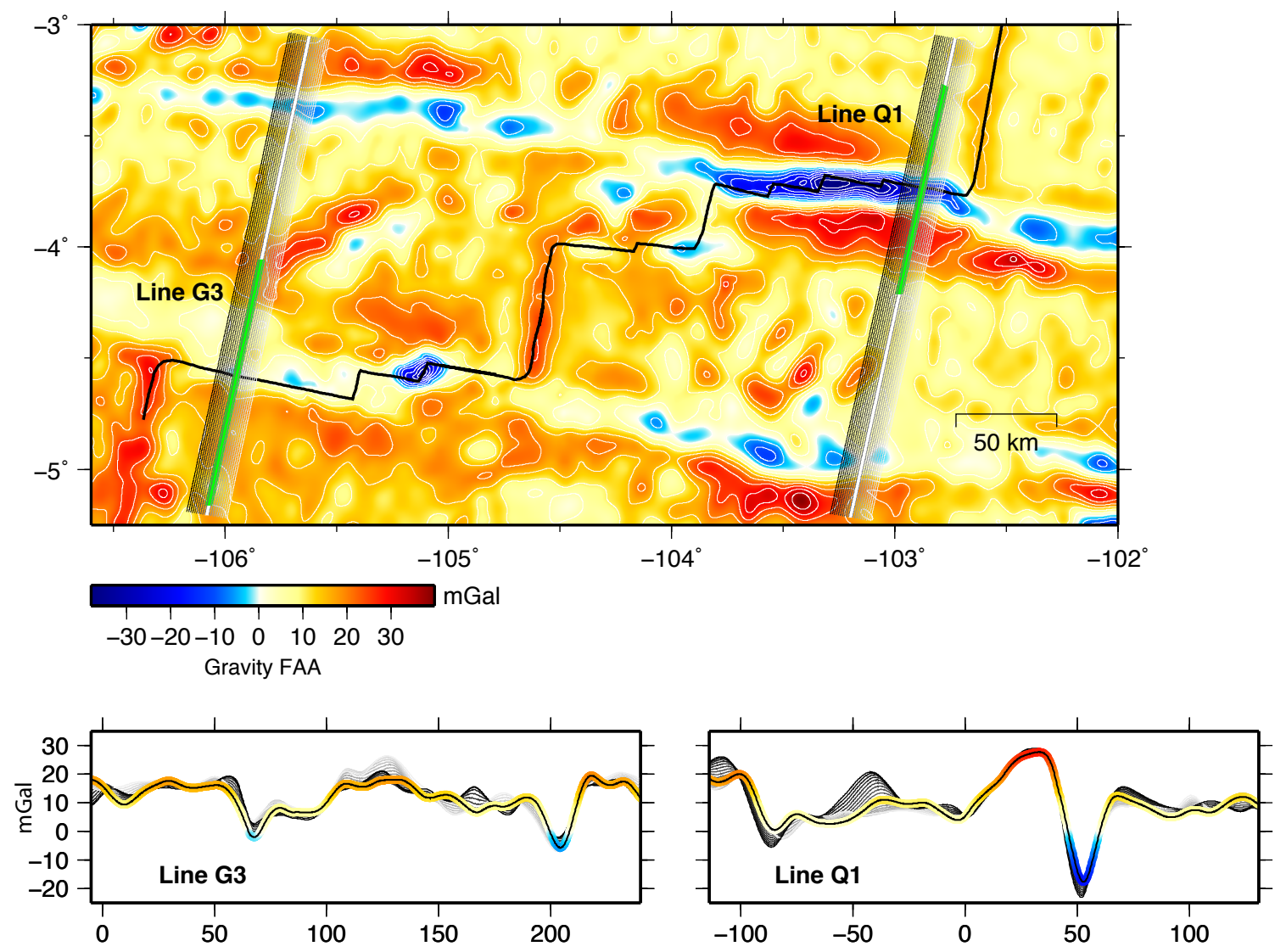

Figure 17: Gravity free-air anomaly acquired on the $R / V$ Knorr over the QDG fault system from Pickle et al. [2009]. Regional map view is shown in top panel and profiles parallel to the G3 and Q1 lines are shown in lower panels. 

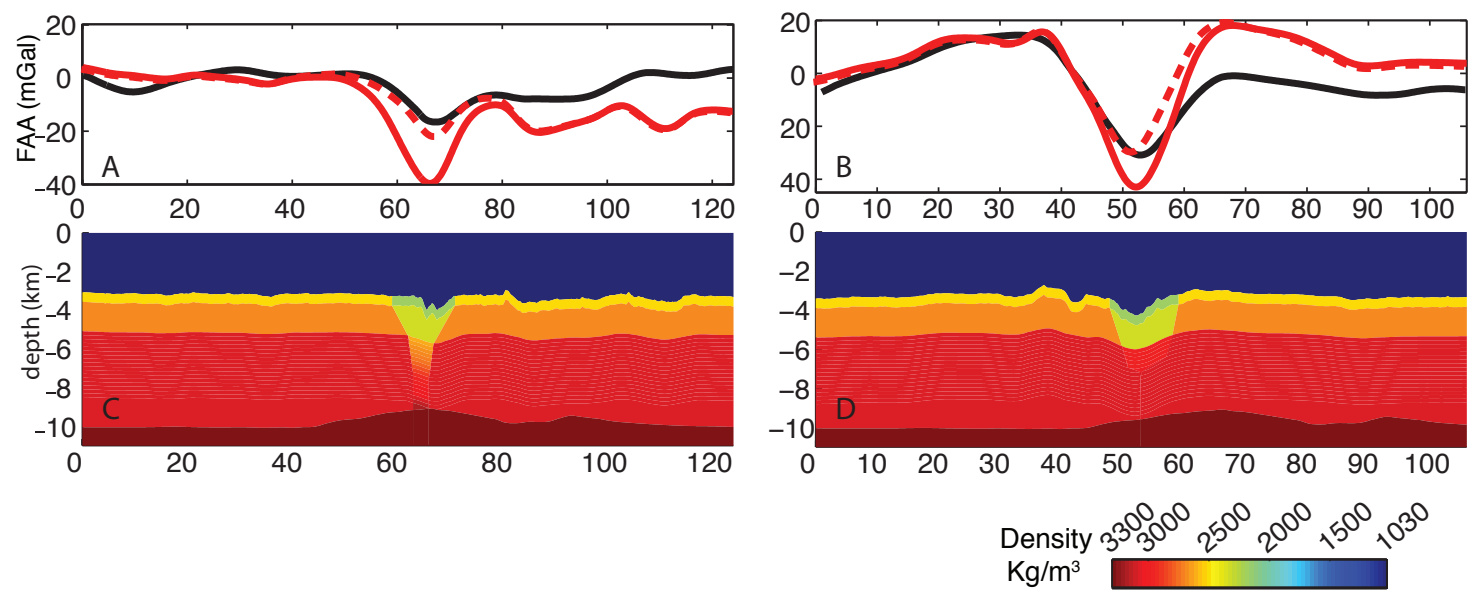

Figure 18: Simple models for the gravity anomaly across the Gofar (A, C) and Quebrada $(B, D)$ faults. The predicted gravity anomaly using a reduced density structure is indicated by the solid red lines in the upper panels (A) and (B). Dashed red lines show the gravity anomaly calculated assuming no density contrast in the crust. Black solid lines show the observed free air anomaly. Bottom panels (C) and (D) show crustal density profile and Moho depth used for the gravity anomaly calculations. Fault zone density structure is determined from the seismic velocity structure and the effective media analysis assuming that reduced seismic velocities in the fault zone are caused by altered peridotite. 

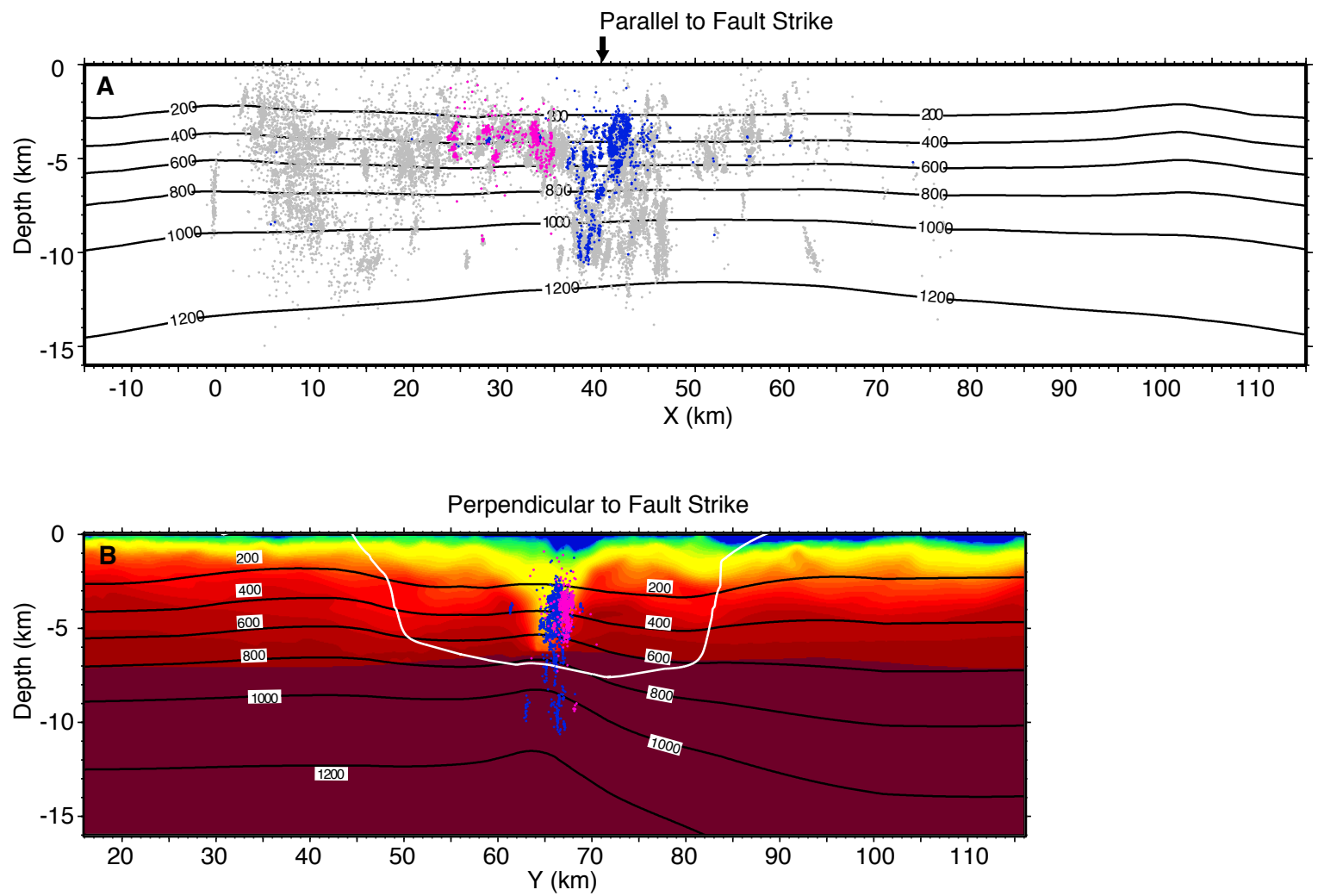

Figure 19: Earthquakes observed during the 2008 OBS deployment on the Gofar fault and isotherms calculated using the numerical model of Roland et al. [2010] (A) along the fault and (B) perpendicular to the fault, approximately along the G3 transect. Earthquakes (grey dots) were located using a double difference relocation scheme [McGuire et al., submitted]. Blue dots indicate the location of foreshock sequence events, and magenta dots show the location of aftershocks. Black arrow in (A) shows the approximate location where the refraction transect crosses the fault and the location of crossfault thermal profile shown in (B). Cross-fault profile (B) also shows the seismic velocity model for the G3 fault, as well as the zone of brittle deformation (white line) calculated using the thermal-mechanical numerical model [Roland et al., 2010]. 


\title{
Chapter 5
}

\section{Seafloor strong-motion observations of intermediate- magnitude earthquakes on the Gofar Fault, EPR}

\begin{abstract}
In 2008, an array of seafloor strong-motion accelerometers successfully recorded the rupture process of an oceanic transform fault earthquake at the local-scale. During the year-long ocean bottom seismograph (OBS) deployment on the Gofar fault, a $\mathrm{M}_{\mathrm{w}} 6.0$ mainshock earthquake and several $\mathrm{M}_{\mathrm{w}}>4.0$ earthquakes associated with seismic swarms were recorded on-scale by an array of 10 accelerometers mounted on the OBS frames. We assess the quality of this dataset by presenting the ambient noise spectra for several stations along with that of the broadband seismometer, also deployed in the array. Peak ground motion recorded during Gofar fault earthquakes is compared to empirical models developed from land-based strong-motion observations. We also outline observations and corrections made to this dataset to account for earthquake-triggered rotation of the accelerometers. We evaluate the strong-motion data in terms of its capacity to be used in regional waveform modeling inversions for the source properties of local earthquakes. Despite relatively minor challenges with poor coupling during the largest earthquakes (due to instrument rotation) and apparent poor coupling throughout the deployment at a few stations, we successfully model two intermediate-magnitude earthquakes using the frequency-wavenumber framework [Zhu and Rivera, 2002]. Both in terms of their reasonable noise levels, and their capacity to be modeled at low frequencies, the Gofar fault strong motion instruments performed well, and should be utilized in future studies of earthquake source processes in marine settings.
\end{abstract}




\subsection{Introduction}

Our understanding of the mechanical behavior of active faults comes from combining numerical models and laboratory friction data with detailed observations of earthquake source properties. Models of temperature- and stress-dependent fault zone rheology are evaluated based on the spatial distribution of moment release during earthquakes. Precise determinations of earthquake source locations and focal mechanisms are used to identify lateral and depth transitions from stable creep to unstable fault slip, and the thermal and material variations that control the location of these transitions. In the oceanic lithosphere, interplate and intraplate earthquake observations [Wiens and Stein, 1983; Engeln et al., 1986; Bergman and Solomon, 1988; Stein et al., 1991] support laboratory data that points to a primarily temperature-dependent rheology, where unstable slip during earthquakes is limited to temperatures below $500-600^{\circ} \mathrm{C}$ in the lower crust and upper mantle [Boettcher et al., 2007; He et al., 2007]. The mechanical behavior of oceanic transform faults represents a puzzling exception to this model. Although teleseismic observations have in general shown slip during earthquakes to be confined to the part of the lithosphere predicted to be cooler than $\sim 600^{\circ} \mathrm{C}$ [Engeln et al., 1986; Bergman and Solomon, 1988; Wilcock et al., 1990b; Abercrombie and Ekstrom, 2001], global studies of moment release indicate that most of the strain within the temperaturedependent seismogenic zone at oceanic transforms actually occurs aseismically [Bird et al., 2002; Boettcher and Jordan, 2004]. Far-field teleseismic earthquake observations lack the resolution to characterize the details of along-strike changes in the depth of seismicity that might help to refine rheological models at transform faults, and distinguish between sources of temperature and material heterogeneity that would influence the mechanical behavior.

Unresolved discrepancies that exist between current rheological models for the oceanic lithosphere and observed seismicity at transform faults are likely due in part to the difficulty in making local observations of transform fault earthquakes. In order to 
determine a detailed picture of the width and along-strike character of the seismogenic zone, focal mechanisms and accurate depth estimates of large earthquakes responsible for releasing most of the seismic moment at transforms must be determined from local seismic observations. Ocean bottom seismographs (OBS), necessary to record and locate transform fault earthquakes at the local scale, currently are only deployed for one year periods, owing to power and timing constraints. Characterizing the size and shape of the seismically coupled portion of the lithosphere at transforms requires making local observations of the full range of regional earthquake behavior, including both small-scale seismicity and large earthquakes that slip over a significant portion of the seismogenic area. Because large-scale regional OBS deployments that would provide good azimuthal distribution for many faults at once are not logistically feasible, smaller-scale OBS deployments must target individual faults and try to capture large earthquakes during their short deployment period.

A successful example of a local-scale OBS deployment to observe oceanic transform fault earthquakes was recently completed at the Quebrada-Discovery-Gofar (QDG) faults [McGuire et al., 2009] that offset the East Pacific Rise by approximately $400 \mathrm{~km}$ between 4 and $5^{\circ}$ South. The QDG Transform Fault Experiment had a num gber of advantages over previous investigations of transform fault seismicity. The Gofar and Discovery faults are some of the most seismically prolific in the world, and as such, were likely to sustain several intermediate magnitude $\left(\mathrm{M}_{\mathrm{w}}>4.0\right)$ earthquakes during a yearlong recording period. Furthermore, in addition to 30 conventional OBS, this experiment included an array of 10 OBS equipped with both a broadband seismometer and strongmotion accelerometers, and was thus capable of observing the full range of possible ground motion in the vicinity of the faults. Accelerometer recordings in particular are extremely valuable for observing moderate- to large-magnitude earthquakes at close range. Broadband seismometer deployed within $\sim 20 \mathrm{~km}$ of the Gofar fault clipped during earthquakes as small as $\mathrm{M}_{\mathrm{w}}$ 3.8, whereas the low-gain accelerometers stayed on-scale during the entire deployment period. For this reason, the strong-motion dataset is a 
powerful resource for characterizing the depth and source properties of transform fault earthquakes that illuminate the details of mechanical variation both along-fault and with depth.

To date, only a few examples of seafloor strong-motion observations exist. Many of these have been acquired by scientists aiming to observe the source properties of earthquakes occurring within the subduction zone offshore Japan using cabled accelerometers [Eguchi et al., 1998; Okada et al., 2004; Shinohara et al., 2009]. Although subduction zone accelerometer recordings have been valuable for characterizing seismic activity and linking it to subduction processes [Okada et al., 2004; McGuire et al., 2008], with the exception of pilot experiments [Romanowicz et al., 2006], seafloor recorded strong-motion waveforms have yet to be successfully modeled to determine detailed source properties of local, large-magnitude events.

Here we present results from the first set of strong-motion observations made on the deep seafloor. We describe the quality of acceleration recordings made during the QDG Transform Fault Experiment and evaluate the utility of this dataset for modeling the source properties of transform fault earthquakes. By utilizing local on-scale observations of moderate- to large-magnitude transform fault events that occurred during an earthquake-cycle-ending rupture of a segment of the Gofar fault, we may be capable of determining the along-strike and depth extent of fault slip. This type of information would greatly improve our understanding of fault rheology and the frictional laws governing the distribution and maximum size of transform fault earthquakes. Furthermore, the successful application of seafloor strong-motion observations for modeling earthquake source properties has important long-term implications for future studies of the seismogenic behavior of other marine and continent-oceanic margin faults, such as subduction zones. 


\subsection{QDG Transform Fault Experiment and accelerometer data quality}

The experiment design adopted during the 2008 QDG transform fault deployment was chosen largely based on the location of expected strong ground motion. The relatively short fault lengths and warm thermal structures of the Gofar and Discovery transform faults limit the largest earthquakes to $\mathrm{M}_{\mathrm{w}}$ 6.0-6.2 [McGuire, 2008]. Along these faults, mainshock events have been observed teleseismically throughout the past $20+$ years to occur quasi-periodically with a period of roughly 5 years on several distinct seismic asperities. At the time of the QDG deployment, the westernmost segment of the Gofar fault, termed G3 [Searle, 1983] had last experienced an $M_{w} 6.0$ earthquake in September 2003 , approximately $\sim 4.5$ years earlier, and was thus poised for another large mainshock rupture. With this in mind, seven Woods Hole Oceanographic Institution (WHOI) combined broadband ocean bottom seismometer (OBS) and accelerometer (OBA) recorders were deployed surrounding the western half of the G3 fault, in an array centered just to the west of a $2007 \mathrm{M}_{\mathrm{w}} 6.0$ rupture area (Figure 1a,b). Three OBS with accelerometers were also deployed at the Discovery fault (Figure 1c). Seafloor accelerometers were designed to augment WHOI broadband OBS, providing a "lowgain" sensor, capable of recording strong ground motions at close range up to two times Earth's gravity (g) that would otherwise be clipped on "high-gain" broadband seismometers. These instruments were constructed specifically for this experiment with funding from the W. M. Keck Foundation. The accelerometer utilized three of the six available data-logger channels and is mounted directly onto the OBS frame, whereas the broadband seismometer is decoupled from the instrument frame and sits directly on the sea floor (Figure 2). The sensors chosen for this experiment are Kinemetrics ${ }^{\circledR}$ Episensor ${ }^{\circledR}$ accelerometers, which are engineered with a pressure housing and a simple passive selfleveling device [Barash et al., 1994] to be deployed on the seafloor. During the QDG experiment broadband seismometers and accelerometers recorded at 50 samples/second $(0.02 \mathrm{~Hz})$. 
QDG OBS recorded data throughout most of the year of 2008, and were successfully recovered in January of 2009. On September $18^{\text {th }}, 2008$ an $M_{w} 6.0$ earthquake occurred along the G3 fault, centered within the seafloor strong-motion array. This mainshock event was preceded by a significant foreshock swarm and followed by an aftershock sequence that together included at least four $M_{w}>4.0$ events and an $M_{w}$ 5.2. Several months later, in December of 2008, a second large seismic swarm occurred to the west of the $M_{w} 6.0$ rupture area that included nine $M_{w}>4.0$ and two $M_{w}>5.0$ events. The large ground motions generated by these events saturated the broadband seismometers deployed within $\sim 40 \mathrm{~km}$ surrounding these intermediate-magnitude earthquakes, and seismograms were clipped for most events above an $M_{w}$ 4.0. However, strong-motions were successfully recorded on-scale by the accelerometers.

The utility of the accelerometer data to characterize the strong-motion seismic behavior of the QDG faults is influenced by many factors, some of which are relevant for all seismic recording stations on land and in the oceans, and other factors that are unique to the seafloor environment. The frequency-dependent noise level of seismic recordings is affected by both the installation of the sensor, how well the sensor is coupled to the earth, as well as the natural sources of noise at the deployment site. Ocean bottom sensors face a special challenge in dealing with high noise levels associated with a wide microseism peak that results from the interaction of wind-generated surface gravity waves [Webb, 2002]. In Figures 2-5, ambient noise spectra recorded during a 24-hour period are shown for the accelerometer and broadband seismometer recordings at G-p7 and G-p8. Compared to the seismometers, the accelerometers show increased noise levels at high frequencies $(>0.5 \mathrm{~Hz})$ by $15-20 \mathrm{~dB}$, likely due to their mounting on the OBS frame rather than sitting directly on the seafloor. Particularly prominent features in the accelerometer spectra are peaks in the high-frequency noise (i.e. $\sim 1.1$ and $1.5 \mathrm{~Hz}$ peaks). One possible explanation is that these peaks represent the frequency of higherorder Stoneley/Scholte modes, generated by the scattering of longer wavelength microseisms energy that gets trapped in the sediment layer [Collins et al., 2001; 
Schreiner and Dorman, 1990]. The fact that the the frequencies differ on the seismometer and accelerometer spectra does not favor this explanation however, and an alternate possibility is that the peaks represent sensor coupling resonances [Sutton et al., 1981; Sutton and Duennebier, 1987; Duennebier and Sutton, 1995]. Within the range of the microseism peak observed on land stations $(\sim 0.2-0.5 \mathrm{~Hz})$ the accelerometers perform almost as well as the broadband seismometers. For modeling accelerometer data, this is likely the frequency range that would be used. In these examples, G-p7 is slightly quieter within the $<0.4 \mathrm{~Hz}$ range than G-p8. We would expect lower noise levels to improve the capacity to model strong motion recordings.

\subsubsection{Earthquake-triggered rotation of broadband seismometers and accelerometers}

Prior to the 2008 QDG Transform Fault Experiment, seafloor measurements had been used to record only a few hundred transform fault earthquakes locally, all of which were microearthquakes or small events with moments equivalent to less than $\mathrm{M}_{\mathrm{w}} 3.0$ [Tréhu and Solomon, 1983; Wilcock et al., 1990a]. The dramatic, large-magnitude seafloor earthquake observations made during this study are unprecedented, and it is thus not surprising that these recording would expose new engineering challenges associated with observing large earthquakes at close range on the seafloor. One new challenge of principal importance to efforts of strong-motion waveform modeling is related to the stability of the seafloor instruments during extreme shaking caused by local large earthquakes, and their ability to maintain position, orientation, and seafloor coupling. Seismic observations from the QDG experiment indicate that both the sensor ball containing the broadband seismometer and the entire OBS frame likely experienced some amount of rotation during the $\mathrm{M}_{\mathrm{w}} 6.0$ event. At some stations, rotation also appears to have occurred during a few intermediate-magnitude events. Characterizing the orientation of horizontal seismometer and accelerometer components throughout a deployment is vital for projecting measured horizontal seismograms to radial and transverse components, in order to pick specific seismic phases with superior signal-tonoise. Determining the timing of when a sensor may have moved and by how much is 
also necessary to evaluate which recordings are viable for modeling strong ground motions.

Here, we determine the orientations of horizontal component OBS/OBAs in order to identify recording periods when waveforms may be influenced during episodes of rotation or sliding on the seafloor. Several strategies can be taken to identify the rotation of the horizontal components of the broadband sensor, and the horizontal accelerometer components mounted on the instrument frame. The simplest indicator of rotation of the broadband seismometer is from recordings of the compass heading, located within the broadband sensor ball, that tracks the azimuth orientation of the $\mathrm{BH} 2$ horizontal component. Although metallic instrument parts may play some role in influencing the accuracy of the compass, stable changes in the compass heading at discrete times during the QDG deployment provide convincing evidence for earthquake-triggered rotation at several of the OBS/OBA stations. Specifically, many station headings show distinct changes at the time of the $M_{w} 6.0$ earthquake on September $18^{\text {th }}$ (day 262), and a few stations also appear to rotate at the time of large events associated with the foreshock and December swarms. In Figure 6 the compass readings from the Gofar broadband OBS sensor balls are displayed for the 2008 QDG deployment period, and in Table 1, compass readings at different periods of the 2008 deployment year are listed. In general, compass readings appear to be fairly stable to $+/ 1$ degree before and after the $M_{w} 6.0$ event on day 262 , though all but one station show a rotation of more than 5 degrees at the time of the $\mathrm{M}_{\mathrm{w}} 6.0$ event. Additionally, one station, G-p4, shows a change in compass reading of three degrees on day 245, likely corresponding with a M 4.3 event that occurred at that time, as well as a change of 5 degrees on day 342 , at roughly the same time as a $\mathrm{M}_{\mathrm{w}} 5.4$ swarm event. This observation may indicate that, in general, seafloor coupling of the G-p4 sensor ball was inferior to that at other Gofar stations, which we would expect to affect the overall quality of the recordings at G-p4 throughout the deployment period. 
Table 1. Broadband Seismometer Orientations

\begin{tabular}{|c|c|c|c|c|c|c|}
\hline Station & $\begin{array}{c}\text { BH2 } \\
\text { compass: } \\
\text { prior to } \\
\text { day 262 }\end{array}$ & $\begin{array}{c}\text { BH2 } \\
\text { compass: } \\
\text { following } \\
\text { day 262 }\end{array}$ & $\begin{array}{c}\text { Estimated } \\
\text { rotation } \\
\text { during } \\
\mathrm{M}_{\mathrm{w}} 6.0\end{array}$ & $\begin{array}{c}\mathrm{BH} 2 \text { from } \\
\text { normal mode: } \\
\text { prior to day } \\
262\end{array}$ & $\begin{array}{c}\text { BH2 from } \\
\text { normal } \\
\text { mode: } \\
\text { following } \\
\text { day 262 }\end{array}$ & $\begin{array}{c}\text { Estimated } \\
\text { rotation } \\
\text { during } \\
\mathrm{M}_{\mathrm{w}} 6.0\end{array}$ \\
\hline G-p4 & $86(83)$ & $59(54)$ & -24 & 75 & 338 & -97 \\
\hline G-p5 & 101 & 102 & 1 & 101 & - & - \\
\hline G-p6 & 230 & 200 & -30 & 256 & 175 & -81 \\
\hline G-p7 & 197 & 193 & -4 & 214 & - & - \\
\hline G-p8 & 264 & 283 & 19 & 261 & 308 & 47 \\
\hline G-p9 & 175 & 176 & 1 & 184 & 285 & 101 \\
\hline G-p10 & 233 & 329 & 96 & 291 & 300 & 9 \\
\hline
\end{tabular}

A second strategy for estimating the orientation of the seismometers takes advantage of normal mode synthetic waveforms calculated for teleseismic earthquakes. Teleseismic arrivals observed on the broadband horizontal components are filtered to low frequencies and rotated to an azimuth that provides the minimum error waveform fit to an equivalent point source normal mode synthetic seismogram. The true orientation of the broadband "North" $(\mathrm{BH} 2)$ and "East" $(\mathrm{BH} 1)$ components are then determined by the angle of rotation necessary to arrive at radial and transverse components relative to the azimuth of the teleseismic arrival. Details of the normal mode synthetic waveform modeling technique will be further described in Section 5.3.2. This method is likely to be more accurate than the compass heading for determining seismometer orientations. However, in this study, normal mode derived orientations calculated for the period following the mainshock event were difficult due to inaccuracies in the synthetic seismograms at frequencies greater than $10 \mathrm{mHz}$, the frequency band in which accelerometers typically record teleseisms. The normal mode-determined orientation values shown here in Table 1 are determined using only one teleseismic earthquake, and orientations for G-p5 and G-p7 could not be able to be calculated using the normal mode technique following day 262 . 
Based on both the compass heading and the teleseismic waveform modeling method, some Gofar broadband seismometers appear to be capable of rotating over 90 degrees during the $\mathrm{M}_{\mathrm{w}} 6.0$ event. Because most broadband instruments clipped at the time of the largest earthquakes, disruption in the recordings associated with rotation or translation of the instrument does not necessarily compromise the quality of the dataset. In contrast, rotation of the accelerometers during a large earthquake would invalidate otherwise on-scale recordings of strong ground motion and would inhibit source characterizations using waveform modeling. In Figure 7, we show the relative degree of rotation of the horizontal accelerometer components at G-p10 to illustrate how unstable some of these instruments appear to be during the most seismically active periods of the 2008 deployment. Black dots indicate the preferred rotation angle of a series of events that are part of an earthquake cluster located roughly $10 \mathrm{~km}$ to the west of the G-p10 station (beneath station G-p8). Orientations are calculated from the rotation angle with the best average correlation coefficient between each cluster event and a well-recorded master event that occurred on day 227. For the relatively harmonic arrivals at stations located within the fault-zone, there is a half-cycle ambiguity due to the fact that seismograms from pairs of earthquakes are not identical and a half-cycle shift often produces a high correlation coefficient. Thus a relative rotation angle of 0 or 180 degrees indicates that no rotation relative to the master event on day 227. This figure shows that the G-p10 accelerometer underwent horizontal rotations on days 222 and 262 (the day of the $\mathrm{M}_{\mathrm{w}} 6.0$ earthquake). Paired populations of earthquakes separated by 180 degrees arise due to an ambiguity between the normal and flipped-polarity waveforms within the low frequency band used in this analysis. An additional interesting observation is that during at least one episode of accelerometer rotation (25 degrees on day 222) the broadband seismometer compass at G-p10 registers no orientation change (Figure 6), indicating that either the broadband seismometer instrument ball did not rotate on that day, while the instrument frame with the accelerometer did, or that the compass was not accurate enough to record the rotation. Although this analysis does not provide 
information on the absolute orientation for the accelerometers, it does highlight the extreme time-variability of the OBS/OBA orientations.

In order to estimate the absolute orientations of the accelerometers mounted on the OBS/OBA frame, we determine the angle of rotation relative to the broadband horizontal components recording separately from the sensor ball on the seafloor. This is accomplished by determining the preferred rotation of the horizontal acceleration recordings to match the broadband seismograms during the time of a local or teleseismic event. Acceleration recordings are integrated to velocity, and both the accelerometer and seismometer recordings are bandpass filtered to approximately 0.08-0.2 Hz. Waveforms are then compared for different rotations of the accelerometer, until the rotation azimuth that best matches the broadband orientation is determined as the minimum error waveform fit. Figure 8 shows an example of this waveform fitting exercise, displaying G-p6 rotated accelerometer and broadband recordings of an event before day 262 and an event afterwards, along with the calculated error associated with different rotations of the integrated accelerometer data. Error is calculated by normalizing the amplitude of the rotated, integrated accelerometer recordings, and subtracting this from the observed amplitude-normalized seismograms. The preferred orientation determined for each of the accelerometer stations relative to the broadband seismometers at that station is displayed in Figure 9. These results along with the absolute orientations for the accelerometer BN2 component are listed in Table 2 in terms of degrees East of North. Remarkably, it appears that even after accounting for the rotation of the broadband seismometers (assuming here the compass orientations) the accelerometers mounted on the anchored instrument frame were capable of rotating by as much as 30 degrees on the seafloor during the September $M_{w} 6.0$ event. This result has important implications for assessing our ability to model strong-motion waveforms during the largest local events. 
Table 2. Accelerometer Orientations

\begin{tabular}{|c|c|c|c|c|c|}
\hline Station & $\begin{array}{c}\text { Relative } \\
\text { orientation of } \\
\text { BN2 East of } \\
\text { BH2: prior to } \\
\text { day 262 }\end{array}$ & $\begin{array}{c}\text { Relative } \\
\text { orientation of } \\
\text { BN2 East of } \\
\text { BH2: following } \\
\text { day 262 }\end{array}$ & $\begin{array}{c}\text { Absolute } \\
\text { BN2: prior } \\
\text { to day 262 }\end{array}$ & $\begin{array}{c}\text { Absolute } \\
\text { BN2: } \\
\text { following } \\
\text { day 262 }\end{array}$ & $\begin{array}{c}\text { Estimated } \\
\text { rotation } \\
\text { during } \\
\mathrm{M}_{\mathrm{w}} 6.0\end{array}$ \\
\hline G-p4 & 152 & 185 & 238 & 244 & 6 \\
\hline G-p5 & 99 & 96 & 200 & 198 & -2 \\
\hline G-p6 & 105 & 153 & 335 & 353 & 18 \\
\hline G-p7 & 105 & 148 & 302 & 341 & 39 \\
\hline G-p8 & 81 & 56 & 345 & 339 & -6 \\
\hline G-p9 & 97 & 120 & 272 & 296 & 24 \\
\hline G-p10 & 76 & 14 & 309 & 343 & 34 \\
\hline
\end{tabular}

\subsubsection{Recorded peak ground acceleration}

Assessing how the amplitude of ground motion recorded on the Gofar fault compares to the other strong-motion recordings of similar sized events provides another way to evaluate the ability of seafloor instruments to produce accurate measurements of strong ground motions. Because characterizing ground motion amplitude in the vicinity of large earthquakes is vital for understanding seismic risk, abundant observations of peak ground acceleration (PGA) and peak ground velocity (PGV) have been made for shallow crustal earthquakes using land-based strong-motion arrays. Here, we compare the recorded peak amplitude of several intermediate-magnitude events to curves calculated using two different empirical models [Abrahamson and Silva, 2008; Campbell and Bozorgnia, 2008] from the Pacific Earthquake Engineering Research Center (PEER) Next Generation Attenuation (NGA) Ground Motion Project [Power et al., 2008].

Several factors that affect the amplitude of strong ground motions associated with large crustal earthquakes are taken into account in the empirical PGA models. In Figure 10, estimated PGA and PGV ground motions using the Abrahamson and Silva [2008] 
(AS) and Campbell and Bozorgnia [2008] (CB) models are shown for an $\mathrm{M}_{\mathrm{w}} 5.1$ earthquake. Also shown are the PGA/PGV values measured at each of the strong-motion stations on the Gofar fault during an $\mathrm{M}_{\mathrm{w}} 5.1$ event that occurred as a part of the December swarm on 12/07/08 (day 342) at 08:53:22. All of these peak ground motion models are valid for a vertical strike-slip fault and a shallow velocity structure that is roughly consistent with the structure in the vicinity of the Gofar fault. The PGA curves calculated using this model assume an upper depth of rupture of 2.0 and $5.0 \mathrm{~km}$ beneath the seafloor. A CB empirical model is also shown for comparison, which is valid for a similar fault geometry and a shallow velocity model characterized by a $V_{p}$ of $2.5 \mathrm{~km} / \mathrm{s}$ at $0.72 \mathrm{~km}$ depth, consistent with the velocity model for the Gofar fault described in Chapter 4. Both the AS and CB curves were calculated using the Southern California Earthquake Center (SCEC) Attenuation Relationship Plotter [Field et al., 2003]. In Figure 11 the same modeled and observed PGA and PGV values are plotted for an $\mathrm{M}_{\mathrm{w}}$ 4.3 event that occurred on 9/01/08 16:30:45 (day 245). The consistency between the empirical curves and the observed peak ground motion amplitudes indicate that, in general, the accelerometers were adequately coupled to the seafloor and capable of recording strong ground motions consistent with what has been recorded on land during intermediate-magnitude earthquakes. One example of an exception to this is the high amplitudes recorded by G-p4 during the $\mathrm{M}_{\mathrm{w}} 5.1$ event (Figure 10). It is somewhat unclear what would cause this station to record amplitudes that are an order of magnitude higher than expected for the distance to the rupture at G-p4. One possibility is that unique elastic properties of the shallow subsurface (associated with unconsolidated sediments, for example) could have some amplifying effect on local ground motion at G-p4. Other December events similarly show large amplitudes recorded at G-p4 that would be consistent with local amplification. However it is interesting to note that earlier in the year, the G-p4 station amplitudes are not amplified to the same extent, as indicated by the 4.3 recordings in Figure 11. Peak ground motions recorded during the $M_{w} 6.0$ earthquake are also consistent with strong-motion amplitudes observed by land-based strong-motion arrays during magnitude $\sim 6.0$ earthquakes. The closest station to the 
centroid of the earthquake, G-p6, recorded PGA values on the order of $0.3 \mathrm{G}$, similar to strong-motion amplitudes recorded at a distance of 1-3 km range during the $2004 \mathrm{M}_{\mathrm{w}} 6.0$ Parkfield earthquake in southern California [Liu et al., 2006].

\subsection{Modeling Strong-motion Recordings for Earthquake Source Properties}

Determining source parameters such as focal mechanism, focal depth, and seismic moment is key for characterizing the spatial and temporal evolution of seismic rupture properties along the Gofar fault. One common way to estimate these parameters for intermediate magnitude earthquakes is by using a regional waveform inversion technique that determines the best-fitting double-couple source parameters through a grid search over moment, mechanism (fault strike, dip, and rake), epicenter location and focal depth [Du et al., 2003]. To date only a few examples of source parameters determined from modeled OBS waveform data exist [Romanowicz et al., 2006], and strong-motions seafloor data has yet to be successfully modeled using typical waveform inversion techniques. Here, we follow a simplified strategy to test whether acceleration waveforms recorded on the Gofar fault are capable of being modeled to determine earthquake source parameters using a regional waveform inversion. This requires matching both waveform amplitude and shape of observed strong-motion seismograms with synthetic seismograms calculated for a possible range of source parameters. In order to present a simplified evaluation of the capability of the strong-motion data recorded at Gofar to be successfully modeled, we fit integrated accelerometer recordings from two earthquakes that occurred during the Gofar OBS deployment to synthetic waveforms calculated using available estimates of the point-source parameters. Although here we do not perform a full grid search inversion, we specify the focal mechanism to match the best double-couple from the Global Centroid Moment Tensor (CMT) catalog, and search over depth and a narrow range of earthquake durations.

\subsubsection{Waveform modeling strategy}


Synthetic seismograms are calculated for a point-source in a layered half space by first determining Green's functions using the frequency-wavenumber (f-k) method [Haskell, 1964; Wang and Herrmann, 1980; Zhu and Rivera, 2002]. In this discussion, we explore the source depth of Gofar earthquakes by cycling through depth dependent Green's functions for a range of plausible source depths. We calculate Green's functions using the FK code developed by Lupei Zhu [Zhu and Rivera, 2002]. This incorporates a 1D velocity and attenuation model and a set of fixed observation ranges specified assuming an earthquake location from locally-recorded body-wave relative relocations [McGuire et al., submitted to Nature Geoscience, 2011]. We use a velocity model consistent with the P-wave model for the inner $10 \mathrm{~km}$ of the fault zone, determined from arrival time tomography across the Gofar fault (presented in Chapter 4). S-wave velocities are specified in this model assuming a constant $\mathrm{V}_{\mathrm{p}} / \mathrm{V}_{\mathrm{s}}$ of 1.73 . Table 3 presents the velocity model used to represent the 1D layered half-space, along with the attenuation and density models that were taken from the $\mathrm{Q}_{\mathrm{p}}$ model of Vera et al. [1990] for ESP1 in young oceanic crust. $\mathrm{Q}_{\mathrm{s}}$ is specified by assuming $\mathrm{Q}_{\mathrm{p}} / \mathrm{Q}_{\mathrm{s}}=2$.

Table 3. Velocity/Attenuation Model Used for $f$ - $k$ Waveform Modeling

\begin{tabular}{cccccc} 
Layer Thickness $(\mathrm{km})$ & $\mathrm{V}_{\mathrm{s}}$ & $\mathrm{V}_{\mathrm{p}}$ & Density $\left(\mathrm{kg} / \mathrm{m}^{3}\right)$ & $\mathrm{Q}_{\mathrm{s}}$ & $\mathrm{Q}_{\mathrm{p}}$ \\
\hline 3.0 & $1 \mathrm{e}-5$ & 1.5 & 1.03 & 0 & $1 \mathrm{e} 4$ \\
0.25 & 1.5 & 2.5 & 2.2 & 25 & 50 \\
0.25 & 2.3 & 4.0 & 2.2 & 25 & 50 \\
0.50 & 2.9 & 5.0 & 2.2 & 25 & 50 \\
1.00 & 3.4 & 5.8 & 2.2 & 25 & 50 \\
1.00 & 3.6 & 6.2 & 2.2 & 37.5 & 75 \\
2.30 & 4.0 & 7.0 & 2.9 & 150 & 300 \\
3.00 & 4.6 & 8.0 & 3.0 & 150 & 300 \\
14.0 & 4.7 & 8.1 & 3.3 & 250 & 500 \\
- & 4.7 & 8.1 & 3.3 & 250 & 500 \\
\hline
\end{tabular}

Surface velocity seismograms are calculated for a double-couple point source as 
the convolution of the source-time function with a linear combination of the Green's functions, whose coefficients are functions of the fault strike, dip and rake. Source parameters used here, including moment magnitude, strike, dip, and rake, were chosen based on the Global CMT solutions when they exist (EVT 1; Table 4), or otherwise by assuming a simple vertical strike-slip focal mechanism (EVT 2). The source-time functions used here were symmetric, with the rise time equal to half of the total duration (i.e. a triangular source-time function). Keeping other source parameters fixed, we investigated a range of source durations and event depths. Duration has a large effect on the amplitude of the synthetic waveform, and the preferred duration values shown here were chosen from comparison of the data to synthetic seismograms as the best-fit waveform over a range of duration values ranging from 0.05 to $1.5 \mathrm{~s}$, with the range appropriate for the moment of the event.

\subsubsection{Waveform modeling results}

Before being compared to synthetic seismograms, recorded broadband acceleration data (sample rate of $50 \mathrm{~Hz}$ ) BN1 and $\mathrm{BN} 2$ components were rotated to transverse and radial components, assuming the absolute orientations listed in Section 5.2.1. Acceleration was then integrated to velocity and both the synthetic and observed data were bandpass filtered using a zero-phase Butterworth filter from 0.1-0.4 Hz. The fit error of the synthetic and observed waveforms is calculated as the L2-norm [Zhao and Helmberger, 1994]. Figures 12 and 13 show observed and synthetic waveforms for the the minimumerror depth synthetic from a search over depths from $0-18 \mathrm{~km}$ beneath the seafloor. Source parameters used in the $F K$ synthetic seismogram code to model these waveforms are displayed in Table 4. The amplitude of the unfiltered synthetic waveforms is also compared to the observed and empirical PGA/PGV curves in Figures $10\left(\mathrm{M}_{\mathrm{w}} 5.1\right)$ and 11 $\left(M_{w} 4.3\right)$. As is clear from the amplitude comparison shown in those figures, the G-p4 stations recorded anomalously high amplitudes during both the both events. Even in the low frequency range used for the f-k modeling, G-p4 seismograms exhibited an order of magnitude higher amplitudes than the synthetics, and fitting modeled waveforms to 
recordings at this station was not possible.

Table 4. Source Properties of Modeled Gofar Earthquakes

\begin{tabular}{|c|c|c|c|c|c|c|c|}
\hline $\begin{array}{l}\text { Event and } \\
\text { Source Time }\end{array}$ & Epicenter & $\mathrm{M}_{\mathrm{w}}$ & $\begin{array}{l}\text { Strike } \\
(\operatorname{deg} \mathrm{E} \text { of } \mathrm{N})\end{array}$ & Dip & Rake & Duration* (s) & $\begin{array}{l}\text { Depth* } \\
\text { (km b.s.f.) }\end{array}$ \\
\hline $\begin{array}{l}\text { EVT 1 } \\
\text { 12/07/08 } \\
08: 53: 22\end{array}$ & $\begin{array}{l}-4.4749 \\
-106.2945\end{array}$ & $5.1^{t}$ & $102^{t}$ & $76^{t}$ & $6^{t}$ & 0.3 & 5.0 \\
\hline $\begin{array}{l}\text { EVT } 2 \\
9 / 01 / 08 \\
16: 30: 45\end{array}$ & $\begin{array}{l}-4.5390 \\
-106.0965\end{array}$ & 4.3 & 100 & 90 & 0 & 0.1 & 4.0 \\
\hline
\end{tabular}

* free parameters explored here

${ }^{t}$ parameter used from Global CMT solution

Using these source models, synthetic seismograms fit the observed strong-motion data quite well on some stations and components (i.e. transverse components at most stations), whereas several do a poor job of matching observed data in shape or amplitude. In particular, the amplitude of the synthetic radial-component under-predict the observed amplitudes at several stations for EVT 1, and to a lesser degree, for the EVT 2 radialcomponent. At a few stations, there appears to be a nearly monochromatic coda several seconds after the main arrival (i.e. G-p8 during EVT2) that is not apparent in the synthetics. Stations G-p5, G-p7, and G-p9 consistently show observed waveforms that match the synthetics quite well.

Several factors could be responsible for the poor fit exhibited by some of the synthetics calculated here. The poor fit of the radial-component seismograms is likely related to the fact that the on-fault stations lie on a nodal plane of the radial component of displacement for a strike-slip double-couple source. Inaccuracies in the velocity model could cause unusual amplifications or changes in the phase shape that will be difficult to model using this framework, and would provide for large errors relative to the small amplitude of radial component seismograms located on the fault. Small errors in the focal mechanism, particularly inaccuracy in the assumed strike of the fault, could also cause significant error in radial-component seismogram amplitude for stations located on 
the fault. 3D effects, which would be expected within the central fault zone at Gofar, may also be responsible for some of the misfit between the synthetics and observed data. In California, high-amplitude $\mathrm{SH}$ wave pulses have been recorded by strong motion arrays and attributed to horizontal bending and focusing of $\mathrm{SH}$ waves associated with lateral crustal velocity contrast across the San Andreas Fault [Lomax and Bolt, 1992]. Amplification of coda thought to arise from scattering and focusing of waves within lowvelocity basin fill is also common in strong motion recordings in California [PHILLIPS and $A K I, 1986]$. It may be possible to improve the waveform fit significantly at several Gofar stations by modifying the assumed velocity model or Q model, the latter of which has an important effect on synthetic waveform amplitude.

As shown by the noise spectra (Figures 2-5), different stations will have different signal-to-noise ratios due to site effects and differences in coupling. This could be the cause of the consistently poorer waveform fits at certain stations. Another likely, and more easily-resolved cause for some of the difficulty fitting observed and synthetic waveforms here could be inaccuracy in the source epicenter or focal mechanism we assume in this simple modeling exercise. Because we do not search over most of the source parameters, changes in the modeled radiation pattern associated with a slightly different focal mechanism could provide for significantly better waveform fits. Relative amplitude discrepancies between the horizontal components may also result from a poorly determined instrument orientation.

In general, this simple modeling exercise produced encouraging results for evaluating the quality of these strong-motion records. Though not all recordings are well-modeled with the estimated source parameters used here, the amplitude and shape of the waveforms on multiple components are quite similar. Based on this assessment, it seems likely that regional waveform inversions will be possible to determine accurate source properties for intermediate-magnitude earthquakes using Gofar seafloor strongmotion records. 


\subsubsection{Modeling normal mode teleseismic events with seafloor accelerometer data}

To evaluate the performance of the accelerometers for low-frequency applications, we present a comparison of the vertical data recorded by all ten accelerometers for an $\mathrm{M}_{\mathrm{w}} 6.1$ earthquake on the Wilkes transform (10/30/2008) with synthetic seismograms. The synthetic seismograms in this analysis were calculated for a point source in both space and time through normal mode summation for the PREM earth model [Dziewonski and Anderson, 1981], corrected for 3-D elastic structure using the degree 12 aspherical model of Su et al. [1994] and the asymptotic approximations of Woodhouse \& Dziewonski [1984]. We also corrected fundamental modes above $7 \mathrm{mHz}$ for smaller scale heterogeneity using the degree 40 phase velocity maps of Ekström et al. [1997]. The source is specified by a centroid location, centroid time and moment tensor from the Global CMT catalogue. Figure 14 shows a comparison of the synthetic and data seismograms at true amplitudes for the Rayleigh wave recorded on all ten accelerometers. Both the data and synthetics have been bandpass filtered between 20 and $35 \mathrm{mHz}$. The synthetic seismograms for the Gofar stations predict the observed waveforms almost exactly while for the 3 stations on Discovery the Rayleigh-wave amplitude is slightly over predicted. This comparison demonstrates the fidelity of the accelerometer recordings in the low-frequency surface-wave band.

\subsection{Summary}

We have presented the first example of seafloor strong-motion observations made in the deep ocean during the 2008 QDG Transform Fault Experiment. Moderate- to largemagnitude earthquakes on the Gofar fault were well recorded by a local array of 10 OBS with strong motion accelerometers mounted on the instrument frame. We have determined that in general, these recordings are of high quality. Peak amplitudes recorded by the accelerometers during several earthquakes are consistent with those 
recorded on land-based strong-motion arrays. Initial modeling results indicate that the accelerometers for the most part, were well coupled to the seafloor, and that strong ground motions recorded during $\mathrm{M}_{\mathrm{w}} 4$ and 5 earthquakes will be suitable for waveform inversions in the future. However, evidence for multiple episodes of earthquaketriggered rotation of both the broadband seismometer instrument ball and the accelerometer mounted on the OBS frame indicates that some large earthquake records will likely be disordered and not capable of being modeled. Because the $M_{w} 6.0$ event appears to have triggered rotation at all 7 Gofar stations, it is unlikely that waveform inversions will be possible to determine the slip characteristics of that earthquake.

These results represent an exciting new development in seafloor seismic observation capabilities. Never before have local recordings been made of an oceanic transform fault rupture process. Strong-motion observations from the Gofar fault have the potential to illuminate new details of the seismic slip distribution that may improve mechanical models of transform faults in the ocean and the continental setting. Based on our modeling results, it appears that these new strong-motion recordings are capable of being modeled using typical regional waveform inversion techniques. In time, this experiment may open the door for future deployments of ocean bottom accelerometers, to be used to characterize seismic slip phenomena with the advantage of offshore strong-motion observations. 


\subsection{Bibliography}

Abercrombie, R. E., and G. Ekstrom (2001), Earthquake slip on oceanic transform faults, Nature, 410(6824), 74-77.

Abrahamson, N., and W. Silva (2008), Summary of the Abrahamson \& Silva NGA ground-motion relations, Earthquake Spectra, 24, 67.

Barash, T. W., C. G. Doll, J. A. Collins, G. H. Sutton, and S. C. Solomon (1994), Quantitative evaluation of a passively leveled ocean bottom seismometer, Marine Geophysical Research, 16(5), 347-363.

Bergman, E. A., and S. C. Solomon (1988), Transform fault earthquakes in the North Atlantic: Source mechanisms and depth of faulting, Journal of Geophysical Research, 93(B8), 9027-9057.

Bird, P., Y. Y. Kagan, and D. D. Jackson (2002), Plate tectonics and earthquake potential of spreading ridges and oceanic transform faults, Plate Boundary Zones, 203-218.

Boettcher, M. S., and T. H. Jordan (2004), Earthquake scaling relations for mid-ocean ridge transform faults,

Boettcher, M. S., G. Hirth, and B. Evans (2007), Olivine friction at the base of oceanic seismogenic zones,

Campbell, K. W., and Y. Bozorgnia (2008), Empirical ground motion model for shallow crustal earthquakes in active tectonic environments developed for the NGA project, in 14 th World Conference on Earthquake Engineering: Innovation Practice Safety.

Collins, J., F. Vernon, J. Orcutt, R. Stephen, K. Peal, F. Wooding, F. Spiess, and J. Hildebrand (2001), Broadband seismology in the oceans: lessons from the ocean seismic network pilot experiment, Geophys. Res. Lett, 28(1), 49-52.

Du, W., W. Y. Kim, and L. R. Sykes (2003), Earthquake source parameters and state of stress for the northeastern United States and southeastern Canada from analysis of regional seismograms, Bulletin of the Seismological Society of America, 93(4), 1633.

Duennebier, F. K., and G. H. Sutton (1995), Fidelity of ocean bottom seismic observations, Marine Geophysical Researches, 17(6), 535-555.

Dziewonski, A. M., and D. L. Anderson (1981), Preliminary reference Earth model* 1 , Physics of the earth and planetary interiors, 25(4), 297-356. 
Eguchi, T., Y. Fujinawa, E. Fujita, S. I. Iwasaki, I. Watabe, and H. Fujiwara (1998), A real-time observation network of ocean-bottom-seismometers deployed at the Sagami trough subduction zone, central Japan, Marine Geophysical Research, 20(2), 73-94.

Ekstrlöm, G., J. Tromp, and E. W. F. Larson (1997), Measurements and global models of surface wave propagation, Journal of geophysical research, 102(B4), 8137-8157.

Engeln, J. F., D. A. Wiens, and S. Stein (1986), Mechanisms and depths of Atlantic transform earthquakes, Journal of Geophysical Research, 91(B1), 548-577.

Field, E. H., T. H. Jordan, and C. A. Cornell (2003), OpenSHA: A developing community-modeling environment for seismic hazard analysis, Seismological Research Letters, 74(4), 406.

Haskell, N. (1964), Total energy and energy spectral density of elastic wave radiation from propagating faults, Bulletin of the Seismological Society of America, 54(6A), 1811.

He, C., Z. Wang, and W. Yao (2007), Frictional sliding of gabbro gouge under hydrothermal conditions, Tectonophysics, 445(3-4), 353-362.

Liu, P., S. Custodio, and R. J. Archuleta (2006), Kinematic inversion of the 2004 M 6.0 Parkfield earthquake including an approximation to site effects, Bulletin of the Seismological Society of America, 96(4B), S143.

Lomax, A., and B. A. Bolt (1992), Broadband waveform modelling of anomalous strong ground motion in the 1989 Loma Prieta earthquake using three-dimensional geologic structures, Geophysical research letters, 19(19), 1963-1966.

McGuire, J. J. (2008), Seismic cycles and earthquake predictability on East Pacific Rise transform faults, Bulletin of the Seismological Society of America, 98(3), 1067.

McGuire, J. J., J. A. Collins, E. C. Roland, and M. D. Behn (2009), Seismicity of the Quebrada, Discovery, and Gofar Transform Faults, [online] Available from: http://adsabs.harvard.edu/abs/2009AGUFM.S52A..07M (Accessed 26 September 2011)

McGuire, J. J., F. J. Simons, and J. A. Collins (2008), Analysis of seafloor seismograms of the 2003 Tokachi-Oki earthquake sequence for earthquake early warning, Geophysical Research Letters, 35, doi:10.1029/2008GL033986. [online] Available from: http://europa.agu.org.libproxy.mit.edu/?view=results (Accessed 30 September 2011) 
Okada, T., K. Sakoda, T. Matsuzawa, R. Hino, A. Hasegawa, S. Sakai, and T. Kanazawa (2004), Characteristic seismic activity in the subducting plate boundary zone off Kamaishi, northeastern Japan, revealed by precise hypocenter distribution analysis using ocean-bottom seismometers, Geophys. Res. Lett, 31(10.1029).

PHILLIPS, W. S., and K. AKI (1986), Site amplification of coda waves from local earthquakes in central California, BULLETIN OF THE SEISMOLOGICAL SOCIETY OF AMERICA, 76(3), 627-648.

Power, M., B. Chiou, N. Abrahamson, Y. Bozorgnia, T. Shantz, and C. Roblee (2008), An overview of the NGA project, Earthquake Spectra, 24, 3.

Romanowicz, B., D. Stakes, D. Dolenc, D. Neuhauser, P. McGill, R. Uhrhammer, T. Ramirez, and others (2006), The Monterey Bay broadband ocean bottom seismic observatory, Annals of geophisycs.

Schreiner, A. E., and L. R. M. Dorman (1990), Coherence lengths of seafloor noise: Effect of ocean bottom structure, The Journal of the Acoustical Society of America, 88, 1503.

Searle, R. (1983), Multiple, closely spaced transform faults in fast-slipping fracture zones, Geology, 11(10), 607.

Shinohara, M., T. Yamada, and T. Kanazawa (2009), Development of Ocean Bottom Accelerometer for Observation of Strong Motion on Sea Floor, Journal of the Japan Society for Marine Surveys and Technology, 21(2).

Stein, S., A. Pelayo, R. Wortel, S. Stein, L. Fleitout, S. Murrell, J. Bull, E. Jones, and M. Zoback (1991), Seismological Constraints on Stress in the Oceanic Lithosphere [and Discussion], Philosophical Transactions of the Royal Society of London. Series A: Physical and Engineering Sciences, 337(1645), 53.

Su, W., R. L. Woodward, and A. M. Dziewonski (1994), Degree 12 model of shear velocity heterogeneity in the mantle, Journal of Geophysical Research, 99(B4), 6945-6980.

Sutton, G. H., and F. K. Duennebier (1987), Optimum design of ocean bottom seismometers, Marine Geophysical Research, 9(1), 47-65.

Sutton, G., F. Duennebier, B. Iwatake, J. Tuthill, B. Lewis, and J. Ewing (1981), An overview and general results of the Lopez Island OBS experiment, Marine Geophysical Research, 5(1), 3-34. 
Tréhu, A. M., and S. C. Solomon (1983), Earthquakes in the Orozco transform zone: seismicity, source mechanisms, and tectonics, Journal of Geophysical Research, 88(B10), 8203-8225.

Vera, E. E., J. C. Mutter, P. Buhl, J. A. Orcutt, A. J. Harding, M. E. Kappus, R. S. Detrick, and T. M. Brocher (1990), The structure of 0-to 0.2-my-old oceanic crust at $9 \mathrm{~N}$ on the East Pacific Rise from expanded spread profiles, Journal of Geophysical Research, 95(B10), 15529.

Wang, C., and R. Herrmann (1980), A numerical study of P-, SV-, and SH-wave generation in a plane layered medium, Bulletin of the Seismological Society of America, 70(4), 1015.

Webb, S. C. (2002), 19 Seismic noise on land and on the sea floor, International Geophysics, 81, 305-318.

Wiens, D. A., and S. Stein (1983), Age dependence of oceanic intraplate seismicity and implications for lithospheric evolution, Journal of Geophysical Research, 88, 6455-6468.

Wilcock, W. S. ., G. M. Purdy, and S. C. Solomon (1990a), Microearthquake evidence for extension across the Kane transform fault, Journal of Geophysical Research, 95(B10), 15439-15.

Wilcock, W. S. D., G. Purdy, and S. C. Solomon (1990b), Microearthquake evidence for extension across the Kane transform fault, Journal of Geophysical Research, 95(B10), 15439-15.

Woodhouse, J. H., and A. M. Dziewonski (1984), Mapping the upper mantle: threedimensional modeling of Earth structure by inversion of seismic waveforms, Journal of Geophysical Research, 89(B7), 5953-5986.

Zhao, L.-S., and D. V. Helmberger (1994), Source estimation from broadband regional seismograms, BULLETIN OF THE SEISMOLOGICAL SOCIETY OF AMERICA, 84(1), 91-104.

Zhu, L., and L. A. Rivera (2002), A note on the dynamic and static displacements from a point source in multilayered media, Geophysical Journal International, 148(3), 619-627. 

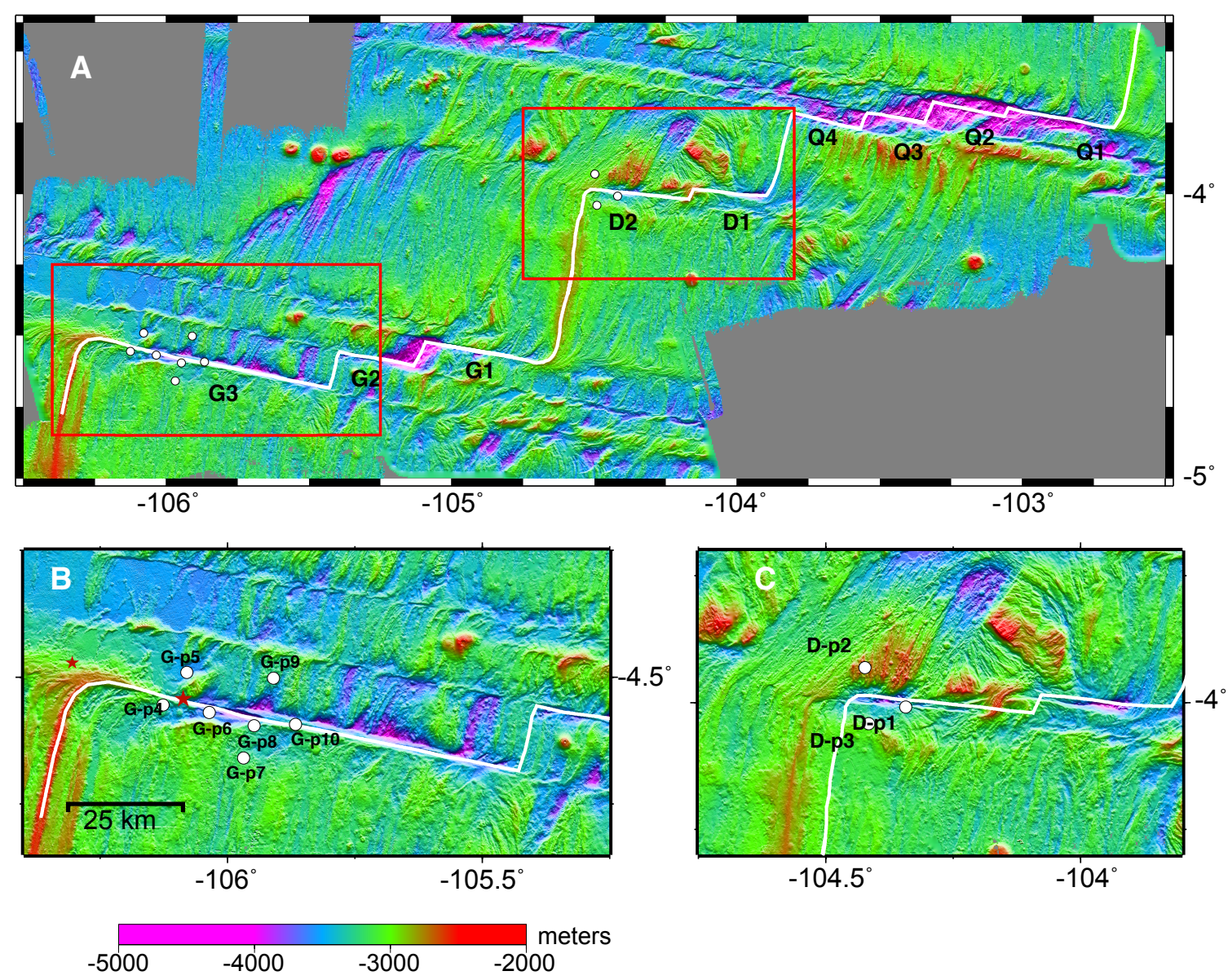

Figure 1: A) Regional map of Quebrada (Q1-Q4) Discovery (D1 and D2), and Gofar (G1-G3) faults. White line shows the plate boundary as indicated by pseudo-sidescan backscatter [Langmuir and Forsyth, 2007]. White circles show the location of OBS equipped with both broadband seismometer and strong-motion accelerometer. Red boxes show outline of maps in (B) and (C). B) Gofar, G3 fault segment that ruptured during the 2008 OBS deployment. White circles again show location of OBS/OBA stations. Red stars show the location of two events modeled here: EVT1 on 12/07/08 (western event) and EVT2 on 9/1/08 (eastern). C) Discovery fault with three OBS/OBA stations (white circles). 


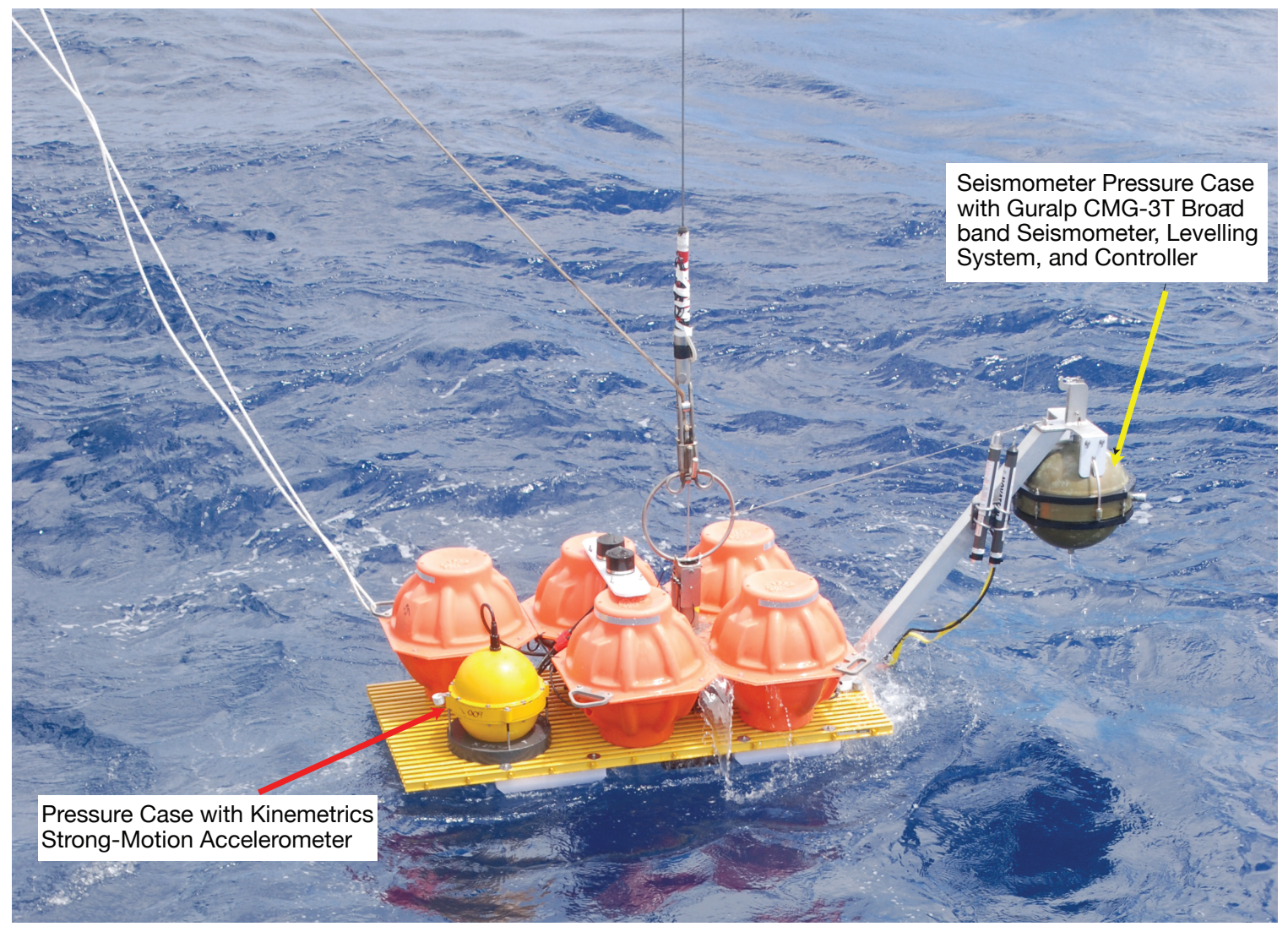

Figure 2: Photograph of OBS with both broadband seismometer and strong-motion accelerometer mounted on the OBS frame. The pressure case that contains the broadband seismometer (grey-green) is released from the sensor arm after the instrument reaches the seafloor. The seismometer thus sits directly on the seafloor and is decoupled from the instrument frame. The accelerometer (yellow pressure case) remains attached to the OBS frame throughout the deployment period. 

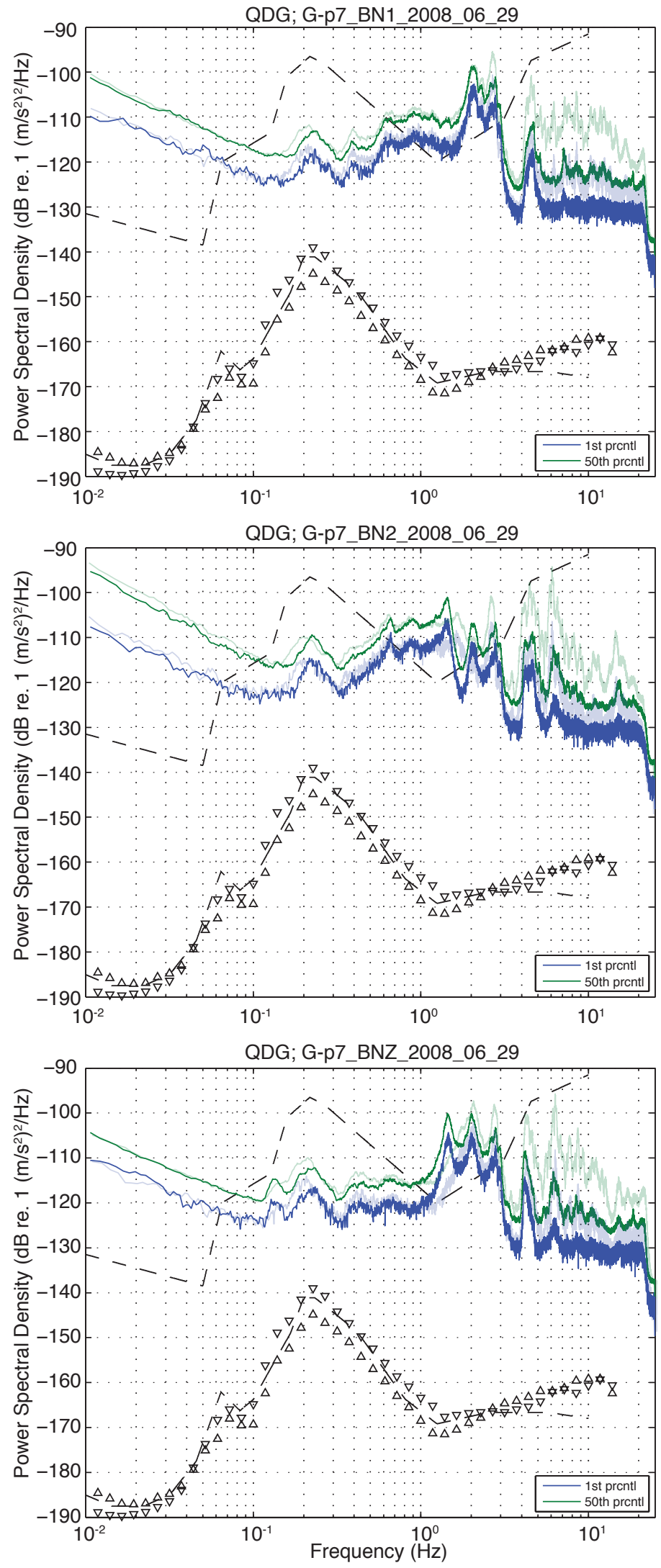

Figure 3: A) Horizontalcomponent, BN1 B) horizontal component, BN2 and C) vertical-component BNZ acceleration spectra from the accelerometer at G-p7. Dark blue and green lines show the 1 st percentile (i.e. quietest $1 \%$ ) and 50th percentile (median) power spectral density noise levels calculated by averaging the spectra of 131 contiguous accelerogram windows over a day of recordings on $6 / 29 / 2008$. Light green and blue lines show the same calculation for $9 / 11 / 2008$. Dashed grey lines show the low- and high- noise plots of Peterson [1993]. Triangles show the Berger, et al. [2004] GSN noise models. 

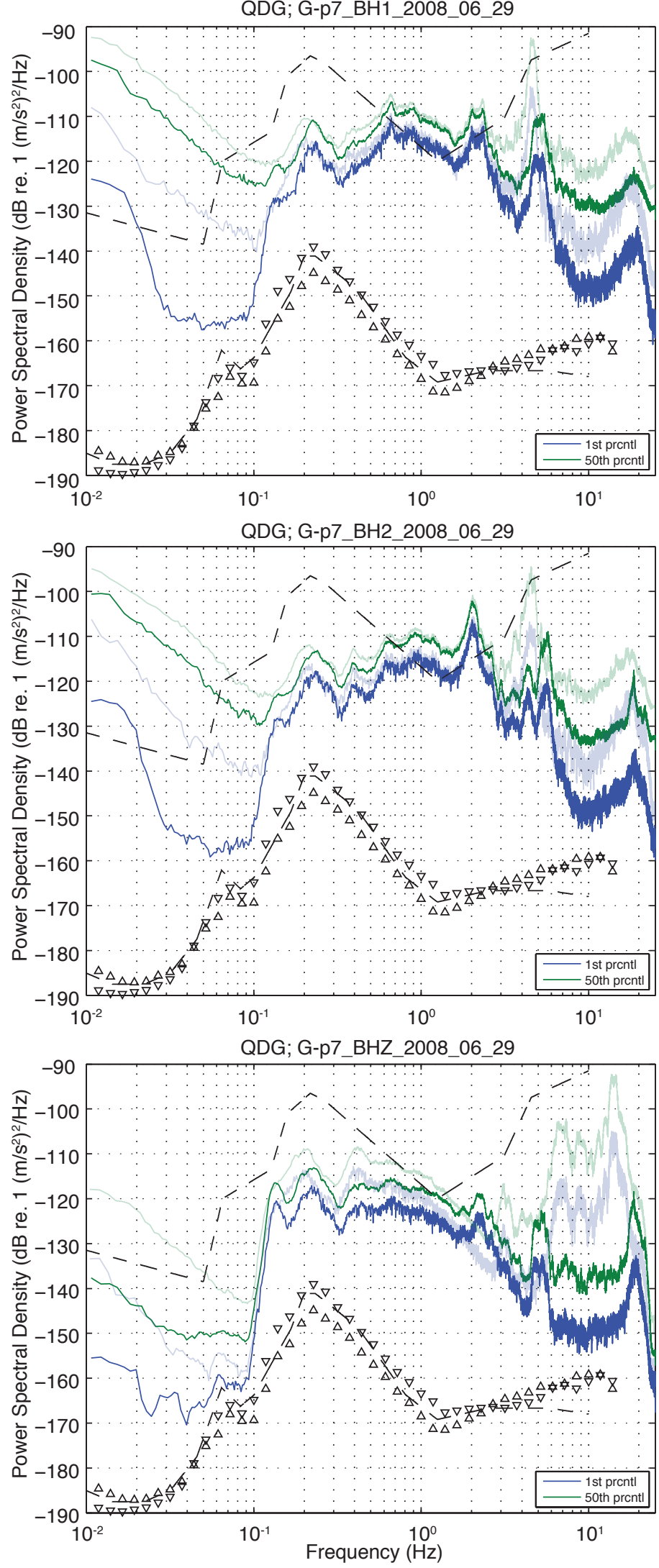

Figure 4: A) Horizontalcomponent, BH1 B) horizontal component, $\mathrm{BH} 2$ and $\mathrm{C}$ ) vertical-component $\mathrm{BHZ}$ acceleration spectra from the broadband seismometers at G-p7. See Figure 3 caption for an explanation of individual power spectral density noise level curves. 

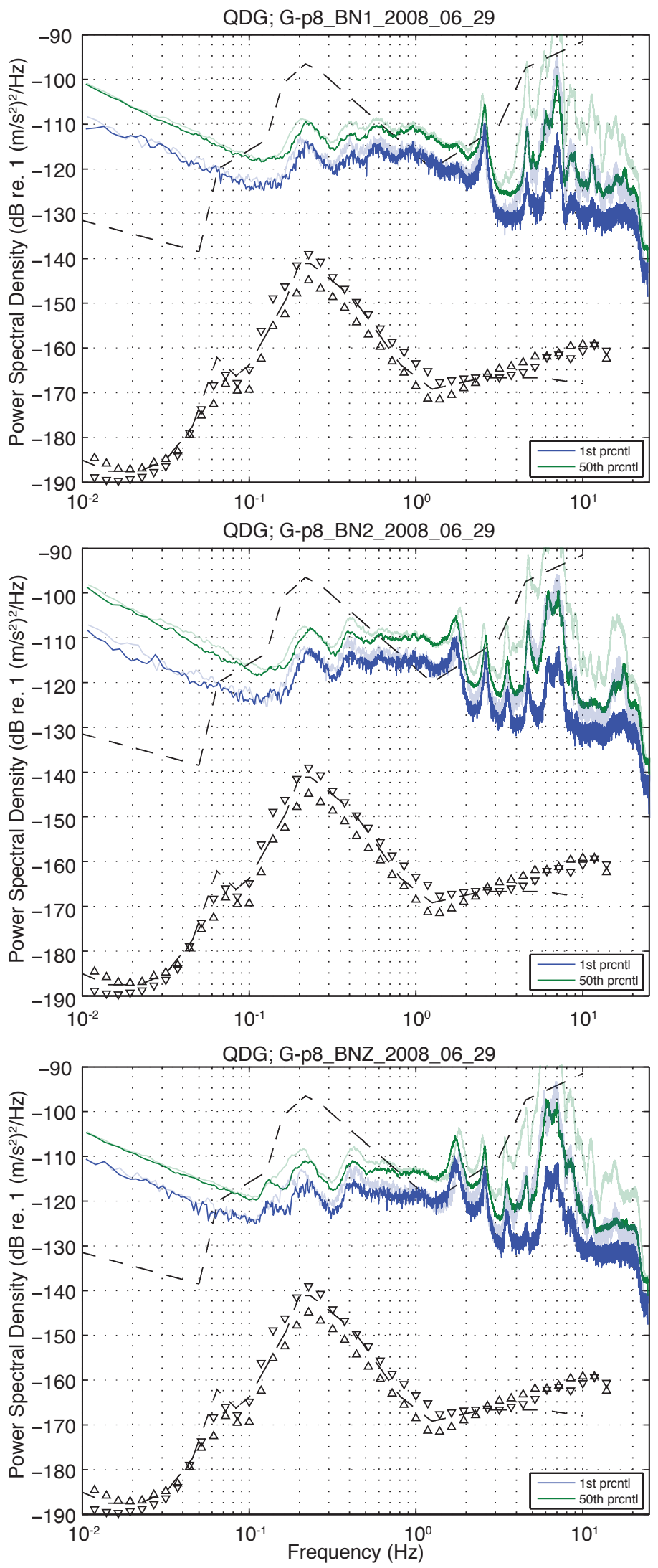

139
Figure 5: A) Horizontalcomponent, BN1 B) horizontal component, BN2 and C) vertical-component $\mathrm{BNZ}$ acceleration spectra from the accelerometers at G-p8. Dark blue and green lines show the 1 st percentile (i.e. quietest $1 \%$ ) and 50th percentile (median) power spectral density noise levels calculated by averaging the spectra of 131 contiguous accelerogram windows over a day of recordings on 6/29/2008. Light green and blue lines show the same calculation for $9 / 11 / 2008$. Dashed grey lines show the low- and high- noise plots of Peterson [1993]. Triangles show the Berger, et al. [2004] GSN noise models. 

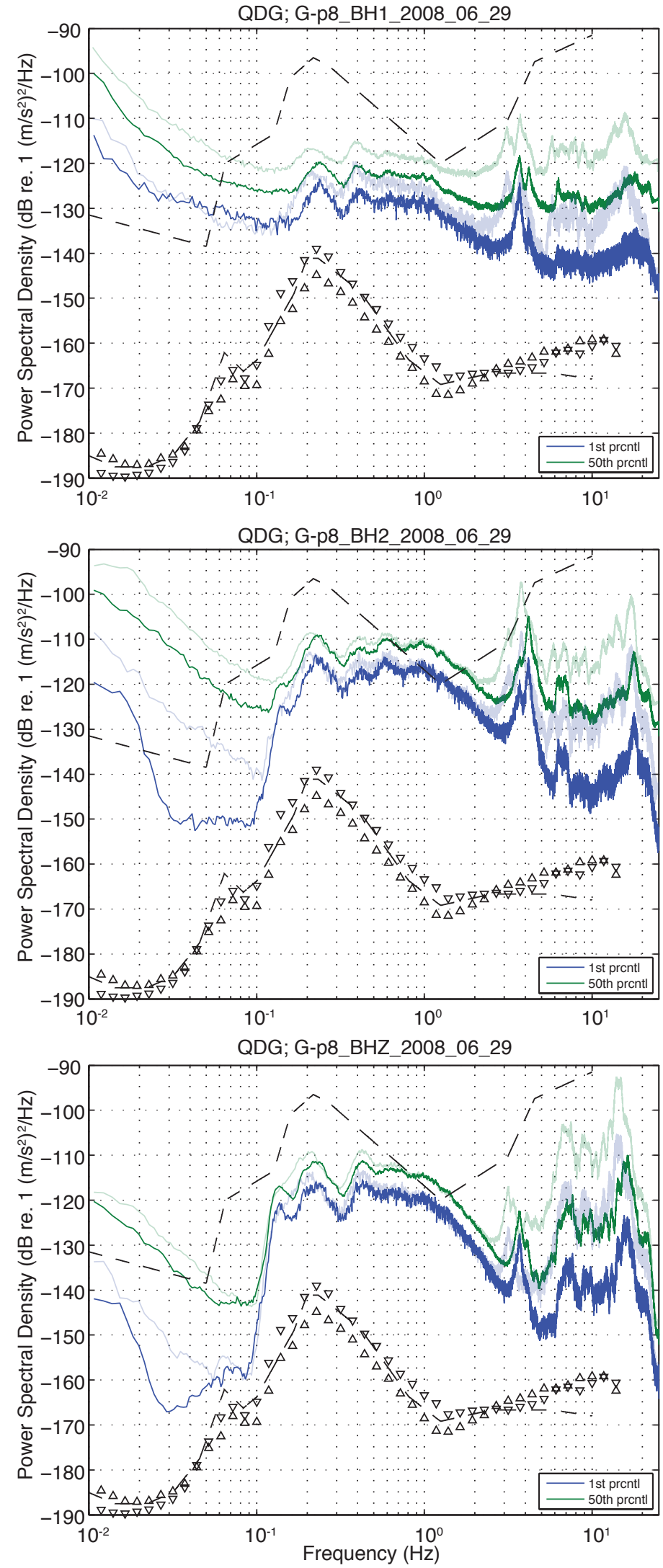

Figure 6: A) Horizontalcomponent, BH1 B) horizontal component, $\mathrm{BH} 2$ and $\mathrm{C}$ ) vertical-component $\mathrm{BHZ}$ acceleration spectra from the broadband seismometers at G-p8. See Figure 5 caption for an explanation of individual power spectral density noise level curves. 


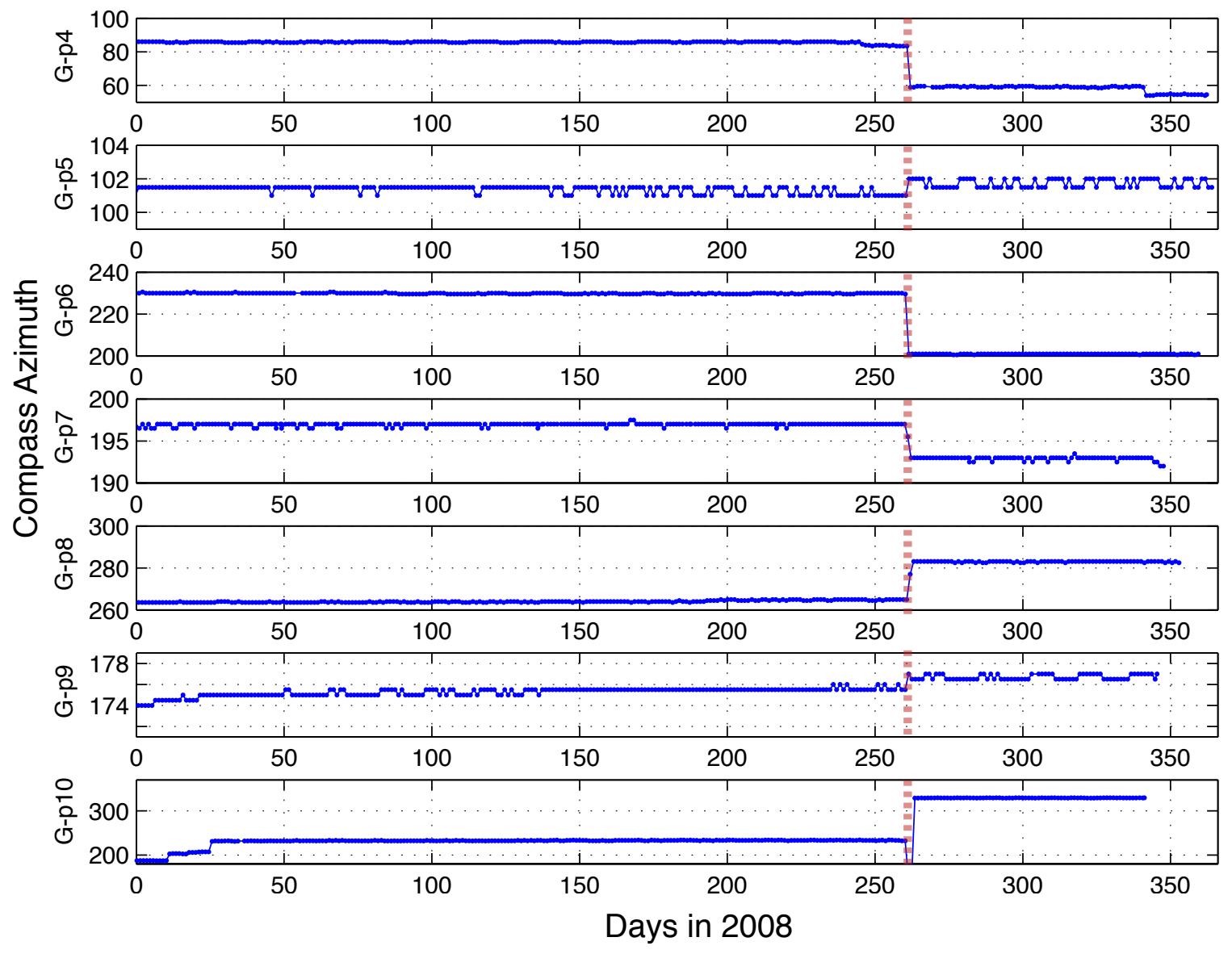

Figure 7: Azimuth readings for the $\mathrm{BH} 2$ component of the Gofar OBS stations with accelerometers, from the compass mounted within the broadband seismometer sensor ball. Red dashed line shows the time of the Mw 6.0 Gofar earthquake. 


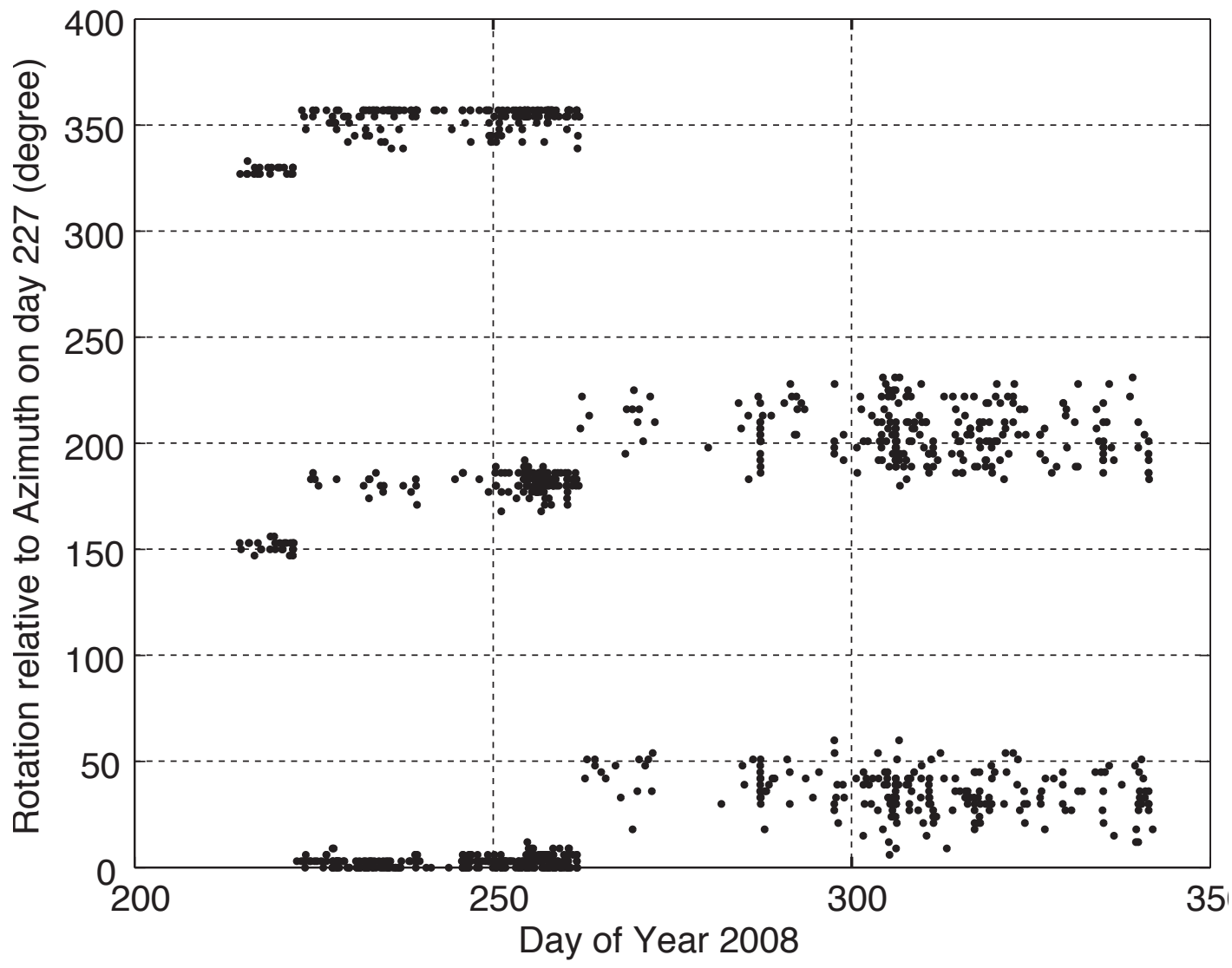

Figure 8: Preferred rotation angle observed at the G-p10 station of events in an earthquake cluster that is located roughly $10 \mathrm{~km}$ to the west (roughly under the G-p8 station). The relative azimuth calculation method is described in the text, and is relative to a well-recorded master event that occurred on day 227. Relative rotation angle of 0 or 180 degrees indicates that no rotation has happened relative to the master event on day 227. 
a) G-p6 - 2008129 11:47:00
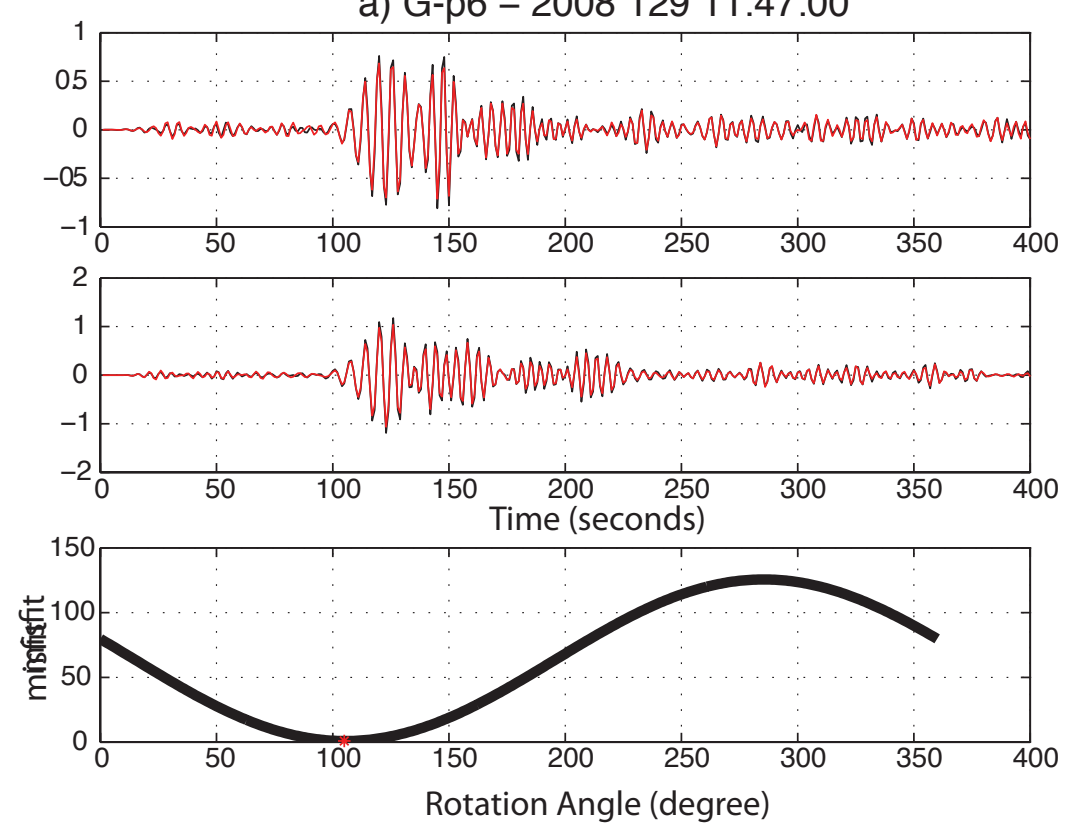

b) G-p6 - 2008326 07:02:30
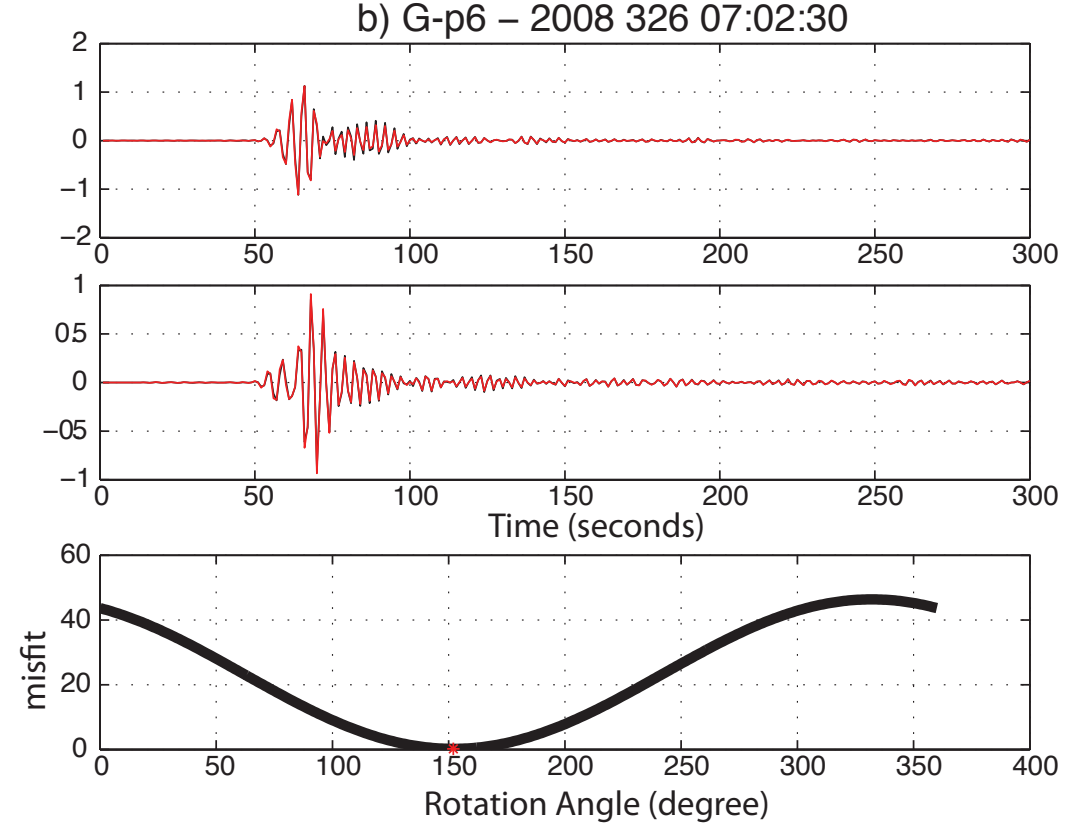

Figure 9: Example of relative azimuth calculation method for determining the accelerometer orientation relative to the broadband seismometer. A) Recordings of an event on day 129 at G-p6. Horizontal components (top two panels) of the broadband (black) and preferred azimuth rotated- and integrated-accelerometer recordings (red). Minimum error rotation angle is shown in bottom panel of 105 degrees. B) Second example of a recording of an event on day 326 recorded at station G-p6. Following the Mw 6.0 earthquake on day 262, the minimum-error rotation at G-p6 is shown to change to 153 degrees. 

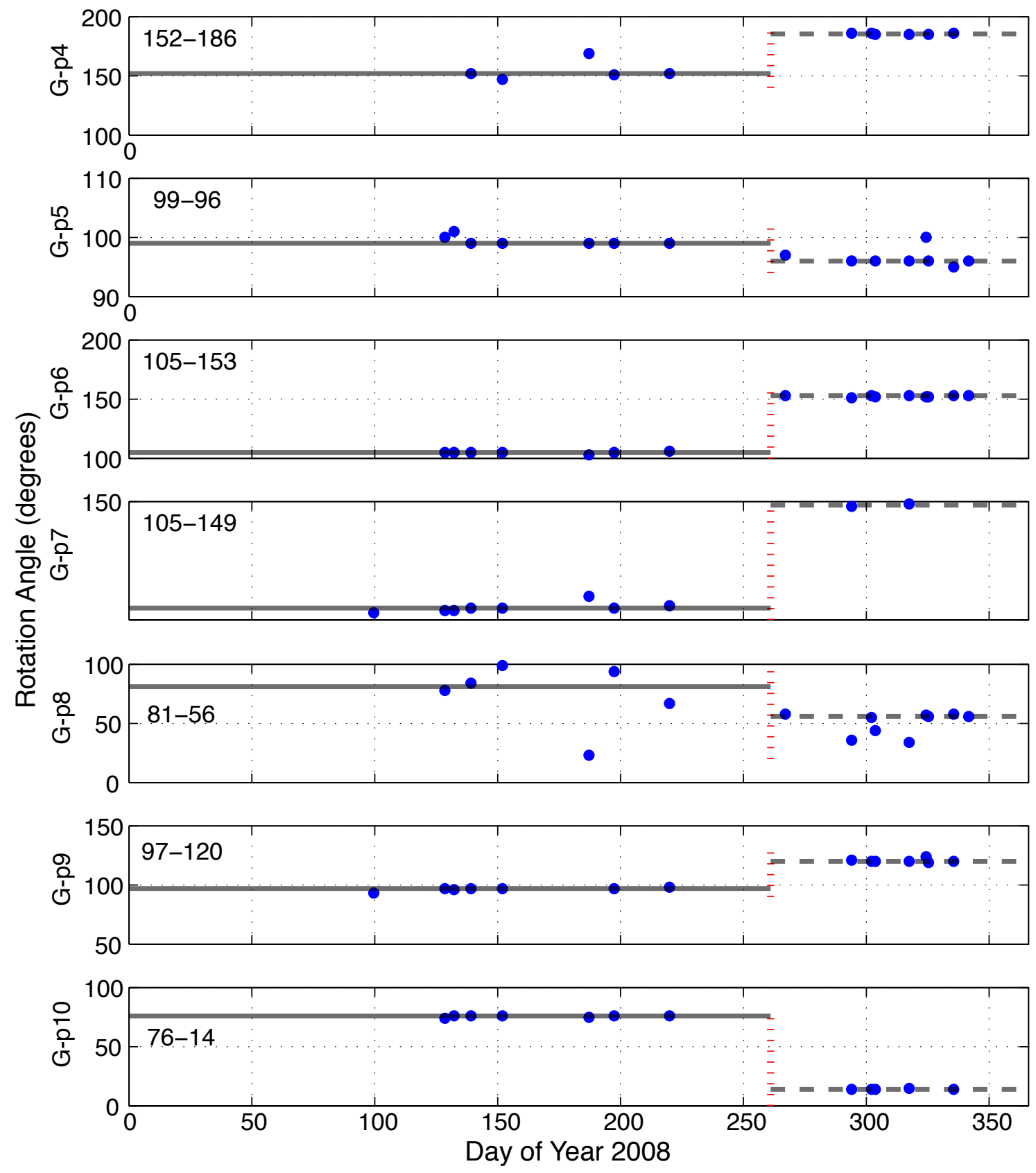

Figure 10: Preferred rotation of accelerometers relative to the broadband seismometers for seven Gofar OBS stations. Each instrument shows some change in azimuth after the Mw 6.0 event (red dashed line). This calculation does not account for any rotation of the broadband seismometers that also occurs on day 262 . 

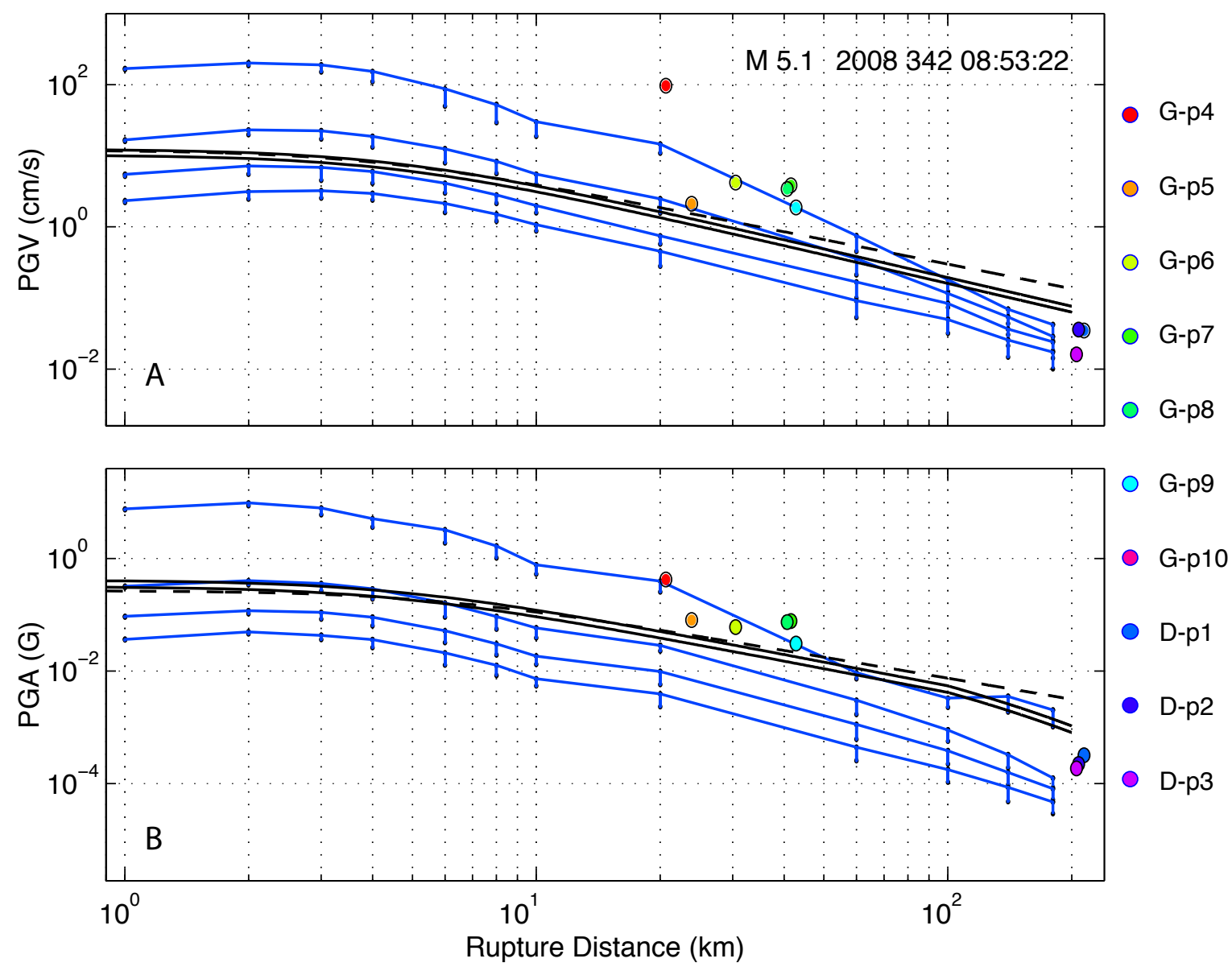

Figure 11: (A) Peak ground velocity (PGV) and (B) peak ground acceleration (PGA) observed at each of the QDG accelerometers from an Mw 5.1 earthquake that occurred on 12/07/08 on the western end of the Gofar fault (western red star, Figure 1). Black lines show the PGA and PGV empirical curves calculated using the SCEC Attenuation Relationship Plotter [Field et al., 2003]. Solid lines show curves calculated using the Abrahamson and Silva [2008] model for two different depths to top of rupture: $2 \mathrm{~km}$ (top) and $5 \mathrm{~km}$ (bottom). Dashed black line shows the Campbell and Bozorgnia [2008] model. Blue lines show the PGA and PGV values from synthetic waveforms calculated for various rupture distances, all assuming a Mw 5.1 strike slip earthquake at $4 \mathrm{~km}$ depth with source characteristics outlined in Table 4. Four curves represent different values of source duration, $0.1,0.5,1.0$ and $1.5 \mathrm{~s}$ from highest to lowest amplitude. 

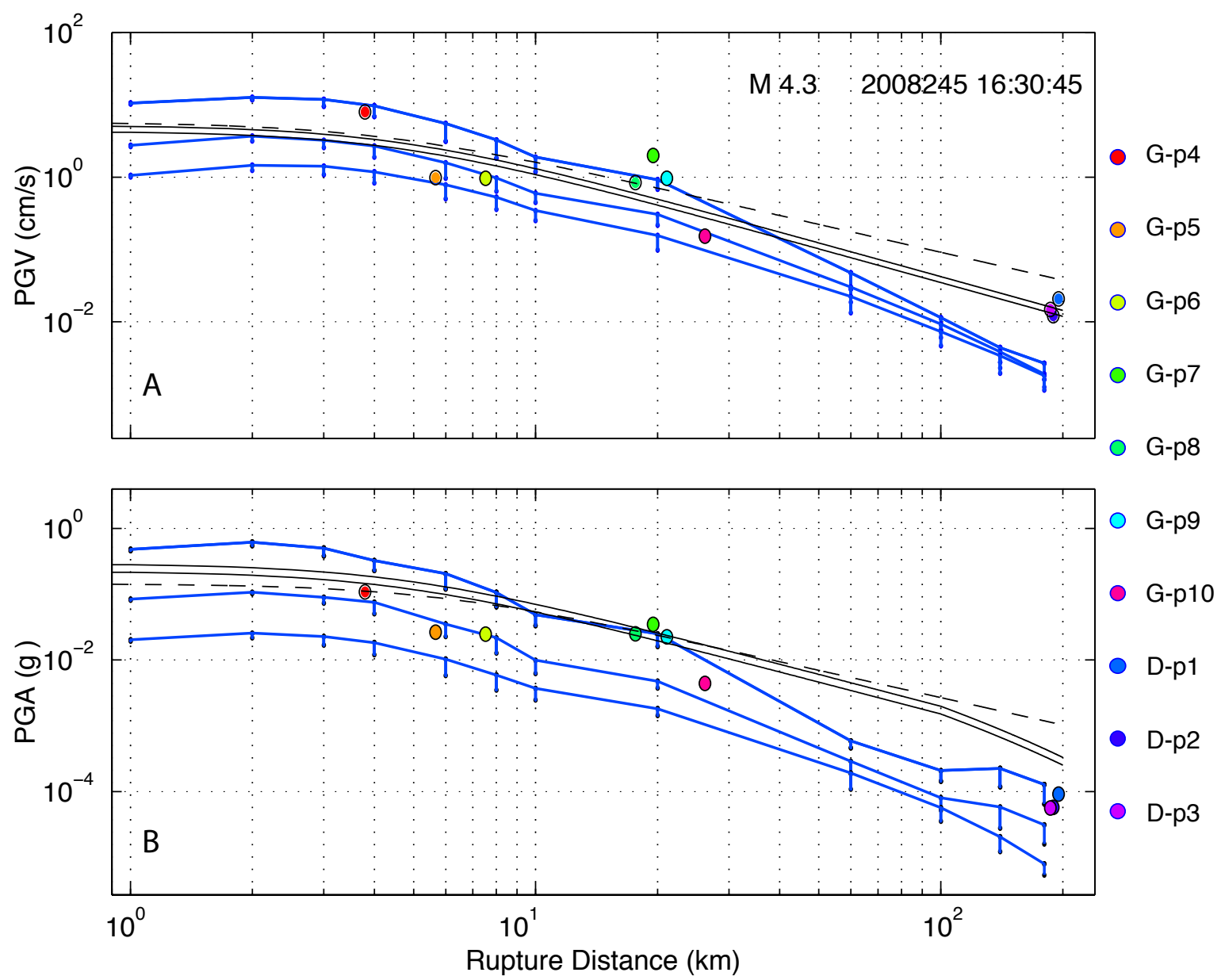

Figure 12: (A) Peak ground velocity (PGV) and (B) peak ground acceleration (PGA) observed at each of the QDG accelerometers from an Mw 4.1 earthquake that occurred on 9/01/08 on the Gofar fault (eastern red star, Figure 1). Black empirical curves are similar to those described in Figure 11 caption, except for a Mw 4.1 event. Blue lines are similarly equivalent to synthetic seismogram amplitudes described in Figure 11 caption, except three lines represent source durations of $0.1,0.3$, and $0.5 \mathrm{~s}$ (from highest to lowest amplitude). 

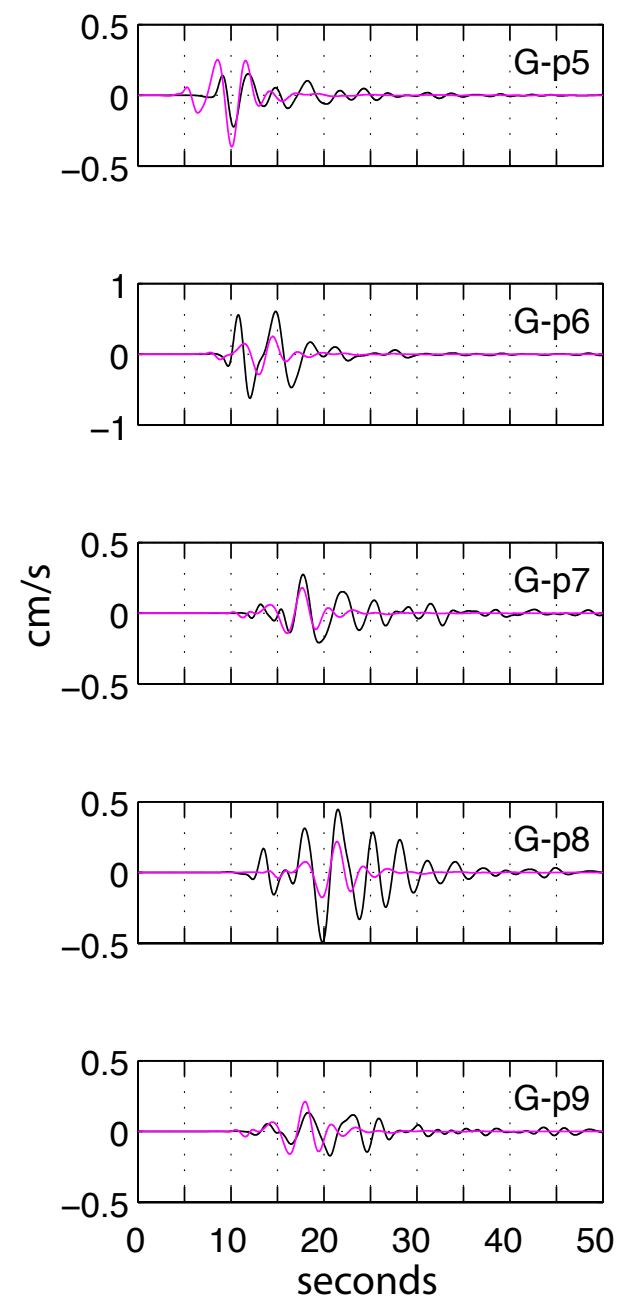

Figure 13a: Transverse component of $\mathrm{Mw} 5.1$ event on 12/07/08 at 08:53:22. Black line shows observed data from accelerometers, integrated to velocity. Magenta lines show synthetic waveforms. A bandpass filter is applied to the observed and synthetic data with corner frequencies of 0.15 and $0.4 \mathrm{~Hz}$. 

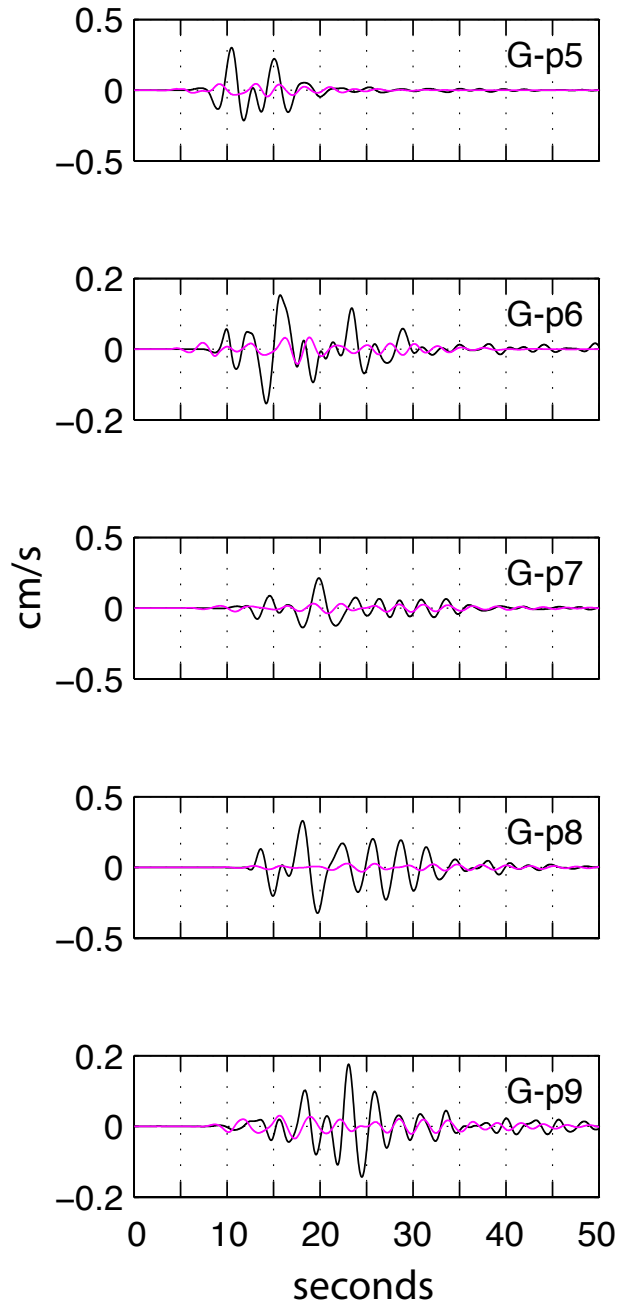

Figure 13b: Radial component of Mw 5.1 event on 12/07/08 at 08:53:22. Black line shows observed data from accelerometers, integrated to velocity. Magenta lines show synthetic waveforms. A bandpass filter is applied to the observed and synthetic data with corner frequencies of 0.15 and $0.4 \mathrm{~Hz}$. 

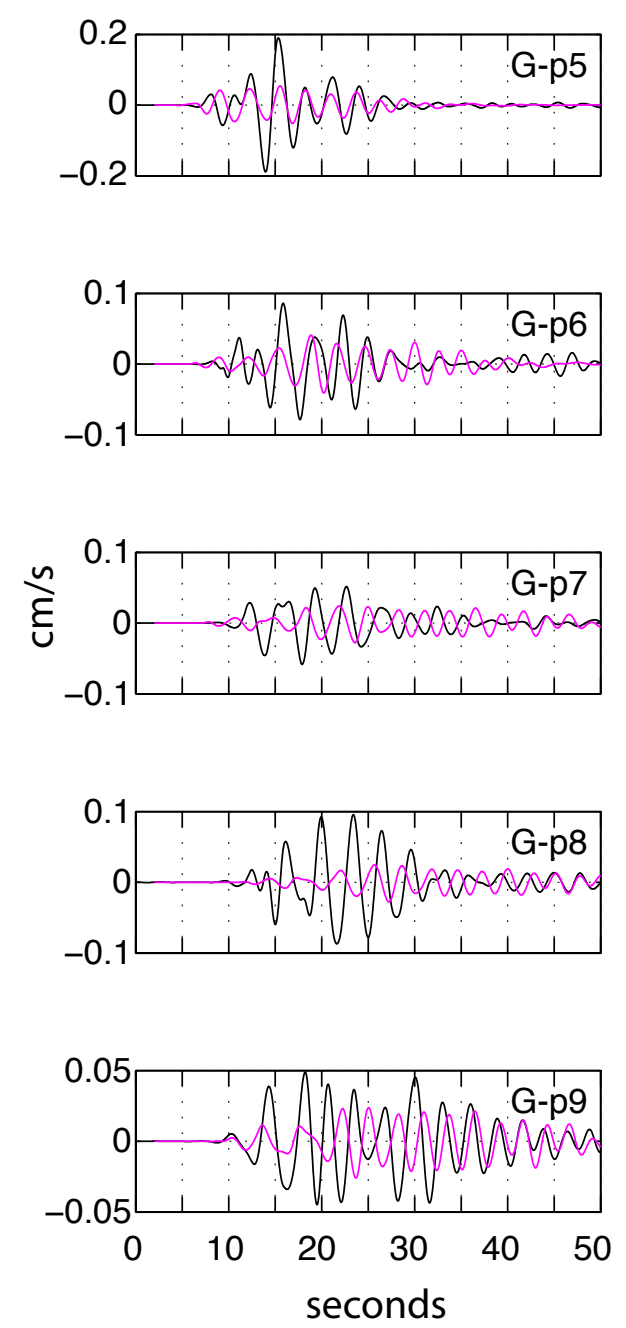

Figure 13c: Vertical component of Mw 5.1 event on 12/07/08 at 08:53:22. Black line shows observed data from accelerometers, integrated to velocity. Magenta lines show synthetic waveforms. A bandpass filter is applied to the observed and synthetic data with corner frequencies of 0.15 and $0.4 \mathrm{~Hz}$. 

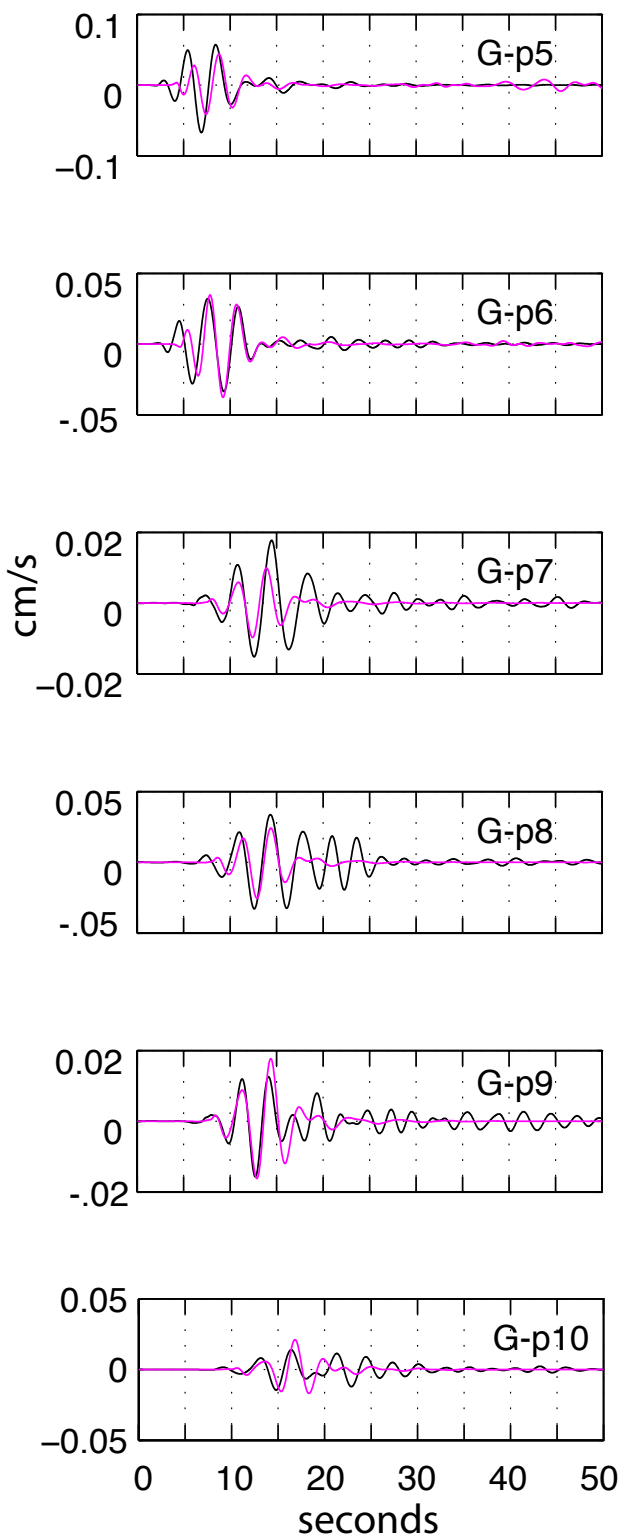

Figure 14a: Transverse component of $\mathrm{Mw} 4.3$ event on 9/01/08 at 16:30:45 . Black line shows observed data from accelerometers, integrated to velocity. Magenta lines show synthetic waveforms. A bandpass filter is applied to the observed and synthetic data with corner frequencies of 0.15 and $0.4 \mathrm{~Hz}$. 

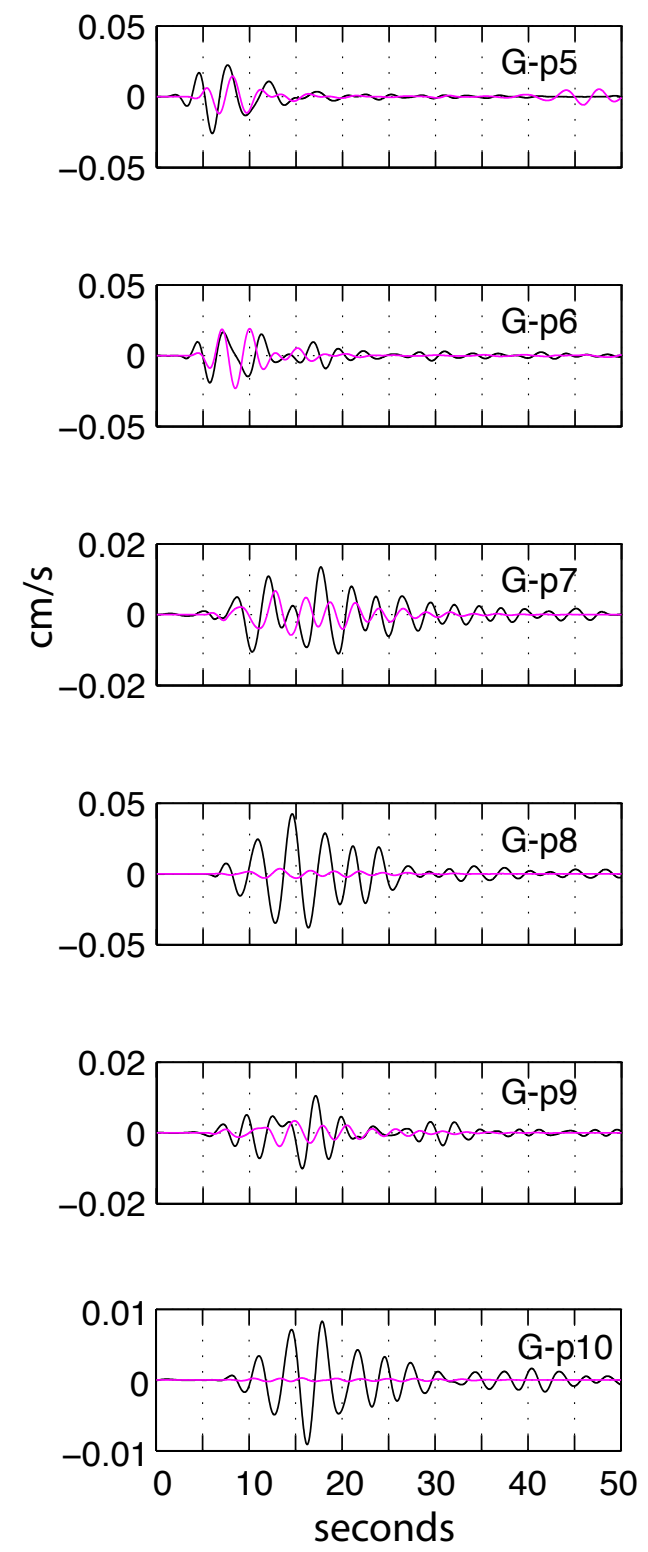

Figure 14b: Radial component of Mw 4.3 event on 9/01/08 at 16:30:45. Black line shows observed data from accelerometers, integrated to velocity. Magenta lines show synthetic waveforms. A bandpass filter is applied to the observed and synthetic data with corner frequencies of 0.15 and $0.4 \mathrm{~Hz}$. 

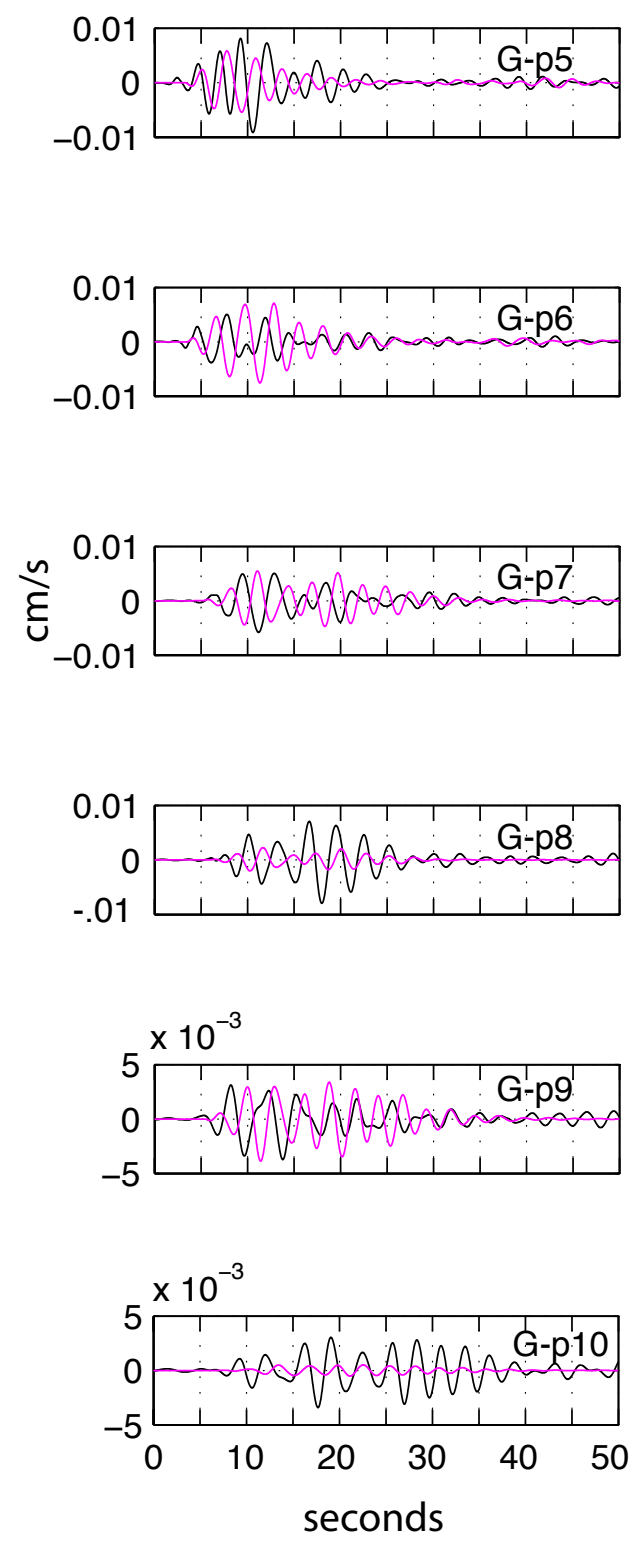

Figure 14c: Vertical component of Mw 4.3 event on 9/01/08 at 16:30:45. Black line shows observed data from accelerometers, integrated to velocity. Magenta lines show synthetic waveforms. A bandpass filter is applied to the observed and synthetic data with corner frequencies of 0.15 and $0.4 \mathrm{~Hz}$. 


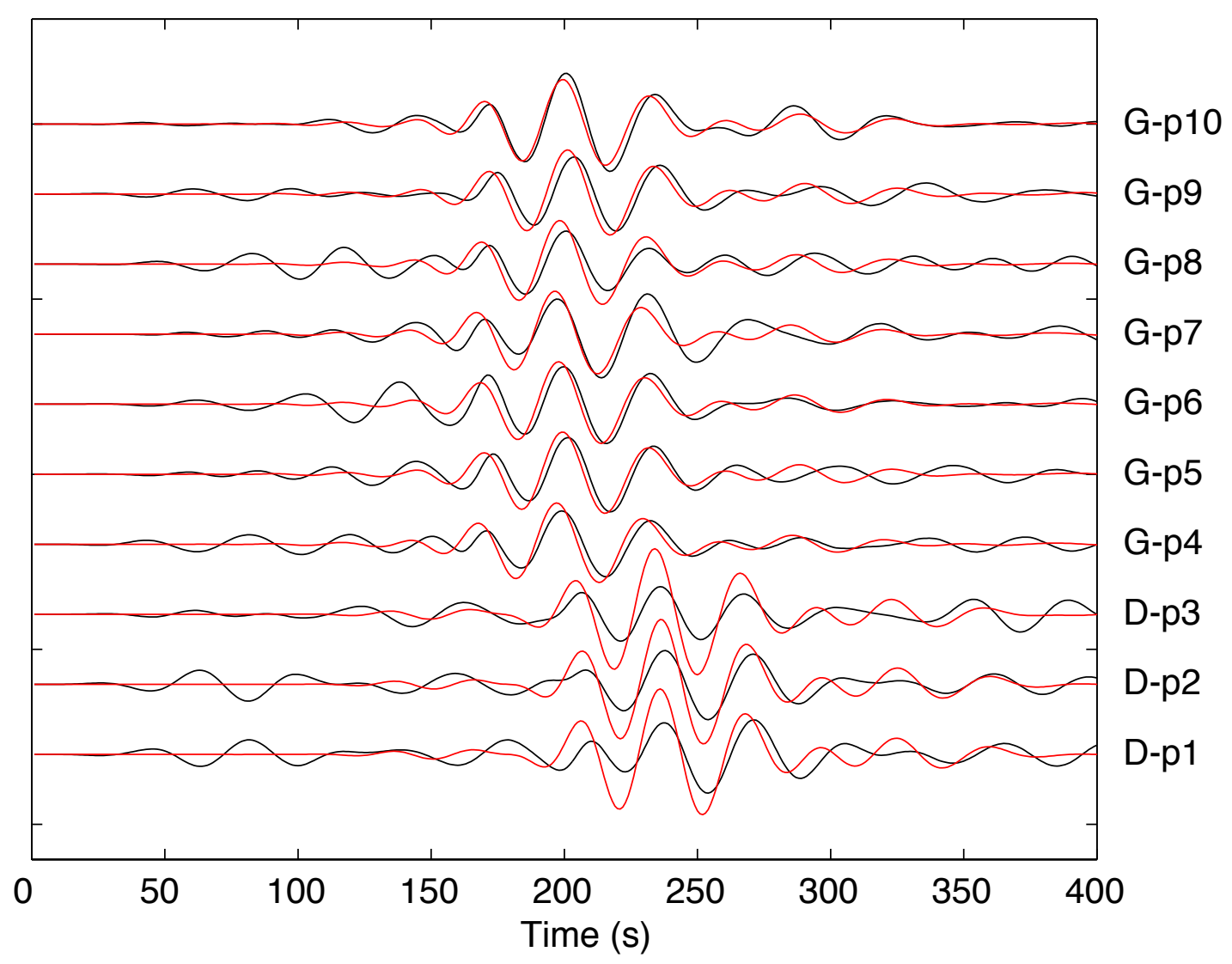

Figure 15: Rayleigh waves observed on the accelerometers (black) and normal modemodeled synthetic seismograms (red) for an Mw 6.1 earthquake on the Wilkes transform (10/30/2008). See text for details of modeling procedure. Observed accelerometer data shown here has been integrated to velocity. Both the data and synthetics have been bandpass filtered between 20 and $35 \mathrm{mHz}$. 
